\title{
SYNTHESIS GAS PRODUCTION VIA HYBRID STEAM REFORMING OF NATURAL GAS AND BIO-LIQUIDS
}

Ragavendra Prasad Balegedde Ramachandran UNIVERSITY OF TWENTE. 
Synthesis gas production via Hybrid Steam Reforming

of Natural gas and Bio-liquids

Ragavendra Prasad Balegedde Ramachandran 
Promotion committee:

Chairman:

Promoter:

Promoter:

Assistant Promoter:

Members:
Prof.dr.G.J. Vancso

Prof.dr.S.R.A.Kersten

Prof.dr.ir.W.P.M.van Swaaij University of Twente

Dr.ir.G.van Rossum

Prof.dr.K.Seshan

Dr.ir.D.W.F.Brilman

Prof.dr.ir. A. Nijmeijer

Prof.dr.J.M.Arauzo Pérez

Prof.dr.ir.W.Prins
University of Twente

University of Twente

University of Twente

University of Twente

University of Twente

University of Twente

University of Zaragoza, Spain

Ghent University, Belgium

The research described in this thesis was financially supported by Agentschap (www.agentschap.nl) in the EOSLT project (project number 07007). The research was carried out at the Sustainable Process Technology group, Faculty of Science and Technology, University of Twente, P.O.Box 217, 7500 AE, Enschede, The Netherlands

Ph.D. Thesis, University of Twente

Ragavendra Prasad Balegedde Ramachandran, Enschede, The Netherlands, 2013.

Printed by Ipskamp Drukkers B.V., Enschede, The Netherlands.

Front cover page and Chapter photos taken in Vaalparai, India by Aditya Murali. Back cover page photo: Taken in Manali, Chennai, India

PDF copy available at:

http://dx.doi.org/10.3990/1.9789036535182

ISBN: 978-90-365-3518-2

DOI: $10.3990 / 1.9789036535182$

Copyright (C) Ragavendra Prasad Balegedde Ramachandran, 2013

All rights reserved. No part of the material protected by this copyright notice may be reproduced or utilized in any form or by any means, electronic or mechanical without prior permission from the author and the Promotors. 


\section{SYNTHESIS GAS PRODUCTION VIA HYBRID STEAM REFORMING OF \\ NATURAL GAS AND BIO-LIQUIDS}

\section{PROEFSCHRIFT}

ter verkrijging van

de graad van doctor aan de Universiteit Twente,

op gezag van de rector magnificus,

Prof.dr.H. Brinksma,

volgens besluit van het College voor Promoties in het openbaar te verdedigen

op donderdag 14 Februari 2013 om 14.45 uur

door

Ragavendra Prasad Balegedde Ramachandran geboren op 27 oktober 1980

Chennai, India

[iii] 
This dissertation has been approved by the Promoters

Prof.dr.ir. W.P.M van Swaaij

Prof.dr.S.R.A.Kersten

and the Assistant Promoter

Dr.ir. G. van Rossum 
Dedicated to my parents 


\section{Contents}

Summary 9

$\begin{array}{ll}\text { Samenvatting } & 13\end{array}$

பொழிப்புரை 17

Chapter $1 \quad$ Introduction: Reforming of bio-liquids for 23

synthesis gas production

Chapter 2 Gasification of pyrolysis oil-Product distribution 43

and residue char analysis

Chapter 3 Evaporation of biomass fast pyrolysis oil-Evaluation 75

of char formation

Chapter 4 Preliminary assessment of synthesis gas production

via hybrid steam reforming of methane and glycerol

Chapter 5 Synthesis gas production via steam reforming of

pyrolysis oil - Assessment of catalyst performance and hybrid reforming with methane

Chapter 6 Techno-economic assessment of methanol production via hybrid steam reforming of bio-liquids with natural gas

Outlook

Publications

About the Author

Acknowledgements 


\section{Summary}

This thesis deals with (catalytic) steam reforming of bio-liquids for the production of synthesis gas. Glycerol, both crude from the biodiesel manufacturing and refined, and pyrolysis oil are tested as bio-based feedstocks. Liquid bio-based feeds could be preferred over inhomogeneous fibrous solid biomass because of their logistic advantages, better mineral balance, and better processability. Especially the ease of pressurization, which is required for large scale synthesis gas production, is another clear advantage of liquid biomass. In addition to this, liquefied biomass contains less contaminants than the biomass from which it originates which will be beneficial with respect to catalyst poisoning.

The proposed steam reforming process is a hybrid one (HSR - Hybrid Steam Reforming) in which the bio-liquids are co-reformed with a fossil feed such as natural gas or naphtha. In this thesis, methane as a model compound for natural gas is investigated. By co-reforming, implying partnering with the current fossil-based industry, use is made of the existing infrastructure and markets which should help the introduction of bio-based synthesis gas. At the level of the chemistry, co-feeding may minimize the adverse characteristics of the bio-liquid as has been observed for cofeeding upgraded pyrolysis oil with long residue in a micro Fluid Catalytic Cracking (FCC) unit.

The HSR process investigated consists of:

1. Evaporation and gasification of the bio-liquid $\left[T>500{ }^{\circ} \mathrm{C}\right]$,

2. (Pre)-reforming of the gases and vapors produced under (1) $[T=500-800$ $\left.{ }^{\circ} \mathrm{C}\right]$,

3. Co-reforming of the product of (2) together with methane $\left[T=800-900{ }^{\circ} \mathrm{C}\right]$.

All three process steps are investigated in newly designed automated dedicated setups. Evaporation has been investigated in an empty tube reactor that allows a complete and precise carbon balance closure over produced gases, vapors and char. Steam reforming is tested in fixed bed reactors. 
In these reactors, long duration runs of up to $\sim 100 h$ are performed under commercially practiced gas hourly space velocities. These tests have been designed to give more insight into the actual status and remaining challenges of the process, compared to the often reported idealized (batch) screening experiments.

The first step of the process is the evaporation and cracking of the bio-liquid. The results obtained are of value not only for the HSR process, but also for all other processes in which bio-liquids are injected into a hot environment, such as engines, boilers and gasifiers. Cracking to gases occurs because the evaporation is carried out at elevated temperature. An imported issue is the undesired production of char. Pure glycerol could be evaporated without producing char. Crude glycerol and pyrolysis oil require very fine and controlled atomization to minimize char production. For crude glycerol, the formation of char has been clearly linked to the presence of $\mathrm{KOH} / \mathrm{NaOH}$ (the remaining catalyst from the biodiesel production) which catalyzes polymerization reactions in the liquid phase. A direct relationship has been found between the heating rate (coupled to droplet size) and the amount of char produced. Pyrolysis oil droplets of ca. $100 \mu \mathrm{m}$ still result in ca. 8\% char on carbon basis. There are indications that under even more severe atomization conditions less char can be produced, but this would not result in a practical process.

Neutralized glycerol yields salt(s) as byproducts but no carbonaceous deposits during the evaporation. For such realistic feeds a facility to remove and to deal with the produced solids has to be included in the process design. It has turned out that the temperature of the environment itself, when varied between 500 and $900{ }^{\circ} \mathrm{C}$, hardly has an effect on the char production. At higher temperatures of up to $850{ }^{\circ} \mathrm{C}$ and at higher vapor/gas residence times more gas is produced at the expense of less vapors. The maximum carbon to gas conversion for pyrolysis oil observed is $\sim 80 \%$ which means that the pre-reform system has to cope with at least $10 \%$ of the feed present as oxygenated vapors and remaining carbon being char ( 10\%). 
It has been found that there is no fundamental problem in the chemistry / catalysis of steam reforming of bio-liquids. Three catalysts have been tested, viz. a commercial $\mathrm{Ni} / \mathrm{K} / \mathrm{Mg}$ on $\mathrm{Al}_{2} \mathrm{O}_{3}$ pre-reform catalyst, a commercial $\mathrm{Ni}$ on $\mathrm{Al}_{2} \mathrm{O}_{3}$ catalyst and an inhouse made $\mathrm{Ni} / \mathrm{Mg}$ on $\mathrm{Al}_{2} \mathrm{O}_{3}$ catalyst, which all showed near equilibrium yields of the steam reforming reaction for glycerol and pyrolysis oil for $S / C=1-15$ and $T=600$ - $850{ }^{\circ} \mathrm{C}$. Pure glycerol can be reformed with $100 \%$ carbon to gas conversion and equilibrium yields at temperatures as low as $600{ }^{\circ} \mathrm{C}$. In contrast, pyrolysis oil shows excessive coke formation on the catalyst at this low temperature leading to too short operation times. Even refined glycerol containing only limited amounts of contaminants (e.g. FAME - Fatty acid methyl esters) shows deactivation of the catalyst with respect to methane slip already after a few hours. When using this latter feed the catalysts can be regenerated. With respect to deactivation a distinction has been made between the activity of the catalyst for carbon to gas conversion (gasification) and activity for methane (hydrocarbon) conversion via steam reforming $(M S R)$

For pyrolysis oil vapors reforming at $\sim 800{ }^{\circ} \mathrm{C}$, it has been showed that the commercial $\mathrm{Ni} / \mathrm{K} / \mathrm{Mg}$ pre-reforming catalyst retains a high carbon to gas activity (conversion) but loses its methane steam reforming (MSR) activity. The MSR activity of this catalyst could not be regenerated via oxidation of the coke and subsequent reduction. It is postulated that the carbon to gas conversion is maintained because of enhanced coke gasification by potassium $(K)$. However, a dedicated series of experiments in which the $K$ amount on the catalyst was varied has shown that $K$ reduces the MSR activity. The catalysts having only $\mathrm{Mg}$ as promoter show a decreasing carbon to gas conversion and MSR activity. However, the initial activity of both could be recovered via regeneration, but after this immediate activity loss occurred again. From a process point of view, high and stable carbon to gas conversion in the first steps of the process is more important than good MSR activity. If the carbon conversion is high enough in the bio-liquid gasifier and pre-reformer, any methane will be dealt with in the primary reformer. 
Several preliminary longer duration tests of co-reforming (HSR) have been performed at space velocities close to industrial practice. For pyrolysis oil reforming it has been found that indeed the co-reformer benefited from the combined fossil and bio-feed: coke on catalyst was more than ten times lower than in the upstream bio-liquid prereformer. However, apparently this is not enough as the catalyst still deactivated for pyrolysis oil, both with respect to carbon to gas conversion and MSR, during coreforming. For pure and high grade (with regeneration) glycerol the proof of principle of HSR has been delivered by long duration runs of more than $30 \mathrm{~h}$.

A detailed techno-economic analysis shows that at the current market scenario (2012) with a natural gas price of $0.2 € / \mathrm{Nm}^{3}$ and with an assumed crude glycerol price of $200 € /$ tonne, the average cost of (bio)methanol is estimated as $430 € /$ tonne for a feed of 54 wt\% of glycerol (on carbon basis) with natural gas, which is 75 €/tonne higher than for the methanol obtained via only natural gas steam reforming. However, with current regulations for second generation biofuels (they can be counted double) a commercial attractive business case could be developed. 


\section{Sammenvating}

Dit proefschrift gaat over (katalytisch) stoom reformen van bio-vloeistoffen voor de productie van synthesegas. Glycerol, zowel in ruwe als opgewerkte vorm (als bijproduct van biodiesel productie), en pyrolyse-olie zijn getest als bio-gebaseerde grondstoffen. Vloeibare bio-gebaseerde voedingen zouden de voorkeur kunnen hebben boven inhomogene vaste biomassa door hun logistieke voordelen en betere mineralenbalans en verwerkbaarheid. Vooral het gemak van het onder druk brengen, welke nodig is voor grootschalige productie van synthesegas, is een duidelijk voordeel van bio-vloeistoffen. Daarnaast bevatten bio-vloeistoffen minder verontreinigingen dan de biomassa waarvan het afkomstig is; dit zou vergiftiging van de katalysator kunnen beperken.

Het voorgestelde stoom reform proces is een hybride (HSR - Hybrid steam reforming) soort waarin de bio-vloeistoffen worden ge-co-reformed met een fossiele voeding, zoals aardgas of nafta. In dit proefschrift wordt methaan als een modelstof voor aardgas onderzocht. Door co-reformen, wat samenwerking met de huidige fossiele industrie impliceert, wordt gebruik gemaakt van de bestaande infrastructuur en markten die de introductie van bio-gebaseerd synthese gas zou moeten helpen. Op het niveau van de chemie zou het co-voeden de nadelige eigenschappen van de biovloeistof kunnen onderdrukken zoals is aangetoond met het co-voeden van opgewaardeerde pyrolyse olie met "long residue" in een micro FCC opstelling.

Het onderzochte HSR proces bestaat uit:

1. Verdampen en vergassen van de bio-vloeistof $\left[\mathrm{T}>500^{\circ} \mathrm{C}\right]$

2. (Pre)-reformen van de gassen en dampen die bij (1) zijn gevormd $\left[T=500-800{ }^{\circ} \mathrm{C}\right]$

3. Co-reformen van het product van (2) met methaan $\left[T=800\right.$ tot $\left.900{ }^{\circ} \mathrm{C}\right]$.

Al deze drie processtappen zijn onderzocht in nieuw ontworpen geautomatiseerde opstellingen. Verdamping is onderzocht in een lege buis reactor waar een volledige en nauwkeurige koolstofbalanssluiting over de geproduceerde gassen, dampen en kool mogelijk was. Stoom reformen is getest in vaste-bed reactoren. 
In deze opstellingen zijn lange duur experimenten tot 100 uur uitgevoerd met commercieel relevante contacttijden. Deze testen waren zodanig uitgevoerd dat er inzicht in de actuele status en resterende uitdagingen van het proces werden verkregen, dit in tegenstelling tot de vaak in literatuur gerapporteerde geïdealiseerde (batch) experimenten.

De eerste stap in het proces is het verdampen en kraken van de bio-vloeistof. De verkregen resultaten zijn niet alleen van waarde voor de HSR-proces, maar voor alle processen waarbij bio-vloeistoffen worden geïnjecteerd in een warme omgeving, zoals motoren, verbrandingsketels en vergassers. Omdat de verdamping wordt uitgevoerd bij verhoogde temperatuur ontstaan ook gassen door middel van thermisch kraken. Een probleem is de ongewenste productie van kool. Zuivere glycerol kan worden verdampt zonder koolvorming. Ruwe glycerol en pyrolyse-olie hebben een zeer fijne en gecontroleerde verneveling nodig om de koolvorming te minimaliseren. Voor ruwe glycerol, is de vorming van kool duidelijk gerelateerd aan de aanwezigheid van KOH/ $\mathrm{NaOH}$ (katalysator restant van de biodieselproductie) die polymerisatiereacties in de vloeistoffase katalyseert. Een direct verband werd gevonden tussen de opwarmsnelheid (gerelateerd aan druppelgrootte) en de hoeveelheid geproduceerde kool. Pyrolyse-olie druppels van ca. $100 \mu \mathrm{m}$ resulteren nog steeds in ca. $8 \%$ kool op koolstof basis. Er zijn aanwijzingen dat bij nog betere verstuiving nog minder kool wordt geproduceerd, maar dit is waarschijnlijk niet haalbaar in een praktisch uitvoerbaar proces.

Geneutraliseerd glycerol heeft zout(en) als vaste bijproducten maar geen koolstof houdende afzettingen tijdens de verdamping. Voor dit soort realistische voedingen moeten in het procesontwerp voorzieningen getroffen worden om geproduceerde vaste stoffen te verwijderen. Gebleken is dat de omgevingstemperatuur, welke is gevarieerd tussen 500 en $900{ }^{\circ} \mathrm{C}$, nauwelijks een invloed heeft op de koolproductie. Bij hogere temperaturen tot $850{ }^{\circ} \mathrm{C}$ en bij hogere damp / gas verblijftijden wordt meer gas geproduceerd ten koste van damp. De maximale koolstof naar gas conversie gemeten voor pyrolyse olie is $\sim 80 \%$, hetgeen betekent dat de pre-reformer ten minste $10 \%$ van de voeding als geoxygeneerde dampen moet verwerken. 
Het is gebleken dat er geen fundamenteel probleem is wat betreft de chemie / katalyse van het stoom reformen van bio-vloeistoffen. Drie katalysatoren zijn getest, namelijk een commerciële $\mathrm{Ni} / \mathrm{K} / \mathrm{Mg}$ op $\mathrm{Al}_{2} \mathrm{O}_{3}$ pre-reform katalysator, een commerciële $\mathrm{Ni}$ op $\mathrm{Al}_{2} \mathrm{O}_{3}$ reform katalysator en een eigen gemaakte $\mathrm{Ni} / \mathrm{Mg}$ op $\mathrm{Al}_{2} \mathrm{O}_{3}$ katalysator. Alle drie de katalysatoren hadden aanvankelijk opbrengsten gelijk aan het evenwicht voor het stoom reformen van glycerol en pyrolyse-olie bij $S / C=1-15$ en $T=600-850{ }^{\circ} \mathrm{C}$. Pure glycerol kan worden gereformd met 100\% koolstof naar gas conversie waarbij het gas op thermodynamisch evenwicht is vanaf ongeveer $600{ }^{\circ} \mathrm{C}$. Pyrolyse olie vertoont bij deze lage temperatuur echter overmatige coke-vorming op de katalysator wat leidt tot te korte operatietijden. Zelfs opgewerkte glycerol welke slechts beperkte hoeveelheden verontreinigingen (zoals FAME - Fatty acid methyl esters) bevat leidt al na enkele uren tot deactivatie van de katalysator wat zich uit in methaan doorbraak. Bij gebruik van deze voeding kunnen de katalysatoren wel worden geregenereerd. Met betrekking tot katalysator deactivatie moet er een onderscheid gemaakt worden tussen de activiteit van de katalysator voor de omzetting van koolstof naar gas (vergassing) en de activiteit voor de omzetting van methaan (koolwaterstof) via stoomreformen (MSR).

Voor her reformen van pyrolyse-olie dampen op $\sim 800^{\circ} \mathrm{C}$ is gebleken dat de commerciële $\mathrm{Ni} / \mathrm{K} / \mathrm{Mg}$ pre-reform katalysator een hoge koolstof naar gas activiteit (conversie) behoudt, echter de MSR activiteit gaat verloren. De MSR activiteit van deze katalysator kan niet worden geregenereerd door oxidatie van de coke en opeenvolgende reductie. Er wordt gepostuleerd dat de koolstof naar gas conversie behouden blijft vanwege verhoogde coke vergassing door kalium. Echter, een speciale reeks experimenten waarin het kalium gehalte op de katalysator is gevarieerd heeft aangetoond dat kalium ook verantwoordelijk is voor de vermindering van de MSR activiteit. De katalysatoren die slechts $\mathrm{Mg}$ als promotor hadden lieten een dalende koolstof naar gas conversie en MSR activiteit zien. Echter, de initiële activiteit van beide katalysatoren kon worden hersteld via regeneratie, waarna er echter direct weer activiteitverlies optreedt. Vanuit een proces oogpunt is een hoge en stabiele koolstof naar gas conversie in de eerste stappen van het proces belangrijker dan een hoge MSR activiteit. Als de koolstof naar gas conversie hoog genoeg is in de bio- 
vloeistof vergasser en pre-reformer, dan kan het methaan vervolgens worden omgezet in de primaire reformer.

Verscheidende lange duur testen van het co-reformen (HSR) zijn uitgevoerd met contacttijden dicht bij industriële praktijk. Voor pyrolyse olie reformen is gebleken dat de co-reformer inderdaad profiteert van de gecombineerde fossiele en biovoeding: coke op de katalysator was meer dan tien keer lager dan in de voorop geschakelde bio-vloeistof pre-reformer. Dit effect is echter nog niet voldoende aangezien de katalysator nog steeds deactiveerde tijdens het co-reformen van pyrolyse-olie, zowel voor de koolstof naar gas conversie als de MSR activiteit. Voor pure en opgewerkte (met regeneratie) glycerol is het HSR concept succesvol gedemonstreerd voor meer dan 30 uur.

Een gedetailleerde technisch-economische analyse toont aan dat met de huidige markt (2012) met een aardgasprijs van 0,2 $\mathrm{\epsilon} / \mathrm{Nm}^{3}$ en aangenomen ruwe glycerol prijs van $200 € /$ ton, de gemiddelde kosten van (bio) methanol wordt geschat op $430 € /$ ton voor een voeding van 54 gewichts-\% glycerol (op koolstof-basis) met aardgas. Dit is 75 €lton hoger dan voor methanol verkregen uit enkel aardgas. Echter, met de huidige regelgeving voor tweede generatie biobrandstoffen (ze mogen dubbel geteld worden) kan een commercieel aantrekkelijke business case ontwikkeld worden. 


\section{பொழிப்புரை}

இந்த ஆய்வுக் கட்டுரையில் bio-திரவத்தில் இருந்து Synthesis gas $\left(\mathrm{CO}^{+} \mathrm{H}_{2}\right)$ எவ்வாறு தயாரிக்க வேண்டும் என்பது விவரிக்கப்பட்டுள்ளது. இந்த ஆய்வில் பரிசுத்தமான Glycerol, Crude Glycerol மற்றும் Biomassஇல் (தாவரம்/விலங்குக் கழிவு பொருட்கள்) இருந்துத் தயாரிக்கப்படும் Pyrolysis oil போன்ற bio-திரவங்கள் பரிசோதனைச் செய்யப்பட்டுள்ளது. உறுதியான திண்மையுடைய solid biomassஐ காட்டிலும் திரவம் தலைச் சிறந்தது. ஏனெனில்,

1. திரவத்தை எளிதாக இடம் மாற்றலாம்.

2. திரவம் சீராக இருக்கும்.

3. தாதுப்பொருள் எடையும் சீராக இருக்கும் மற்றும்

4. எளிதான முறையில் திரவத்தைக் கையாளலாம்.

5. குறிப்பாக, அதிக அளவு Methanol உற்பத்திக்கும், அதிக அளவு அழுத்தமுள்ள பயன்பாடுகளுக்கும் (High pressure applications) திரவம் சரியானதாக இருக்கும்.

6. மேலும், bio-திரவத்தில் குறைந்த அளவு கழிவுத்தின்மங்கள் இருப்பதால், அதனை Catalytic Reforming செய்யவும், catalyst மாசுபடாமல் இருக்கவும் பயனுள்ளதாக இருக்கும்.

இதனை, இந்த ஆய்வில் Catalytic Reformingஐ, Hybrid steam Reforming (HSR) என்ற புதிய கோட்பாடு விவரிக்கப்பட்டுள்ளது. HSR எனப்படுவது, Methanol என்ற திரவத்தை Synthesis gas மூலம் தயாரிக்க, எரிவாயு (Natural gas) உடன் bio-திரவத்தை கலந்து Catalytic Reforming செய்வதாகும். பல ஆண்டுகளாக Methanol என்ற திரவத்தைப் புதைவடிவம் (Fossil) கொண்ட எரிவாயு (Natural gas), Naphtha, நிலக்கரி, நில எண்ணெய் (Petroleum) முதலியவற்றிலிருந்து பெரும்பாலும் தயாரிக்கப்பட்டு வருகிறது. Bio-திரவத்தை எரிவாயுடன் அறிமுகப்படுத்தினால், Methanol தயாரிக்கத் தற்போது இருக்கும் சுத்திகரிப்புச்சாலைகளை உபயோகப்படுத்தலாம். HSR

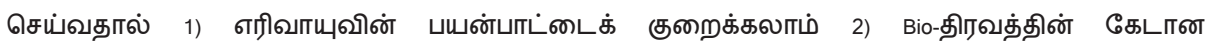
இயல்பை HSR மூலம் குறைக்கலாம். இதனை முன்பே FCC processஇல் ஆய்வில் குறிப்பிடப்பட்டுள்ளது.

HSR process இல்

1. Bio-திரவத்தில் இருக்கும் நீரை ஆவியாக (Evaporation) மாற்றுதலும், பின் கூடுதல் வெப்பம் மூலமாக (T>500ํ) வாயுவாக (Gasification) மாற்றம் செய்ய வேண்டும்.

2. அப்படி உருவாக்கிய வாயுவை Catalytic reforming மூலமாக (T=500-800ํ) மாற்றிய பின், 
3. வாயுவை, எரிவாயுடன் கலந்து ( $T=800$ - 900 ㅇ) HSR செய்ய வேண்டும். மேலே குறிப்பிட்ட அனைத்து Process களையும் நாங்கள் வடிவமைத்த சாதனங்களில் பரிசோதனை செய்தோம். அதன் முடிவுகள் பின்வரும் பகுதிகளில் காணலாம்.

வாயுவாக மாற்றும் செய்முறையை (1) காலியான Reactor tubeஇல் வெப்பம் மற்றும் துளி அளவை (droplet size) மாற்றி வாயு (Gas), ஆவி (Vapor), மற்றும் கரி (Char), போன்றவைகள் அளக்கப்பட்டன. தயாரித்த வாயுவையும், ஆவியையும் Fixed bed reactorஇல் Catalyst ஐ பயன்படுத்தி சுமார் 100 மணி நேரம் பரிசோதனைச் செய்யப்பட்டது. இப்படிச் செய்வதால், Catalystஐ மிக நுணுக்கமாகவும் மற்றும் இந்த துறையில் இருக்கின்ற சவால்களைக் கற்கலாம். மேலே குறிப்பிட்ட செய்முறை விளக்கம் (1) bio-திரவத்தை அதிக அளவு வெப்பமுடைய சூழலில் செலுத்துவது, Reforming பரிசோதனை மட்டுமல்ல மற்ற செயல்முறைகளான Combustion மற்றும் Cracking (Engines, boilers, gasifiers) போன்றவற்றைக் கற்க பயனுள்ளதாக இருக்கும். இந்த செயல்முறையில், Char மட்டுமே விருப்பத்துக்கு மாறாக தயாராகும் பொருள். Char reactor tubeஐ அடைக்கும், Engine பயன்பாடுகளுக்கு இடையுறாக இருக்கும். மேலும், tube இன் அழுத்தத்தை அதிகரிக்கும். இதனைத் தவிர்ப்பது மிகக் கடினம். பரிசுத்தமான Glycerol ஐ வாயுவாக மாற்றம் செய்யும் போது, கரி (Char) தயாராகவில்லை. ஆனால், Crude Glycerol மற்றும் Pyrolysis oil போன்ற bio-திரவங்களை வாயுவாக மாற்றம் செய்யும் போது மட்டுமே கரி (char) உருவாகிறது. இதனைக் கட்டுப்படுத்த bio-திரவத்தின் துளி அளவை (droplet size) குறைக்க வேண்டும். Crude Glycerolஇல் இருந்து உருவாகும் கரிக்கு crude இல் இருக்கும் KOH/NaOH (Catalyst for transesterification) உடன் தொடர்பு இருக்கிறது (இதன் விவரம் அறிய பாகம் நான்கைப் படிக்கவும்). ஆனால், Pyrolysis oil க்கு துளி அளவிலும், வெப்ப விகிதத்திற்கும் தொடர்பு இ இருக்கிறது. இதன் விளைவாக, சுமார் 8\% கரி (எடை அளவில்), Pyrolysis oil இல் இருந்து உருவாகிறது (வெப்ப விகிதம் : $10^{6} \quad$ 드/min). இதனை அதிக வெப்பத்தாலும் குறைக்க இயலவில்லை ( 850ํㅡ). ஆகையால், Pyrolysis oilஐ பெரிய அளவு கொண்ட ஆலையில் செயல்முறை செய்வது கடினம். Crude Glycerolஐ செயல் முறை செய்யும் போது அதில் KOH மூலம் உருவாகும் உப்பு (KCl) Reactorஇல் படிகிறது. பெரிய அளவில் இந்த திரவத்தை எளிதான முறையிலும், இடை விடாமல் செயல் முறை செய்யவும் சிறந்த catalyst தேவை. உருவாகும் உப்பை தொடர்ச்சியாக நீக்க வசதிகள் தேவை. Pyrolysis oilஇல் இருந்து சுமார் 80\% வாயு தயார் செய்யலாம். எஞ்சி இருக்கும் 20\% இல் 10-15\% Organic ஆவி இருக்கும். இந்த ஆவியை Catalyst reforming மூலம் வாயுவாக மாற்றம் செய்தல் வேண்டும். 
இதனை நடைமுறையில் உள்ள Catalystகள் செயலாற்றுமா என்பது மிகப் பெரிய கேள்வி. இந்த கேள்விக்கு விடை அறிய இரண்டு Catalystகள் 1) நடைமுறையிலுள்ள Ni/K-Mg- $\mathrm{Al}_{2} \mathrm{O}_{3}$ Naphtha prereforming catalyst 2) நாங்கள் தயார் செய்த ஆராய்ச்சி $\mathrm{Ni}^{\prime} / \mathrm{Mg}^{-\mathrm{Al}_{2} \mathrm{O}_{3}}$ catalyst பரிசோதனை செய்யப்பட்டன. இந்த இரண்டு Catalyst களும், இந்த சூழ்நிலைகளில் (S/C = 1 - 15 மற்றும் T = 600 - 850 ํ) எந்த வித தடங்கல் இல்லாமல் அதிகபட்ச வாயு (equilibrium gas yield) தயாராகிறது. ஆனால், அதிக நேரம் (சுமார் 2 மணி நேரத்திற்கு மேல்) Pyrolysis oilஐ Reforming செய்யும் போது, Catalyst மீது கரி (coke) படிகிறது. Catalyst மீது கரி படிவதால், அது Reforming தன்மையை இழக்கிறது. இதனால், Pyrolysis oil இல் இருந்து உருவாகும் வாயுவின் அளவு குறைகிறது. இதனால் தொடர்ச்சியாக பரிசோதனை புரிய கடினமான சூழ்நிலை ஏற்படுகிறது. மேல் குறிப்பிட்ட சூழலில், Crude Glycerol ஐ Reforming செய்யும் போது, அதிலுள்ள கூட்டுப்பொருட்களான Fatty acids methyl esters, di,tri glycerides, Reforming தன்மைக்கு கேடு விளைவிக்கிறது. Reforming தன்மைக்கு கேடு வரும் போது, Catalyst மீது படிந்திருக்கும் கரியை (Coke) நீக்கி மீண்டும் Reforming ஐ ஆரம்பிக்கலாம் (Regeneration/coke removal). இப்படிச் செய்யும் போது Methane Reforming தன்மைக்கும் மற்றும் bio-திரவத்தில் இருக்கும் கரியை வாயுவாக மாற்றும் திறனுக்கும் (carbon conversion to gases) உள்ள வித்தியாசத்தை கண்டறிவது முக்கியம். மேலும், இந்த இரண்டு திறனையும் குறையாமல் Catalyst ஐ உபயோகிக்க வேண்டும். ஆனால், இந்த தத்துவம் Crude glycerol/Pure glycerol க்கு சரி வருகிறது. ஆனால், Pyrolysis oil உபயோகிக்கும் போது மீது அதிகமாக கரி (Coke) படிவதாலும், மேலும் Methane Reforming தன்மையும் குறைகிறது.

இதற்கு காரணம் கண்டறிய $\mathrm{Ni}_{\mathrm{A}} \mathrm{Al}_{2} \mathrm{O}_{3}$ Catalyst இல் potassium என்ற தனிமத்தை கலந்து Glycerol Reforming செய்யப்பட்டது. Glycerol ஐ தேர்ந்தெடுத்ததற்கு காரணம் : Glycerol reforming செய்யும் போது Catalyst மீது கரி படியவில்லை. Potassium கலந்த $\mathrm{Ni}^{2} \mathrm{Al}_{2} \mathrm{O}_{3}$ Catalyst ஐ பரிசோதனை செய்த போது, Methane Reforming தன்மை ஆரம்பம் முதலே குறைந்து காணப்பட்டது. Potassium பதிலாக Magensium கலந்த போது Methane Reforming தன்மையும், bio-திரவத்தில் இருக்கும் கரியை வாயுவாக மாற்றும் திறனும் விரைவாக குறைந்தது. ஆனால், இதனை Regeneration மூலம் திரும்பப் பெற்று விடலாம். ஆகையால், இதனை செயல்முறை பொறியியல் (process engineering) மூலமாக சொல்ல வேண்டுமெனில், அதிக அளவு bio-திரவத்தில் இருக்கும் கரியை வாயுவாகவும் மற்றும் தொடர்ச்சியாகவும் இருந்தாலே போதும். Methane Reforming திறன் குறைந்தாலும் அதனை Primary reforming என்னும் செயல்முறையால் Synthesis gas ஆக மாற்றலாம். 
பின்பு HSR செயல்முறை பரிசோதனை செயப்பட்டது. இதில் 1) ஆவி/வாயு உருவாக்கும் செயல்முறை 2) catalytic Pre-reforming (செயல் முறை) 3) catalytic Primary reforming செயல் முறைகளை ஒரே இயந்திரத்தில் செய்யப்பட்டது. இதில் Pyrolysis oil மற்றும் எரிவாயு (Methane) உபயோகிக்கப்பட்டது. இந்த பரிசோதனை சுமார் 100 மணி நேரம் எரிவாயுவையும் பின்னர் எரிவாயு Pyrolysis oilம் கலவையும் மாற்றி மாற்றி செய்யப்பட்டது. இதன் விளைவு, Primaryreforming செயல் முறையில் உள்ள Catalyst மீது சுமார் 10 மடங்கு குறைவான கரி pre-reforming catalyst காட்டிலும் காணப்பட்டது. இந்த புதிய HSR செயல்முறையை அனைத்து bioதிரவத்திற்கும் நிரூபிக்கப்படது.

இறுதிக் கட்டமாக, இதுவரை பரிசோதனை செய்த HSR செயல்முறைக்கு ஒரு பொருளாதார பகுப்பாய்வு செய்யப்பட்டது. தற்போது இருக்கின்ற Natural gas விலையும் 0.2 €/Nm³ , Crude glycerol க்கு 200 €/tonne என்ற விலையை நாங்களே நிர்ணயித்து பகுப்பாய்வு செய்யப்பட்டது. HSR மூலமாக bio-Methanol தயாரித்தால் (54\% Glycerol, 46\% Methane), அதன் விலை சுமார் 430 €/tonne, அதாவது, தற்போது இருக்கும் Methanol விலையை விட 75 €/tonne கூடுதலாக கொடுக்க நேரிடும். ஆனால், இந்த செயல்முறையால் பல நன்மைகள் இருக்கின்றன. இருப்பினும், இந்த ஆய்வின் மூலமாக, HSR செயல்முறையை ஒரு மாபெரும் வியாபார ரீதியான ஆய்வை இனி வரும் காலங்களில் செய்ய வேண்டுமென பரிந்துரை செய்கிறோம். 


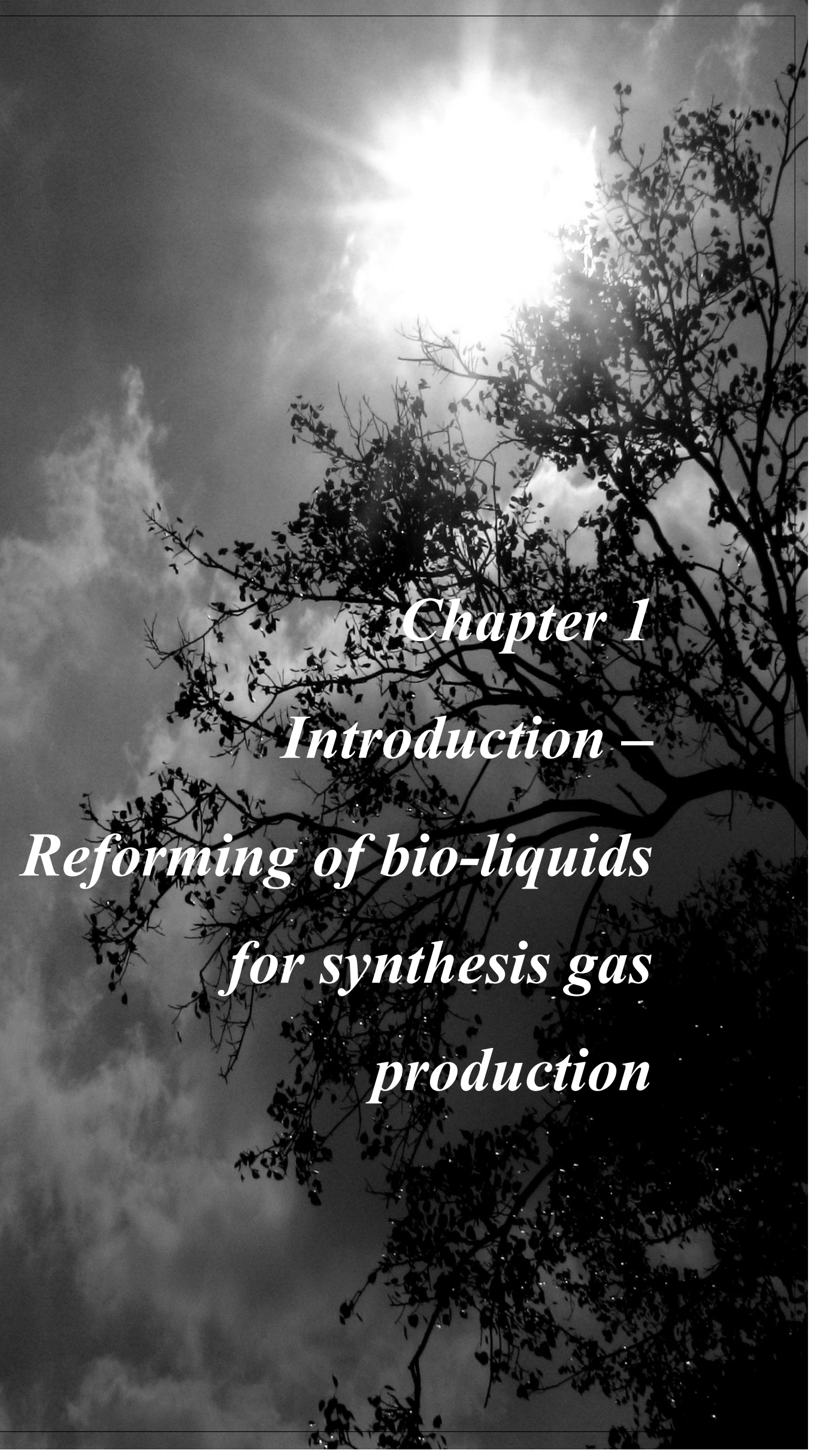




\section{Abstract}

In this Thesis, hybrid steam reforming of methane together with bio-liquids such as biomass fast pyrolysis oil and crude glycerol to produce synthesis gas is investigated. The hybrid steam reforming concept summarizes the following items: 1) Gasification of bio-liquids 2) Steam reforming of bio-liquids 3) Hybrid steam reforming of bioliquids together with methane to produce synthesis gas. In this Chapter, the topic is introduced by summarizing the major research achievements in the field of steam reforming of bio-liquids. Followed by that, a brief overview about the scope of this Thesis is given. 


\subsection{General Introduction}

The controlled use of fire in the Stone Age was one of the earliest discoveries by mankind [1]. From the Stone Age, mankind used wood (biomass) to fulfill the basic energy needs by burning it. Although biomass may have proven to be the original fuel source, other sources such as peat and coal became important in various places where availability of wood resources became scarce. A major shift from wood to coal and later crude oil happened during the industrial revolution [2]. This was mainly because of the increasing energy demands per capita, increase in the population, urbanization and deforestation. Since then, burning and utilization of fossil fuels has increased several times to produce energy and chemicals [3]. As a result, presently, fossil fuels are depleting, their prices are fluctuating and there are concerns that fossil fuels induced climate change. Therefore, in the last few decades, the search for an alternative renewable raw material to replace fossil reserves has been intensified all over the world.

Renewable energy is a form of energy that can be produced from direct solar, wind, hydro, geothermal, tidal and biomass sources. Presently, biomass contributes to ca. 55 $\mathrm{EJ} / \mathrm{y}$ to the global energy consumption which may go up to ca. $90 \mathrm{EJ} / \mathrm{y}$ according to Shell by 2050 [4]. The main advantages of using renewable energy sources are:

1. reducing the dependence on non-renewable fossil resources and thus decreasing greenhouse gas emissions and increasing security of supply,

2. meeting the additional demand created by the growing increasingly energy consuming population and therewith providing energy for future generations,

3. creation of jobs (economic growth) in both developed and developing areas.

Among the renewable resources, biomass is interesting because it can be stored and transported and because of its composition. Biomass contains carbon and hydrogen which are also the constituting atoms of our current fuels and petrochemicals. Biomass includes plant, wood, crop residues, animal waste, sewage, waste from food processing etc. 


\subsection{Biomass conversion}

Biomass can be converted into useful forms of energy and chemicals by using a number of different processing routes. There are thermochemical and biotechnological conversions and for producing fuels and chemicals also separations are of paramount importance. For good overviews on these subjects the reader is referred to Chum et al. [5], Bridgwater et al. [6] and Sanders et al. [7]. Figure 1 shows a schematic overview of the thermochemical routes to fuels and chemicals.

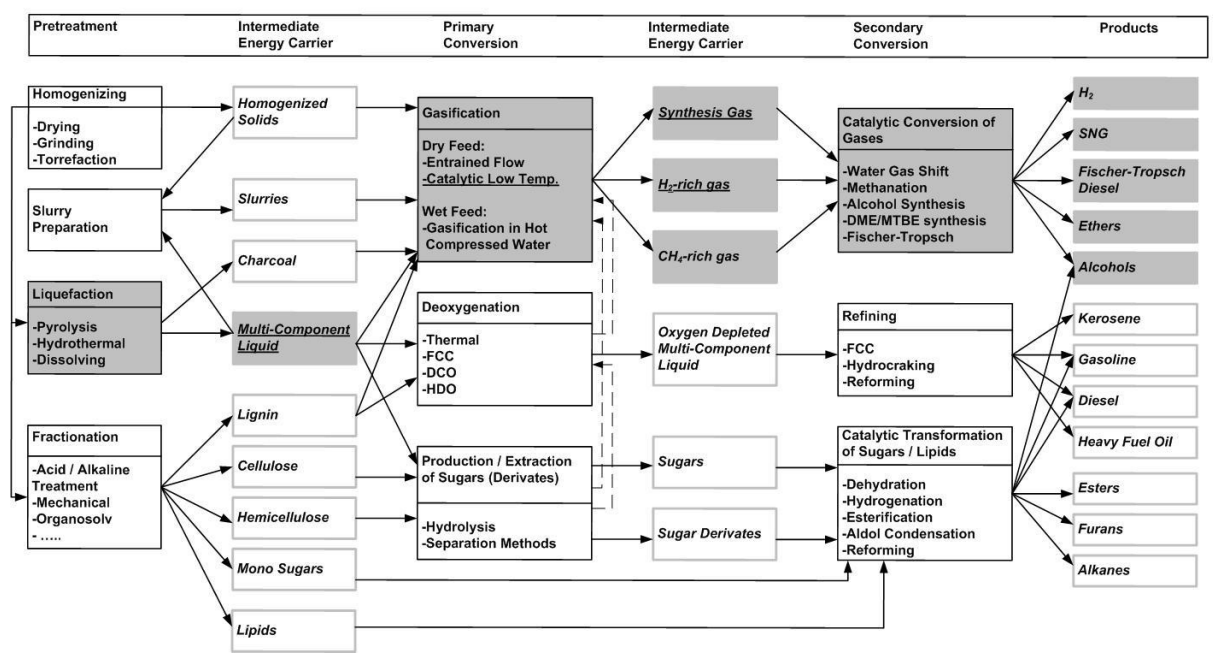

Figure 1: Overview of biomass thermochemical conversion of biomass (adapted from Kersten et al. [8]. The highlighted route encompasses pyrolysis oil steam reforming / gasification for the production of synthesis gas: a conversion route investigated in this Thesis. 


\subsection{Synthesis gas}

Synthesis gas is a mixture of $\mathrm{CO}$ and $\mathrm{H}_{2}$ that can be converted into various fuels and chemicals (see Figure 1). According to thermodynamics biomass $(<40 \mathrm{wt} \%$ water) can be converted to synthesis gas at temperatures as low as $800{ }^{\circ} \mathrm{C}$ when enough steam and/or oxygen is supplied. However, in practice higher gasification temperatures of above $1200{ }^{\circ} \mathrm{C}$ are required to produce synthesis gas without the usage of a catalyst. This process is referred to as entrained flow gasification and is proven at demonstration scale for biomass [9] and biomass-coal mixtures [10, 11]. At ca. $800{ }^{\circ} \mathrm{C}$ a fuel gas is produced containing substantial amounts of tars and hydrocarbons, mainly $\mathrm{CH}_{4}$, which can be converted into synthesis gas by extensive cleaning and conditioning $[12,13]$. Catalytic gasification of solid biomass has been investigated to produce synthesis gas from biomass at lower temperatures and thus at lower costs. This Thesis deals with the production of synthesis gas from relatively dry bio-liquids $\left(<30 \mathrm{wt} \% \mathrm{H}_{2} \mathrm{O}\right)$ via steam reforming (catalytic gasification). Wet biomass streams [ $\left.>70 \mathrm{wt} \% \mathrm{H}_{2} \mathrm{O}\right]$ can be converted into gas by aqueous phase reforming [14] and supercritical water gasification [15-18]. Due to the very high water concentration these processes do not yield synthesis gas, but $\mathrm{H}_{2}\left(+\mathrm{CO}_{2}\right)$ or $\mathrm{CH}_{4}$ at lower temperature.

\subsection{Reforming of bio-liquids}

Steam reforming of bio-liquids is analogous to steam reforming of methane and naphtha and is supposed to run at ca. $800{ }^{\circ} \mathrm{C}$. The overall stoichiometric reactions are:

$\mathrm{C}_{6} \mathrm{H}_{9} \mathrm{O}_{3}+3 \mathrm{H}_{2} \mathrm{O} \rightarrow 6 \mathrm{CO}+7.5 \mathrm{H}_{2}$

$\mathrm{CO}+\mathrm{H}_{2} \mathrm{O} \Leftrightarrow \mathrm{CO}_{2}+\mathrm{H}_{2}$ 
Glycerol and pyrolysis oil are investigated as feeds in this work. Glycerol becomes available on the market as a by-product from biodiesel manufacturing via transesterification [19]. Pyrolysis is a thermochemical process to converted biomass into pyrolysis oils that can be further upgraded or refined for electricity, transportation fuels and chemicals production. At the time of writing, several demonstration plants are considered aiming at maturing the technology and maximizing oil production [20, 21]. Biomass particles decompose in the absence of oxygen at temperatures between $250^{\circ} \mathrm{C}$ and $550^{\circ} \mathrm{C}$ into char, liquids (removed from the solid as vapors or as aerosols), and gases by a process known as pyrolysis. The liquid product, called pyrolysis oil or bio-oil, is typically condensed and captured downstream of the reactor in single or multistep (staged) condensers. When the pyrolysis is conducted at temperatures between $400{ }^{\circ} \mathrm{C}$ and $550{ }^{\circ} \mathrm{C}$ and small particles are used, very high heating rates are achieved resulting in maximal liquid production. This process is called fast pyrolysis. For good reviews on pyrolysis and the applications of pyrolysis oil the reader is referred to Westerhof et al. [20], Mercader et al. [22], Czernik et al. [23], Bridgwater et al. [6] and Van Rossum et al. [24]. Table 1 lists typical properties of pyrolysis oil and glycerol. 
Table 1: Typical properties of wood pyrolysis oil [25, 26]

\begin{tabular}{|l|c|c|}
\hline Physical property & Pyrolysis oil & $\begin{array}{c}\text { Neutralized } \\
\text { Crude glycerol }\end{array}$ \\
\hline Moisture content (wt\%) & $15-30$ & 11 \\
\hline $\mathrm{pH}$ & 2.5 & $\mathrm{n} . \mathrm{m}$ \\
\hline Specific gravity & 1.2 & $\sim 1.1-1.2$ \\
\hline Elemental composition (wt\%) & & \\
\hline Carbon & $54-58$ & 31.9 \\
\hline Hydrogen & $5.5-7.0$ & 8.6 \\
\hline Oxygen & $35-40$ & 59.5 \\
\hline Nitrogen & $0-0.2$ & 0 \\
\hline Ash & $0-0.2$ & $6.6^{*}$ \\
\hline HHV (MJ/kg) & $16-19$ & 19 \\
\hline Viscosity (at $\left.50{ }^{\circ} \mathrm{C}, \mathrm{cP}\right)$ & $40-100$ & n.m \\
\hline Solids (wt \%) & $0.2-1$ & n.m \\
\hline
\end{tabular}

\footnotetext{
n.m-not measured

${ }^{*}$ Ash content of crude glycerol is $6.6 \mathrm{wt} \%$ (consists of $\mathrm{K}_{2} \mathrm{O}$ and trace amounts of $\mathrm{CaO}$ and $\mathrm{Fe}_{2} \mathrm{O}_{3}$ ) and crude glycerol is $\sim 4.3 \mathrm{wt} \%$ (consists of $\mathrm{Na}_{2} \mathrm{O}$ )

Crude glycerol contains about $\sim 83$ wt\% of glycerol, 1.8 wt\% of organics (Consists of diglycerides (0.78\%), triglycerides (0.5\%), FAME (0.3\%), Free fatty acids (0.2\%), Methanol (0.01\%), trace amounts of citric acid and acetic acid), $4.4 \mathrm{wt} \%$ of inorganics (Consists of $4.3 \mathrm{wt} \%$ Sodium Chloride, 0.09 wt\% Magnesium Sulphate and 0.01 wt\% of Calcium Sulphate)
}

Reforming bio-liquids instead of gasifying/reforming solid biomass could have some advantages:

- The volumetric energy density of bio-liquids is higher (ca. 5 times). This makes transport of biomass to the synthesis production site, especially over long distances, economically more attractive.

- Generally a liquid is easier to store, transport and process. Especially pressurization, which is required for large scale gasification/reforming, will be easier for liquid feeds. 
- Bio-liquids could be cleaner than solid raw biomass. Pyrolysis oil for instance is cleaner than the original feedstock. Because of the relative low process temperature, the minerals and metals remain in the solid state and are concentrated in the char. In this way, an option is created to recycle the metals and minerals locally to the soil. Additionally, catalytic upgrading of pyrolysis oil to high value fuels and chemicals becomes easier since most of the impurities $(\mathrm{S}, \mathrm{Cl}$, alkali) which deactivate catalysts are separated in the fast pyrolysis process.

\subsection{Literature review}

In the following section, a literature review on catalytic reforming of bio-liquids such as pyrolysis oil, glycerol and representative model compounds of pyrolysis oil is presented. Most of the reported work focusses on catalyst screening, selection and development. Only few publications discuss process development issues.

Pyrolysis oil contains numerous compounds with different functional groups such as acids, ketones, aldehydes, alcohols etc. Because of this complexity, many scientific contributions are based on the model compounds to gain insight into oxygenates reforming over a catalyst bed. The overall stoichiometric reactions for reforming of any bio-liquid can be written as:

- Cracking of oxygenates

$$
\mathrm{C}_{n} \mathrm{H}_{m} \mathrm{O}_{k} \Rightarrow \text { gases }\left(\mathrm{CO}+\mathrm{CO}_{2}+\mathrm{CH}_{4}+\mathrm{C}_{2-4}+\mathrm{H}_{2}\right)+\text { vapors }\left(\mathrm{C}_{\mathrm{a}} \mathrm{H}_{\mathrm{b}} \mathrm{O}_{\mathrm{c}}\right)+\text { solid char }
$$

- Steam reforming of oxygenates

$$
\mathrm{C}_{\mathrm{n}} \mathrm{H}_{\mathrm{m}} \mathrm{O}_{\mathrm{k}}+(\mathrm{n}-\mathrm{k}) \mathrm{H}_{2} \mathrm{O} \Rightarrow \mathrm{nCO}+(\mathrm{n}+\mathrm{m} / 2-\mathrm{k}) \mathrm{H}_{2}
$$

- Dry reforming of oxygenates

$$
\mathrm{C}_{\mathrm{n}} \mathrm{H}_{\mathrm{m}} \mathrm{O}_{\mathrm{k}}+(\mathrm{n}-\mathrm{k}) \mathrm{CO}_{2} \Rightarrow(2 \mathrm{n}-\mathrm{k}) \mathrm{CO}+(\mathrm{m} / 2) \mathrm{H}_{2}
$$

- Polymerization of oxygenates (liquid and vapor)

$$
\mathrm{C}_{\mathrm{n}} \mathrm{H}_{\mathrm{m}} \mathrm{O}_{\mathrm{k}} \Rightarrow \mathrm{C}_{\mathrm{a}} \mathrm{H}_{\mathrm{b}} \mathrm{O}_{\mathrm{c}}+\mathrm{dH}_{2} \mathrm{O}+\mathrm{eCO}_{2}
$$


- Methanation

$\mathrm{CO}+3 \mathrm{H}_{2} \Leftrightarrow \mathrm{CH}_{4}+\mathrm{H}_{2} \mathrm{O}(\Delta \mathrm{H}=-206 \mathrm{~kJ} / \mathrm{mol})$

- Water-gas shift $\mathrm{CO}+\mathrm{H}_{2} \mathrm{O} \Leftrightarrow \mathrm{CO}_{2}+\mathrm{H}_{2}(\Delta \mathrm{H}=-41.1 \mathrm{~kJ} / \mathrm{mol})$

- Bouduoard $\mathrm{C}_{(\mathrm{S})}+\mathrm{CO}_{2} \Leftrightarrow 2 \mathrm{CO}(\Delta \mathrm{H}=170 \mathrm{~kJ} / \mathrm{mol})$

- Water-gas reaction $\mathrm{C}_{(\mathrm{S})}+\mathrm{H}_{2} \mathrm{O} \rightarrow \mathrm{CO}+\mathrm{H}_{2}(\Delta \mathrm{H}=\sim 131 \mathrm{~kJ} / \mathrm{mol})$

Over the last decade, several researchers investigated acetic acid steam reforming using catalysts which have $\mathrm{Ni}$ as an active metal phase. Acetic acid has been chosen because it is one of the compounds present in pyrolysis oil [27]. Wang et al. [28] demonstrated stable reforming activity of a mixture of acetic acid, m-cresol and syringol at $700{ }^{\circ} \mathrm{C}, \mathrm{S} / \mathrm{C}=5, \mathrm{t}=0.09 \mathrm{~s}$ using commercial ICI 46 series $\mathrm{Ni}$ on alumina catalyst over a period of $\sim 15 \mathrm{~h}$. Similar stability was reported for $25 \mathrm{~h}$ during acetic acid steam reforming at $600{ }^{\circ} \mathrm{C}$ and $\mathrm{S} / \mathrm{C}=3$ in a fixed bed [29]. Also, pure glycerol showed similar stability for 24 hours during reforming at $600{ }^{\circ} \mathrm{C}$ and $\mathrm{S} / \mathrm{C} \sim 3$ using a 3 wt $\%$ Ru on $\mathrm{Y}_{2} \mathrm{O}_{3}$ catalyst [30]. Wang et al. [31] reported that the coke deposited on the Nickel on alumina catalyst during steam reforming of acetic acid could be gasified by steam at the reforming conditions itself.

Basagiannis et al. [32] reported that the coke formation may take place via e.g. the Boudouard reaction and thermal decomposition via oligomers such as ketene from acetic acid. To overcome excessive coke formation, several researchers studied steam reforming of different oxygenates at high molar steam-to-carbon in feed ratio $(>3)$ [31-36].

The results showed that high temperature $\left(>650{ }^{\circ} \mathrm{C}\right)$ and high molar steam-to-carbon in feed ratio (>3) were required for Nickel on alumina catalysts to achieve almost complete carbon conversion to gases. An et al. [37] found that the type of carbon (amorphous or graphitic type) deposited on the catalyst was set by the amount of $\mathrm{Ni}$ loaded on the catalyst. To promote the gasification of carbonaceous deposits several works were based on Nickel on zirconia catalysts using many oxides of $\mathrm{Ce}, \mathrm{Zr}, \mathrm{La}$, 
$\mathrm{Mg}$, $\mathrm{K}$ etc. as promoters. Somsak et al. [38] compared the catalyst performances of $\mathrm{Ni}$ on $\mathrm{Al}_{2} \mathrm{O}_{3}, \mathrm{Ce}-\mathrm{Zr}$ and $\mathrm{MgO}$. The Ce- $\mathrm{Zr}$ system provided good redox properties and oxygen mobility prevented the deposition of coke on the catalyst during acetic acid steam reforming. Matas Güell et al. [39] observed that addition of $\mathrm{K}$ and $\mathrm{La}$ on Nickel-zirconia catalyst increased the stability of the catalyst by decreasing the accumulation of coke on the catalyst. The results obtained by Yan et al. [40] showed that the Nickel on Ce-Zr catalyst showed a higher yield and better stability than its commercial Nickel on alumina catalyst counterpart using the aqueous phase of pyrolysis oil as feed. Takanabe et al. [41] found that even an unpromoted Pt on zirconia catalyst lost its activity due to the coke deposition via thermal decomposition of acetic acid on the Pt surface. Bimetallic catalyst systems such as Ni-Co, Co-Fe systems were also investigated and reported to have stable adsorption of the reactive coke precursors on the catalyst surface [42]. Li et al. [43] compared impregnation method with precipitation method for Ni on alumina catalysts on crude ethanol steam reforming. They [43] reported that the Nickel was easily reducible and obtained a higher yield of $\mathrm{H}_{2}$ when it was prepared by precipitation method than impregnation technique. Matas Güell et al. [44] reported that addition of Nickel to $\mathrm{K}-\mathrm{La}-\mathrm{ZrO}_{2}$ support increased phenol conversion to gases up to $\sim 85 \%$. The gas productions were fairly stable over a period of $22 \mathrm{~h}$ with no $\mathrm{CH}_{4}$ in the product gas was observed.

From the work on model compounds the following can be concluded:

By choosing appropriate process conditions such as temperature, steam over carbon ratio and catalysts, it is possible to obtain a stable reforming operation over $20 \mathrm{~h}$ in laboratory set-ups. Moreover, mechanisms and pathways leading to coke formation have been proposed.

Catalyst performance depends on:

1. catalyst preparation methods [45]

2. choice of the promoters and active metal phase [31-46]

3. amount of the active metal phase loaded on the support [47] 


\subsubsection{Steam reforming of pyrolysis oil and its fractions}

National renewable energy limited (NREL, Colorado, United States of America) was the first to test actual available bio-liquids for the development of a catalytic steam reforming process to produce hydrogen. The bio-liquids (next to model compounds) were the aqueous fraction of pyrolysis oil/waste streams [33, 48]. Their initial strategy to separate pyrolysis oil in an aqueous phase which could be steam reformed for the production of hydrogen. The heavy phase could then be used for the production of phenolic resins or adhesive formulations. NREL together with its partners demonstrated at the laboratory scale using fixed and fluidized bed reactors to produce $\mathrm{H}_{2}$ from model compounds such as acetic acid, acetol, hydroxyl acetaldehyde, methanol, sugar fractions, trap grease, crude glycerin, etc. [33,48]. A fluidized bed was preferred over a fixed bed for bio-liquid streams (aqueous phase of pyrolysis oil and crude glycerin) since it was less susceptible to plugging due to coking/charring of the bed [48]. NREL reported that major issues in the development of catalysts for a fluidized bed are activity (steam reforming and resisting coking) and mechanical strength (attrition) [28, 31, 49, 50].

Van Rossum et al. [24] worked on the process development of pyrolysis oil reforming and demonstrated synthesis gas production in a two-stage process where pyrolysis oil was first atomized/gasified in a fluidized bed and then catalytically converted in the second stage using commercial steam reforming catalyst in a fixed bed. In this staged system they showed syngas production for $\sim 12 \mathrm{~h}$ with no $\mathrm{CH}_{4}$ or $\mathrm{C}_{2-3}$ generation at a relatively low $\mathrm{GC}_{1} \mathrm{HSV}$ of $\sim 100 \mathrm{~h}^{-1}$. Davidian et al. [51] worked on alternating cracking / steam reforming and regeneration steps. More easily gasifiable coke was formed on a $\mathrm{Ni} / \mathrm{Al}_{2} \mathrm{O}_{3}$ catalyst promoted using $\mathrm{La}$ and $\mathrm{K}$.

Wang et al. [28] reported that the UCI G-91 steam reforming catalyst activity was completely recovered after regeneration using steam during steam reforming of the aqueous phase of pyrolysis oil. However, the carbon deposits above the catalyst bed blocked the reactor and $\mathrm{H}_{2}$ production decreased with time. In line with that, Garcia et al. [49] reported that the coke formation takes place via (i) volatile components due to gas phase reactions and (ii) deposition of char during pyrolysis prior to the catalytic 
reforming. To overcome this problem, new catalysts were developed using promoters such as $\mathrm{Ce}, \mathrm{Zr}$, etc. that can enhance steam adsorption and provide gasification of coke.

Rioche et al. [52] showed that an active phase of platinum metal was sintered during steam reforming of pyrolysis oil at high $\mathrm{S} / \mathrm{C}$ of 10.8. Salehi et al. [53] reported that Ruthenium promoted Nickel on alumina catalyst showed better dispersion while considerable loss in the surface area and pore volume were not observed during steam reforming of pyrolysis oil at $850{ }^{\circ} \mathrm{C}$. Due to this phenomenon, Ru promoted Ni on alumina catalyst showed higher hydrogen production than unpromoted $\mathrm{Ni}$ on alumina catalyst. Azad et al. [54] reported that the Nickel on zirconia catalyst had higher carbon deposition than a $\mathrm{Ni}$ on alumina catalyst when reforming pyrolysis oil. Nevertheless, steam reforming of benzene at $700{ }^{\circ} \mathrm{C}$ using a commercial $\mathrm{Ni}$ on alumina catalyst (KATALCO 46) showed a stable gas production for 5 hours. Lan et al. [55] investigated catalytic steam reforming of pyrolysis oil using a $\mathrm{Mg}$ and $\mathrm{La}$ promoted Ni on alumina catalyst in a fixed and fluidized bed. At the same temperature $\left(800^{\circ} \mathrm{C}\right)$ and residence time $(1 \mathrm{~h})$, fixed bed catalyst had $\sim 0.4 \mathrm{wt} \%$ coke, whereas fluidized bed had almost half of it. Moreover, the coke deposited in the fluidized bed catalyst was more easily gasified than the coke from the fixed bed.

$\mathrm{Xu}$ et al. [56] reported that the sintering of the metal on the support was the main reason for the deactivation of the catalyst in a fluidized bed. Coke deposition was eliminated as the main reason for the deactivation of the catalyst because of its gasification behavior at reaction conditions. To protect the catalyst from the deactivation, sorption assisted reforming using a mixture of commercial naphtha reforming Ni on alumina catalyst (Z417 Source China catalyst limited) and dolomite (to capture $\mathrm{CO}_{2}$ ) was investigated by Yan et al. [57]. The mixture had higher $\mathrm{H}_{2}$ yield than without sorbent, nevertheless, the mixture catalyst lost its activity and a regeneration of sorbent had to be proposed. 
Based on the literature studies, the following conclusions can be drawn from the catalyst perspective:

Initially, the activity of the catalyst is high both in terms of $\mathrm{H}_{2}$ yield or synthesis gas production. It is possible to achieve a high activity by several catalyst systems such as $\mathrm{Ni} / \mathrm{Pt} / \mathrm{Ru}$ etc, on zirconia or alumina, promoted using $\mathrm{K}, \mathrm{Mg}, \mathrm{Ca}$, etc. However, till now, none of the catalysts showed stable behavior for more than a few hours during pyrolysis oil steam reforming.

Process development is in its early stages. Spraying pyrolysis oil directly on to fixed beds cause coke build-up and blocking which prevents stable continuous operation. The work of Lan et al. [55] indicated that fluidized bed reforming showed slightly better performance than its counterpart fixed bed reforming. A staged system of gasifying the pyrolysis oil as a first step and subsequent catalytic conversion (e.g. steam reforming) seems to minimize the problems related to deactivation of the reforming catalyst [24]. 


\subsection{This Thesis}

An interesting strategy proposed is to integrate bio-refinery with the existing fossil based industry. One of the possibilities is to produce synthesis gas from biomass and fossil resources such as natural gas via steam reforming. This so-called hybrid steam reforming (HSR) concept is schematically visualized in Figure 2. Partnering and integrating with the fossil based industry has some advantages, such as: making use of existing infrastructure and producing existing products for existing markets.

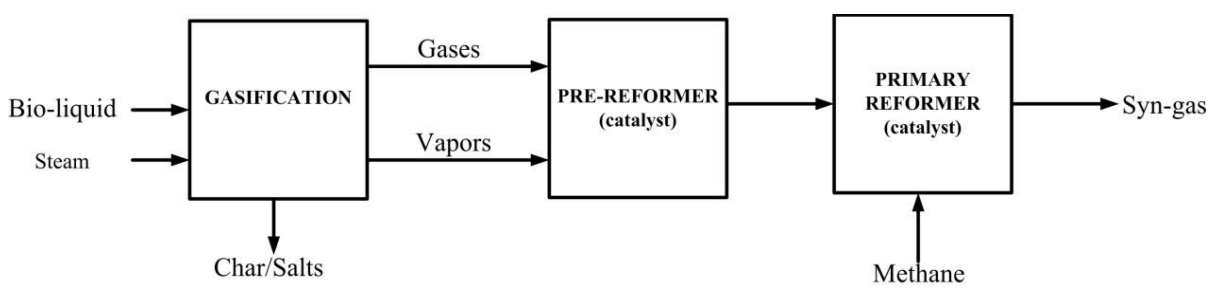

Figure 2: HSR concept for syngas production from bio-liquids and methane (natural gas).

The HSR process consists of the following stages:

(1) Gasification: the controlled atomization of bio-liquids into small droplets $(\sim 100$ $\mu \mathrm{m})$ in a gasifier around at $500-800{ }^{\circ} \mathrm{C}$. This leads to the production of vapor, gases, and char via thermal decomposition.

(2) Pre-reforming: the vapors and gases from (1) are steam reformed. This step is similar to pre-reforming of naphtha/natural gas. In the case of naphtha and natural gas, higher hydrocarbons are partially reformed to produce gases whereas in the case of bio-liquids, vapors (oxygenates) are reformed to produce gases.

(3) Primary reforming: co-steam reforming of a fossil source and the product from (2) e.g. the product gas obtained from the pre-reforming step is mixed with desulphurized methane and this mixture is subsequently reformed in the primary reformer. Because 
this is similar to natural gas reforming, a high temperature of $\sim 800{ }^{\circ} \mathrm{C}$ is preferred for this step. The whole concept is summarized in Figure 2.

The following items are investigated in this Thesis:

1. Atomization and gasification of bio-liquids,

2. Reforming of several grades of glycerol, stand-alone and via the hybrid system with natural gas

3. Reforming of pyrolysis oil, stand-alone and the via hybrid system with natural gas

4. The techno-economic viability of the HSR concept coupled to methanol production

In Chapters 2 to 4 atomization followed by gasification (non-catalytic) was investigated to determine the product distribution from pyrolysis oil and several grades of glycerol by changing parameters such as temperature, pressure, droplet size, and pyrolysis oil concentration. The carbon distribution from the pyrolysis oil to lumped product groups such as gases, vapor (tars) and char was studied in detail. The results obtained in these Chapters are also of value for design of gasifiers, boilers, engines fed with bio-liquids, i.e. all processes where bio-liquids are injected in a hot environment.

The development is continued in Chapter 4 by investigating the behavior of the commercial steam reforming catalysts in a fixed bed when several grades of glycerols with different purity are brought in to contact with the catalyst bed. Steam reforming of pure and crude glycerol was studied at $800{ }^{\circ} \mathrm{C}$ and S/C 3 . HSR of glycerol (both pure and crude) together with methane using commercial steam reforming catalysts was investigated.

After in depth knowledge is obtained from the gasification of pyrolysis oil and reforming of crude glycerol (Chapters 2, 3 and 4), the behavior of commercial naphtha pre-reforming and in-house $\mathrm{Mg}$ promoted $\mathrm{Ni}$ on alumina catalysts during steam reforming of pyrolysis oil in a fixed bed is investigated in Chapter 5. The performance of the catalysts was evaluated based on the gas production and carbon to 
gas conversion before and after regeneration. A special focus is given to potassium as promoter during steam reforming of bio-liquids. Additionally, initial results on HSR of pyrolysis oil together with methane using a commercial naphtha steam reforming catalyst are presented.

Finally, in Chapter 6, a techno-economic evaluation of HSR of glycerol together with methane was performed. The HSR process was designed according to a systematic procedure and simulated in the commercial $\mathrm{UniSim}^{\circledR}$ design suite process simulator. Based on this window of operation, mass and energy balances for different amount of glycerol in the HSR concept and a techno-economic evaluation (TEE) were performed. From the TEE, the cost price of bio-methanol produced via the HSR process was estimated. An outlook about the future of HSR and how to develop this process further is presented.

\section{References}

1. K.S.Brown, C.W.Marean, A.I.R Herries, Z.Jacobs, C.Tribolo, D. Braun, D.L.Roberts, M. C.Meyer, J.Bernatchez, Science (2009), vol 325, 859-861

2. P.J.G Pearson, T.J. Foxo, Energy Policy (2012), vol 50, 117-127

3. S.Shafiee, E.Topal, Energy Policy (2009), vol 37, 181-189

4. Open source : Shell energy scenarios to 2050 (2008), http:/www.static.shell.com/static/public/downloads/brochures/corporate_pkg/ scenarios/shell_energy_scenarios_2050.pdf

5. H.L.Chum, R.P.Overend, Fuel processing technology (2001), vol 71, 187-195

6. A.V.Bridgwater, Catalysis today (1996), vol 29, 285-295

7. J.P.M.Sanders, J.H.Clark, G.J.Harmsen, H.J.Heeres, J.J.Heijnen, S.R.A.Kersten, W.P.M.van Swaaij, J.A.Moulijn, Chemical Engineering and Processing (2012), vol 51, 117-136

8. S.R.A.Kersten, W.P.M.van Swaaij, L.Lefferts, K.Seshan, Options for Catalysis in the Thermochemical Conversion of Biomass into Fuels, In: 
Catalysis for Renewables: From Feedstock to Energy Production, ed. Centi, G.; Van Santen, R.A., Wiley-VCH, Weinheim, Germany, 2007.

9. E.Henrich, F.Weirich, Environmental Engineering Science (2004), vol 21, 5364

10. C.Higman, M.van der Burgt, Gasification book (2003), Elsevier publications, ISBN 07506-7707-4

11. Co-gasification at the Buggenum IGCC power plant, A.van Dongen, M.Kanaar, NUON Power, The Netherlands

12. K.A.Magrini-Bair, S.Czernik, R.French, Y.O.Parent, E.Chornet, D.C.Dayton, C.Feik, R.Bain, Applied Catalysis A:General (2007), vol 318, 199-206

13. M.M.Yung, W.S.Jablonski, K.A.Magrini-Bair, Energy \& Fuels (2009), vol 23, $1874-1887$

14. G.W.Huber, R.D.Cortright, J.A.Dumesic, Angewandte Chemie (2004), vol 43, $12(1549-1551)$

15. Y.Matsumura, T.Minowa, B.Potic, S.R.A.Kersten, W.Prins, W.P.M.van Swaaij, B.van de Beld, D.C.Elliott, G.G. Neuenschwander, Andrea Kruse, Michael Jerry Antal Jr., Biomass and Bioenergy (2005), vol 29, 269-292

16. G.van Rossum, B.Potic, S.R.A.Kersten, W.P.M.van Swaaij, Catalysis today (2009), vol 145, 10-18

17. A.G.Chakinala, J.K.Chinthaginjala, K.Seshan, W.P.M. van Swaaij, S.R.A. Kersten, D.W.F.Brilman, Catalysis Today (2012) 1 (83-92)

18. A.Kruse, Journal of Supercritial fluids (2009), vol 47, 391-399

19. M.Pagliaro, M.Rossi, The Royal Society of Chemistry, 2008, ISBN 978-085404-124-4

20. R.J.M.Westerhof, Refining fast pyrolysis of biomass (2011), ISBN:978-946191-124-7

21. www.btgworld.com

22. F.de Miguel Mercader, Pyrolysis oil upgrading for co-processing in standard refinery units (2010), ISBN:978-90-365-3085-9

23. S.Czernik, R.French, C.Feik, E.Chornet, Ind.Eng.Chem.Res (2002), vol 41, 4209-4215

24. G.van Rossum, Steam reforming and gasification of pyrolysis oil (2009), ISBN: 978-90-365-2889-4 
25. S.Czernik, A.V.Bridgwater, Energy \& Fuels (2004) vol 18, 590-598

26. R.P.B.Ramachandran, G. van Rossum, W.P.M van Swaaij, S.R.A.Kersten, Energy \& Fuels 25 (2011), 5755-5766

27. K.Sipila, E.Kuoppala, L.Fagernas, A.Oasmaa, Biomass and Bioenergy (1998) vol

$14,103-113$

28. D.Wang, S.Czernik, E.Chornet, Energy\&Fuels (1998), vol 12, 19-24

29. X.Zheng, C.Yan, R.Hu, J.Li, H.Hai, W.Luo, C.Guo, W.Li, Z.Zhou, International Journal of Hydrogen Energy (2012), vol 37, 12987-12993

30. T.Hirai, N.Ikenaga, T.Miyake, T.Suzuki, Energy \& Fuels (2005) 19, 17611762

31. D.Wang, D.Montane, E.Chornet, Applied Catalysis A:General (1996), vol $143,245-270$

32. A.C.Basagiannis, X.E.Verykios, International Journal of Hydrogen Energy (2007) vol 32, 3343-3355

33. D.Wang, S.Czernik, D.Montane, M.Mann, E.Chornet, Ind.Eng,Chem.Res (1997) vol 36, 1507-1518

34. M.Marquevich, S.Czernik, E.Chornet, D.Montane, Energy and Fuels (1999), vol 13, 1160-1166

35. P.N.Kechagiopoulous, S.S.Voutetakis, A.A.Lemonidou, I.A.Vasalos, Energy and Fuels (2006), vol 20, 2155-2163

36. J.Medrano, M.Oliva, J.Ruiz, L.Garcia, J.Arauzo, International Journal of Hydrogen Energy (2008), vol 33, 4387-4396

37. L.An, C.Dong, Y.Yang, J.Zhang, L.He, Renewable energy (2011), vol 36, 930-935

38. T.Somsak, V.Meeyoob, B.Kitiyanana, P.Rangsunvigita, T.Rirksomboona, Catalysis Today (2011), vol 164, 257-261

39. B.Matas Güell, Doctoral Thesis Book, 2009, ISBN:978-90-365-2879-5

40. C.Yan, F.Cheng, R.Hu, International Journal of Journal Energy (2010), vol 35, 11693-11699

41. K.Takanabe, K.Aika, K.Inazu, T.Baba, K.Seshan, L.Lefferts, Journal of Catalysis (2006), vol 243, 263-269 
42. S.Wang, X.Li, L.Gui, Z.Luo, International Journal of Hydrogen Energy (2012), vol 37, 11122-11131

43. X.Li, S.Wang, Q.Cai, L.Zhu, Q.Yin, Z.Luo, Applied Biochemistry and Biotechnology (2012), vol 168, 10-20

44. B.M. Güell, Doctoral Thesis Book, 2009, ISBN:978-90-365-2879-5

45. X.Li, S.Wang, Q.Cai, L.Zhu, Q.Yin, Z.Luo, Applied Biochemistry and Biotechnology (2012), vol 168, 10-20

46. P.N.Kechagiopoulous, S.S.Voutetakis, A.A.Lemonidou, I.A.Vasalos, Energy and Fuels (2006), vol 20, 2155-2163

47. F.Bimbela, M.Oliva, J.Ruiz, L.García, J.Arauzo, Journal of Analytical and Applied pyrolysis (2009), vol 85, 204-213

48. S.Czernik, R.French, C.Feik, E.Chornet, Ind.Eng.Chem.Res (2002), vol 41, 4209-4215

49. L.García, R.French, S.Czernik, E.Chornet, Applied Catalysis A:General (2000), vol 201, 225-239

50. K.Magrini-Bair, S.Czernik, R.French, Y.Parent, M.Ritland, E.Chornet, (2002). Fluidizable Catalysts for Producing Hydrogen by Steam Reforming Biomass Pyrolysis Liquids.Proceedings of the 2002 U.S. DOE Hydrogen and Fuel Cells Annual Program/Lab R\&D Review, 6-10 May 2002, Golden, Colorado

51. T.Davidian, N.Guilhaume, E.Iojoiu, H.Provendier, C.Mirodatos, Applied Catalysis B:Environmental (2007), vol 73, 116-127

52. C.Rioche, S.Kulkarni, F.C.Meunier, J.P.Breen, R.Burch, Applied catalysis B:Environmental (2005), vol 61, 130-39

53. E.Salehi, F.S.Azad, T.Harding, J.Abedi, Fuel processing technology (2011), vol 92, 2203-2210

54. F.S.Azad, J.Abedi, E.Salehi, T.Harding, Chemical engineering journal (2012), vol 180, 145-150

55. P.Lan, Q.Xu, M.Zhou, L.Lan, S.Zhang, Y.Yan, Chemical engineering technology (2010), vol 33, 2021-2028

56. Q.Xu, P.Lan, B.Zhang, Z.Ren, Y.Yan, Energy \& Fuels (2010), vol 24, 64566462

57. C.Yan, E.Hu, C.Cai, International Journal of Hydrogen Energy (2010), vol 35, 2612-2616 


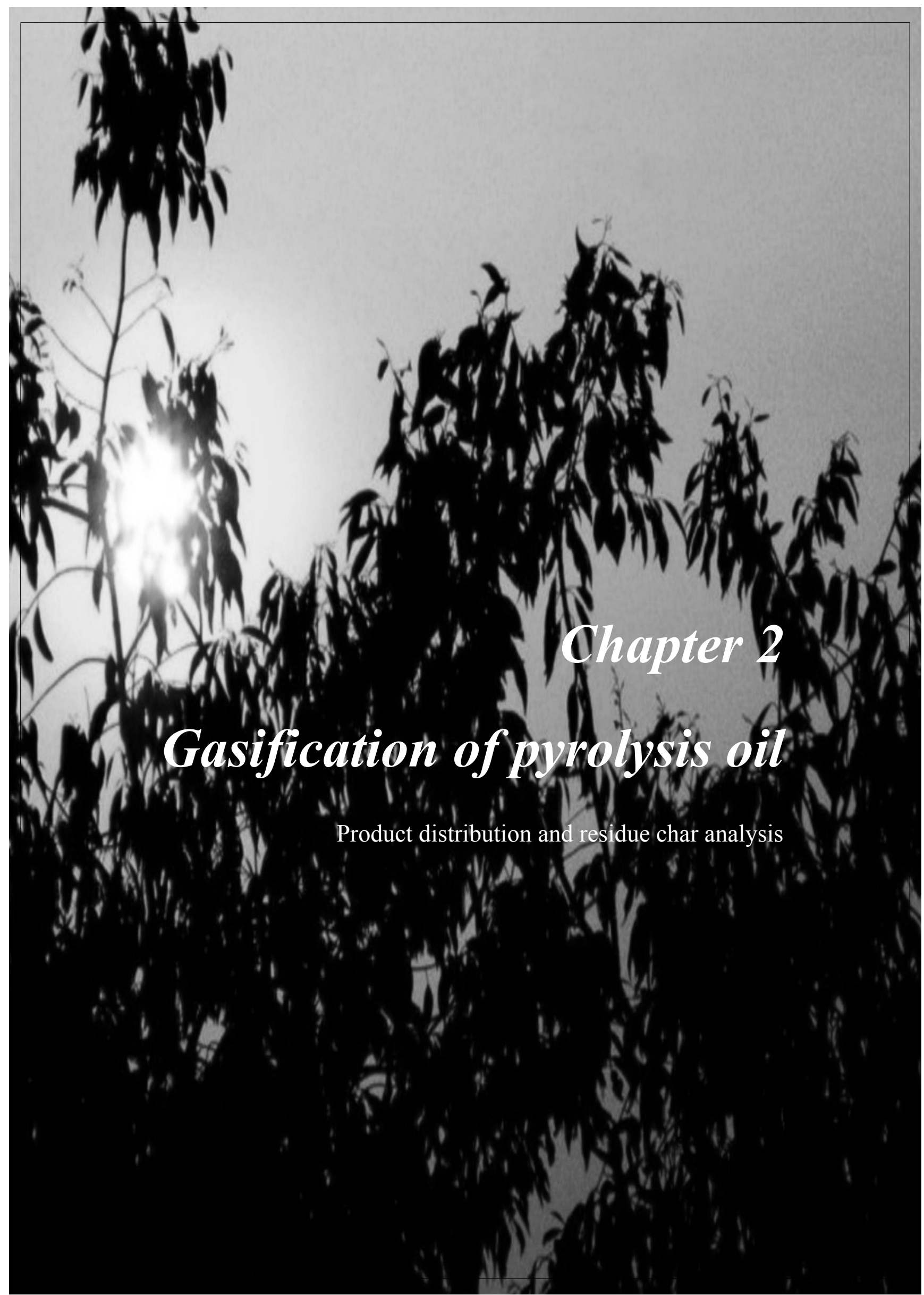




\section{Abstract}

The evaporation of pyrolysis oil was studied at varying heating rates $\left(\sim 1-10^{6}\right.$ ${ }^{\circ} \mathrm{C} /$ min) with surrounding temperatures up to $850{ }^{\circ} \mathrm{C}$. A total product distribution (gas, vapor and char) was measured using two atomizers with different droplet sizes. It was shown that with very high heating rates $\left(\sim 10^{6}{ }^{\circ} \mathrm{C} / \mathrm{min}\right)$, the amount of char was significantly lowered ( $8 \%$, carbon basis) compared to the maximum amount which was produced at low heating rates using a Thermo-gravimetric-analyzer ( $30 \%$, carbon basis; heating rate $1{ }^{\circ} \mathrm{C} / \mathrm{min}$ ). The char formation takes place in the 100-350 ${ }^{\circ} \mathrm{C}$ liquid temperature range due to polymerization reactions of compounds in the pyrolysis oil. All pyrolysis oil fractions (whole oil, pyrolytic lignin, glucose and aqueous rich/lean phase) showed charring behavior. The pyrolysis oil chars age when subjected to elevated temperatures $\left(\geq 700{ }^{\circ} \mathrm{C}\right.$ ), show similar reactivity towards combustion and steam gasification compared to chars produced during fast pyrolysis of solid biomass. However, the structure is totally different where the pyrolysis oil char is very light and fluffy. To be able to use the produced char in conversion processes (energy or syngas production) it will have to be anchored to a carrier.

This Chapter is published as

Evaporation of pyrolysis oil: Product distribution and residue char analysis, AIChE journal, 2010, 56, 2200-2210 


\subsection{Introduction}

Syngas production from biomass can play an important role for producing renewable fuels and chemicals especially when waste streams are being considered. For logistics and processing advantages, pyrolysis oil is proposed to become an intermediate energy carrier as the new 'crude oil' for refining $[1,2]$. To convert pyrolysis oil to syngas/hydrogen, which is the basis for the production and upgrading (hydrogen) of many fuels and chemicals, catalytic steam reforming is considered as a very attractive route since moderate process conditions can be applied and different scale sizes can be used as compared to high temperature entrained flow gasification [3].

When pyrolysis oil is being catalytically steam reformed, it is always accompanied by thermal reactions such as gasification and cracking. Already during the evaporation of the pyrolysis oil, three different products can be identified, namely: permanent gases, vapors and a carbonaceous solid material (here called char). Especially due to char formation, a fluidized bed has been preferred [3, 4] to steam reform pyrolysis oil since clogging of the reactor can be avoided. The char particles are then evenly distributed into the bed or elutriated from the bed. The distribution between these products is likely to be influenced by the heating trajectory of the pyrolysis oil droplet and the final evaporation temperature.

Various groups [3-6] have steam reformed pyrolysis oil or its fractions in a single fluidized catalytic bed where in most cases, a relatively clean fuel gas was being produced. However, irreversible catalytic activity loss (leading to increasing methane levels) was being observed which has mostly been ascribed to attrition/sintering of the catalyst. Due to this, up till now, no long-term operation of steam reforming (or its fractions) was feasible to see the influence of other impurities present in the pyrolysis oil (like sulfur) on the activity of the catalyst. Furthermore, optimization of the evaporation of pyrolysis oil is limited while using a single reactor because the reforming catalyst needs a high temperature to produce a methane free syngas at higher pressures due to the chemical equilibrium [7]. To overcome these problems which limits the applicability of the process, Van Rossum et al. [3, 7, 8] proposed a staged reactor concept where the evaporation and catalytic conversion are decoupled 
using a fluidized bed for oil evaporation followed by a fixed bed which contains a steam reforming catalyst. In this way, optimization of both, essentially different, processes is possible. A clean syngas could be produced when both the fluidized and fixed bed were at a temperature $\sim 800^{\circ} \mathrm{C}$. A decrease of the evaporation temperature showed promising results in such a way that the catalyst was able to actually be in contact with the primary tars (oxygenated pyrolysis vapors) which are easier to reform instead of a thermally cracked gas.

A full carbon balance, however, could not be made since not all product streams could be analyzed; for instance formed char inside the fluidized bed was partly elutriated from both reactors and ended up in the condenser section. To have a high overall efficiency of the process, all char has to be converted in the process instead of partly being considered as a loss. For this, two options seem likely: (i) the char is either combusted in a separated combustor to supply heat for the endothermic steam reforming reactions and evaporation (ii) or the char is kept in the reactor and gasified using steam and/or $\mathrm{CO}_{2}$. An efficiency evaluation [7] showed that internal gasification is preferable. Additionally, this option would also allow an easier process operation; external heating is easier to control than maintaining a heat carrier circulation especially at elevated pressures.

To get more insight in the evaporation of pyrolysis oil, the process is isolated and studied in this paper. Initially, the effect of temperature, droplet size and heating rate on the product distribution (char, vapor and gas) is studied. Secondly, the produced chars are evaluated on its general properties, reactivity and shape. Finally, the implications will be discussed on designing a process for steam reforming of pyrolysis oil. In this article, the term 'char' refers to char originating from pyrolysis oil evaporation unless clearly stated otherwise (e.g. char from fast pyrolysis). 


\subsection{Experimental}

\subsubsection{Materials}

The pyrolysis oils were produced in the Process Development Unit of VTT, Finland [9]. Two different biomass sources were used, namely pine wood (PW) and forest residue (FR). The FR oil was also separated into an aqueous rich and aqueous lean phase via water addition. Pyrolyctic lignin was obtained by adding pine pyrolysis oil into ice-cooled water as described by Scholze et al. [10]. Activated carbon was obtained from Norit. The corresponding elemental analyses and water determinations are given in Table 1.

Table 1: Elemental analyses (wet) and water content determination of the pyrolysis oil and related fractions/compounds used. The rest is mainly oxygen with also compounds like sulfur, nitrogen and ash not determined (n.d)

\begin{tabular}{|l|c|c|c|c|}
\hline (wt \%) & C & H & Rest & $\mathrm{H}_{2} \mathrm{O}$ \\
\hline Pyrolysis oil (PW) & 41.1 & 7.4 & 51.5 & 24.5 \\
\hline Pyrolysis oil (FR) & 40.6 & 7.6 & 51.8 & 23.9 \\
\hline Aqueous rich phase (FR) & 23.3 & 9.4 & 67.3 & 52.1 \\
\hline Aqueous lean phase (FR) & 48.8 & 7.5 & 43.7 & 12.3 \\
\hline Wood (PW) & 45.6 & 5.8 & 48.6 & 6.8 \\
\hline Pyrolytic lignin (PW) & 61.2 & 6.1 & 31.7 & n.d \\
\hline Wood pyrolysis char (PW) & 88.7 & 2.5 & 7.5 & n.d \\
\hline Activated carbon (Norit) & 85.9 & 0.6 & 13.5 & n.d \\
\hline
\end{tabular}




\subsubsection{Continuous pyrolysis oil evaporation}

To quantify the distribution of pyrolysis oil during evaporation between the gas, vapor and char phase, a dedicated continuous pyrolysis evaporation set-up was constructed. A schematic overview of the set-up is given in Figure 1. Pyrolysis oil (FR $100 \mathrm{ml} / \mathrm{h}$, duration ca. $\left.1 \mathrm{~h} ; \mathrm{C}_{\mathrm{in} \_ \text {oil }}\right)$ was sprayed into an empty electrically heated stainless steel tube (Ø $40 \mathrm{~mm}$, length $400 \mathrm{~mm}$ ) using two different externally cooled atomizers. Two thermocouples were placed inside the reactor to record the actual temperature in the middle of the reactor during evaporation experiments. The reported reactor temperatures are averaged values of the two thermocouples over the whole experiment. The reactor temperature was varied between $499-847{ }^{\circ} \mathrm{C}$. The two different atomizers were used to create two different extremes of sizes of droplets which were measured by pictures taken with a high speed camera (Photron Fastcam SA1). An ultrasonic atomizer (UA; Lecher US1, spraying angle $30^{\circ}$ ) created a droplet size distribution of which the largest droplets were measured to be $88-117 \mu \mathrm{m}$ (assisting gas $\mathrm{N}_{2} 4.0 \mathrm{Nl} / \mathrm{min}$ ). However, the majority of the droplets was much smaller but below the resolution limit of the camera. The atomizer was specified for water to have a Sauter mean diameter of 30 micron. For pyrolysis oil it is expected to be somewhat higher due to the higher viscosity.

A house-made atomizer consisted (UT) of a needle which was surrounded by an assisting gas $\left(\mathrm{N}_{2} 2.5 \mathrm{Nl} / \mathrm{min}\right)$. A uniform droplet was formed with a diameter of $\sim 1.9$ $\mathrm{mm}$. Additional preheated $\mathrm{N}_{2}$ was added directly under the atomizer in a circular way to avoid vapor condensation on the cooler of the atomizer and to keep the residence time of the gases around 2-3 s over the temperature range measured. At the end of the evaporation chamber a filter (mesh size 5 micron) was placed which together with a small sand layer and enough surface area resulted in a pressure drop of maximal 0.3 bar. The filter temperature was always lower than the reactor temperature (T 498-665 ${ }^{\circ} \mathrm{C}$ ). After the filter the stream was split into two streams: (i) one going to a combustor where the produced gas/vapor mixture was totally combusted with pure oxygen producing $\mathrm{CO}_{2}$ and $\mathrm{H}_{2} \mathrm{O}$. This gas flow was kept constant with a membrane pump which was placed after a condenser. (ii) the other directly fed to a quenching water 
bath which was mechanically stirred to quickly cool the gas/vapor mixture and trap the condensables.

Two micro-GC's (2x Varian CP-4900; detecting $\mathrm{N}_{2}, \mathrm{H}_{2}, \mathrm{CH}_{4}, \mathrm{CO}, \mathrm{CO}_{2}, \mathrm{C}_{2} \mathrm{H}_{4}, \mathrm{C}_{2} \mathrm{H}_{6}$, $\mathrm{C}_{3} \mathrm{H}_{6}$ and $\left.\mathrm{C}_{3} \mathrm{H}_{8}\right)$ measured the gas composition of the combustor $\left(\mathrm{C}_{\text {out_vapor+gas }}\right)$ and of the quench stream ( $\mathrm{C}_{\text {out_gas }}$ ). The integral carbon balance was made based on nitrogen as an internal standard which was fed to the evaporator. After an experiment the collected char on the filter was either collected for analysis and reactivity testing or it was combusted (Cout_char) to make a total carbon balance over the system. The carbon to gas ratios and char conversions are measured directly and the carbon to vapor conversion is calculated by the difference between the combustor and quench stream according to:

$C_{\text {out_vapor }}=C_{\text {out_gastvapor }}-C_{\text {out_gas }}$

Distribution:

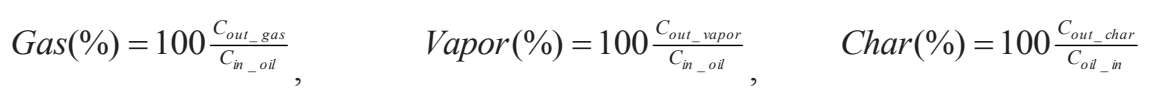

The carbon closures of the three different sections were found to be adequate: (i) Gas only: $101 \pm 1 \%$ based on methane addition and recovery in both the combustor and gas+vapor line, (ii) Gas + vapor: acetic acid was evaporated and partially thermally cracked ( $\mathrm{T} \sim 720-750{ }^{\circ} \mathrm{C}, \mathrm{S} / \mathrm{C} \sim 2.5-5.0$ ). Here, no char is being formed: carbon recovery $96 \pm 1 \%$, (iii) Solid: wood pyrolysis char was combusted with a carbon recovery of $97 \pm 2 \%$. The carbon recovery of all the pyrolysis oil evaporation experiments (gas + vapor + solid) was $98 \pm 4 \%$. 


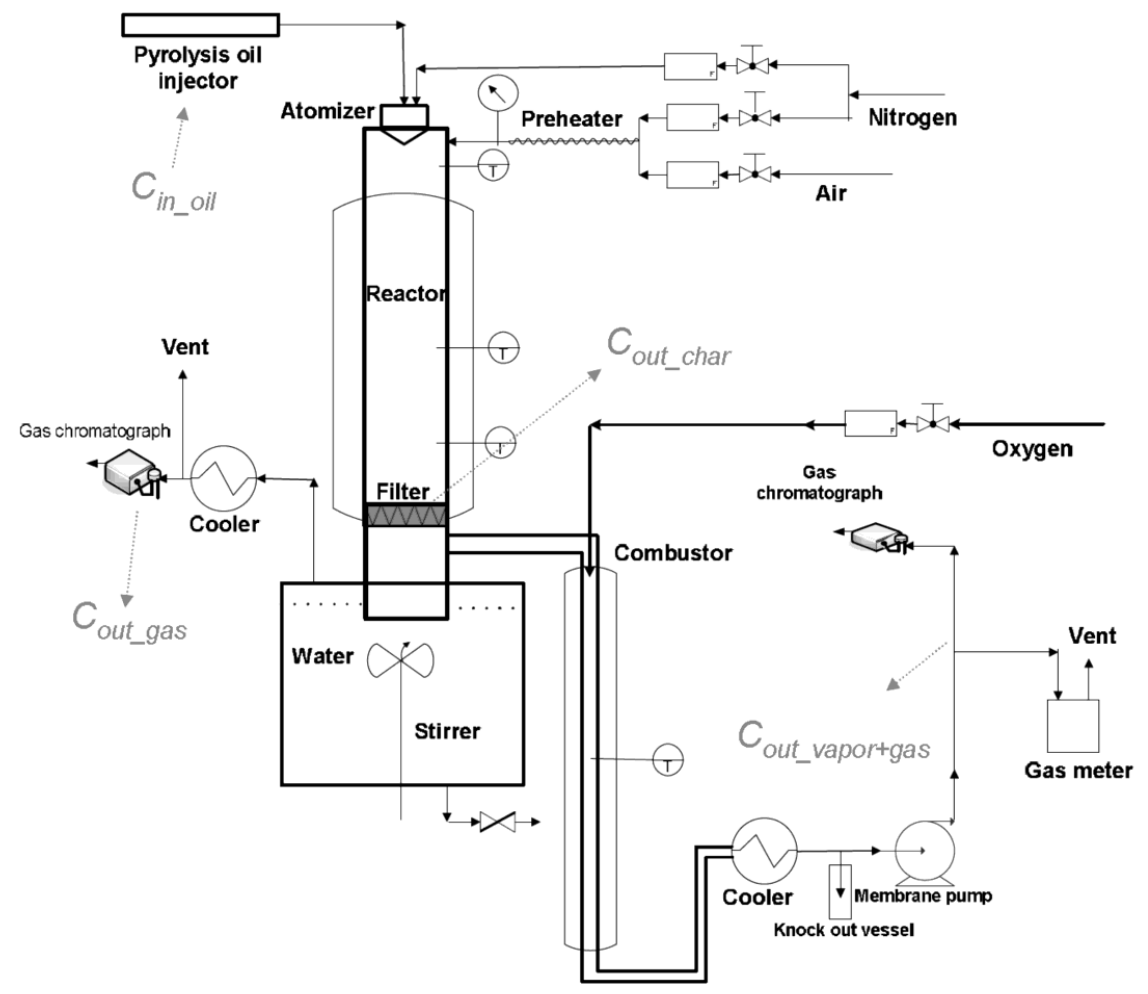

Figure 1: Schematic overview of the continuous pyrolysis evaporation set-up for measuring the carbon distribution from the oil to gas, vapor and char. The amount of gas and char are measured directly, the vapor amount is calculated by difference.

\subsubsection{Batch wise pyrolysis oil evaporation}

A fixed amount of pyrolysis oil (FR, $1.4 \pm 0.1 \mathrm{~g}$ ) was added to the bottom of a glass tube $(\varnothing 10 \mathrm{~mm})$. The glass tube was placed inside a narrow fitting electrically heated oven and the temperatures were measured inside the oil itself and inside the oven (between the glass tube and alumina oven element). The oil was heated to the desired temperature and kept there (total time $1 \mathrm{~h}$ ) and then either cooled down to room temperature or further heated to $550{ }^{\circ} \mathrm{C}$ for 1 additional hour and then cooled down. The remaining solid/liquid is called 'residue' and 'char', respectively. 
A small nitrogen flow was placed just above the oil to avoid direct contact with air and to remove the vapors which were released during evaporation. The remaining residue/Char was weighed. The 'residue' which was completely (or almost) soluble in tetrahydrofuran (THF) was analyzed with Gel permeation chromatograph (GPC) with THF as elutriation liquid and calibrated using polystyrene.

\subsubsection{Thermo-gravimetric Analysis}

Heating experiments (mainly pyrolysis oil) were performed in a Mettler Toledo thermo-gravimetric analyzer (TGA). The samples were heated to $800{ }^{\circ} \mathrm{C}$ at a rate of 1 , 10 or $100{ }^{\circ} \mathrm{C} / \mathrm{min}$ in argon $(60 \mathrm{ml} / \mathrm{min})$. Combustion experiments were performed in the same system. In combustion mode, the samples were heated to $800{ }^{\circ} \mathrm{C}$ at a rate of $5{ }^{\circ} \mathrm{C} / \mathrm{min}$ in a mixture of air $(20 \mathrm{ml} / \mathrm{min})$ and argon $(40 \mathrm{ml} / \mathrm{min})$. Additional to the TGA balance, the overall weight loss of the sample was quantified with a very accurate $( \pm 0.1 \mathrm{mg})$ external balance since some weight loss was already observed during the stabilization time of the TGA. Two different weight rate losses are defined:

$$
\begin{aligned}
& r_{w T} \equiv \frac{d X}{d T}=-\frac{\left(m_{\tau}-m_{\tau+1}\right)}{m_{0}\left(T_{\tau}-T_{\tau+1}\right)} \quad \text { at a constant heating rate } \quad\left(1 \%_{C}\right) \\
& r_{w t} \equiv \frac{d X}{d t}=-\frac{\left(m_{\tau}-m_{\tau+1}\right)}{m_{0}\left(t_{\tau}-t_{\tau+1}\right)}
\end{aligned}
$$

where. $\tau$ and $\tau+1$ are logged times, $\mathrm{T}\left({ }^{\circ} \mathrm{C}\right)$ the temperature of the sample cup and $\mathrm{m} 0$ $(\mathrm{mg})$ the initial amount of pyrolysis oil as weighted with the external balance. The overall char weight conversions $(\mathrm{X})$ and carbon to char conversions were calculated using the external balance. The maximum estimated thermal lag (at a heating rate of $100^{\circ} \mathrm{C} / \mathrm{min}$ using water) using the fusion model is $122^{\circ} \mathrm{C}$. 


\subsubsection{Steam gasification of char}

To gasify, a quartz tube (Ø $45 \mathrm{~mm}$, length $400 \mathrm{~mm}$ ) was used which was placed inside an electrically heated oven. A steam generator was used to create a steady steam flow $\left(\sim 300{ }^{\circ} \mathrm{C}, 0.15-0.5 \mathrm{~g} / \mathrm{min}\right)$ and preheated nitrogen $\left(\sim 200{ }^{\circ} \mathrm{C}, 9 \mathrm{Nml} / \mathrm{min}\right)$ was added as an internal standard. The amount of steam added compared to the char sample (ca. 4-10 mg) was high enough that steam conversions below $1 \%$ were obtained. The char sample was placed at the end of the oven to ensure adequate pre-heating of the steam/nitrogen and allow isothermal gasification. The char sample to be gasified was pre-mixed with quartz $(0.2-0.6 \mathrm{~g})$ to lower the pressure drop which can be created due to the fine structure of the char. The mixed sample (ca. $1 \mathrm{~cm}$ in length) was held in the upper part of the heated quartz tube using quartz wool on both sides. Some pressure drop (0.2 - 0.5 bar) over the sample was being observed. The reactor outlet was cooled and all the steam was condensed out of the sample gas. A micro-GC (Varian CP-4900) was used to analyze the gas composition from which the carbon conversion was calculated. The gasification rate (rwt, $\mathrm{dX} / \mathrm{dt}$ ) was assumed to directly correspond to the calculated carbon conversion rate which introduces a small error since most of the char sample consists out of carbon ( $75 \%$ or more) but also some oxygen and hydrogen are present.

\subsection{Results}

\subsubsection{Continuous pyrolysis oil evaporation: product distribution}

Figure 2 shows the carbon distribution to permanent gas, vapor and solid phase for both the ultrasonic (UA) and the needle (UT) atomizer using FR pyrolysis oil. Over the whole temperature range measured the amount of char produced seems to be constant or a very slight decrease is being observed with increasing temperature. This indicates that the initial distribution between char and vapors/gases is apparently already attained in the temperature trajectory up to $500{ }^{\circ} \mathrm{C}$, an observation which is in line with earlier work [7, 13]. The vapor production decreases with increasing temperature and the amount of gases increases opposite to the vapor production. 
A big difference is seen in char production between the two atomizers where the ultrasonic atomizer gives much less char compared to the needle atomizer, $\sim 8$ and $\sim 22$ $\%$ on carbon basis, respectively. The vapor production seems more or less comparable. However, it is likely that initially more vapors are being produced using the UA atomizer leading to less char and that the main conversion pathway for gas production is via vapor cracking. Small droplets (UA) are much quicker evaporated than larger droplets (UT) and in this way vapors have more time to be cracked to permanent gases.

Compared to the fluidized and staged reactor bed system used by Van Rossum et al. [3] to study the gasification/steam reforming of pyrolysis oil, for the present set-up (gasification set-up explained in this Chapter) much more vapors are being measured ( $\sim 20-30$ wt $\%$ versus $\sim 1 \mathrm{wt} \%$ on carbon basis at $\mathrm{T} \sim 800{ }^{\circ} \mathrm{C}$, non-catalytic). This difference is probably caused by the longer residence time at high temperatures, which enhances thermal vapor cracking ( $\sim 10 \mathrm{~s}$ versus $2-3 \mathrm{~s})$.

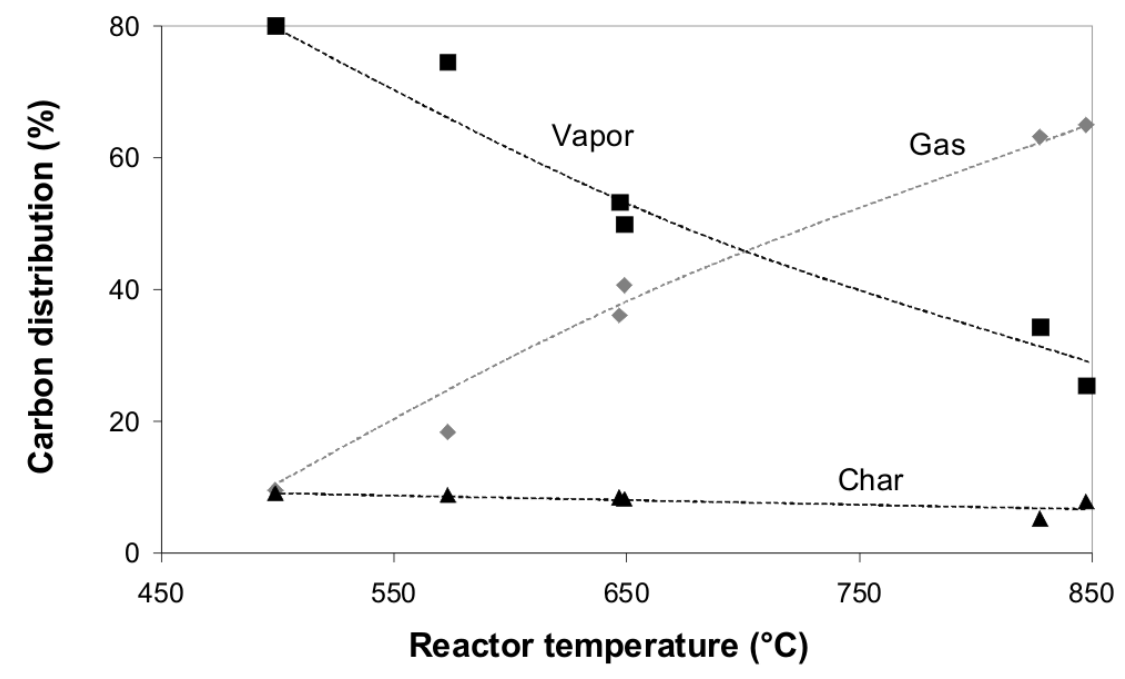

$2 A$ 


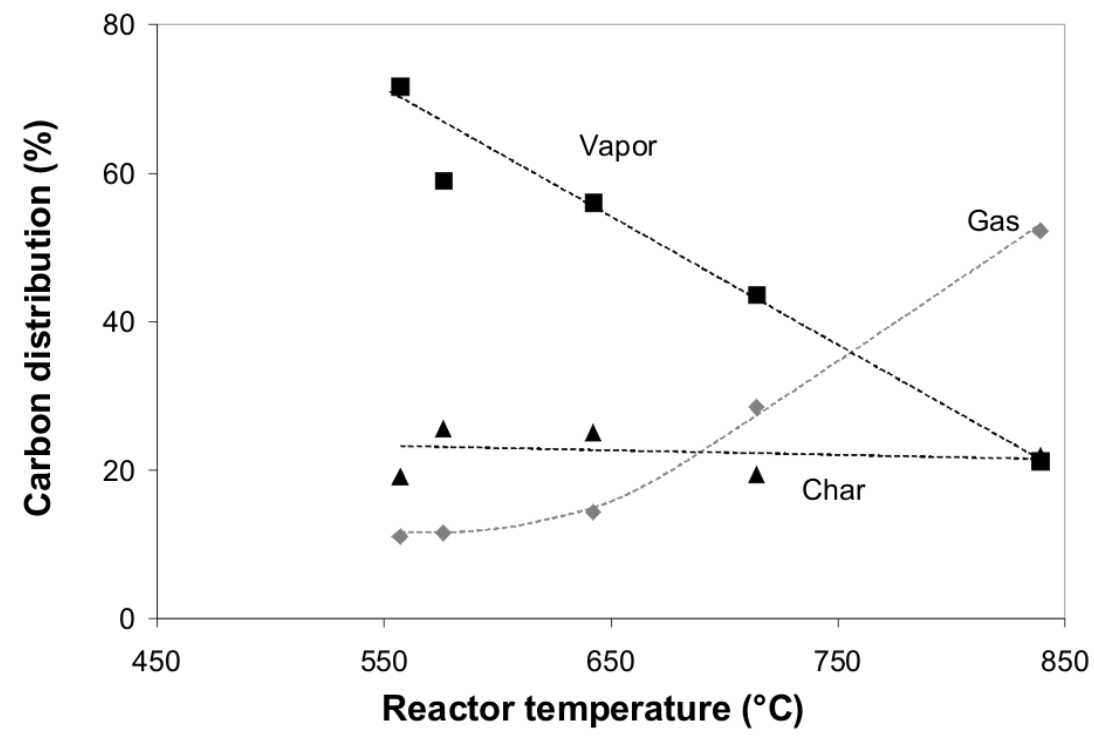

2B

Figure 2: $(\mathrm{A}, \mathrm{B})$ : carbon distribution over the gas, vapor and solid (char) phase during the evaporation of FR pyrolysis oil using an ultrasonic (A, UA) and needle $(B, U T)$ atomizers at a pyrolysis oil feeding rate of $100 \mathrm{ml} / \mathrm{min}$.

\subsubsection{Batch wise pyrolysis oil evaporation: residue analysis}

Figure 3 and Table 2 shows the results of the pyrolysis oil evaporation carried out in glass reactor tubes which are heated at $\sim 50{ }^{\circ} \mathrm{C} / \mathrm{min}$ (oven) to different temperatures. The residue (Figure 3A) shows a steady decrease in amount with increasing temperature which stabilizes around $\mathrm{T} \sim 500{ }^{\circ} \mathrm{C}$. The amount of char shows more or less a constant production ( 17 wt \%, $32 \%$ carbon basis) although the timetemperature trajectory has been totally different. The heating trajectory shows quite a difference between the measured oven temperature and the actual sample temperature. The oven temperature (Figure 3B), which is usually measured in heating experiments as for instance with a TGA, shows roughly a constant heating rate till its desired setpoint temperature. However, the sample temperature strongly deviates from the oven heating trajectory and shows four heating stages as is best illustrated for the $\mathrm{T}_{\text {oven }}=$ $550^{\circ} \mathrm{C}$ experiment: 
Table 2: Averaged temperatures (at 'steady-state) and solubility of the obtained 'residue' in THF (T:Totally, P:partly, N:not soluble) from FR pyrolysis oil glass reactor tube heating experiments

\begin{tabular}{|l|c|l|l|l|l|l|l|l|}
\hline$(\mathrm{wt} \%)$ & 1 & 2 & 3 & 4 & 5 & 6 & 7 & 8 \\
\hline $\mathrm{T}_{\text {oven }}\left({ }^{\circ} \mathrm{C}\right)$ & - & 101 & 152 & 203 & 254 & 368 & 452 & 556 \\
\hline $\mathrm{T}_{\text {sample }}\left({ }^{\circ} \mathrm{C}\right)$ & 20 & 79 & 110 & 154 & 209 & 350 & 418 & 544 \\
\hline Solubility in THF & $\mathrm{T}$ & $\mathrm{T}$ & $\mathrm{T}$ & $\mathrm{T}$ & $\mathrm{T} / \mathrm{P}$ & $\mathrm{P}$ & $\mathrm{P}$ & $\mathrm{N}$ \\
\hline
\end{tabular}

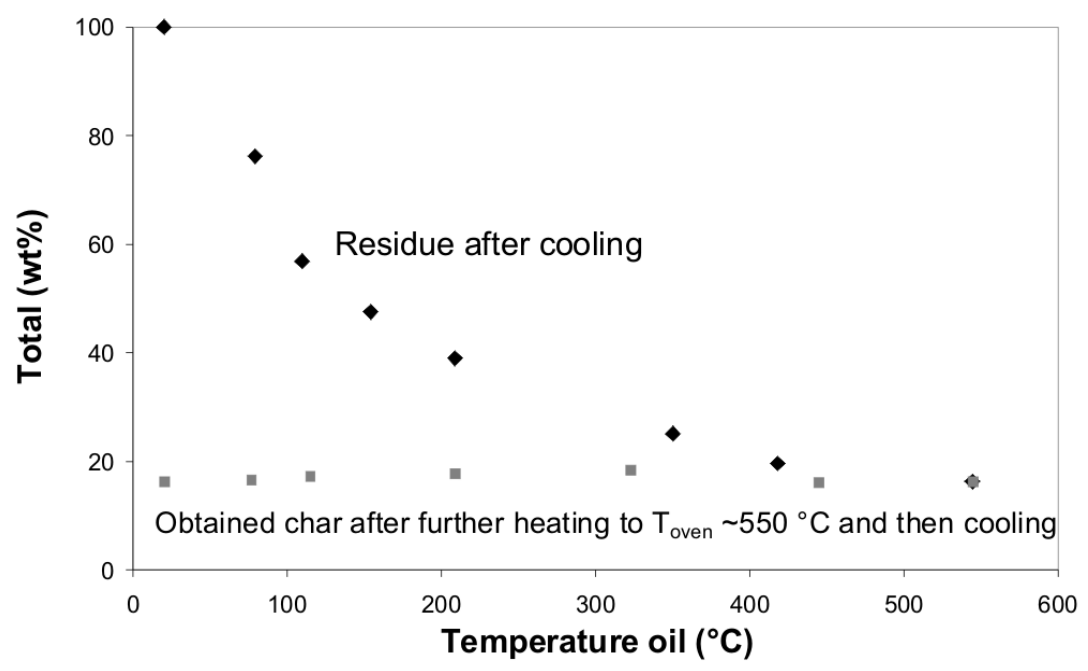

$3 \mathrm{~A}$ 


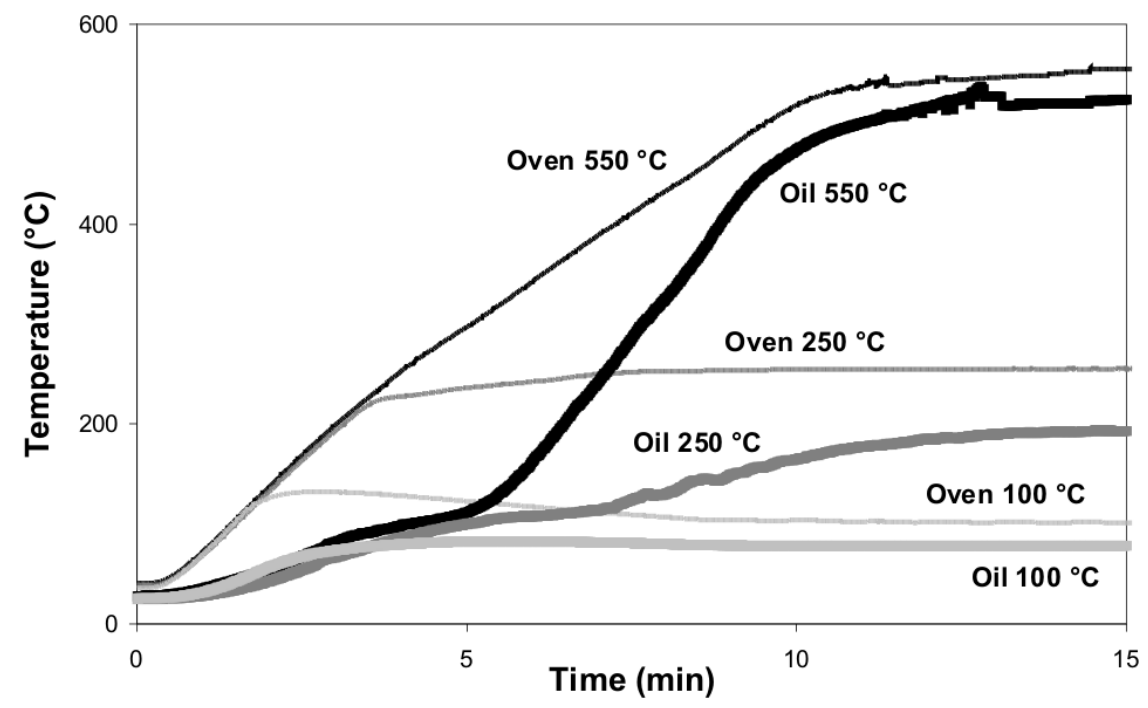

3B

Figure 3: Results of pyrolysis oil evaporation done in glass reactor tubes. (A) residue after a heating-cooling cycle and char after a heating-further heatingcooling cycle. (B) temperature profiles of both the oven (heating rate ca. 50 ${ }^{\circ} \mathrm{C} / \mathrm{min}$ ) and the liquid/solid itself at three different oven set-points, namely: 100 , 250 and $550{ }^{\circ} \mathrm{C}$.

0-3 min: heating of the liquid, some vapor release can already be visually observed.

3-5 min: the liquid temperature increases very slow; this can predominantly be ascribed to water which is evaporated together with some lights. The vapors which are being released are colorless and transparent. The difference in oven and sample temperature almost reaches $200{ }^{\circ} \mathrm{C}$.

5-9 min.: the sample temperature increases at a constant heating rate. The vapors which are being released get more and more dark with increasing temperature and at a sample temperature $\sim 220{ }^{\circ} \mathrm{C}$ a phase transition occurs and a solid is being formed which is accompanied with a volumetric expansion ( \pm three times) which has also been described by Wornat et al. [14] during the combustion of pyrolysis oil. 
9 min. until - end: the sample temperature reaches a constant value/level and the vapor release stops. The produced char has a very porous structure and is brittle.

Figure 4 shows GPC results of the residue samples 1 until 5 (Table 2) which were (almost) completely soluble in THF. The initial oil heating, which is accompanied with already some vapor release, did not result in a significant differences in the profile of the distribution of the higher fractions present in pyrolysis oil. This suggests that even though the oil was at $79{ }^{\circ} \mathrm{C}$ for almost an hour, no significant polymerization, which would result in heavier product formation, took place. Further heating of the oil created heavier fractions as seen in the increasing molecular weight measured with the GPC. This is also in line with the observation of lesser solubility in THF and the visual change from liquid to solid during the experiment. This suggests that polymer formation takes place in the liquid phase directly after water (and lights) evaporation $\left(\mathrm{T}_{\text {liquid }}>100^{\circ} \mathrm{C}\right.$ ). These polymers eventually react further to char (solvent insoluble) fractions which were observed from $250{ }^{\circ} \mathrm{C}$ (see Table 2).

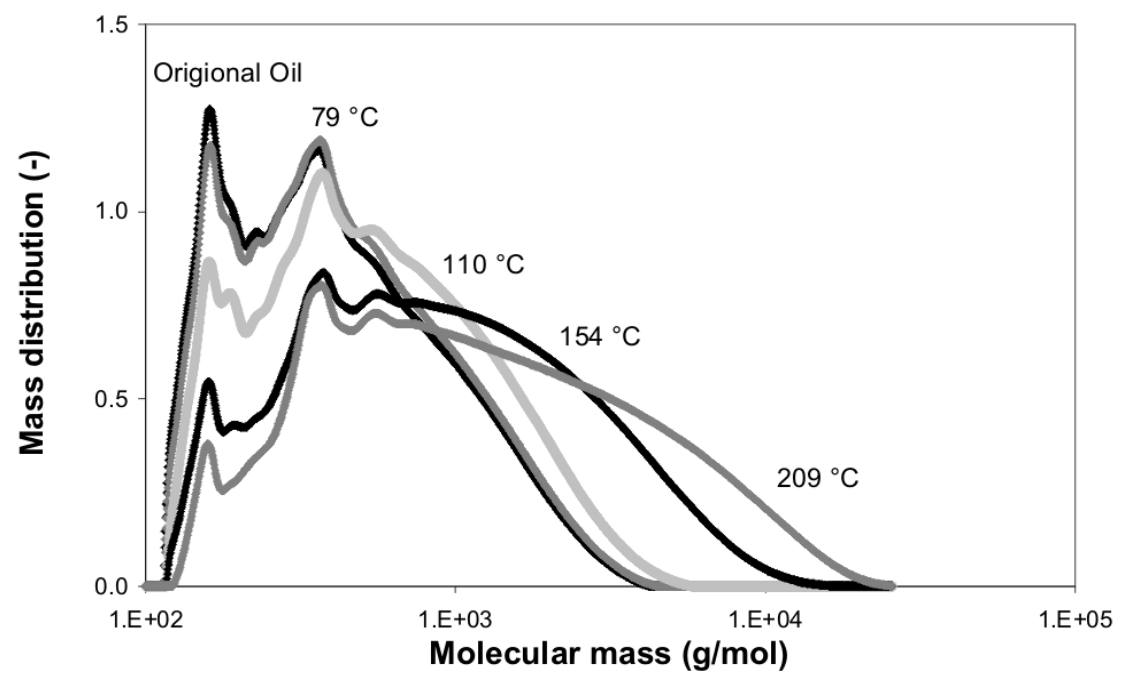

Figure 4: GPC results of the original pyrolysis oil (sample 1) and of residues after heating (samples 2 till 5). The displayed temperatures are of the actual liquid (at 'steady-state'). 


\subsubsection{TGA: evaporation}

Figure 5 shows the evaporation of pyrolysis oil using TGA with increasing sample cup temperature. Table 3 shows the amounts of char (both weight and carbon basis) being produced with TGA for pyrolysis oil and related fractions/compounds. When the heating rate is varied, the following observations can be made:In the initial heating stage (up to $175^{\circ} \mathrm{C}$ ), a clear peak of mass release (Figure 5B) can be identified. This is the evaporation of water and lights when the liquid temperature is almost constant similar to as can be seen in Figure 3B (region 3-5 min in the $\mathrm{T}_{\text {oven }}=550{ }^{\circ} \mathrm{C}$ experiment).

The $\mathrm{dX} / \mathrm{dt}$ profile (Figure 5C) shows that between the three experiments roughly a factor of 10x change in conversion rate is being observed which corresponds to the step change applied in the heating rates. This is an indication that the reactions/evaporation of the component groups seem to follow first order kinetic behavior which has been the basis for modeling pyrolysis oil droplet evaporation [13, 15]. The $\mathrm{dX} / \mathrm{dT}$ (Figure 5B) profiles are quite similar. The small differences observed are most likely caused by a difference in actual liquid sample temperature and sample cup temperature which is expected to be large at high heating rates (next to the first order behavior of the evaporation and reactions).

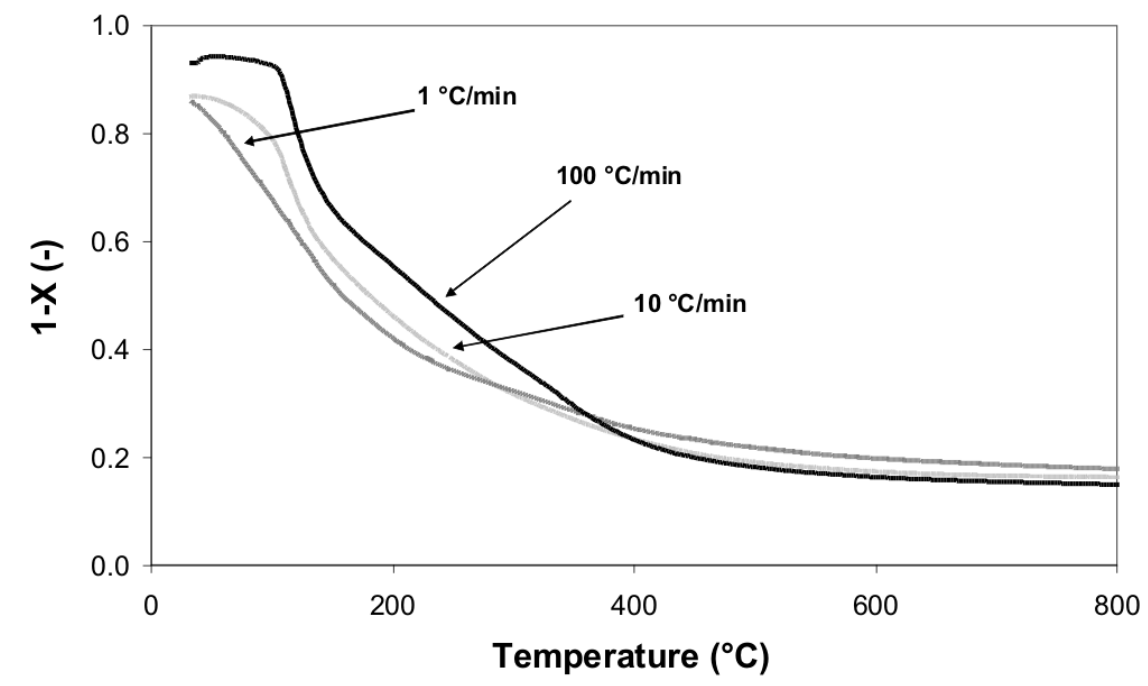

$5 \mathrm{~A}$ 


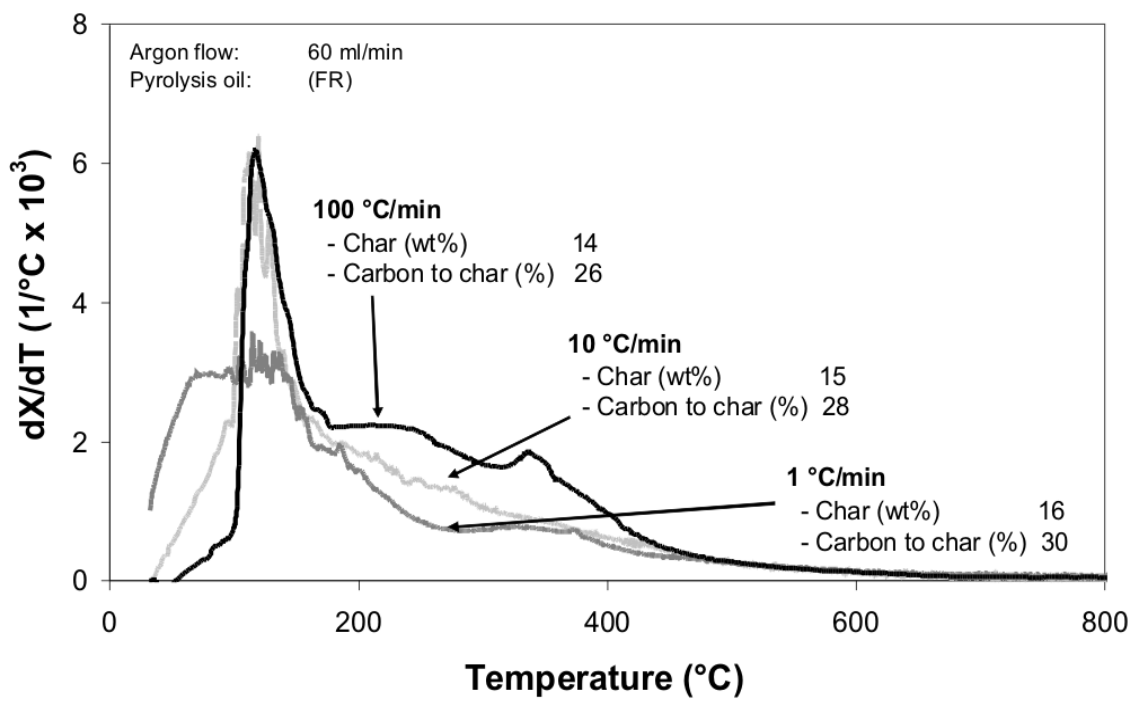

$5 \mathrm{~B}$

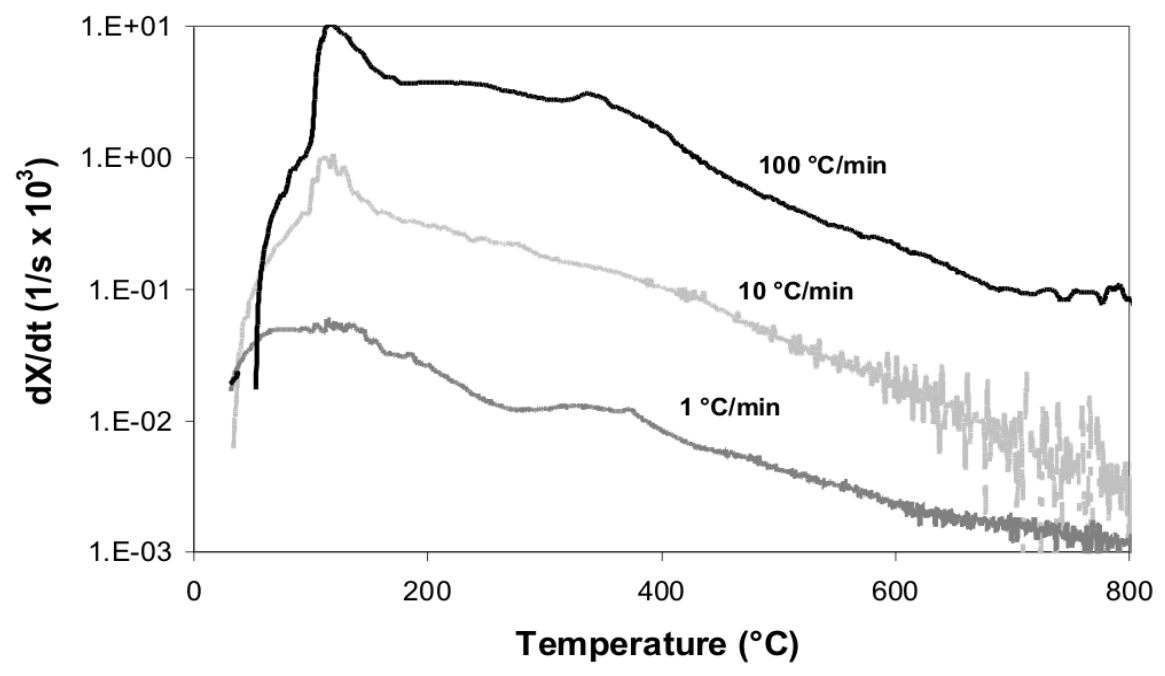

$5 \mathrm{C}$

Figure 5: TGA of pyrolysis oil at different heating rates $\left(1,10\right.$ and $\left.100{ }^{\circ} \mathrm{C} / \mathrm{min}\right)$ in inert (Argon) gas. (A) weight conversion (X) versus temperature profile. (B) reaction rate $\mathbf{r}_{\mathrm{wT}}$ (temperature based) versus temperature. (C) reaction rate $\mathbf{r}_{\mathrm{wt}}$ (time based) versus temperature. The reported measured temperatures are of the sample cup, not of the actual liquid inside. $m_{0}$ is measured with an external balance since some weight loss is being observed during the stabilization time of the TGA; this results in that the starting point is always lower than 1. 
Table 3: Char production using TGA of pyrolysis oil and related fractions/compounds. The amounts are given on both weight and carbon basis. The sample was heated to $800{ }^{\circ} \mathrm{C}$ at a heating rate of $10^{\circ} \mathrm{C} / \mathrm{min}$ and an Argon flow of $60 \mathrm{ml} / \mathrm{min}$

\begin{tabular}{|l|c|c|}
\hline \multicolumn{2}{|c|}{ Weight of feed } & Carbon to char \\
\hline Pyrolysis oil (FR) & 15 & 28 \\
\hline Aqueous rich phase (FR) & 7 & 24 \\
\hline Aqueous lean phase (FR) & 21 & 33 \\
\hline Wood (PW) & 15 & 25 \\
\hline Pyrolytic lignin (PW) & 43 & 54 \\
\hline Glucose solution (40 wt\%) & 7 & 28 \\
\hline
\end{tabular}

The carbon to char conversion shows a slight trend of increasing char production with lower heating rates. The produced char amounts are similar to the glass tube heating experiments and higher than the droplet evaporation experiments. The heating of different fractions of pyrolysis oil and related compounds (Table 3) all resulted in the formation of considerable amounts of char. The aqueous, rich fraction of pyrolysis oil, which is considered to be an important hydrogen resource and easy to steam reform $[4,5]$ still resulted in $24 \%$ of carbon which was converted to char. The heavier fractions of pyrolysis oil (aqueous lean phase and pyrolictic lignin) form high amounts of char.

The amount of char formed with evaporating pyrolysis oil is under slow heating rates (1-100 $\left.{ }^{\circ} \mathrm{C} / \mathrm{min}\right)$ similar to pyrolysis of solid biomass at $\sim 500{ }^{\circ} \mathrm{C}(25 \%$ carbon to char conversion, Table 3). It is striking that such high amounts of char are formed since the large molecular structures which were present in the original biomass are being depolymerized in the pyrolysis process to end up in the pyrolysis oil or are mainly concentrated in the char by-product. Char formation during pyrolysis oil evaporation seems to be mainly due to polymerization reactions of the oil as illustrated in

Figure 4. 
However, some polymerization reactions and heavies elutriation [16] already take place during the pyrolysis oil production/condensation directly leading to products which cannot be re-evaporated. It is then interesting to see if these products can be readily gasified or that they always lead to the production of char.

It will be important to heat up quickly through the $100 \rightarrow 350{ }^{\circ} \mathrm{C}$ temperature zone where the polymerization takes place. The lower amount of char formation at higher heating rates shows clearly that steering is possible. Figure 6 shows heating rates for the TGA, heated glass tubes and droplet evaporation. The 'droplet evaporation' heating rates after "lights" evaporation when char formation starts were estimated with a heat balance over a droplet according to:

$$
\begin{gathered}
\frac{d T}{d t}=\frac{6 N u \lambda}{c_{p} \rho d_{p}^{2}} \Delta T \quad \text { with Nusselt (flow around sphere) } \\
N u=2+0.66 \operatorname{Re}^{\frac{1}{2}} \operatorname{Pr}^{\frac{1}{3}} \approx 7
\end{gathered}
$$

With dp the droplet size of the pyrolysis oil, cp the heat capacity of a liquid $\sim 2000$ $\mathrm{J} / \mathrm{kg} /{ }^{\circ} \mathrm{C}, \rho$ the density of the liquid $\sim 1000 \mathrm{~kg} / \mathrm{m}^{3}, \lambda$ thermal conductivity of gas $\sim 0.06$ $\mathrm{W} / \mathrm{m} /{ }^{\circ} \mathrm{C}$ and $\Delta \mathrm{T}$ the temperature difference $\sim 500{ }^{\circ} \mathrm{C}$ (a $50 \%$ spread over the calculated heating rate values is assumed in Figure 6). The estimated heating rates are in the same order of magnitude as estimated by Garcìa Pèrez et al. [17]. Only very high heating rates $\left(\geq 10^{5}{ }^{\circ} \mathrm{C} / \mathrm{min}\right)$ results in significant reductions of char production. This shows that with widely used heating analyzing equipment such as TGA, an analysis can be made of maximum char production that is probable from a certain compound/oil. This can be useful to predict gasification behavior but it must be kept in mind that the process of evaporation is most likely/essentially different between a TGA and an atomizer. Probably there is also a minimum amount of char which will be formed.

Glucose like compounds and heavier fractions are always present in the pyrolysis oil (both aqueous rich and lean phases) which tend to polymerize rather than to evaporate/decompose (see Table 3). However, it is possible that with extremely high heating rates or diluted solutions (e.g. water and methanol) compounds remain 
isolated and due to the vigorous nature of such evaporation end up in the gas/vapor phase before they can fully react in the liquid phase. With this 'evaporation' the density of the reactive compounds is lowered significantly (factor $\sim 10^{3}$ ) which will result in less polymerization since polymerization has a reaction order higher than one [18].

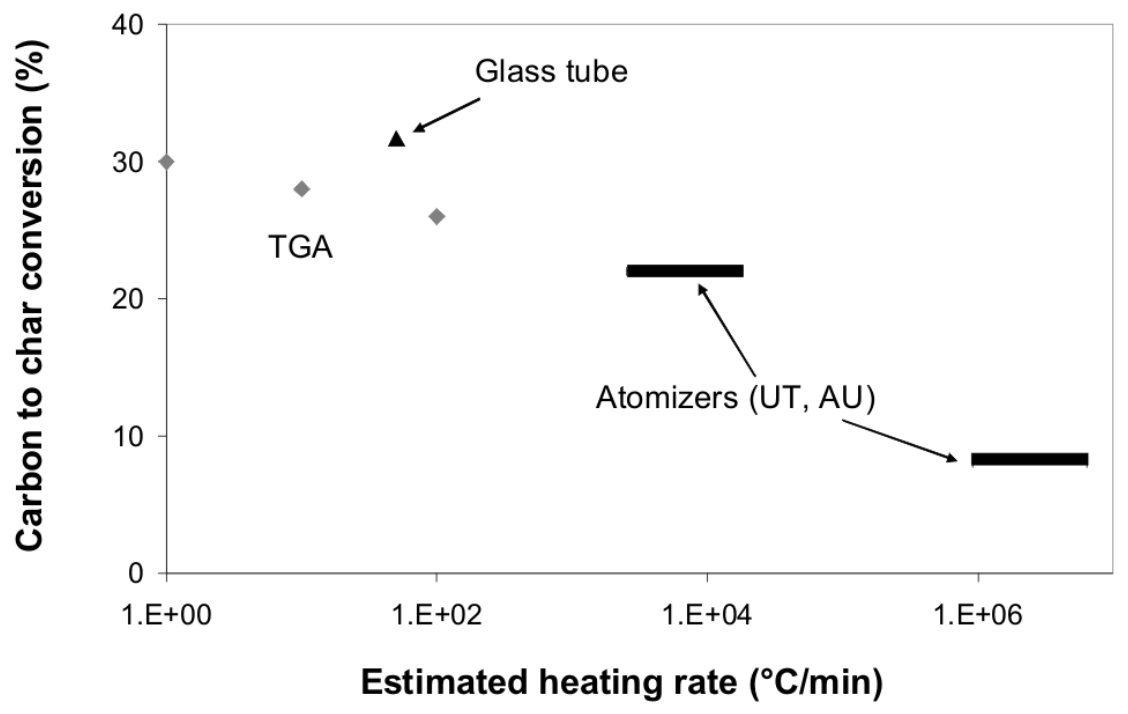

Figure 6: Carbon to char conversion of pyrolysis oil versus estimated heating rates of the following equipment: Thermo-Gravimetric Analysis (TGA), heated glass tube and droplet evaporation using two different atomizer types (UT and UA).

\subsection{Results of char analysis}

\subsubsection{Char combustion}

From the continuous pyrolysis oil evaporation set-up, char samples (called pyrolysis oil char) were collected from the installed filter (see Figure 1) which were produced at different temperatures and using the two different atomizers. Figure 7 shows the combustion experiments done in a TGA when the samples were heated in an air/argon mixture at a constant heating rate of $5{ }^{\circ} \mathrm{C} / \mathrm{min}$. Two different types of carbon 
containing materials were initially heated to see the difference in the start and the peak of the combustion process (see Figure 7A), namely char from fast pyrolysis (wood pyrolysis char) which is known to have a high reactivity and activated carbon which is quite stable char. The difference in combustion peaks is significant; around $500{ }^{\circ} \mathrm{C}$ for wood pyrolysis char and $645^{\circ} \mathrm{C}$ for activated carbon.

The collected chars (Figure 7B) show reactivities more similar to char from wood fast pyrolysis than from activated carbon. This is different to what Branca et al. [19] measured where the pyrolysis oil char reactivities were lower than those of wood pyrolysis char. This difference is most likely due to the different char production methods (cup heating versus atomization). The use of different atomizers shows a slight difference in reactivity where UA (small droplets) is combusted at a lower temperature than UT (big droplets). This is remarkable since with small droplet evaporation, the amount of char being produced is much less and one could think only a lesser reactive fraction would remain. The reactivity is most likely determined by the composition of the char and the accessibility for gases. Besides this the temperature, to which the char has been produced, seems to have an important influence on the activation and peak temperatures. When pyrolysis oil evaporation chars are being produced at high temperatures $\left(\sim 850^{\circ} \mathrm{C}\right)$, they are less reactive. Up till a temperature of $654{ }^{\circ} \mathrm{C}$, the reactivity seems similar. This was also confirmed when chars were produced at different final temperatures (heating rate: $10{ }^{\circ} \mathrm{C} / \mathrm{min}$ ), kept at those temperatures for $15 \mathrm{~min}$, and then cooled down. The reactivity of these chars increase with decreasing final temperature of production as is shown in Figure $7 \mathrm{C}$. 


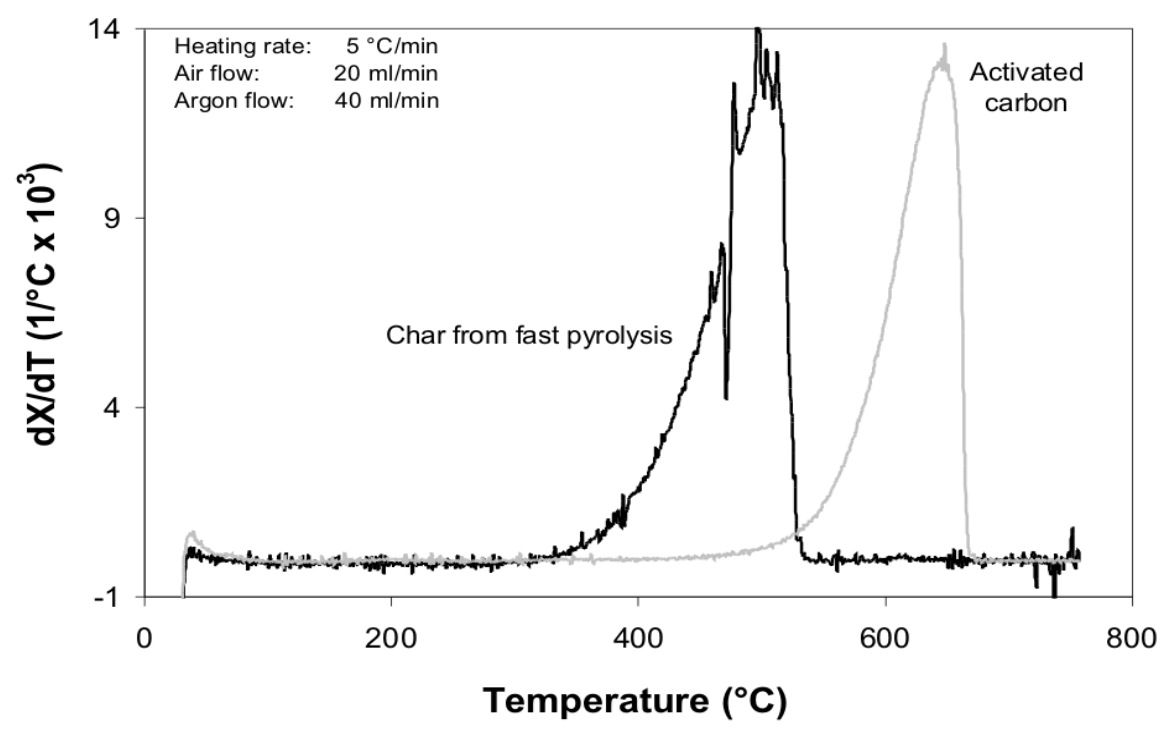

$7 \mathrm{~A}$

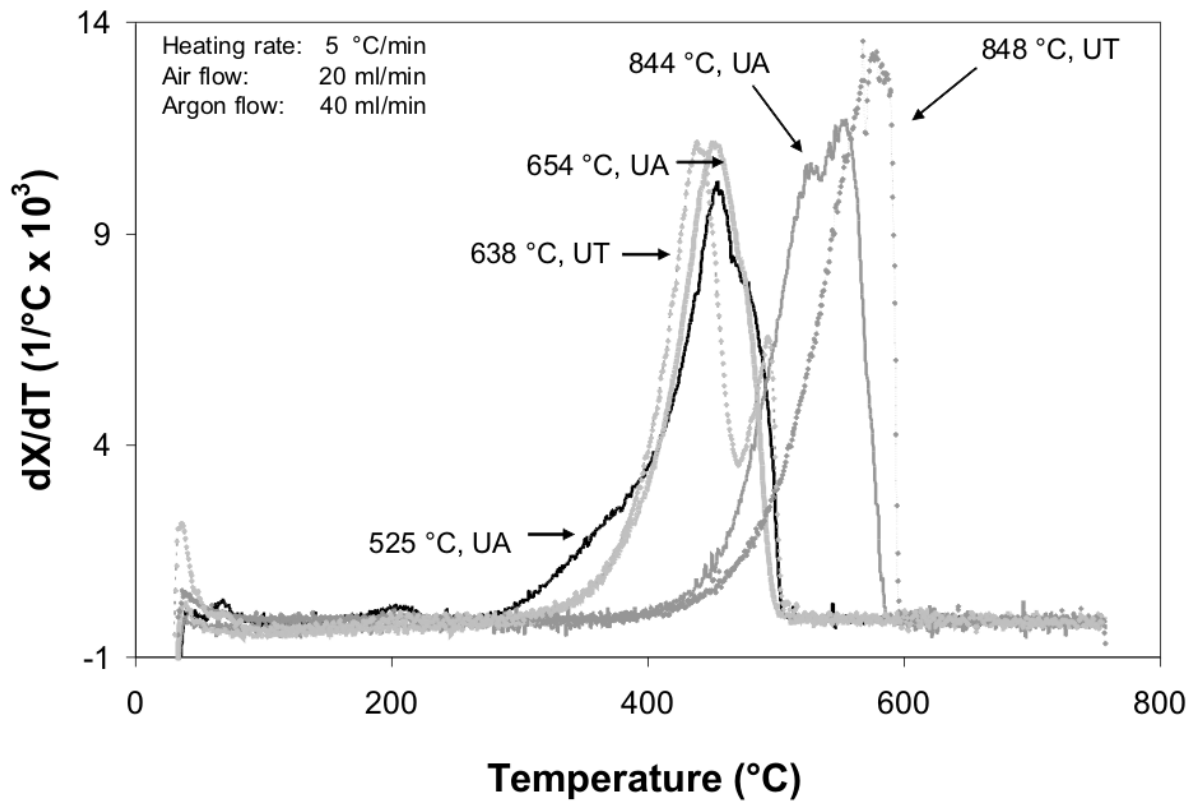

7B 


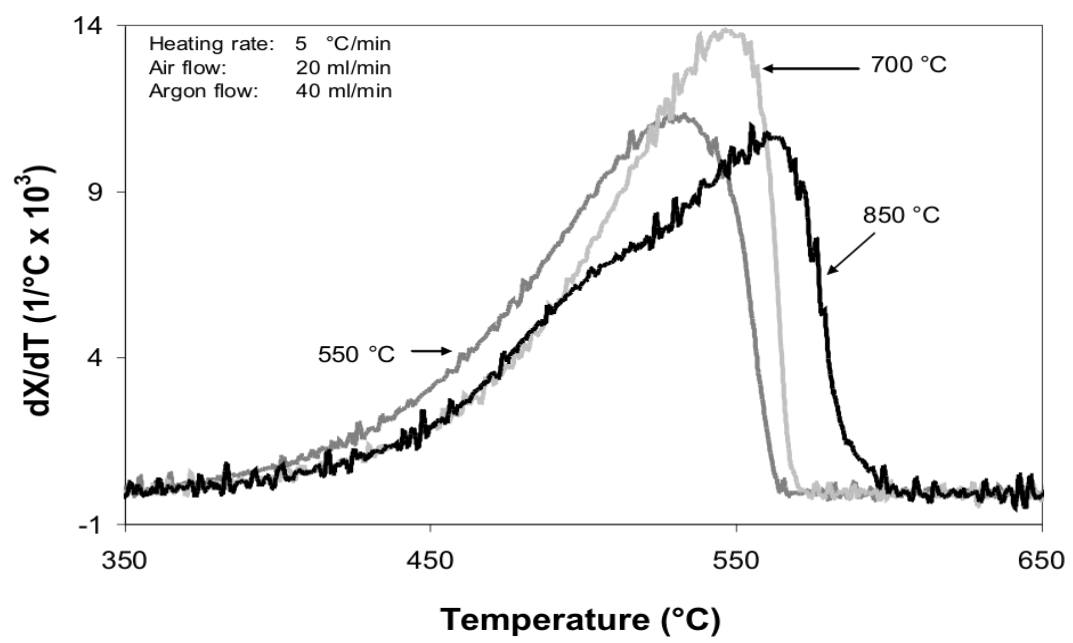

$7 \mathrm{C}$

Figure 7: TGA in an air flow. (A) shows combustion profiles during a constant heating of the sample for char produced during the fast pyrolysis of pine wood and of activated carbon. (B) shows combustion profiles of chars collected from the continuous evaporation set-up which was operated at different temperatures using two different atomizers. $(C)$ shows chars produced at a constant heating rate of $10{ }^{\circ} \mathrm{C} / \mathrm{min}$ and then cured $(15 \mathrm{~min})$ at different peak temperatures $(550$, 700 and $850^{\circ} \mathrm{C}$ ).

\subsubsection{Structural analysis of char}

From the chars produced, one was selected for further analysis, namely the pyrolysis oil char produced at $525{ }^{\circ} \mathrm{C}$ with the ultrasonic atomizer (UA, elemental analysis (wt\%): C: 76.7, H: 3.4, Rest: 19.9). This choice was based upon (i) evaporation experiments showed the lowest char yields with this atomizer and (ii) combustion activity measurements showed that this chars is among the most reactive. Figure 8 shows SEM photos of the char. The char shows to be consisting of mostly hollow spheres (wall thickness order magnitude of a few hundred nanometers) which have been ruptured. Onto and into these larger structures, smaller particles are deposited. The char is very light/fluffy as compared to char produced during fast pyrolysis of wood. This is believed to be the reason for the high carbon elutriation from an earlier used fluidized bed for steam reforming of pyrolysis oil $[3,7,8]$. 
The largest sizes of the spheres (around 100 micron) are in the same size range as the largest pyrolysis oil droplets (88-117 micron) which were photographed with the high speed camera. The spheres seem to be similar to the glassy/cenosphere solids produced during pyrolysis oil evaporation and/or combustion [14, 17].

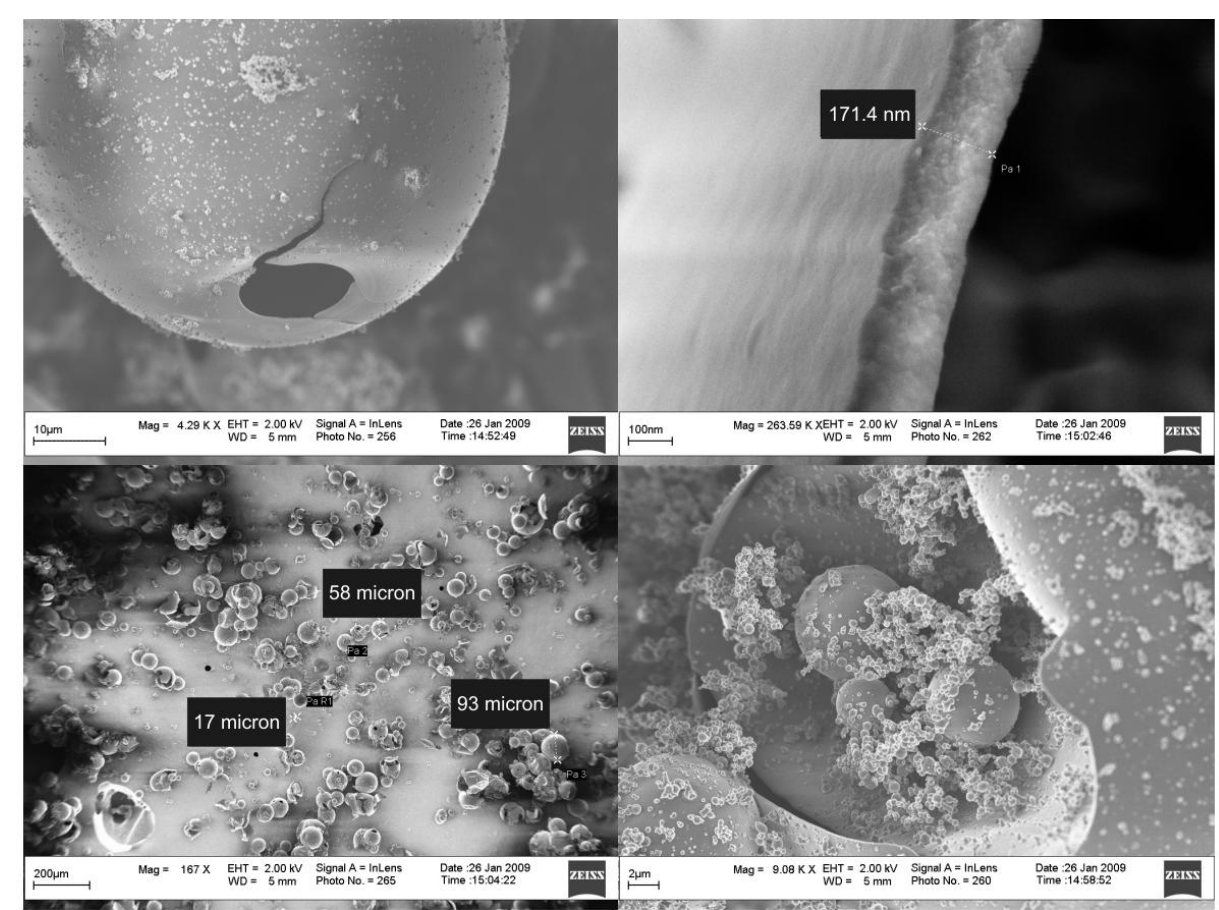

Figure 8: SEM photos taken of char from the continuous pyrolysis oil droplet evaporation set-up produced at $525^{\circ} \mathrm{C}$ using an ultrasonic atomizer.

\subsubsection{Char steam gasification}

Besides combustion reactivity, the reactivity of char towards steam gasification was also studied. A high surface area is seen using the SEM photo's (Figure 8) which promises a high reactivity since the steam should be able to penetrate deep into the char structure. Figure 9A shows measured reaction rates of the char for steam gasification at a char conversion (X) of 0.3 . The steam gasification was always preceded by some devolatilization of the char, which is also expected when looking at TGA pyrolysis oil heating (Figure 5B) where above $525^{\circ} \mathrm{C}$ a small but significant amount of solid conversion is attained. At low temperatures $\left(700^{\circ} \mathrm{C}\right)$ this effect is 
still significant but at higher temperature it is negligible compared to the steam gasification.

The gasification rate of pyrolysis oil char can be well described with an Arrhenius type of temperature dependence giving an activation energy (Ea) of $274 \mathrm{~kJ} / \mathrm{mol}$ which is at the higher end compared to earlier measured activation energies of steam gasification of biomass originating chars (Ea: $105-271 \mathrm{~kJ} / \mathrm{mol}$ ) [20]. The reactivity profiles at the same temperature for pyrolysis oil char, wood pyrolysis char and activated carbon show distinct behavior (Figure 9B). The activated carbon shows a constant activity over the whole conversion range measured which can be interpreted as zero order gasification reactivity in char. The pyrolysis oil char and wood pyrolysis char show quite similar profile namely a readily decreasing reactivity with increasing conversion which was also observed by Barrio et al. [20]

The following explanation can be given for this change in reactivity: (i) the reaction order in char is not zero, (ii) there is inhibition (for instance hydrogen and carbon monoxide), (iii) the carbon structure changes/is less accessible which results in an apparent different reaction order and (iv) the char ages in time leading to less reactive chars. (iii) and (iv) are expected to be dominant in explaining this behavior. The carbon surface structure has been shown on SEM photos to be very complex (Figure 8) where big hollow spheres are present which could be assumed to be reacting as a flat plate and smaller deposits which could react away as small porous spheres. This complex structure could lead to a higher initial rate decreasing with increasing conversion. The char has shown 'aging' (reactivity loss due to thermal exposure) behavior when it is subjected to elevated temperatures for a certain time (Figure 7C) leading to a decreasing reactivity rate. The activated carbon giving its constant reactivity over time is then due to that the overall structure does not change (in the conversion range measured) and does not undergo 'aging' since it was already subjected to higher temperatures during production. 


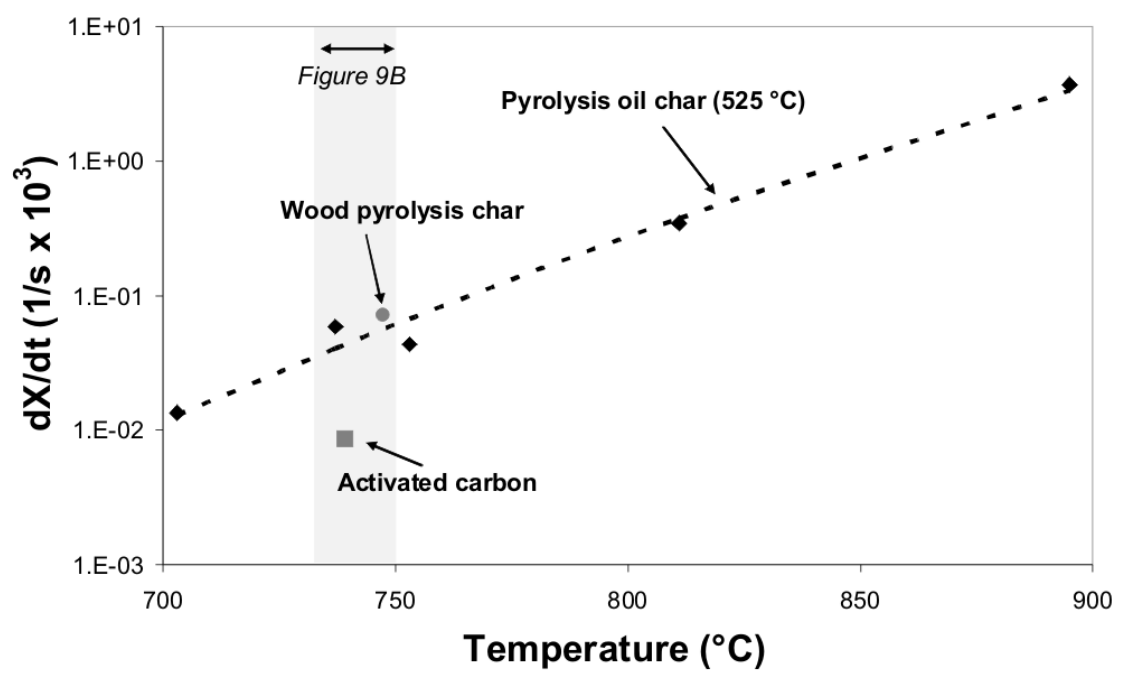

$9 \mathrm{~A}$

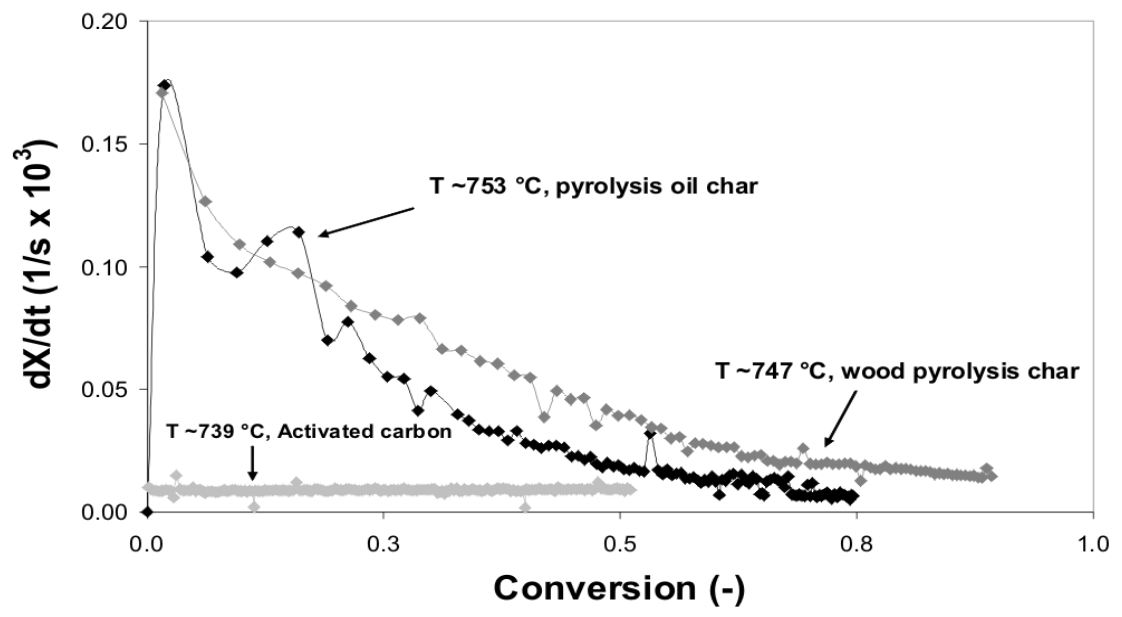

$9 \mathrm{~B}$

Figure 9: (A) Steam gasification rate versus temperature (including devolatilization) of char produced from evaporation of pyrolysis oil at $525^{\circ} \mathrm{C}$ with the ultrasonic atomizer (UA) at a char conversion of $X=0.3$. The dotted line is the Arrhenius kinetic fit with an Ea of $274 \mathrm{~kJ} / \mathrm{mol}$. The steam gasification rates of wood pyrolysis char and activated carbon are added for comparison. (B) Gasification rate profiles $\left(r_{w t}\right)$ of pyrolysis oil char, wood pyrolysis char and activated carbon at a similar temperatures $\left(\mathrm{T} 739-753^{\circ} \mathrm{C}\right)$. 


\subsubsection{Mechanism of pyrolysis char evaporation}

The temperature-time history of a pyrolysis droplet determines not only the amount of char being formed but also its reactivity as is illustrated in Figure 10. Our results show that a part of the pyrolysis oil seems to always evaporate, leading to gases and vapors which can be reformed to create syngas. Another part can either be converted to char or similar to the abovementioned route generate gases/vapors which is determined by the heating rate. With higher heating rates the ratio of the rate of polymerization/gasification is lowered. The formed chars show 'aging' behavior when they are exposed to higher temperatures (above $650{ }^{\circ} \mathrm{C}$, see Figure $7 \mathrm{~B}$ and $\mathrm{C}$ ). This aging behavior, together with the complex structure of the char, results in steam gasification rates which decrease with increasing extend of conversion. When the whole evaporation process would be pressurized, the evaporation curve (Figure 3 and 5 ) is expected to shift to higher temperatures. This will probably lead to more char formation since polymerization rates are higher.

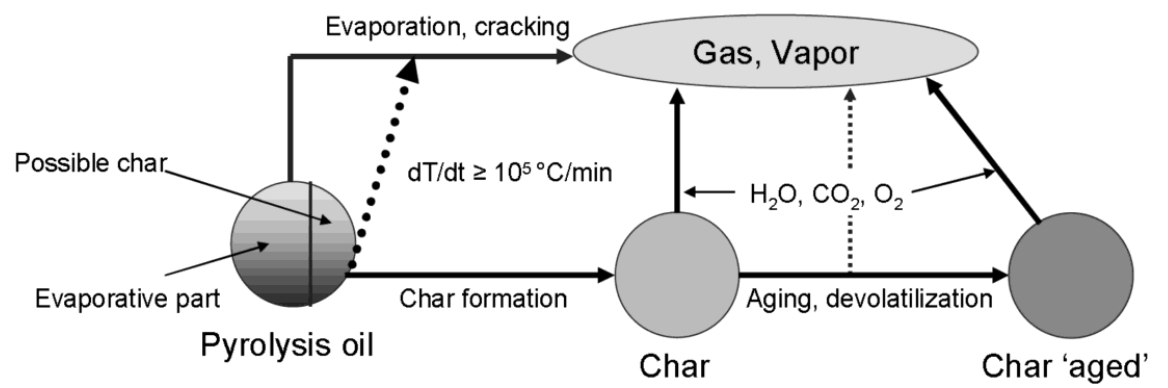

Figure 10: Evaporation scheme of pyrolysis oil leading to gases, vapors and char. The formed char can age to form a less reactive char. Both chars can be converted either by gasification (steam and $\mathrm{CO}_{2}$ ) or combustion. The temperature-time trajectory will determine which pathways are more dominant. 


\subsection{Implications for steam reforming of pyrolysis oil}

The presented results have shown that with the evaporation of pyrolysis oil (or its fractions) always char will be formed. This has a large impact on steam reforming process of pyrolysis oil whether single or staged reactor concepts are envisaged. This char amount can be considerable: a maximum of $32 \%$ on carbon basis was obtained using FR pyrolysis oil under slow heating conditions. This amount differs with varying types/qualities of pyrolysis oil [7]. Char formation during slow evaporation is much higher than other possible reactions leading to solid carbonaceous species such as coke which can be formed on the steam reforming catalyst (at sufficient high temperatures) and soot formed via vapor cracking. By applying very high heating rates the amount of char formed can be significantly reduced where the underlying mechanism seems to be dilution of the reactive species $\left(\sim 10^{3}\right.$ times with evaporation) and/or higher gasification rates of char precursors relative to polymerization. Specially designed atomizers create very small droplets which can be evaporated quickly. The speed of evaporation can be further increased with the use of a fluidized bed which has excellent heat transfer properties. However, not only the amount of char is important but also in which form it is being created.

Droplet evaporation in a heated empty space leaves a very light/fluffy char residue which easily elutriates from the reactor before it can be converted. It is therefore necessary to bind the char to a carrier. Sand has shown to not have enough binding capacity (fluidization scrapes char of its surface) and therefore more porous materials are probably preferred so that char formation takes place inside the carrier. How to contact the pyrolysis oil to such a carrier is not yet straightforward and has to be investigated further. The initial high temperature difference between the droplet and the carrier can limit the effectiveness of contacting. The Leidenfrost effect (which was shown to occur with large pyrolysis oil droplets on a hot surface) can let droplets bounce off the carrier and it has to be investigated what would be the ideal oil/carrier particle diameter ratio: a high ratio will cool down the carrier which then would allow carrier soaking and a low ratio would instantly heat the oil. 
Another option could be to modify the shape of the steam/dry reforming catalyst in such a way that residual char which elutriates from the fluidized bed is bound to it in the secondary reactor. In this way the char could get sufficient residence time to react. Preliminary tests in a bubbling fluidized with a more porous bed material have shown higher carbon to gas conversions as compared to 'inert' sand [22]. The char itself has combustion and gasification properties comparable to other biomass originated chars. When pyrolysis oil steam/dry reforming is considered, the char can be combusted to supply heat for the endothermic reforming reactions and evaporation. However, direct internal gasification of the char is preferred from an efficiency and process operation point of view [7]. Current steam gasification tests have shown that at the preferred temperature regime $\left(<700{ }^{\circ} \mathrm{C}\right)$ for operating a fluidized bed for evaporation, the rate of char conversion is too low. Higher operating pressures will probably enhance this conversion rate but catalytic active materials seem to be necessary to change char gasification conversion times from hours to minutes.

\subsection{Conclusions}

Pyrolysis oil (and all its fractions) evaporation is always coupled with the formation of char which is formed via polymerization reactions. The speed through which the pyrolysis oil liquid goes through the $100-350{ }^{\circ} \mathrm{C}$ temperature zone determines the total amount of char that is formed. Very high heating rates $\left(\geq 10^{5}{ }^{\circ} \mathrm{C} / \mathrm{min}\right)$ which can be achieved with small droplets lead to much less char ( $\sim \%$, carbon basis $)$ than the 'maximum' amount ( $30 \%$, carbon basis) which is measured with analytical heating equipment like TGA.

Char from pyrolysis oil evaporation has a very open structure and it consists out of large hollow spheres onto which smaller particles are being deposited. The char has reactivities towards combustion and steam gasification comparable to char formed during the pyrolysis of biomass. The char shows aging behavior when subjected to higher temperatures $\left(\geq 650-700^{\circ} \mathrm{C}\right)$. 


\section{References}

1. F.de Miguel Mercader, A.Ardiyanti, A.Gutierrez, S.Khromova, E.Leijenhorst, S.R.A.Kersten, J.A.Hogendoorn, W.Prins, M.J.Groeneveld, Proceedings of the 16th European Biomass Conference and Exhibition. Valencia, Spain, June 2-6, 2008:2103-2106.

2. A.Corma, G.W.Huber, L.Sauvanaud, P.J.O’Conner, J.Catal. (2007) vol 247, 307-327.

3. G.van Rossum, S.R.A.Kersten, W.P.M.van Swaaij, Ind. Eng. Chem. Res. (2007) vol 46, 3959-3967.

4. Czernik S, French R, Feik C, Chornet E, Ind. Eng. Chem. Res.(2002) vol 41, 4209-4215.

5. P.N.Kechagiopoulos, S.S.Voutetakis, A.A.Lemonidou, I.A.Vasalos, Ind. Eng. Chem. Res. ( 2009) vol 48, 1400-1408.

6. J.A.Medrano, M.Oliva, J.Ruiz, L.Garcia, J.Arauzo, Proceedings of the 16th European Biomass Conference and Exhibition. Valencia, Spain, June 2-6, 2008, 2158-2162.

7. G.van Rossum, S.R.A.Kersten, W.P.M.van Swaaij, Ind. Eng. Chem. Res. (2009) vol 48, 5857-5866.

8. G.van Rossum, B.Potic, S.R.A.Kersten, W.P.M.van Swaaij, Catal. Today. (2008) vol 145, 10-18.

9. A.Oasmaa, K.Sipilä, Y.Solantausta, E.Kuoppala, Energy \& Fuels (2005) vol $19,2556-2561$.

10. B.Scholze, D.Meier, J. Anal. Pyrolysis (2001) vol 60, 41-54.

11. B.Scholze, C.Hanse, D.Meier, J. Anal. Pyrolysis (2001) vol 58-59, 387-400.

12. R.Narayan, M.J.Antal, Ind. Eng. Chem. Res. (1996) vol 35, 1711-1721.

13. C.Branca, C.Di Blasi, Ind. Eng. Chem. Res. (2006) vol 45, 5891-5899.

14. M.J. Wornat, B.G. Porter, N.V.C.Yang, Energy \& Fuels (1994) vol 8, 11311142.

15. W.L.H.Hallett, N.A.Clark, Fuel (2006), vol 85, 532-544.

16. E.Daugaard, R.C.Brown, Science in Thermal and Chemical Biomass Conversion. (2006) vol 2, 1189-1202. 
17. M.Garcìa Pèrez, P.Lappas, P.Hughes, L.Dell, A.Chaala, D.Kretschmer. C.Roy IFRF Combustion Journal (2006) 200601.

18. D.Knežević, W.P.M.van Swaaij, S.R.A.Kersten, Ind. Eng. Chem. Res. (2009) vol 48, 4731-4743.

19. C.Branca, C.di Blasi, R.Elefante, Ind. Eng. Chem. Res. (2005) vol 44, 799810.

20. M.Barrio, B.Gøbel, H.Risnes, U.Henriksen, J.E.Hustad, L.H.Sørensen, Editor: A.V.Bridgwater, progress in Thermochemical Biomass conversion, MPG Books Ltd. (2001), vol 1, 32-46.

21. G.Chen, Q.Yu, K.J.Sjőstrőm, Anal. Appl. Pyrolysis (1997) vol 40-41, 491499.

22. M.F.Bleeker, H.J.Veringa, S.R.A.Kersten, Applied Catalysis A:General (2009) vol 357, 5-17 


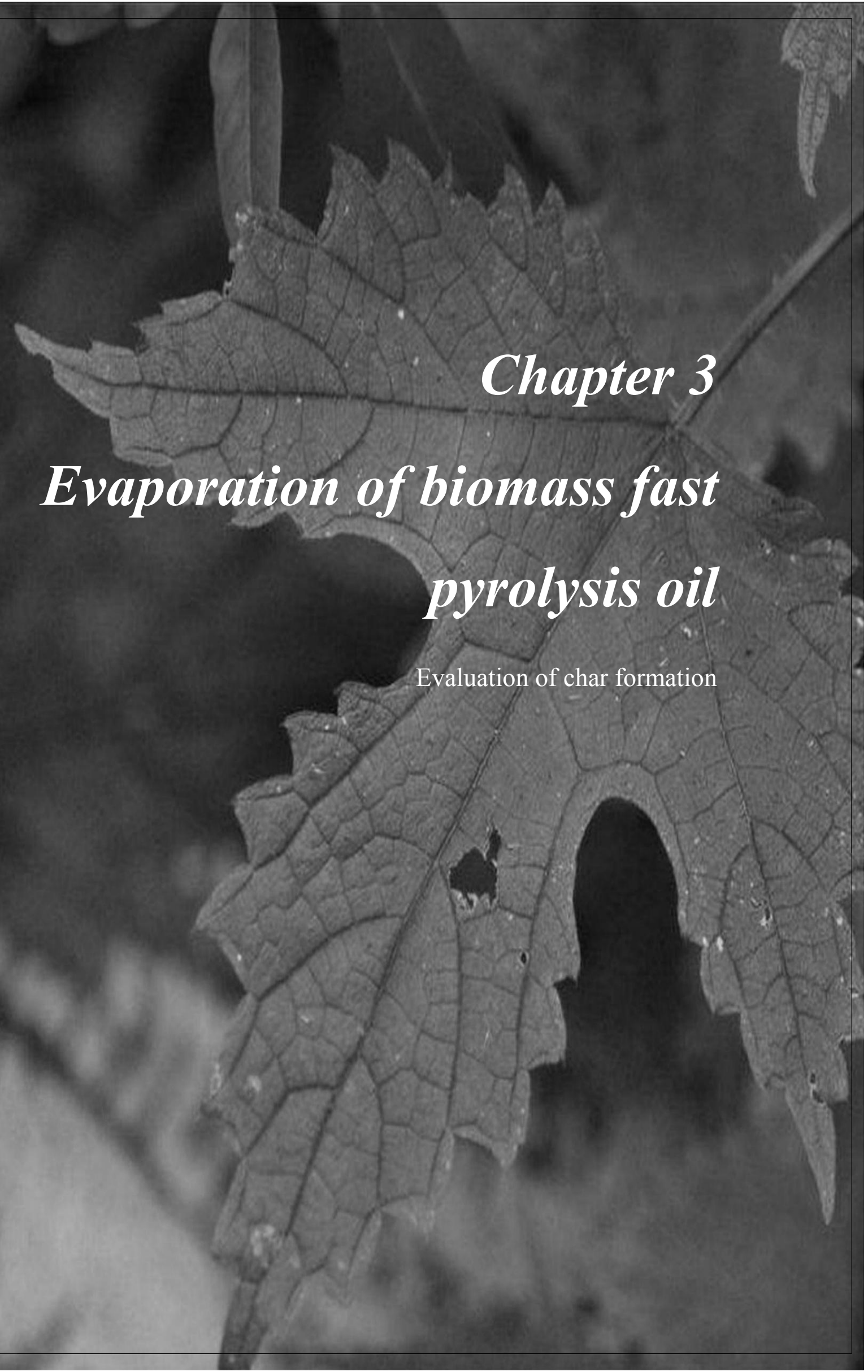




\section{Abstract}

Evaporation experiments of biomass fast pyrolysis oil and its aqueous fractions at low (TGA-10 ${ }^{\circ} \mathrm{C} / \mathrm{min}$, Glass tube-100 ${ }^{\circ} \mathrm{C} / \mathrm{min}$ ) and high (atomization $\sim 10^{6}{ }^{\circ} \mathrm{C} / \mathrm{min}$ ) heating rates are performed. Slow heating of pyrolysis oil produced $\sim 28 \%$ char (on carbon basis) while atomization of oil droplets $(\sim 117 \mu \mathrm{m})$ produced $\sim 9 \%$ char in the temperature range of 500-850 ${ }^{\circ} \mathrm{C}$. Aqueous fractions and glucose solutions also produced less amount of char by evaporating at higher heating rates ( $3 \%$ char) when compared to slower heating ( 24\% char). The results obtained show that in pyrolysis oil not a single lumped components class can be identified that is primarily responsible for the char formation. At low heating rate, higher concentrations of organics in the bio-liquids result in higher char yields, which reveals that a certain fraction in the oil produce char with a reaction order higher than one (polymerization reactions). The measured trends in char yield can be described by a model in which certain fraction of oil is converted by two parallel reactions to char and gas/vapor. Under high heating rate conditions of the droplets, the vapor/gas phase residence time (0.8-2.8 s), steam over carbon ratio (0.4-10) and pressure (1-16 bar) turned out to have no significant on the char yield.

Part of this Chapter has been published as: "Evaporation of biomass fast pyrolysis oil:Evaluation of char formation in Environmental Progress and Sustainable Energy,

2009, 28, 410-417"'. 


\subsection{Introduction}

In gasification, reforming and combustion of pyrolysis oil, evaporation of the oil is the first step. For these applications the oil is usually introduced as a fine spray (atomization) into a hot environment $\left(\geq 500^{\circ} \mathrm{C}\right)$. Atomization of pyrolysis oil into a hot environment is a complex process involving a vigorous phase change and a multicomponents reaction network leading to gas / vapor and char (particulate matter), all in a very short period of time (milliseconds). Char formation leads to blockage and wear and tear problems in the atomizer and down-stream applications. Char formation therefore has to be minimized or to be dealt within the process by combustion, gasification or separation / recovery. However, char can also be a useful by-product that can be combusted to generate the energy required for gasification and reforming. The current understanding (both qualitative and quantitative) of char formation during atomization of pyrolysis oil is not sufficient to improve the design of the evaporation section in various applications. Therefore, comprehending the pyrolysis oil evaporation in high temperature and pressure ambience is very important to process pyrolysis liquids directly in the existing compression engines, boilers and reformers.

There are only a few publications dealing with the evaporation of pyrolysis oil. Branca et al. [1] studied evaporation in a TGA (at low heating rates of $5-20{ }^{\circ} \mathrm{C} / \mathrm{min}$ up to $327^{\circ} \mathrm{C}$ ) and focussed on the evaporation pattern of the "light" components and the reactivity of the char residue. They reported that for the low heating rates applied the char yield of pyrolysis oil evaporation was in the range of 25 to $40 \%$ for four different oils (on weight basis). To describe the evaporation they proposed a model of eight parallel first order reactions of lumped component classes to vapors. In this model it was assumed that a fixed fraction of pyrolysis oil reacted to char. Hallet et al. [2] used a furnace holding single droplets of ca. $1.6 \mathrm{~mm}$ diameter at $750{ }^{\circ} \mathrm{C}$ (estimated heating rate $\sim 6 \times 103{ }^{\circ} \mathrm{C} / \mathrm{min}$ above $120{ }^{\circ} \mathrm{C}$ ) and developed a model based on continuous thermodynamics and a decomposition reaction of "lignin" to gas and char. Also in this study it was found that the char formation was severe during evaporation (ca. 25\% on weight basis). Wornat et al. [3] and Garcìa Pèrez et al. [4] studied the combustion of pyrolysis oil droplets by visualization techniques and analysis of the char residue. 
Wornat et al. [3] did experiments at $1375^{\circ} \mathrm{C}$ with droplets of $320 \mu \mathrm{m}$. With respect to formation of particulate matter they concluded that soot was produced by vapor phase pyrolysis reactions and liquid phase polymerization reactions yielded char. GarcìPèrez and co-workers [4] were able to produce very fine droplets of ca. $60 \mu \mathrm{m}$ and injected them in a heated tube of $700-800{ }^{\circ} \mathrm{C}$. By a sophisticated measurement technique of the droplet diameter in a hot environment, they could show that the droplet size first decreased and then increased again as a function of residence time. Lederlin et al. [5] developed a model for evaporation of pyrolysis oil droplets based on oil with an artificial composition. This model included no char forming mechanism.

To the best of our knowledge, quantitative information is not yet available in the open literature on the product distribution (gas, vapor and char) of pyrolysis oil evaporation when using small droplets $(<2 \mathrm{~mm})$. In Chapter 2 , it is already mentioned that the atomizer produced droplets of $117 \mu \mathrm{m}$ (maximum droplet size). This work showed that these $117 \mu \mathrm{m}$ droplets of pyrolysis oil injected into an inert environment of $500-$ $850{ }^{\circ} \mathrm{C}$ at atmospheric pressure yielded significantly less char than oil slowly evaporating in a TGA ( 8 vs. $30 \%$ on carbon basis).

The present investigation deals with the product distribution of pyrolysis oil, its fractions and glucose solutions using the same atomizer. These feedstocks have been evaporated at different temperatures $\left(500-850{ }^{\circ} \mathrm{C}\right)$ and heating rates (TGA: 10 ${ }^{\circ} \mathrm{C} / \mathrm{min}$, vaporization from a tube: $50{ }^{\circ} \mathrm{C} / \mathrm{min}$ and atomization: $\sim 1 \times 10^{6}$ to $8 \times 10^{6}$ ${ }^{\circ} \mathrm{C} / \mathrm{min}$ ) in order to clarify the char formation mechanism. To investigate the reaction order of the char formation reactions glucose solutions of different concentration and pyrolysis oil aqueous phases of different dilution are atomized at ca. $510{ }^{\circ} \mathrm{C}$. In the discussion, it is evaluated which of the proposed char forming mechanisms is able to predict our experimental observations. Also the molar steam-to-carbon ratio and residence time of gases/vapors were varied to study their effect on the product distribution. Preliminary high pressure atomization experiments were performed using pure glycerol. 


\subsection{Experimental}

\subsubsection{Materials}

The pyrolysis oil used in this study was produced by VTT (Finland) from FR [7]. Prior to each experiment, the pyrolysis oil was filtered using a $10 \mu \mathrm{m}$ filter. The aqueous and heavy fractions of this oil were prepared by addition of demineralized water according to the schemes shown in Figure 1. The aqueous fractions ii, iii and iv represent a well defined dilution series as they contain exactly the same organic molecules. This series (ii, iii and iv) and glucose solutions of different concentration were used to study the effect of the concentration of organics on the evaporation. Aqueous fraction (v) was prepared in a similar way as Czernik et al. [8] which was widely used for aqueous phase reforming. Glucose was obtained from Sigma Aldrich. Pyrolytic lignin was prepared by adding the pyrolysis oil into ice-cooled water as described by Scholze et al. [9]. The elemental composition and water content of the feedstocks are presented in Table 1. Pure glycerol ( 99.999\%) was obtained from Sigma Aldrich and $\mathrm{KOH}$ ( $\sim 97 \%$ pure) was obtained from Merck.

Table 1: Elemental analysis and water content determination of pyrolysis oil and its fractions. The rest is mainly oxygen with also other elements like sulfur and nitrogen. Ash is not determined. (n.d = not determined)

\begin{tabular}{|c|c|c|c|c|}
\hline Feedstock & $\begin{array}{c}C \\
(w t \%)\end{array}$ & $\begin{array}{c}\text { H } \\
(w t \%)\end{array}$ & $\begin{array}{c}\text { Rest } \\
\text { (wt \%) }\end{array}$ & $\begin{array}{l}\text { Water } \\
\text { (wt \%) }\end{array}$ \\
\hline Pyrolysis Oil & 40.6 & 7.6 & 51.8 & 23.9 \\
\hline Aqueous fraction (i) & 24.4 & 7.2 & 68.5 & 48.5 \\
\hline Aqueous fraction (ii) & 16.1 & 10.7 & 73.2 & 67.3 \\
\hline Aqueous fraction (iii) & 10.8 & 10.8 & 78.4 & 79.2 \\
\hline Aqeuous fraction (iv) & 7.2 & 10.9 & 81.9 & 87.3 \\
\hline Aqeuous fraction (v) & 9.5 & 10.2 & 80.9 & 82.1 \\
\hline Heavy fraction & 46.5 & 5.9 & 47.6 & 13.5 \\
\hline Pyrolytic lignin & 61.2 & 6.1 & 31.7 & n.d \\
\hline
\end{tabular}



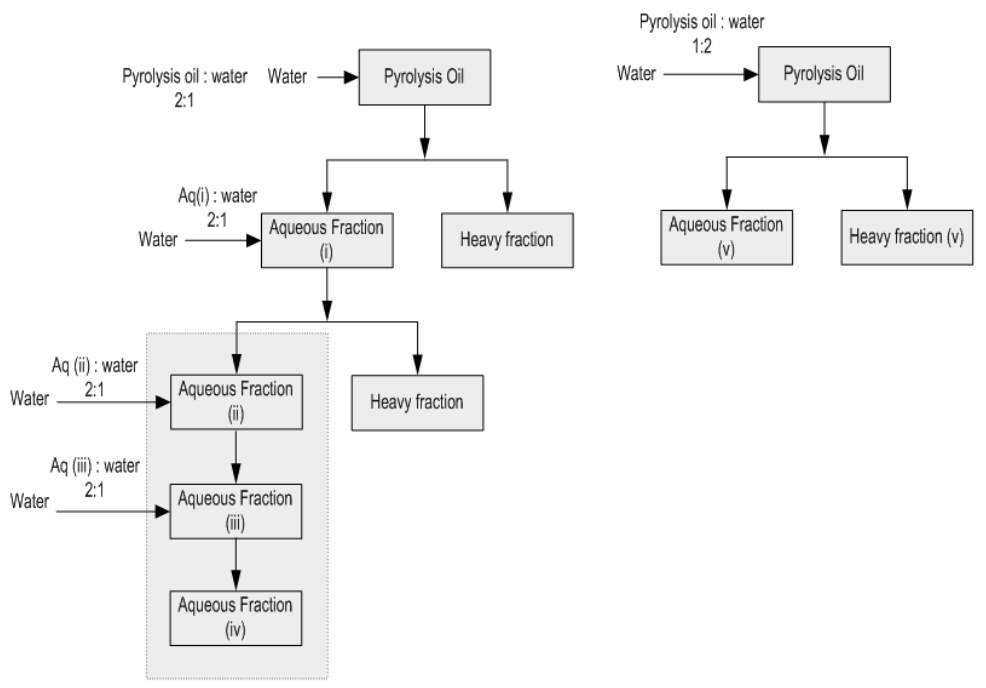

Figure 1: A schematic process diagram of water addition in different amounts to the pyrolysis oil.

\subsubsection{Continuous pyrolysis oil atomization set-up}

To quantify the distribution of pyrolysis oil during evaporation between the gas, vapor and char phase, a dedicated continuous pyrolysis evaporation set-up was constructed. A schematic overview and representation of the set-up were given in Chapter 2.

\subsubsection{Batch wise pyrolysis oil evaporation}

A fixed amount of pyrolysis oil $(1.4 \mathrm{~g})$ was added to the bottom of a glass tube $(\varnothing 10$ $\mathrm{mm}$ ). The glass tube was placed inside a narrow fitting electrically heated oven and the temperatures were measured inside the oil itself and inside the oven (between the glass tube and alumina oven element). A heating rate of the oven of $\sim 50{ }^{\circ} \mathrm{C} / \mathrm{min}$ was applied which resulted in liquid heating rate of $\sim 100{ }^{\circ} \mathrm{C} / \mathrm{min}$ at temperatures above $120^{\circ} \mathrm{C}$. A small nitrogen flow was placed just above the oil to avoid direct contact with air and to remove the vapors which were released during evaporation. The remaining char was weighed and analyzed for its elemental composition. 


\subsubsection{High pressure evaporation of glycerol}

To quantify the carbon distribution of bio-liquids to gases, char and vapors, a continuous high pressure set-up was constructed. The reactor is made of high temperature/pressure steel which can withstand up to $800^{\circ} \mathrm{C}$ and 40 bar. Bio-liquids were continuously sprayed to fine droplets via an ultrasonic atomizer (source: LECHLER, Germany) into the gasifier. Nitrogen was added to enhance atomization and also to maintain pressure inside the reactor, up to 16 bar. A filter was placed at the bottom of the reactor to collect carbonaceous deposits (char). A back pressure regulator was fitted after a cooler to keep the desired pressure inside the reactor. A schematic representation of the set-up is shown in Figure 2.

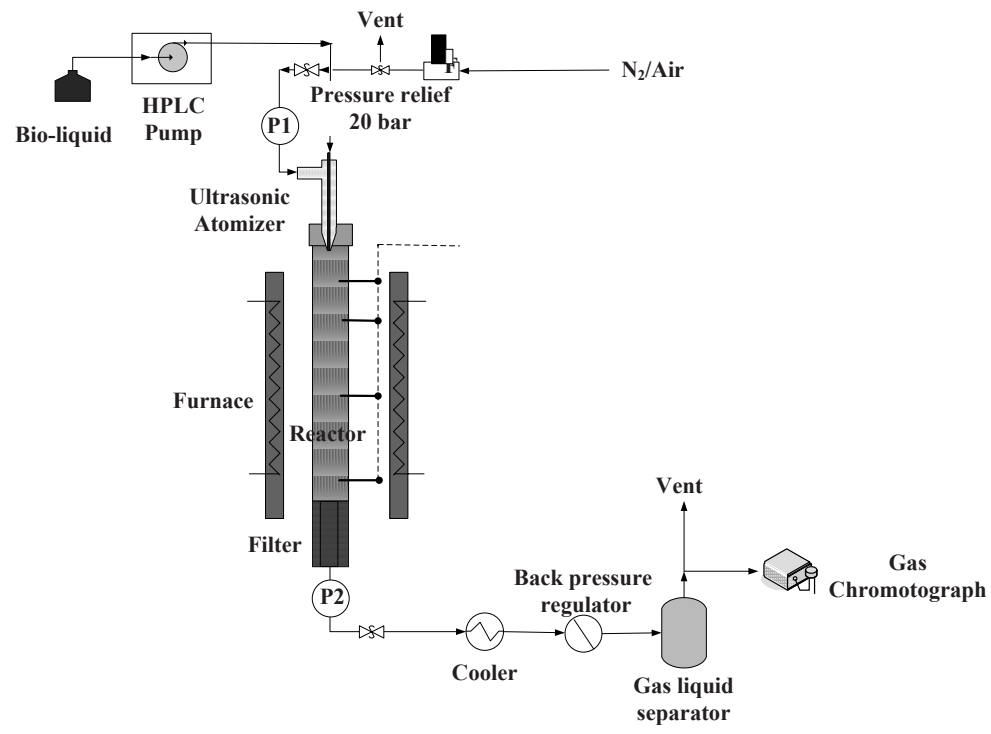

Figure 2: Schematic representation of high pressure gasification of bio-liquids set-up.

\subsubsection{Thermo-gravimetric Analysis}

Heating experiments were performed in a Mettler Toledo thermo-gravimetric analyzer (TGA). The sample cups were heated to $800{ }^{\circ} \mathrm{C}$ at a rate of $10{ }^{\circ} \mathrm{C} / \mathrm{min}$ in argon $(60$ $\mathrm{ml} / \mathrm{min}$ ). Additional to the TGA balance, the samples overall weight loss was quantified with a very accurate external balance since some weight loss was already observed during the stabilization time of the TGA. The weight rate loss is defined: 
$r_{w t} \equiv \frac{d X}{d t}=-\frac{\left(m_{\tau}-m_{\tau+1}\right)}{m_{0}\left(t_{\tau}-t_{\tau+1}\right)}$

Where $\tau$ and $\tau+1$ are logged times, $\mathrm{T}\left({ }^{\circ} \mathrm{C}\right)$ the temperature of the sample cup and $\mathrm{m}_{0}$ (mg) the initial amount of pyrolysis oil as weighted with the external balance. The overall char weight conversions $(\mathrm{X})$ and carbon to char conversions were calculated using the external balance.

\subsubsection{Data analysis}

The integral carbon balance was made based on the nitrogen fed to the reactor as an internal standard. This procedure is reported in detail in Chapter 2. The molar steamto-carbon ratio $(\mathrm{S} / \mathrm{C})$, residence time and dilution factor were calculated as follows:

$\mathrm{S} / \mathrm{C}$ ratio $=\frac{\text { moles of steam added to the sy stem }+ \text { water content in the bio }- \text { liquids }}{\text { moles of carbon in bio }- \text { liquids }}$
Residence time $=\frac{\text { Reactor length }}{\text { Gas velocity (Nitrogen }+ \text { gases produced from bio }- \text { liquids) }}[\mathrm{s}]$

Dilution factor $=\frac{\text { Gases produced from bio }- \text { liquids }}{\text { Gases produced from bio }- \text { liquids }+ \text { Nitrogen flow }}$

\subsection{Results and discussions}

\subsubsection{Thermo-gravimetric analysis}

Figure 3 shows the TGA curve of evaporating pyrolysis oil at $10^{\circ} \mathrm{C} / \mathrm{min}$ up to $800^{\circ} \mathrm{C}$. This curve is typical and in good agreement with the evaporation curves earlier reported.1 At temperatures below $200{ }^{\circ} \mathrm{C}$ water and light components evaporate. Van Rossum et al. [6] showed that above $100{ }^{\circ} \mathrm{C}$ besides evaporation also polymerization reactions are already taking place in the liquid phase. In the range of 100 to $350{ }^{\circ} \mathrm{C}$ 
polymerization and cracking reactions proceed next to evaporation. Solvent solubility tests of the liquid at different temperatures6 showed that the first actual char (THF insoluble material) is formed around $200{ }^{\circ} \mathrm{C}$ and only char remains above $500{ }^{\circ} \mathrm{C}$. The low, but measurable, weight loss rate above $500{ }^{\circ} \mathrm{C}$ (see Figure 3) shows that the char produced is devolatizing / degassing slowly.

Table 2 lists the measured char yields of the feedstocks evaporated in the TGA (10 ${ }^{\circ} \mathrm{C} / \mathrm{min}$ up to $800{ }^{\circ} \mathrm{C}$ ). It has been found that the whole pyrolysis oil containing 23.9 wt $\%$ water gives $28 \%$ char (on carbon basis). Pyrolytic lignin clearly produces higher amount of char (54\%). Evaporation of a glucose solution of $40 \mathrm{wt} \%$ in the TGA results in $28 \mathrm{wt} \%$ char. Remarkably, aqueous fraction i (48.5 wt \% water) also yield a high amount of char (24\%). These results indicate that not a single lumped component class of pyrolysis oil (e.g. pyrolytic lignin) can be identified that is solely or predominantly responsible for char formation. Van Rossum et al. [6] has found that in the range of $1-100{ }^{\circ} \mathrm{C} / \mathrm{min}$ the amount of char produced is not influenced significantly by the heating rate. This suggests that by performing TGA tests at such low heating rates, quantification of the maximum amount of char that can be produced during evaporation is possible. The components in the oil leading possibly to char are in this case not identified but are only quantified as fraction of the feedstock. In a practical model (mechanism) for the evaporation of pyrolysis oil, the fraction of the feed susceptible to char formation can then be assumed to be the TGA char yield. This fraction can then be converted to char, gas and vapor in the model. 


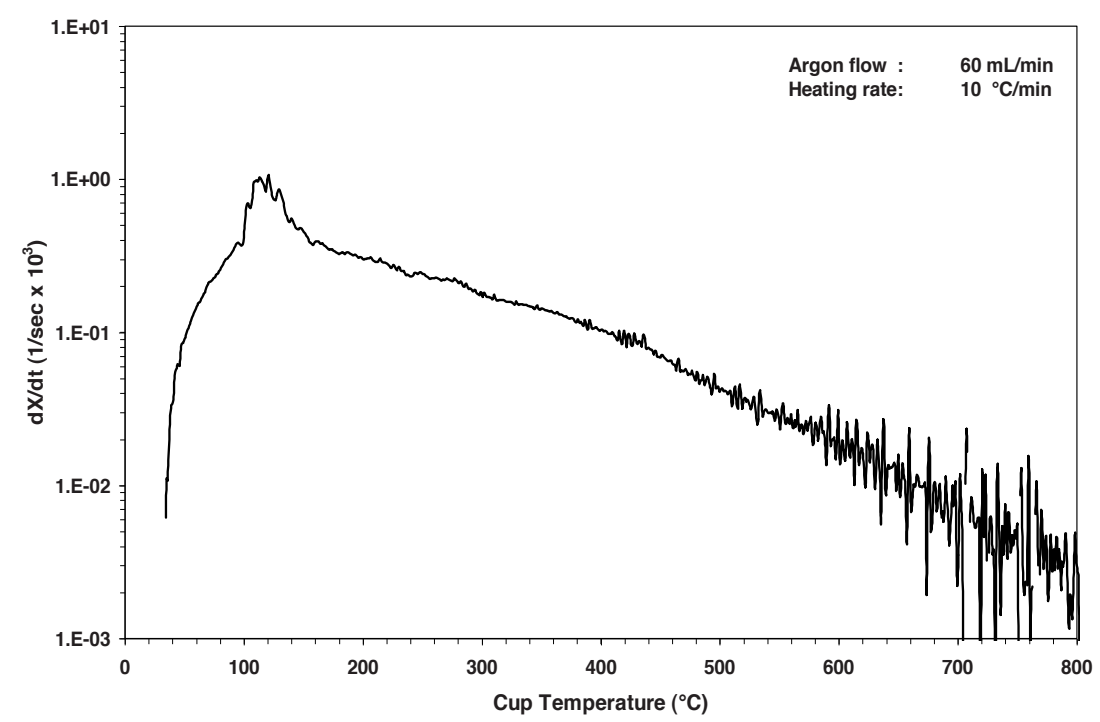

Figure 3: TGA of pyrolysis oil at $10^{\circ} \mathrm{C} / \mathrm{min}$ heating rate in inert (Argon) gas.

\subsubsection{Continuous evaporation by atomization}

The effect of reactor temperature on the amount of char, gas and vapor produced during the atomization of pyrolysis oil and its aqueous fractions is illustrated in the Figure 4. The error bars in this Figure are based on triple measurements which show that the reproducibility is good. A series of atomization experiments were performed in the temperature range between 500 and $850^{\circ} \mathrm{C}$ with a gas/vapor residence time of 2 -3 seconds. The amount of the char produced from the pyrolysis oil is independent or slightly dependent on the temperature. This indicates that for pyrolysis oil, vaporization and the majority of the cracking reactions are completed before $500{ }^{\circ} \mathrm{C}$, which is in agreement with the TGA results (showing only low rates of char degassing above $500^{\circ} \mathrm{C}$ ). 
Table 2: Char productions using TGA of pyrolysis oil and related fractions/compounds. The amounts are given both on weight and carbon to char basis. The sample was heated to $800^{\circ} \mathrm{C}$ with a heating rate of $10{ }^{\circ} \mathrm{C} / \mathrm{min}$ and an Argon flow of $60 \mathrm{ml} / \mathrm{min}$

\begin{tabular}{|l|c|c|}
\hline Feedstocks & Char wt \% & Yc (\%) \\
\hline Pyrolysis Oil & 15 & 28 \\
\hline Aqueous fraction & 7 & 24 \\
\hline Heavy fraction & 21 & 33 \\
\hline Glucose solution & 7 & 28 \\
\hline Pyrolytic lignin & 43 & 54 \\
\hline
\end{tabular}

The char yield from pyrolysis oil obtained with the atomizer is significantly lower compared to TGA results (8-9 vs. $28 \%$ char, carbon basis). This dependence on the heating rate $\left(1-100{ }^{\circ} \mathrm{C} / \mathrm{min}\right.$ for TGA vs. $1 \times 10^{6}-8 \times 10^{6}{ }^{\circ} \mathrm{C} / \mathrm{min}$ for the $117 \mu \mathrm{m}$ droplets $)$ cannot be predicted by the proposed models for pyrolysis oil evaporation that are based on fixed char yields $[1,2]$ The char formation model proposed by Baert et al. [10] for heavy fuel oil, which basically consists of two parallel reactions of a certain fraction of the feed to char and vapors/gases, is able to predict this trend. To predict the trend of decreasing char formation for higher heating rates the activation energy of gas/vapor production reaction needs to be the highest; Baert10 used $100 \mathrm{~kJ} / \mathrm{mol}$ for polymerization and $270 \mathrm{~kJ} / \mathrm{mol}$ for the reaction to gas/vapor. Their model predicted that while increasing the heating rate from $6 \times 10^{4}$ to $6 \times 10^{7}{ }^{\circ} \mathrm{C} / \mathrm{min}$ the char production is decreasing from 12 to $0.5 \mathrm{wt} \%$ (on feed basis) for heavy fuel oil.

It is important to notice that the heating rate of pyrolysis oil evaporation by atomization is a function of the temperature of the droplet. When injected to the hot environment the droplet is heated to $100-120{ }^{\circ} \mathrm{C}$ at which temperature it stays for a certain time (due to water and lights evaporation) where after it is heated again with a reasonably fixed rate. In this latter part of the heating trajectory (above $120^{\circ} \mathrm{C}$ ) char precursors and char are formed and consequently this heating rate is used in this study for comparison. The char yield of the aqueous fractions is lower than the char yield of pyrolysis oil. Probably the aqueous fractions produce less char because of their low or 
zero content of pyrolytic lignin, which produces over $50 \%$ char in TGA (See Table 2). This may also explain why at $500{ }^{\circ} \mathrm{C}$ aqueous fractions ii, iii and iv produce less char than fractions $\mathrm{i}$ and $\mathrm{v}$ ( $\mathrm{i}$ and $\mathrm{v}$ still contain some heavies, see Figure 1). The char produced from aqueous fractions decreases from 500 to $650 / 700{ }^{\circ} \mathrm{C}$ and hereafter remains constant. This char yield decrease may be ascribed to faster gasification reactions of char and/or char precursors (relative to polymerization) of the aqueous fraction of pyrolysis oil compared to the whole oil.

Our results show that when using the aqueous fraction of pyrolysis for steam reforming at temperatures around $850^{\circ} \mathrm{C}$, as described by Czernik and co-workers [7], only a limited amount of char is produced (1- $2 \%$ on carbon basis) in the atomization stage when producing small droplets of $117 \mu \mathrm{m}$. Such low char yields can most likely be dealt with within the evaporator and/or downstream equipment especially when a fluidized bed is being used and will only have a minor impact on the overall efficiency. When the whole oil is used for steam reforming under otherwise identical conditions, as practiced by Van Rossum et al. [11] considerably more char is produced (8-9\%) which makes the design of the evaporator more complex. At the moment of writing we are testing a new atomizer that produces droplets of less than $5 \mu \mathrm{m}$ in order to investigate if it is possible to further reduce the char production from the whole pyrolysis oil.

Figures 4B and 4C show that at increasing temperature the gas yield is increasing and the vapor yield is decreasing which is due to thermal cracking reactions of the vapors. At $500{ }^{\circ} \mathrm{C}, 70$ to $90 \%$ of the carbon in the oil is recovered as vapors, while at high temperature $\left(850^{\circ} \mathrm{C}\right)$ the vapor yield is $30-40 \%$ for pyrolysis oil and only $1-5 \%$ for the aqueous fractions. The carbon to gas conversion is as low as $10-20 \%$ at $500{ }^{\circ} \mathrm{C}$ and increases up to $60-65 \%$ at $850{ }^{\circ} \mathrm{C}$ for pyrolysis oil, whereas for the aqueous fractions a carbon to gas conversion of $90-95 \%$ is achieved at $850{ }^{\circ} \mathrm{C}$. It is not possible to ascribe the higher carbon to gas conversion for the aqueous fractions compared to the whole oil (difference is $30 \%$ on carbon basis) only to the difference in char yield (difference is 6-7\%). It is therefore concluded that, overall, the vapors from the aqueous fractions are easier to crack than vapors from the whole oil. 
Chapter 3 - Evaporation of biomass fast pyrolysis oil - Evaluation of char formation

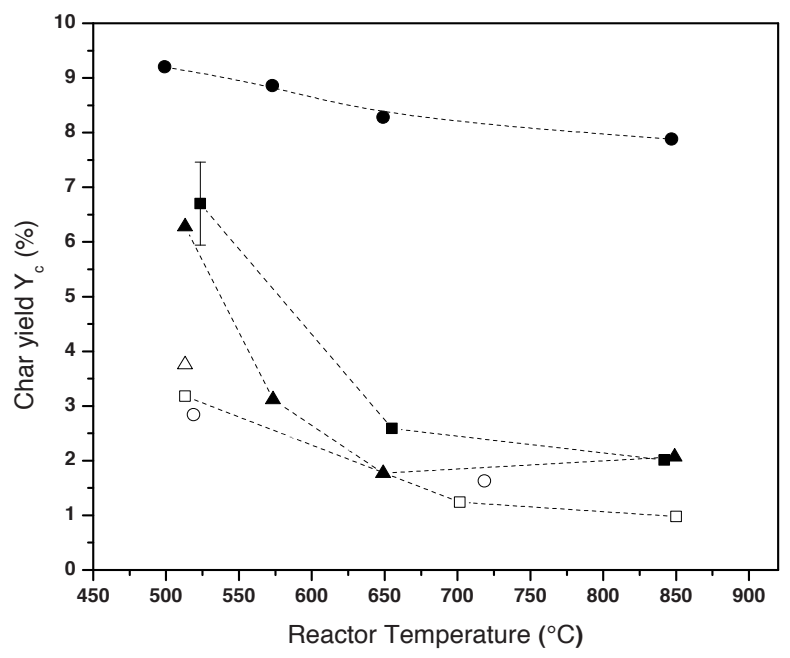

$4 \mathrm{~A}$

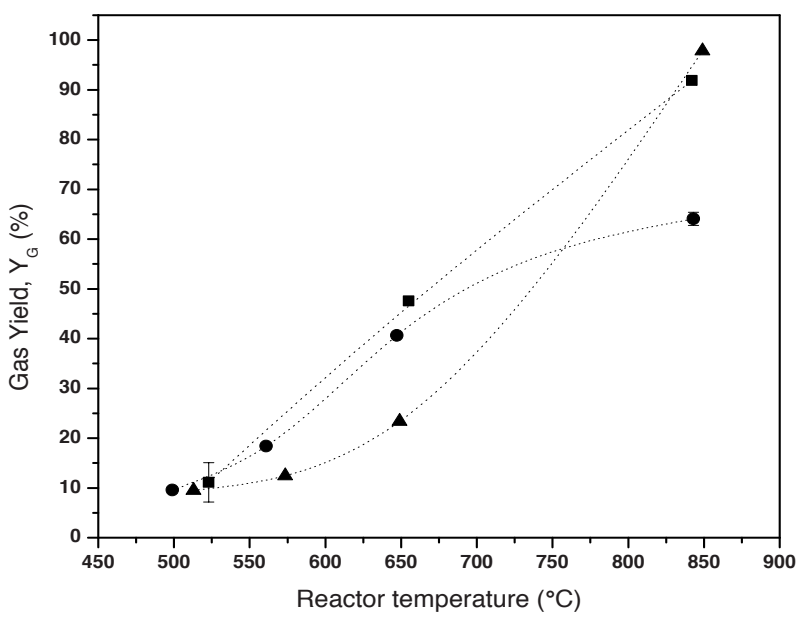

AB

[87] 


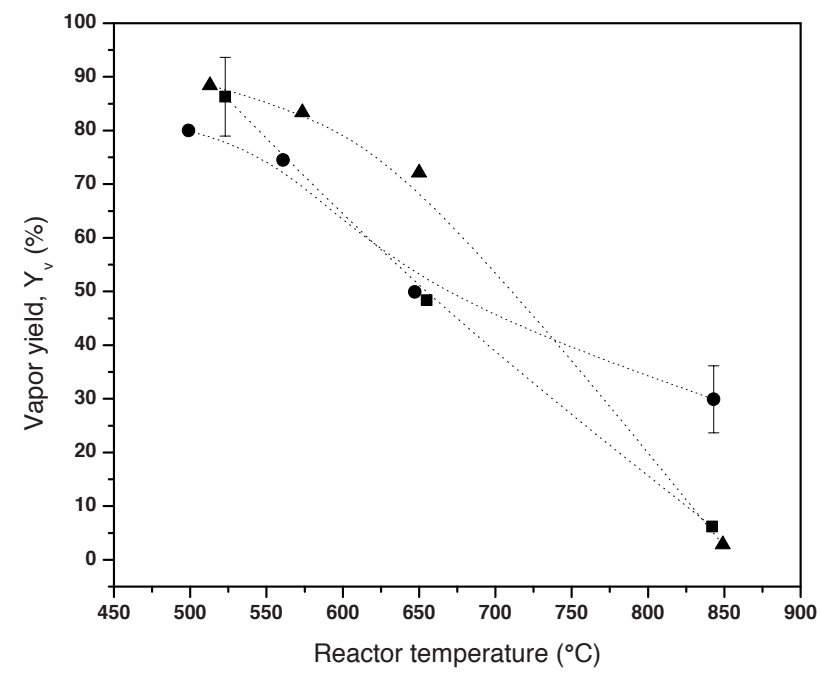

$4 \mathrm{C}$

Figure 4: Carbon distribution over A. Char, B. Gas, and C. Vapor during the evaporation of pyrolysis oil and aqueous fractions.

--๑-- Pyrolysis oil, ----- aqueous fraction (i), -- $\Delta$--aqueous fraction (v)

-- $\Delta$-- aqueous fraction (ii), -- $\square--$ aqueous fraction (iii), -- -- aqueous fraction (iv)

\subsubsection{Effect of the organics concentration on the char yield}

Figure 5 shows the effect of the organics concentration in the bio-liquid $(10-40$ $\mathrm{wt} \%)$ on the char yield for both fast heating with the atomizer $\left(1 \times 10^{6}-8 \times 10^{6}{ }^{\circ} \mathrm{C} / \mathrm{min}\right)$ and slow heating in the batch evaporation tube $\left(100{ }^{\circ} \mathrm{C} / \mathrm{min}\right)$ up to $510{ }^{\circ} \mathrm{C}$. Both glucose solutions and aqueous fractions ii, ii and iv were used as feed stocks. Both feedstocks are well defined dilution series in which the organic molecules type do not change, only their concentration. In the batch evaporation tube the aggregation state of the glucose solution was checked at temperatures above $100{ }^{\circ} \mathrm{C}$ to exclude effects of complete evaporation of the water. In the range of 100 to $200{ }^{\circ} \mathrm{C}$ the samples appears as a boiling liquid suggesting that some water is present or that glucose has already been partly converted. 
Under slow heating conditions the results clearly show that the char yield increases for higher concentration of organics in the bio-liquids. This result indicates that the reactions of char precursors to char are of reaction order higher than 1 , which would be expected for polymerization reactions. For glucose solutions such concentration effect has also been observed under hydrothermal conditions $\left(350{ }^{\circ} \mathrm{C}, 200\right.$ bar $)$ by Knezevic et al. [12] Using the atomizer, the char yield is lower and the effect of the concentration is not observed or, if present, falls within the error margins of the experiments. The absence of a concentration effect may be ascribed to the vigorous nature of the evaporation under very high heating rates. It is thinkable that with extremely high heating rates or diluted solutions compounds remain isolated and end up in the gas/vapor phase before they can fully react in the liquid phase. With this 'evaporation' the density of the reactive compounds is lowered significantly (factor $\sim 10^{3}$ ) which will result in less polymerization.

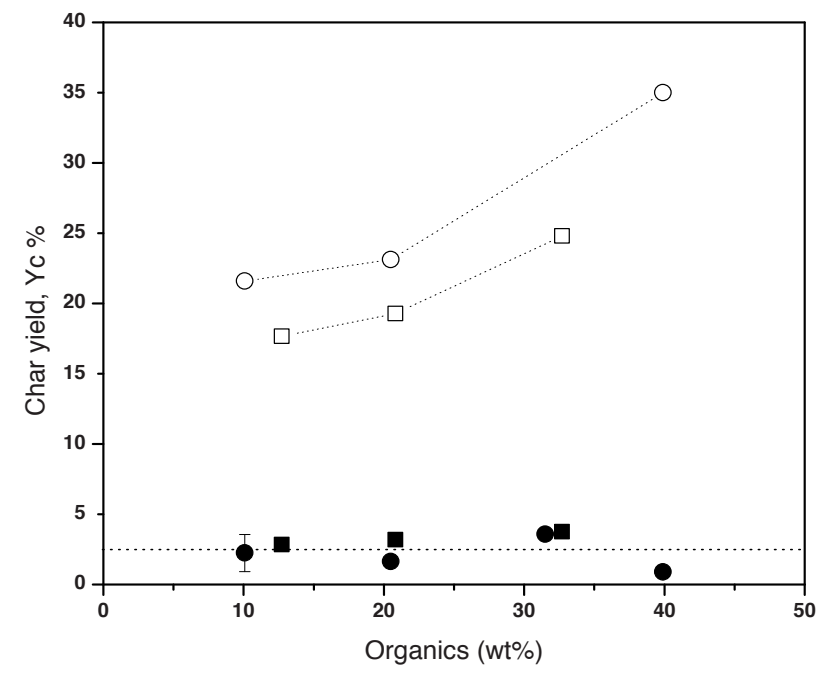

Figure 5: Effect of organics on char yield by different heating rates. reactor temperature $=\mathbf{5 1 0} \pm 10^{\circ} \mathrm{C}$, -- $\bullet-$ Glucose atomization , -- - -- Aqueous fraction atomization , -- -- Glucose (glass tube - $100{ }^{\circ} \mathrm{C} / \mathrm{min}$ ), -- $\square--$ Aqueous fraction (glass tube $-100{ }^{\circ} \mathrm{C} / \mathrm{min}$ ). 


\subsubsection{Char formation model}

To our best knowledge the model proposed for char production [5] in evaporating pyrolysis oil is actually assuming that a fixed value of the oil is converted to char. This model cannot predict the trends we measured of decreasing char yield at increasing heating rate and higher char yields for more concentrated bio-liquids. Models proposed for heavy fuel oil in which a certain fraction of oil is converted by two parallel reactions to char and gas/vapor can describe these trends (see Figure 6).

The cracking reaction is presumably first order, whereas our results with diluted feeds have shown that the reaction to char is of the order higher than one. In order to predict the effect of the heating rate correctly is required that the activation energy of the gas/vapor reaction is considerably higher than the activation energy for char production.

For a practical model, it is proposed to assume that the fraction of oil that reacts to gas/vapor and char equals the char yield obtained in a TGA under slow heating conditions $\left(10^{\circ} \mathrm{C} / \mathrm{min}\right)$.

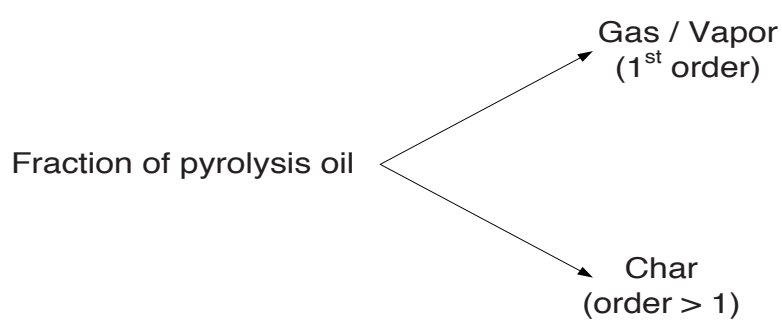

Figure 6: Model (mechanism) for char formation during pyrolysis oil evaporation. 


\subsubsection{Effect of the residence time of gases}

The effect of residence time on product distribution at $\sim 750^{\circ} \mathrm{C}$ without steam addition during pyrolysis oil gasification is shown in Figure $7 \mathrm{a}$. To decrease the residence time of gases, additional amount of $\mathrm{N}_{2}$ was added. This means that the product gas is more diluted with nitrogen. It can be seen in Figure 2 that char formation is almost constant at $750^{\circ} \mathrm{C}(\sim 7 \%$ on carbon basis $)$ with increase in residence time of gases. This is expected because the initial distribution of carbon in the pyrolysis oil to vapor/gas and char has already attained in few milliseconds because of high heating rate of droplets. However, the amount of gases produced increased by increasing the residence time of the gases/vapors from 0.8 to 2.8 seconds and the amount of unconverted vapors was decreased showing the thermal cracking of the vapors.

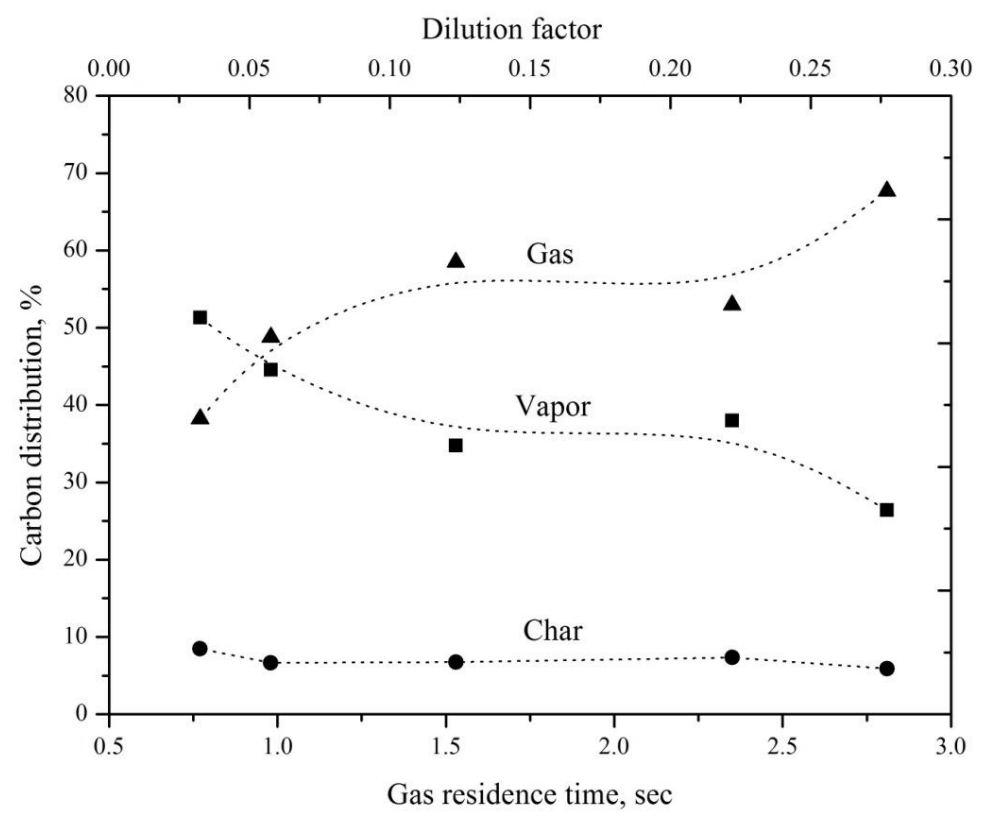

Figure 7: Effect of residence time of gases during gasification of pyrolysis oil, (at $\left.\mathrm{T}=750^{\circ} \mathrm{C}, \mathrm{S} / \mathrm{C}=\mathbf{0 . 4}\right)$. 


\subsubsection{Effect of steam over carbon ratio}

The effect of steam-to-carbon ratio on the product distribution at $\sim 800^{\circ} \mathrm{C}$ is shown in Figure 8. As shown in Figure 8, char formation is slightly decreased from 7.9 to $6.4 \%$ (on carbon basis from $\mathrm{S} / \mathrm{C}$ of 0.4 to 10$)$. However, by considering the error $( \pm 2 \%)$ in the carbon closure, this cannot be considered as a significant effect. Focussing on the gas and vapor production, it can be seen that more gas is produced when excess steam is supplied and the vapor production decreases, although the rates of increase and decrease are smaller at high $\mathrm{S} / \mathrm{C}$-ratios (S/C of 5 and above). These results imply that vapor cracking is slightly enhanced by the addition of steam up.

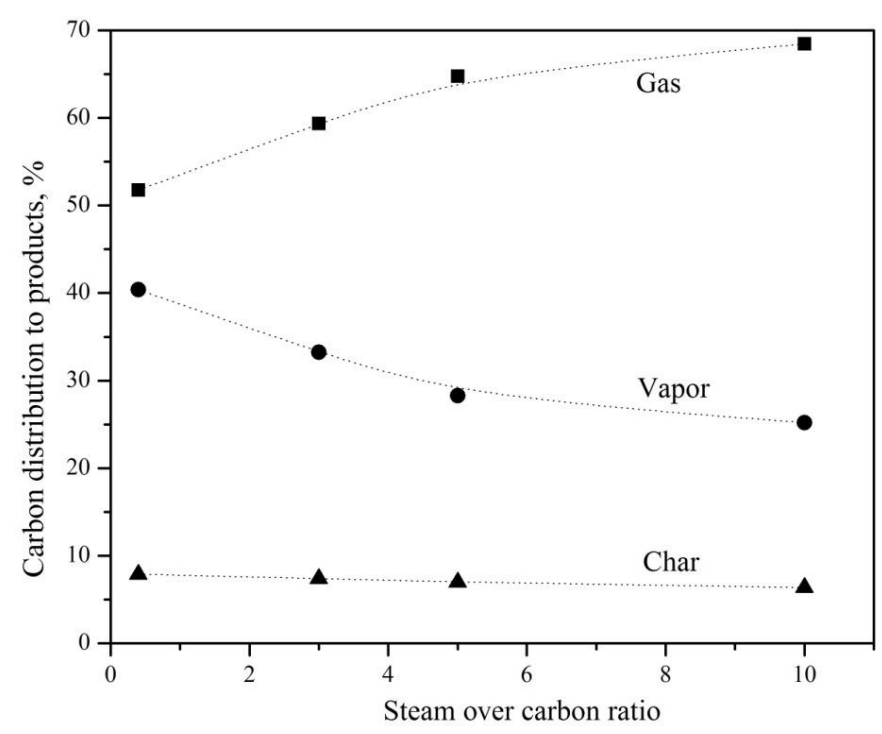

Figure 8: Carbon distribution during gasification of pyrolysis oil, altering the steam-to-carbon ratio (at $800^{\circ} \mathrm{C}$ ). 


\subsubsection{Effect of pressure}

The effect of pressure from 1 to 16 bar was studied at $\sim 650^{\circ} \mathrm{C}, \tau=40 \pm 10$ seconds using pure glycerol and glycerol with $\mathrm{KOH}$. For pure glycerol the carbon to gas conversion increased from $64 \%$ to $\sim 80 \%$ from 1 bar to 6 bar and held constant up to 16 bar. In the whole range char production was not observed. The carbon to gas conversion at 1 bar cannot be explained. However, at high pressure (from 6 to 16 bar), the carbon to gas conversion remained at $80 \pm 2 \%$. By increasing the pressure ( 6 bar and above), all the product gases such as $\mathrm{CH}_{4}, \mathrm{CO}_{2}, \mathrm{CO}$ and $\mathrm{H}_{2}$ are relatively constant.

For glycerol with $\mathrm{KOH}$, the formation of char is $\sim 3 \%$ at all pressures measured. The results showed that the char formation takes place irrespective of pressure and temperature (in the temperature range between 450 and $850^{\circ} \mathrm{C}$ at atomospheric pressure - see Chapter 4). Also, it was observed that carbon to gas conversion with $\mathrm{KOH}$ was slightly lower than the pure glycerol. These results indicate that $\mathrm{KOH}$ has a definite effect on glycerol even at high pressure.

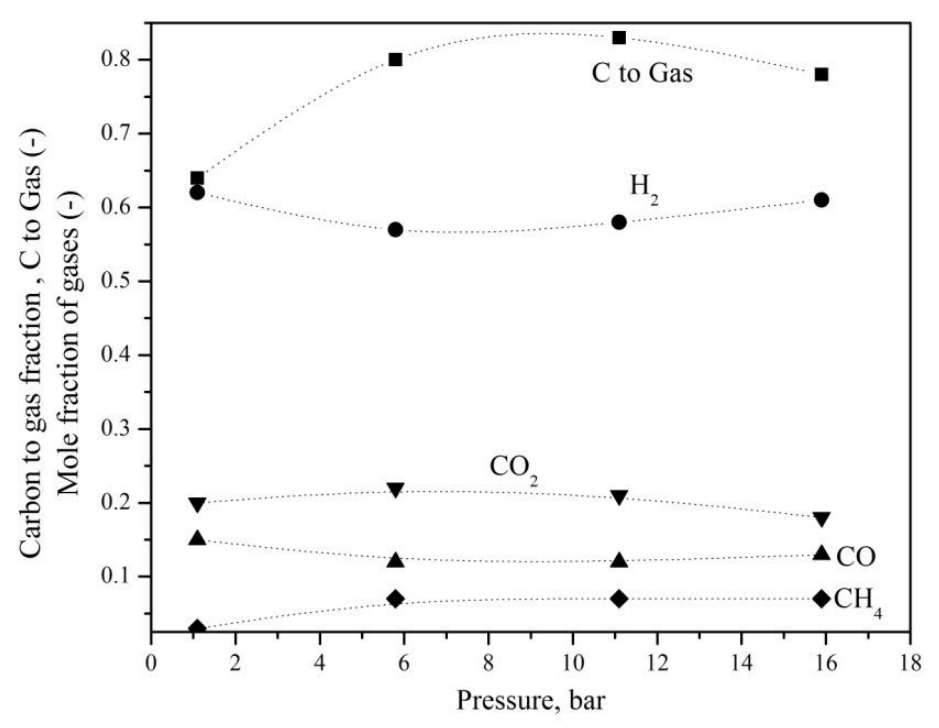

9A 


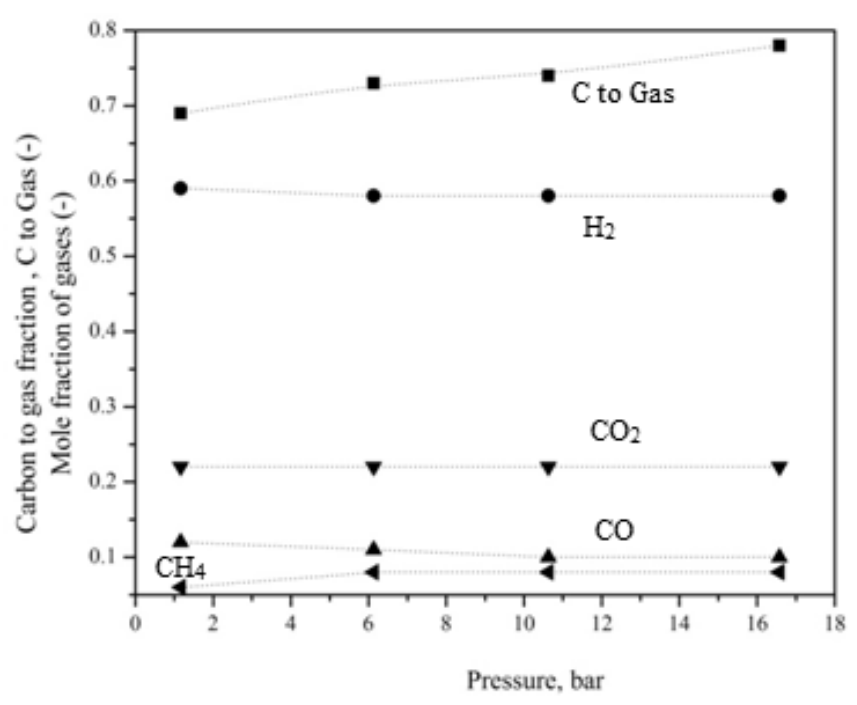

9B

Figure 9: Product distribution during high pressure gasification of $\mathrm{A}$ ) pure glycerol at $\left.650+/-10^{\circ} \mathrm{C}, \mathrm{S} / \mathrm{C}=1 \mathrm{~B}\right)$ glycerol with $4 \%$ by weight $\mathrm{KOH}$ at $650+/-10$ ${ }^{\circ} \mathrm{C}, \mathrm{S} / \mathrm{C}=\mathbf{1}$.

\subsection{Conclusions}

The char yield of pyrolysis oil evaporation in a hot environment depends strongly on the heating rate. A char yield of $28 \%$ (on carbon basis) is measured under slow heating conditions in a TGA $\left(10^{\circ} \mathrm{C} / \mathrm{min}\right.$ to $\left.800{ }^{\circ} \mathrm{C}\right)$ whereas using an atomizer producing droplets of ca. $117 \mu \mathrm{m}$ results in $8-9 \%$ char in the temperature range of the environment of 500 to $850{ }^{\circ} \mathrm{C}$. Aqueous fractions of pyrolysis oil and glucose solution can be atomized $(117 \mu \mathrm{m})$ yielding only 1 to $2 \%$ char for environment temperatures of $650{ }^{\circ} \mathrm{C}$ and higher. Next to pyrolysis oil and its aqueous fractions (with different compositions), pyrolytic lignin and glucose solutions also produced char upon heating, which shows that not a single lumped components class in pyrolysis oil can be identified that is predominantly responsible for char formation. Experiments with low heating rates using aqueous solutions with different concentrations of the same organics have revealed that the char producing reactions are of order higher than one (a higher organics concentration results in higher char yields). The measured trends in 
char yield can be described by a model in which a certain fraction of oil is converted by two parallel reactions to char and gas/vapor, with the reaction to char having order higher than one and the activation energy of gas/vapor production being highest. For a practical model it is proposed to use the char yield obtained in TGA under slow heating conditions (say $10^{\circ} \mathrm{C} / \mathrm{min}$ ) to define the fraction of pyrolysis oil that can react to char, vapor and gas. Under high heating rate conditions of the droplets, the vapor/gas phase residence time (0.8-2.8 s), steam over carbon ratio (0.4-10) and pressure (1-16 bar) turned out to have no significant on the char yield.

\section{References}

1. C.Branca, C. Di Blasi, Ind. Eng. Chem. Res. (2006), vol 45, 5891-5899

2. W.L.H. Hallet and N.A.Clark, Fuel (2006) vol 85, 532-544

3. M.J.Wornat, B.G.Porter, N.Y.C. Yang Energy Fuels (2002), vol 8, 1131-1142

4. M.Garcia-Pèrez, P.Lappas, P.Hughes, L.Dell, A.Chaala, D.Kretschmer and C.Roy IFRF Combustion Journal (2006), 200601

5. T.Lederlin, J.E.D.Gauthier, Pyrolysis and Gasification of Biomass and Waste, Proceedings of an expert meeting (2003), Editor: A.V.Bridgwater, CPL Press, Berks, U.K. pp 203-214

6. G.van Rossum, B.M.Guell, R.P. Balegedde Ramachandran, K.Seshan, L.Lefferts, S.R.A. Kersten, W.P.M. van Swaaij AIChE journal (2010), vol 56, 2200-2210

7. A.Oasmaa, K.Sipilä, Y.Solantausta, E.Kuoppala, Energy \& Fuels (2005), vol 19,2556

8. S.Czernik, R.French, C.Feik,E. Chornet, Ind. Eng. Chem. Res. (2002), vol 41, 4209

9. B.Scholze, D.Meier, J. Anal. Pyrolysis (2001) vol 60, 41-54

10. R.S.G.Baert, Combustion Science and technology (1993), vol 90, 125-147

11. G.van Rossum, S.R.A.Kersten, and W.P.M. van Swaaij, Ind. Eng. Chem. Res(2007), vol 46, 3959-3967

12. D.Knezevic, W.P.M. van Swaaij and S.R.A. Kersten, Ind. Eng. Chem. Res (2009), vol 48, 4731-4743 


\section{Chapter 4}

Preliminary assessment of synthesis gas production via hybrid steam reforming of methane and glycerol 


\section{Abstract}

In this Chapter, hybrid steam reforming (HSR) of desulphurized methane together with crude glycerol in existing commercial steam reformers to produce synthesis gas is proposed. The proposed concept consists of a gasifier to produce vapors, gases and char from crude glycerol, which is coupled with a pre-reformer to further convert the vapors into gases using steam reforming catalyst. These gases are mixed with methane and subsequently reformed to synthesis gas $\left(\mathrm{CO}+\mathrm{H}_{2}\right)$ in a primary reformer using a steam reforming catalyst. In the present work, gasification, steam and hybrid reforming of glycerol is reported. The total product distribution (gas, vapor and char) of pure and crude glycerol gasification was quantified at different reaction temperatures at very high heating rates (atomization: $\sim 10^{6}{ }^{\circ} \mathrm{C} / \mathrm{min}$ ). With pure and neutralized crude glycerol, no char formation was observed. However, with crude glycerol and pure glycerol doped with $\mathrm{KOH}$, a significant amount of char on carbon basis ( 10\%) is produced. The results obtained here show that $\mathrm{KOH}$ present in glycerol was responsible for polymerizing higher molecular components formed during thermal degradation. Steam reforming of pure and neutralized crude glycerol was studied at different process conditions in the presence of commercial reforming catalysts. Pure glycerol was easier (in terms of catalyst activity) to reform when compared to neutralized crude glycerol at high temperature $\left(800^{\circ} \mathrm{C}\right)$. The results from the steam reforming of neutralized crude glycerol show that the loss of catalyst activity was due to the presence of organic impurities such as FAMEs, di and tri glycerides. The proposed HSR concept was demonstrated for pure glycerol and crude glycerol with methane (on $C_{1}$ basis) in a two-stage fixed bed reformer at $800{ }^{\circ} \mathrm{C}$ using commercial steam reforming catalyst.

Part of this Chapter has been published as: "Preliminary assessment of synthesis gas production via hybrid steam reforming of methane and glycerol in Energy \& Fuels, 2011, 25 (12), 5755-5766”. 


\subsection{Introduction}

Over the past several years, there has been an increasing interest in the use of biodiesel as a supplement to the traditional fossil fuels. With the ever-increasing production of bio-diesel, a surplus of crude glycerol, which is a by-product from transesterification process, is available for further processing. The crude by-product stream typically comprises of a mixture of glycerol, methanol, inorganic salts (mainly catalyst residue), free fatty acids and fatty acid methyl esters in varying quantities. Purification is required to transform the crude glycerol to usable state for food and pharmaceutical applications. As a first step in purification, excess methanol is distilled and re-used for the transesterifcation process. An acid neutralization step is required to purify crude glycerol further, to convert alkali hydroxide catalyst into its salts (e.g. chlorides), typically around 5\% present in the crude [1]. The combination of high methanol prices and low crude glycerol prices has made the conversion of crude glycerol to methanol via steam reforming economically attractive [1]. To take advantage of the existing natural gas steam reformers, there is a possibility to replace natural gas by a fraction of crude glycerol on carbon basis. This concept is proposed here as 'hybrid steam reforming' to utilize either a direct crude or purified/neutralized crude glycerol.

HSR process consists of the following stages: (1) Gasification: controlled atomization of crude glycerol into small droplets $(\sim 100 \mu \mathrm{m})$ in a gasifier around $500^{\circ} \mathrm{C}$. This leads to the production of vapor, gases and char via thermal decomposition. (2) Steam reforming: vapor produced from the gasifier can be pre-reformed using a commercial reforming catalyst. Adhikari et al. [2] reported that a minimum temperature of $\sim 600^{\circ} \mathrm{C}$ is required to convert glycerol into gases. This step is similar to pre-reforming of naphtha/natural gas. In the case of naphtha and natural gas, higher hydrocarbons are partially reformed to produce gases whereas in the case of glycerol, vapors (oxygenates) are reformed to produce gases. (3) HSR: The product gas obtained from the pre-reforming step can be mixed with desulphurized methane and reformed in the primary reformer. Since this is similar to natural gas reforming, a high temperature of $\sim 800{ }^{\circ} \mathrm{C}$ is preferred for this step. The whole concept is summarized in Figure 1A. 


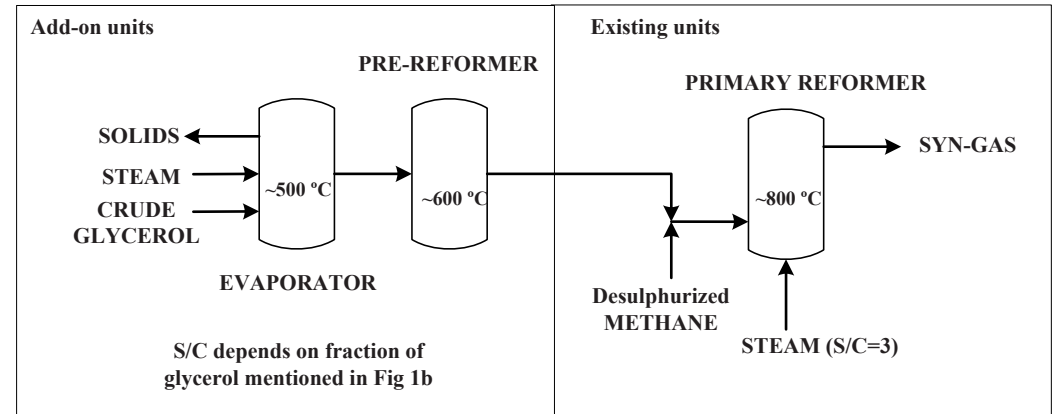

$A$

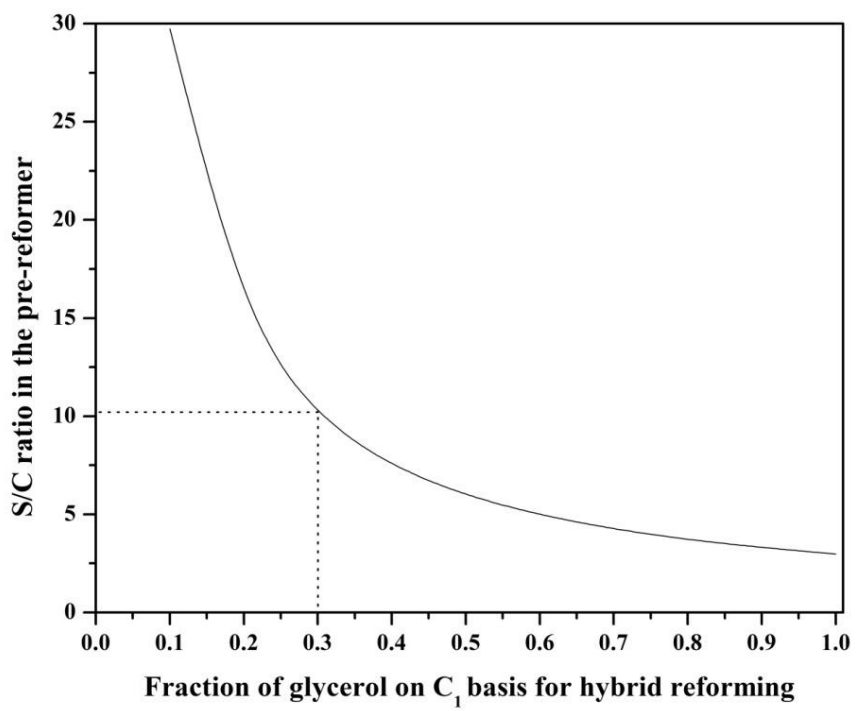

$B$

Figure 1: (A) Proposed concept for HSR of methane with glycerol. (B) Dependence of $\mathrm{S} / \mathrm{C}$ ratio in the pre-reformer during hybrid steam of glycerol fraction with methane. 
Hybrid reforming can be beneficial in many ways:

Steam necessary for the primary reforming (molar S/C 3) can be completely/partly utilized in the pre-reforming step ( $\mathrm{S} / \mathrm{C} \sim 5-15$, depends on glycerol fraction). Here, $\mathrm{S} / \mathrm{C}$ is defined as the ratio of the total moles of water added including the water content of the glycerol, over the moles of carbon present in the glycerol. Therefore, no additional steam is required for the process. Figure $1 \mathrm{~b}$ summarizes the $\mathrm{S} / \mathrm{C}$ required for a specific fraction of crude glycerol (by wt $\%$ on $\mathrm{C}_{1}$ basis) available for HSR. For instance, to process $30 \mathrm{wt} \%$ of glycerol on carbon basis, a S/C upto 10 is necessary in the pre-reforming step, which makes $\mathrm{S} / \mathrm{C}=3$ in the primary reformer with $70 \mathrm{wt} \%$ of remaining carbon from methane. Adding steam to the glycerol reforming step may enhance char and coke gasification. Here, char is defined as the thermal degradation product from the feedstock and coke is defined as the carbon deposited on the catalyst.

A great deal of research has been carried out at the laboratory scale to obtain $\mathrm{H}_{2}$ / synthesis gas from bio-liquids such as glycerol, fast pyrolysis oil or its fractions via steam reforming $[3,4,5,6]$ or partial oxidation [7] or super-critical gasification $[3,8,9,10]$ Several supports such as $\mathrm{Al}_{2} \mathrm{O}_{3}, \mathrm{TiO}_{2}, \mathrm{SiO}_{2}, \mathrm{CeO}_{2}, \mathrm{MgO}$ on Nickel and alumina support modifiers such as $\mathrm{ZrO}_{2}, \mathrm{CeO}_{2}, \mathrm{La}_{2} \mathrm{O}_{3}, \mathrm{MgO}$ have been screened based on $\mathrm{H}_{2}$ production via steam reforming of pure glycerol [2,11] and model compounds [12,13,14]. Adhikari et al. [2] reported that $\mathrm{Ni} / \mathrm{CeO}_{2}$ catalyst has a better activity with $>99 \%$ glycerol conversion at $600^{\circ} \mathrm{C}$ and $\mathrm{S} / \mathrm{C}=12$, whereas $\mathrm{Ni} / \mathrm{Al}_{2} \mathrm{O}_{3}$ catalyst has higher activity at $900^{\circ} \mathrm{C}$ and $\mathrm{S} / \mathrm{C}=9$. Czernik et al. [15] produced $\mathrm{H}_{2}$-rich gas via steam reforming crude glycerin using a commercial steam reforming catalyst at $800^{\circ} \mathrm{C}$ and $\mathrm{S} / \mathrm{C}=2.6$. However, a gradual increase in the methane was reported. To the best of our knowledge, the quantitative information about the effect of alkali hydroxides or its salts and the organic impurities present in the crude glycerol during gasification and steam reforming is not available in the open literature.

In this article, various stages of HSR were tested. To clarify the effect of alkali hydroxide (e.g KOH), gasification of crude glycerol, pure glycerol with and without $\mathrm{KOH}$ was studied in TGA at a heating rate of $5^{\circ} \mathrm{C} / \mathrm{min}$ up to $600^{\circ} \mathrm{C}$. Visual observation tests during the gasification were performed to study the effect of $\mathrm{KOH}$, 
which is present in the untreated crude glycerol and alkali salts (e.g. $\mathrm{KCl}$ ), which is present in the neutralized crude glycerol. Followed by that, gasification of crude glycerol, glycerol with and without $\mathrm{KOH}$ is studied by atomizing it into fine droplets in the temperature range between 400 and $800^{\circ} \mathrm{C}$. The product distribution from the feedstocks to gas, vapor and char has been studied in detail. Finally, the behavior of $\mathrm{K}, \mathrm{Mg}$ promoted naphtha reforming catalyst and unpromoted $\mathrm{Ni} / \mathrm{Al}_{2} \mathrm{O}_{3}$ natural gas reforming catalyst was studied based on their surface area, pore volume and Nickel particle size using neutralized crude glycerol at steam reforming conditions. Several implications of the overall concept are discussed at the end of the article.

\subsection{Experimental}

\subsubsection{Materials}

Pure glycerol (Sigma Aldrich), in-house produced crude glycerol 1 obtained from transesterification of waste cooking oil, crude glycerol 2 (neutralized feedstock, Source: BioMCN, Delfzijl, The Netherlands) and pure glycerol doped with $\mathrm{KOH}$, $\mathrm{NaOH}$ and $\mathrm{KCl}(\mathrm{NaOH}, \mathrm{KOH}$ source: Merck, $\mathrm{KCl}$ source: Sigma Aldrich) were used in this study. Elemental compositions were analyzed with an EA 1108 (Fisons Intruments). The water content of the glycerol was determined by Karl Fishcer titration (titrant: Hydranal composite 5, Metrohm $787 \mathrm{KF}$ Titrino). The elemental composition and the water content of the feedstocks as received are presented in Table 1A. The composition of crude glycerol 2 is given in Table 1B. Organic concentration of $62.5 \%$ by weight (rest: water) was prepared to facilitate atomization for continuous gasification experiments. Prior to the addition of water, methanol was removed from the crude glycerol 1 via vacuum distillation. The molecular mass distribution of condensed liquid obtained after the vaporization of glycerol was measured using a Gel Permeation Chromatograph (GPC, Agilent Technologies, 1200 series RID detector, eluent: $1 \mathrm{ml} / \mathrm{min}$ ). The solvent used was di-methyl sulfoxide (DMSO; $10 \mathrm{mg}$ sample/ml DMSO). The columns used were 3 PLgel3 $\mu \mathrm{m}$ MIXED-E placed in series. 
The RID signal is calibrated with polystyrene standards (MW) 162-30000. Two $\mathrm{Ni} / \mathrm{Al}_{2} \mathrm{O}_{3}$-based commercial steam reforming catalysts (catalyst $\mathrm{A}$ : $\mathrm{NiO} \sim 23 \%$, promoted using $\mathrm{MgO}, \mathrm{K}_{2} \mathrm{O}$; Catalyst $\mathrm{B}$ : $\mathrm{NiO} \sim 18 \%$, here termed as unpromoted) were used in this study. The catalyst pellets were crushed and sieved between 3 and $5 \mathrm{~mm}$ particle sizes. The catalyst was mixed with quartz particles of similar particle size range to have a reasonable bed height of $\sim 100 \mathrm{~mm}$.

Table 1A: Elemental analyses (wet) and water content determination of different glycerol feedstocks (as received). The rest is mainly oxygen also with other elements such as sulfur and nitrogen

\begin{tabular}{|l|c|c|c|c|}
\hline Feedstock & $\mathrm{C}(\mathrm{wt} \%)$ & $\mathrm{H}(\mathrm{wt} \%)$ & Rest (wt\%) & Water (wt\%) \\
\hline Pure glycerol & 39.1 & 8.7 & 52.2 & 0 \\
\hline Crude glycerol 1 & 45.5 & 7.7 & 46.8 & 0 \\
\hline Crude glycerol 2 & 31.9 & 8.6 & 59.5 & 11 \\
\hline
\end{tabular}

Ash content of crude glycerol 1 is $6.6 \%$ (consists of $\mathrm{K}_{2} \mathrm{O}$ and trace amounts of $\mathrm{CaO}$ and $\mathrm{Fe}_{2} \mathrm{O}_{3}$ ) and crude glycerol 2 is $\sim 4.3 \%$ (consists of $\mathrm{Na}_{2} \mathrm{O}$ )

Table 1B: Composition of crude glycerol 2

\begin{tabular}{|l|l|}
\hline Component & Weight \% \\
\hline Glycerol & 83 \\
\hline Water & 11 \\
\hline Organics* & 1.78 \\
\hline Inorganics^$^{\wedge}$ & 4.4 \\
\hline
\end{tabular}

* Consists of diglycerides (0.78\%), triglycerides (0.5\%), FAME (0.3\%), Free fatty acids $(0.2 \%)$, Methanol $(0.01 \%)$, trace amounts of citric acid and acetic acid. ${ }^{\wedge}$ Consists of $4.3 \%$ sodium chloride, $0.09 \%$ Magnesium sulphate and $0.01 \%$ of Calcium sulphate 


\subsubsection{Thermo-gravimetric analysis}

Thermo-gravimetric analysis (TGA) was carried out in aluminum cups using NETZSCH STA $449 \mathrm{~F} 3$ instrument. The heating rate for all the samples was $5^{\circ} \mathrm{C} / \mathrm{min}$ from $25^{\circ} \mathrm{C}$ to a maximum temperature of $600^{\circ} \mathrm{C}$ using $\mathrm{N}_{2}$ flow of $20 \mathrm{ml} / \mathrm{min}$ together with a protective flow of $40 \mathrm{ml} / \mathrm{min}$. Initial mass of the samples was determined using an external weighing balance.

The mass rate loss is defined as:

$r_{w t} \equiv \frac{d X}{d T}=-\frac{\left(m_{\tau}-m_{\tau+1}\right)}{m_{0}\left(T_{\tau}-T_{\tau+1}\right)}$

where $\tau$ and $\tau+1$ are logged times, $\mathrm{T}\left({ }^{\circ} \mathrm{C}\right)$ the temperature of the sample cup and $\mathrm{m} 0$ $(\mathrm{mg})$ the initial amount of glycerol as weighed with the external balance.

\subsubsection{Batch wise gasification}

A fixed amount of glycerol solution ( $2 \mathrm{~g}$ ) was added to the bottom of a glass tube ( $\varnothing$ $10 \mathrm{~mm})$. The glass tube was placed inside an electrically heated oven and the temperatures were measured in the solution itself. A heating rate of $\sim 50{ }^{\circ} \mathrm{C} / \mathrm{min}$ was applied to the oven. A small nitrogen flow was placed just above the glycerol to avoid direct contact with air and to remove the vapors, which were released during gasification. Snapshots were taken during the gasification tests. A brief description of the procedure was given by Van Rossum et al. [16].

\subsubsection{Gasification of glycerol via atomization}

To quantify the distribution of glycerol during gasification (atomization) over the gas, vapor and char, prior to the reforming step and to measure individual gas yields, a dedicated continuous gasification set-up was constructed. About $1.7 \mathrm{ml} / \mathrm{min}$ of glycerol was sprayed onto an empty electrically heated stainless steel tube $(\varnothing 40 \mathrm{~mm}$, length $400 \mathrm{~mm}$ ) using an externally cooled atomizer that produced droplets of ca. 100 $\mu \mathrm{m}$. A detailed description of the set-up was given by Ramachandran et al. [17] 


\subsubsection{Steam and hybrid steam reforming-experimental set-up}

A schematic overview of the hybrid reforming set-up is shown in Figure 2. The set-up consists of three stages: gasification of glycerol, followed by catalytic pre-reforming of vapors and catalytic reforming of methane together with the gas/vapor produced from the pre-reforming. All the equipment components were made of stainless steel (type:R543). The set-up was operated at near atmospheric pressure.

\section{Gasification section:}

The gasifier has an internal diameter of $40 \mathrm{~mm}$ and a height of $350 \mathrm{~mm}$. It consists of an ultrasonic atomizer that sprays droplets of $\sim 100 \mu \mathrm{m}$ with a liquid flow rate ranging from 0.2 to $0.4 \mathrm{ml} / \mathrm{min}$, using a HPLC pump (Instrument Solutions). Nitrogen stream (flow rate: $0.2 \mathrm{Nl} / \mathrm{min}$ ) was used to facilitate atomization. The atomizer was fitted in a copper ring in which water was circulated to keep the temperature below $70^{\circ} \mathrm{C}$. This is to protect the piezo-electric parts of the atomizer from thermal damage. A pre-heater (temperature $450^{\circ} \mathrm{C}$ ) was attached to the top of the gasifier to supply additional nitrogen (flow rate: $0.4 \mathrm{Nl} / \mathrm{min}$ ) and steam required for the reaction. This added stream kept the top of the gasifier at $\sim 400^{\circ} \mathrm{C}$ to minimize vapor condensation at the upper part of the gasifier. A filter was placed at the bottom of the gasifier to collect the solids. Temperatures were measured at the top, middle and bottom section of the gasifer. The reported gasification temperature was the average temperature of the middle and the bottom section of the gasifier.

\section{Pre-reforming section:}

Beneath the evaporator, the pre-reformer (40 $\mathrm{mm}$ internal diameter and $150 \mathrm{~mm}$ height) was placed, where the gas/vapor mixture from the gasifier is catalytically converted using a commercial steam reforming catalyst. The catalyst was placed in an inconel distribution plate at the bottom of the pre-reformer. The temperature of the pre-reforming section was kept at $\sim 600^{\circ} \mathrm{C}$ and measured at the middle. Methane was supplied at the exit of the pre-reformer for HSR experiments. 


\section{Primary reforming section:}

The primary reformer ( $35 \mathrm{~mm}$ internal diameter and $300 \mathrm{~mm}$ height) was fitted with an inconel distribution plate at the middle of the reactor. The bed consists of a mixture of quartz and catalyst particles (3:1, quartz: catalyst), which was placed over the plate with a bed height of $\sim 100 \mathrm{~mm}$. Both the pre-reforming and primary reforming catalyst beds were fixed. The catalyst bed and the exit gas temperatures were $\sim 800^{\circ} \mathrm{C}$ respectively. Both the pre-reforming and primary reforming catalyst were reduced insitu with hydrogen $(0.2 \mathrm{Nl} / \mathrm{min})$ diluted with nitrogen $(0.4 \mathrm{Nl} / \mathrm{min})$ at $800^{\circ} \mathrm{C}$ for $\sim 8 \mathrm{~h}$ before each experiment. Temperatures of the primary reformer were measured at the bottom (product gas from pre-reformer) and also at the middle of the catalyst bed, which was the reported temperature.

For hybrid reforming experiments, the pre-reformer was used together with the primary reformer, whereas for "stand-alone" low temperature reforming of glycerol (LTR, single catalyst bed) and steam reforming or high temperature reforming of methane or glycerol (HTR, single catalyst bed), the catalyst was placed in the primary reformer. A representation of the experimental set-up configuration is shown in Figure 2B \& C. Performance of catalysts $\mathrm{A}$ and $\mathrm{B}$ were screened based on configuration, as shown in Figure 2B. Catalyst A was used as both pre-reforming and primary reforming catalyst for HSR experiments. The products from the reformer were immediately cooled after the cyclone to collect the condensables. A micro-GC (Varian CP-4900; $10 \mathrm{~m}$ mol sieve 5A Ar, $10 \mathrm{~m}$ mol sieve 5A He, $10 \mathrm{~m}$ PPQ He, $8 \mathrm{~m}$ Sil-5CB He) was used to detect $\mathrm{H}_{2}, \mathrm{O}_{2}, \mathrm{~N}_{2}, \mathrm{CH}_{4}, \mathrm{CO}, \mathrm{CO}_{2}, \mathrm{C}_{2} \mathrm{H}_{4}, \mathrm{C}_{2} \mathrm{H}_{6}, \mathrm{C}_{3} \mathrm{H}_{6}$ and $\mathrm{C}_{3} \mathrm{H}_{8}$. The integral carbon balance and gas production for both the gasification and catalytic reforming experiments were made based on nitrogen as an internal standard, which was fed to the atomizer and pre-heater. The gas production from the primary reformer is reported as $\mathrm{Nm}^{3}$ of $\mathrm{H}_{2}$ or $\mathrm{CH}_{4}$ or $\mathrm{CO}$ or $\mathrm{CO}_{2}$ per kilogram of the dry feedstock.

The catalysts were regenerated using $200 \mathrm{ml} / \mathrm{min}$ of air diluted with $100 \mathrm{ml} / \mathrm{min}$ of nitrogen to estimate the amount of carbon deposited (coke) on the catalyst. The carbon to gas conversion or fraction of carbon converted to gases was calculated at the steady-state operation that excludes the start-up profile. Gas hourly space velocity 
on $\mathrm{C} 1$ basis is defined as the volume of $\mathrm{C}_{1}$ equivalent species in the feed at the STP (standard temperature and pressure) per unit volume of the catalyst. $\mathrm{C}_{1}$ equivalent is used to compare feed stocks containing different number of carbon atoms per molecule. The carbon closure of experimental set-up was found to be adequate (i) 100 $\pm 3 \%$ using methane and steam at $795{ }^{\circ} \mathrm{C}, \mathrm{S} / \mathrm{C}=3$, (ii) $99 \pm 3 \%$ using pure glycerol at $805^{\circ} \mathrm{C}, \mathrm{S} / \mathrm{C}=3$. There is a slight degree of fluctuation in the gas production due to glycerol, steam and nitrogen flows.

\subsubsection{Catalyst characterization}

Commercial steam reforming catalysts (promoted and unpromoted) were characterized for their surface area, pore volume and active metal dispersion before and after the steam reforming of crude glycerol 2. Specific surface area measurements were carried out by the BET method (Micromeritics Tristar). $\mathrm{H}_{2}$ chemisorption (Chemisorb 2750, Micromeritics) measurements were carried out to determine Ni dispersion, Ni particle size and the metallic surface area. Prior to the measurement, the catalyst was reduced using temperature programmed reduction equipped with a thermal conductivity detector. After reduction, the sample was heated to $800^{\circ} \mathrm{C}$ at a rate of $5^{\circ} \mathrm{C} / \mathrm{min}$ in a $5 \% \mathrm{H}_{2} / \mathrm{Ar}$ flow $(30 \mathrm{ml} / \mathrm{min})$. 


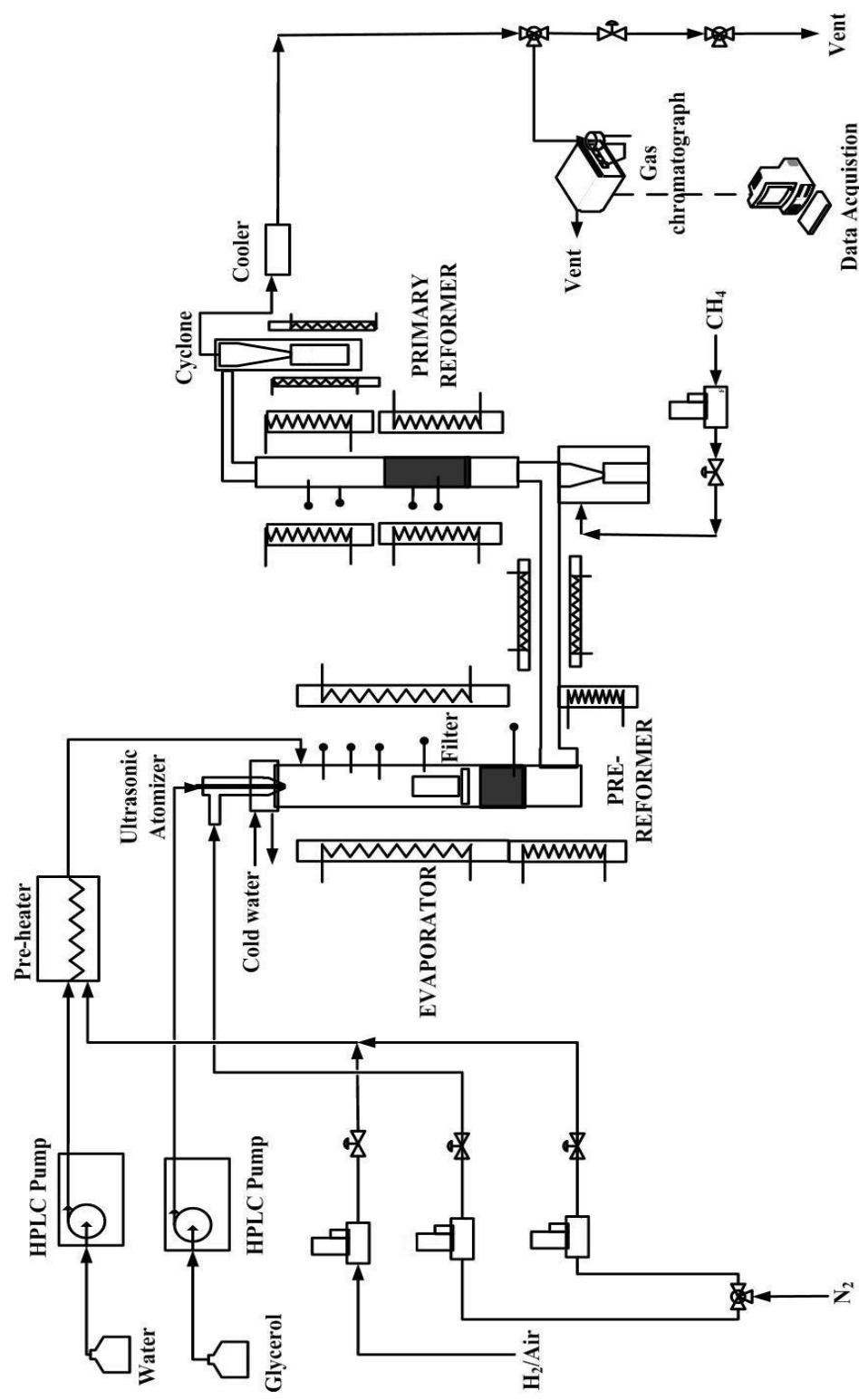

$\stackrel{\infty}{\varrho}$ 


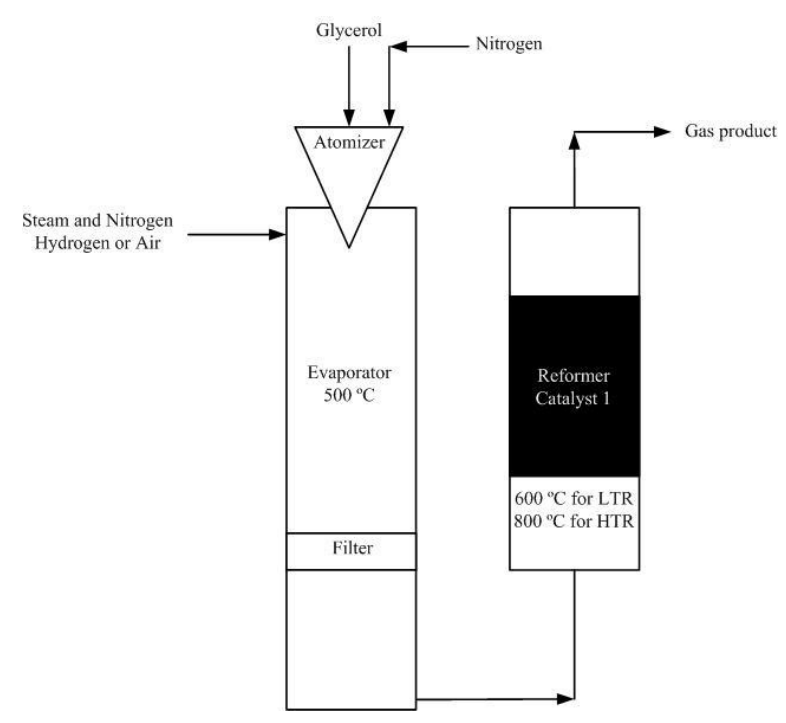

$2 B$

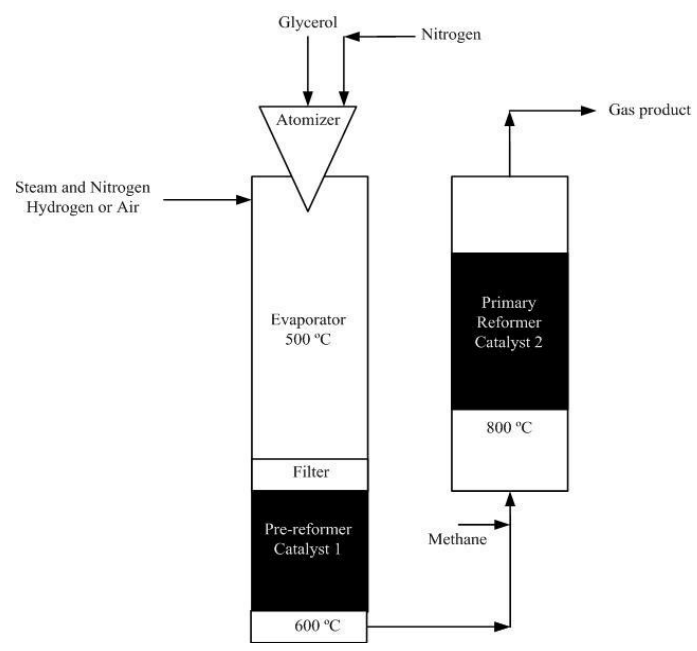

$2 C$

Figure 2: (A) Schematic overview of the HSR set-up. (B) Representation of "stand-alone" reforming reactor configuration in which catalyst A or B used. (C) Hybrid reforming configuration (catalyst $A$ used as both pre-reforming and primary reforming catalyst). 


\subsection{Results and discussions}

\subsubsection{Batch gasification of glycerol}

TGA measurements: TGA results for glycerol solution with and without $\mathrm{KOH}(\mathrm{KOH}$ $\sim 3 \%$ on glycerol mass basis) and crude glycerol 1 and 2 at $5^{\circ} \mathrm{C} / \mathrm{min}$ up to $600^{\circ} \mathrm{C}$ are shown in Figure 3, where the rate of gasification and mass loss is plotted versus the temperature trajectory. The gasification rate for each sample is expressed on the initial mass basis, excluding the amount of $\mathrm{KOH}$ added.

From the TGA measurements,

A peak around $100^{\circ} \mathrm{C}$ is observed for all feedstocks, which is due to the evaporation of water. From Figure 3, it can be observed that the gasification rate of crude glycerol 1 and glycerol with $\mathrm{KOH}$ proceeds at a slower rate than pure and crude glycerol 2 in the temperature range between 200 and $270^{\circ} \mathrm{C}$.

It is also observed that the rate of gasification for the pure glycerol and the crude glycerol 2 is ceased completely at temperature around $230^{\circ} \mathrm{C}$, whereas the conversion rate for crude glycerol 1 and glycerol with $\mathrm{KOH}$ proceeds slowly above $230^{\circ} \mathrm{C}$.

At temperature between 400 and $450^{\circ} \mathrm{C}$, a peak was observed for crude glycerol 1 , which is presumably due to the presence of fatty acids in the crude. This peak is not observed for crude glycerol 2 due to low amount of FAMEs, di and tri glycerides $(1.78 \%)$ present in it.

Crude glycerol 1 gives $\sim 10 \%$ residue on mass basis, glycerol with $\mathrm{KOH}$ gives $\sim 6-7 \%$ residue, pure and crude glycerol 2 gives $\sim 3 \%$ of residue at $600^{\circ} \mathrm{C}$. Similar results for pure and crude glycerol were obtained at $5{ }^{\circ} \mathrm{C} / \mathrm{min}$ by Dou et al. [18] To clarify the observed phenomena from the TGA measurements, visual observation tests were performed. 
Table 2: Char productions from batch gasification of glycerol. The amounts are given both on mass and carbon to char basis. The sample was heated to $400^{\circ} \mathrm{C}$ with a heating rate of $\sim 50^{\circ} \mathrm{C} / \mathrm{min}$

\begin{tabular}{|l|c|c|c|}
\hline Feedstocks & \multicolumn{1}{c}{$\begin{array}{c}\text { Salt \% (on } \\
\text { dry basis) }\end{array}$} & $\begin{array}{c}\text { Residue, } \\
\text { wt \% }\end{array}$ & $\begin{array}{c}\text { Char yield, } \\
\text { wt\% }\end{array}$ \\
\hline Pure glycerol & 0 & 0.85 & No soild residue \\
\hline Pure glycerol with $\mathrm{KOH}$ & 0.90 & 6.10 & 9.6 \\
\hline Pure glycerol with $\mathrm{NaOH}$ & 0.94 & 7.51 & 11.1 \\
\hline Pure glycerol with $\mathrm{KCl}$ & 1.22 & 3.83 & 0 \\
\hline Glycerol (62.5\%) & 2.91 & 4.81 & 10.9 \\
\hline Crude glycerol 1 & n.m & 10.2 & 15.9 \\
\hline Crude glycerol 2 & n.m & 4.8 & 0 \\
\hline
\end{tabular}

n.m not measured

Visual study in batch tubes: Figure 4 shows the snapshots taken during the gasification of glycerol with and without $\mathrm{K}, \mathrm{NaOH}, \mathrm{KCl}$, crude glycerol 1 and 2 . The glass tubes were heated at a heating rate of $\sim 50^{\circ} \mathrm{C} / \mathrm{min}$ upto $400^{\circ} \mathrm{C}$. Figure $4 \mathrm{a}$ shows that the pure glycerol was almost completely evaporated above the boiling point $\left(290^{\circ} \mathrm{C}\right)$, leaving no solid residue in the glass tube. Pure glycerol with $1 \% \mathrm{KOH}$ polymerized above $\sim 350^{\circ} \mathrm{C}$, which resulted in $\sim 10 \%$ char on carbon basis. This is illustrated in Figure $4 \mathrm{~b}$. To crosscheck the effect of $\mathrm{KOH}, 1 \% \mathrm{NaOH}$ was added to pure glycerol. Similar effect as $\mathrm{KOH}$ was observed for $\mathrm{NaOH}$ (not shown in Figure 4). However, $\mathrm{KCl}$ did not polymerize pure glycerol above $350^{\circ} \mathrm{C}$. Figure $4 \mathrm{C} \& \mathrm{D}$ illustrates the gasification of crude glycerols. The visual study suggests that crude glycerol 1 has similar effect on polymerization, as glycerol with $\mathrm{KOH}$ and crude glycerol 2 showed similar behavior as glycerol with $\mathrm{KCl}$. Table 2 summarizes the char yield on carbon basis. It has been visually observed that at the boiling point $\left(290^{\circ} \mathrm{C}\right)$, the solution behaves like a boiling liquid and increase in temperature resulted in polymerization in the liquid phase. The visual tests indicate that the formation of char via polymerization is due to the presence of hydroxides and not because of its salt present in the pure glycerol or crude glycerol 2. GPC analysis of 
liquids obtained after the vaporization of glycerol with and without $\mathrm{KOH}$, crude glycerol 1 and 2 was performed to confirm the causes of polymerization.

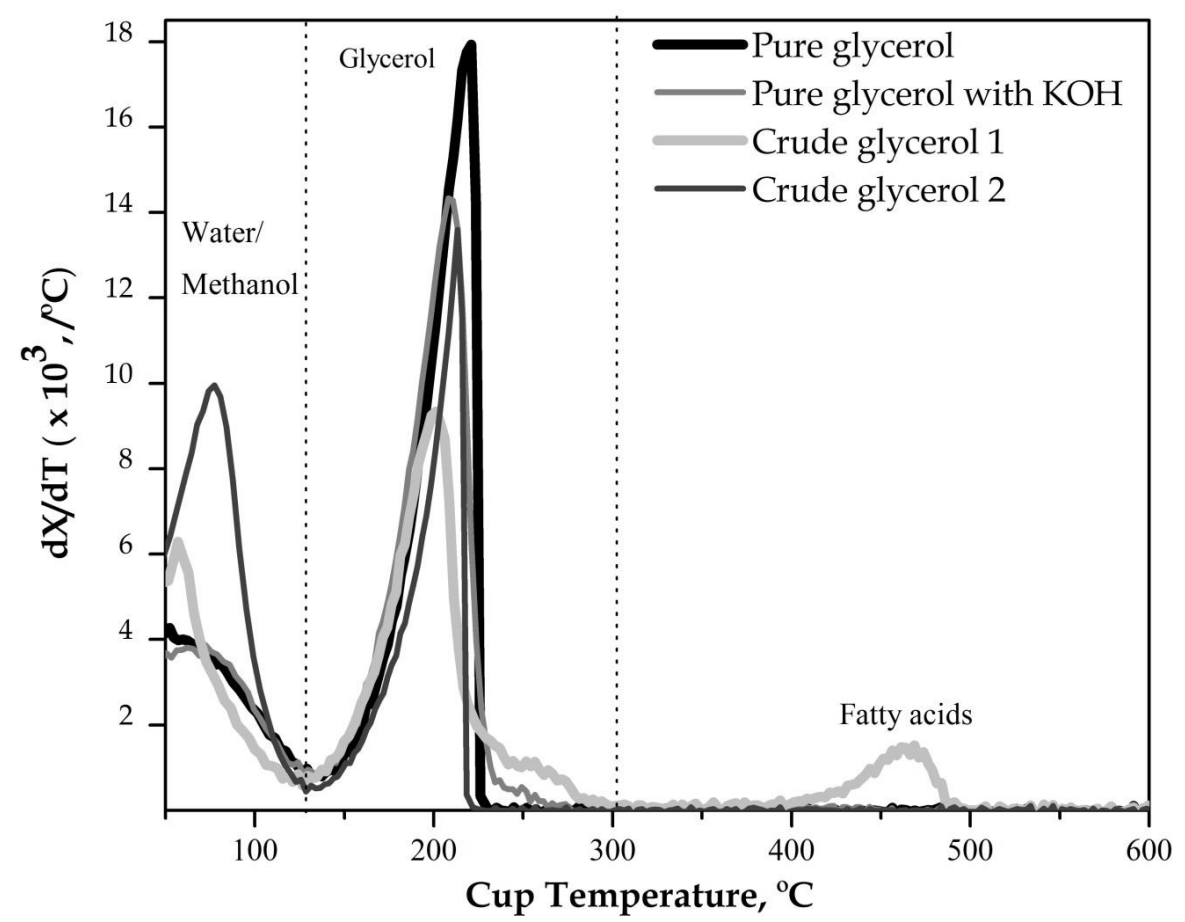

Figure 3: TGA of crude glycerol, pure glycerol with and without $\mathrm{KOH}$ at 5 ${ }^{\circ} \mathrm{C} /$ min heating rate in inert $\mathrm{N}_{2}$ gas.

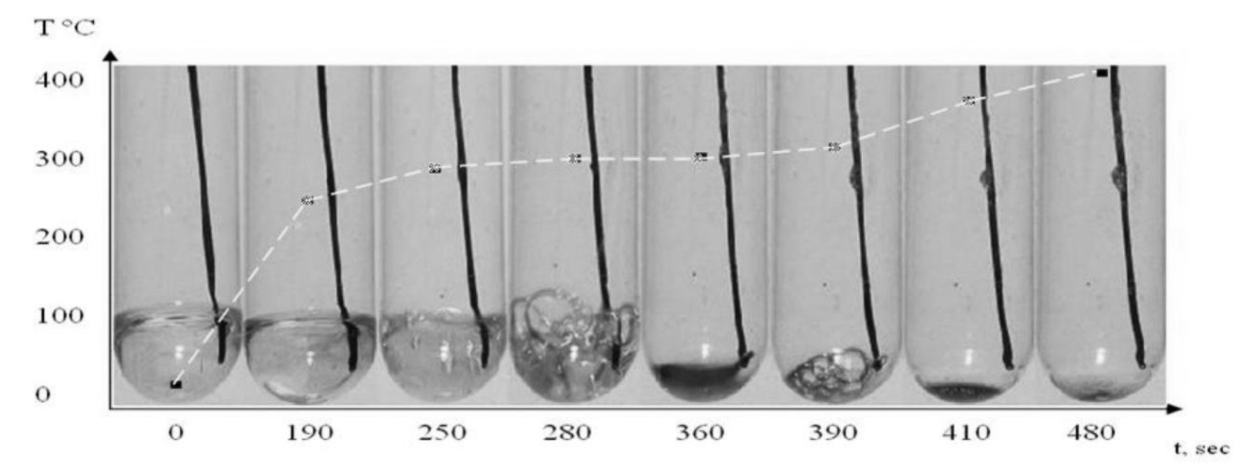

$4 A$ 

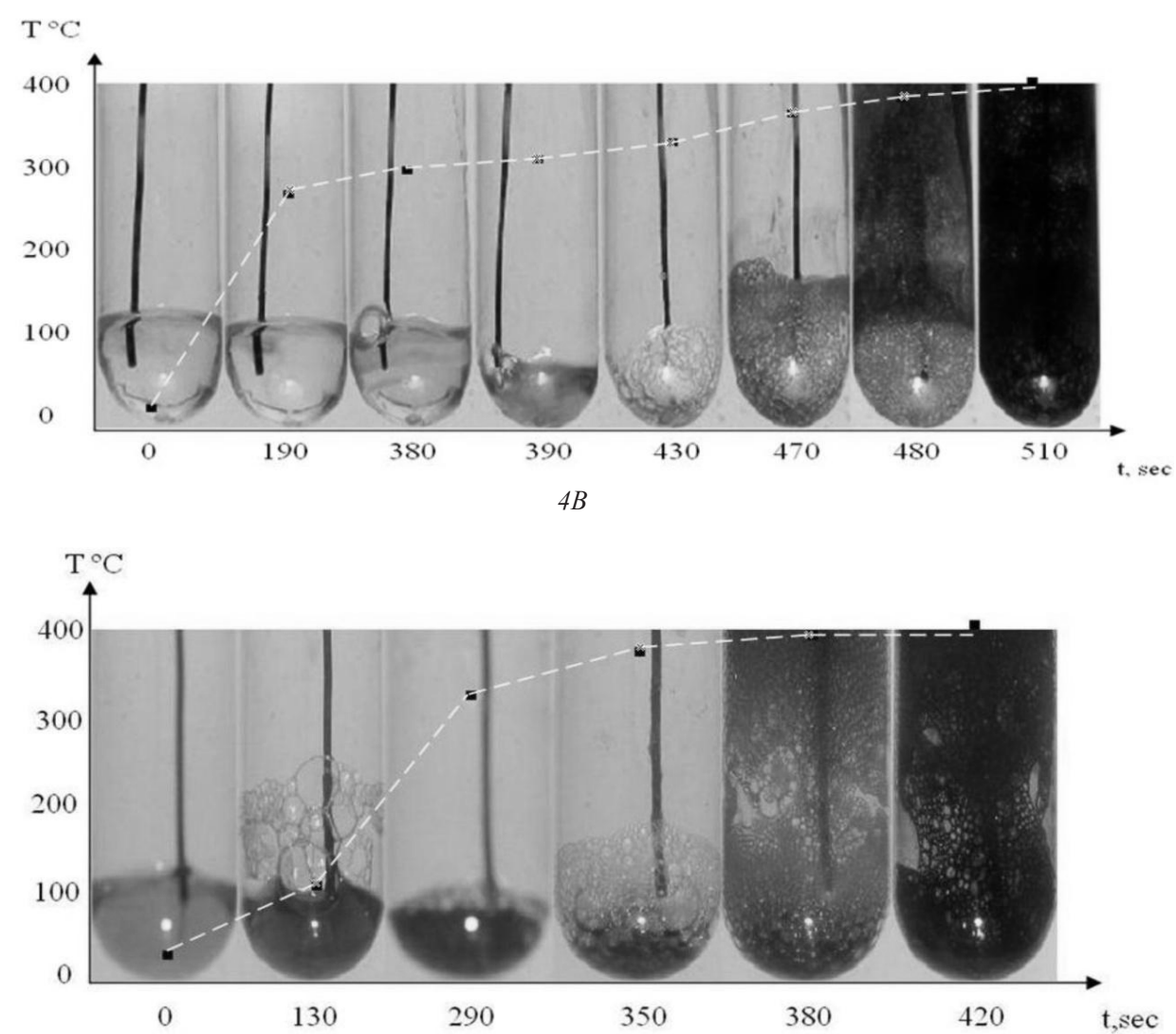

$4 C$

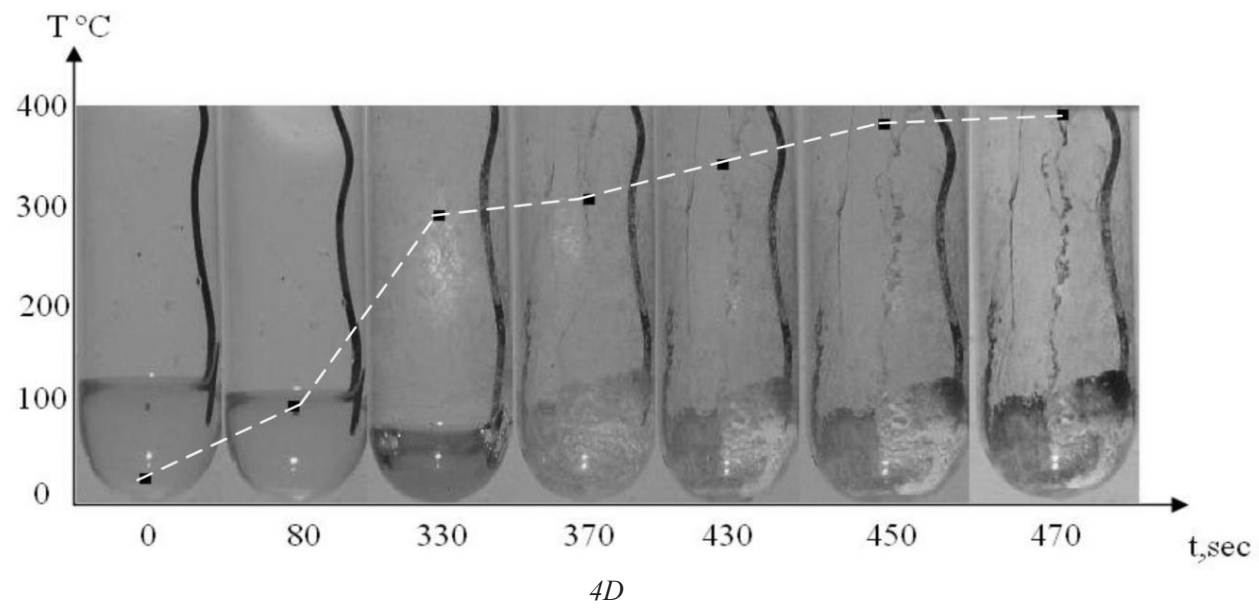

Figure 4: Snapshots of batch tubes during gasification of (a) Glycerol; (b) glycerol with KOH; (c) crude glycerol 1; (d) crude glycerol 2. 


\subsubsection{Molecular mass distribution}

The feedstocks were heated in the batch tubes and when the temperature reached near to glycerol boiling point $\left(290{ }^{\circ} \mathrm{C}\right)$, the remaining liquids were cooled before the polymerization begins. Figure 5 shows the molecular mass distribution of liquids obtained from the crude glycerol 1 and 2, glycerol with and without KOH. From Figure 5 it can be observed that no larger molecules are formed during the vaporization of pure glycerol, whereas with the addition of $\mathrm{KOH}$ to glycerol, a single peak of molecules as twice as glycerol is formed. To differentiate the temperature effect, the liquids were collected before the boiling point of glycerol $\left(\sim 275^{\circ} \mathrm{C}\right)$ with $\mathrm{KOH}$. It is clearly observed that the larger molecules formed before the boiling temperature of glycerol itself. This indicates that the intermediates that have higher molecular mass than glycerol are formed in the liquid phase in the presence of $\mathrm{KOH}$. This may be due to glycerol dimerization in the presence of $\mathrm{KOH}$ [19]. Crude glycerol 1 showed three prominent peaks between 250 and $500 \mathrm{~g} / \mathrm{mol}$. This may be due to the presence of fatty acids and di and tri glycerides in crude glycerol 1. Since the amount of aforementioned compounds is small in crude glycerol 2, the peaks are not identified. 


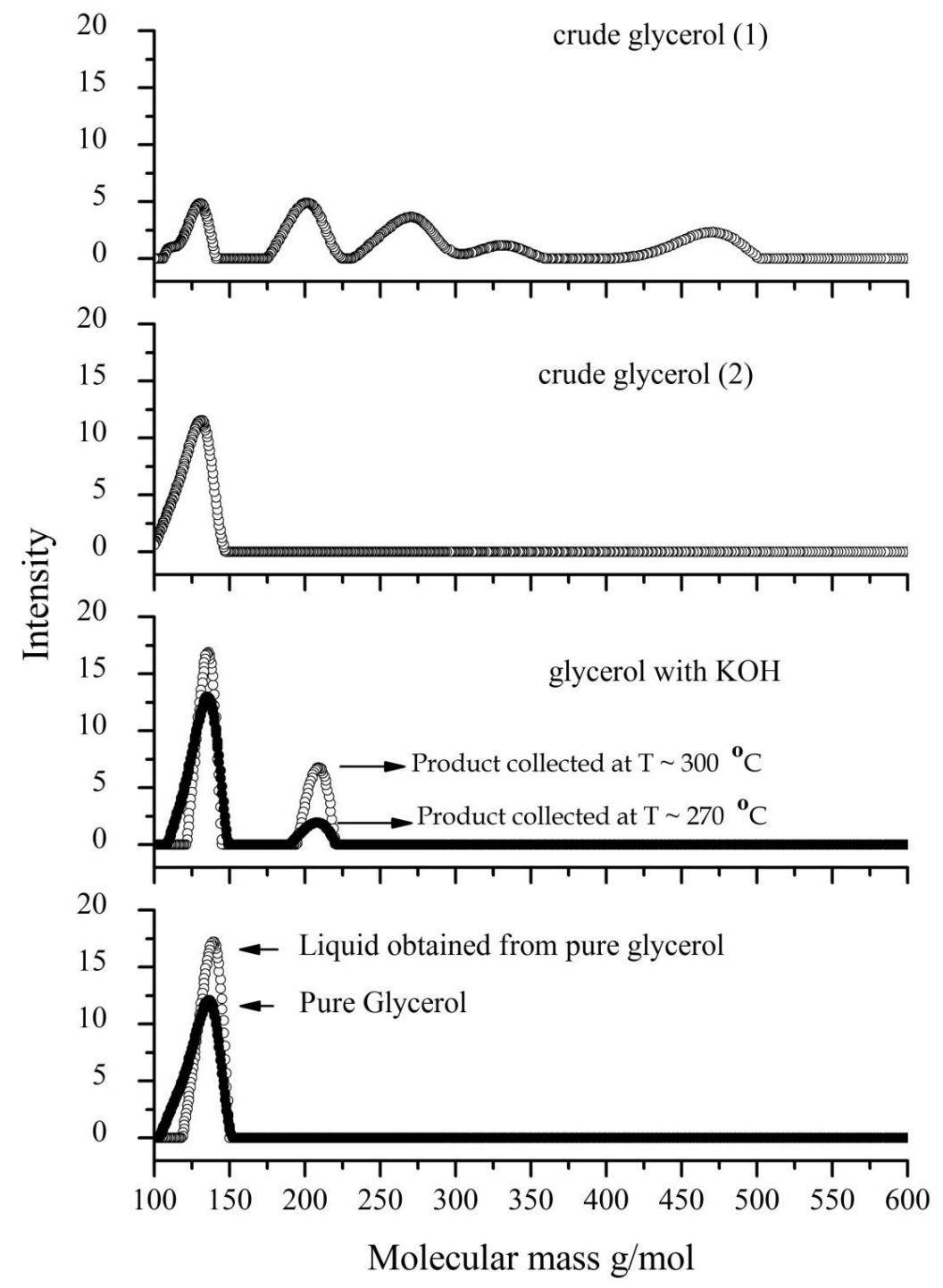

Figure 5: Molecular mass distribution of liquid products obtained after gasification from different glycerol feedstocks. 


\subsubsection{Continuous gasification by atomization}

The effect of the evaporator temperature $\left(400-800^{\circ} \mathrm{C}\right.$, vapor residence time $\left.=2-3 \mathrm{sec}\right)$ on the amount of char, gas and vapor produced from the gasification of crude glycerol 1 and 2, glycerol with and without $\mathrm{KOH}$ by controlled atomization (heating rate $\sim 106$ ${ }^{\circ} \mathrm{C} / \mathrm{min}$ as described by Van Rossum et al. [16] is showed in Figure 6. Over the whole temperature range studied, the amount of the char produced from the crude glycerol 1 (Figure 6c) and glycerol with $\mathrm{KOH}$ (Figure 6b) is nearly constant. This indicates that the initial distribution of carbon from the glycerol to the vapor/gas and char has already attained well before the gasifier temperature of $450^{\circ} \mathrm{C}$. This is an observation in line with the gasification of pyrolysis oil [16]. It is observed from Figure 6a\&d that glycerol and crude glycerol 2 do not form any char at the temperature range studied. The amount of char formed on the carbon basis for pure glycerol with $\sim 3 \% \mathrm{KOH}$ was found in the range of $8-10 \%$, whereas for crude glycerol the amount was found to be between 5 and $7 \%$. Above $\sim 600{ }^{\circ} \mathrm{C}$, for all the feed stocks, vapor cracking reactions to gases was found to be predominant.

The formation of char for glycerol with $\mathrm{KOH}$ and crude glycerol 1 signifies that the presence of $\mathrm{KOH}$ accelerates the formation of char even at high heating rate. By comparing the batch and continuous tests, it is observed that the heating rate does not have a significant effect on the polymerization as these reactions happen extremely fast in the temperature range $<350{ }^{\circ} \mathrm{C}$. However, for pyrolysis oil gasification, heating rate has tremendous effect in controlling the char formation [16]. The gasification experiments from both batch and continuous processes indicate that to prevent polymerization or carbon leading to char, potash free glycerol has to be processed in the reformer. However, solids handling either as char and salts (in the case of crude glycerol 1 and glycerol with $\mathrm{KOH}$ ) and salts (for crude glycerol 2) become mandatory in the gasifier. 


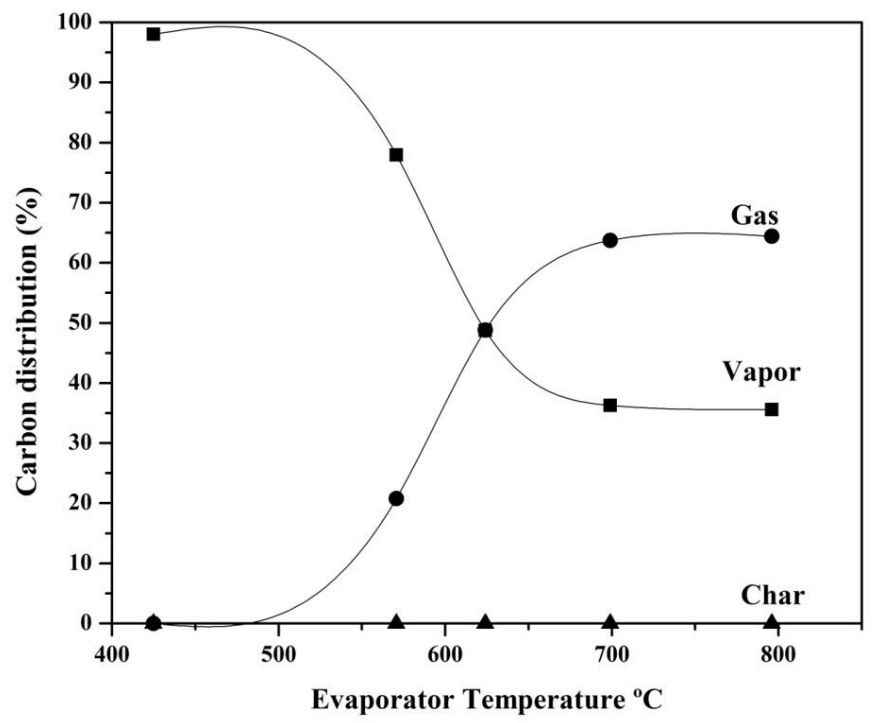

$6 A$

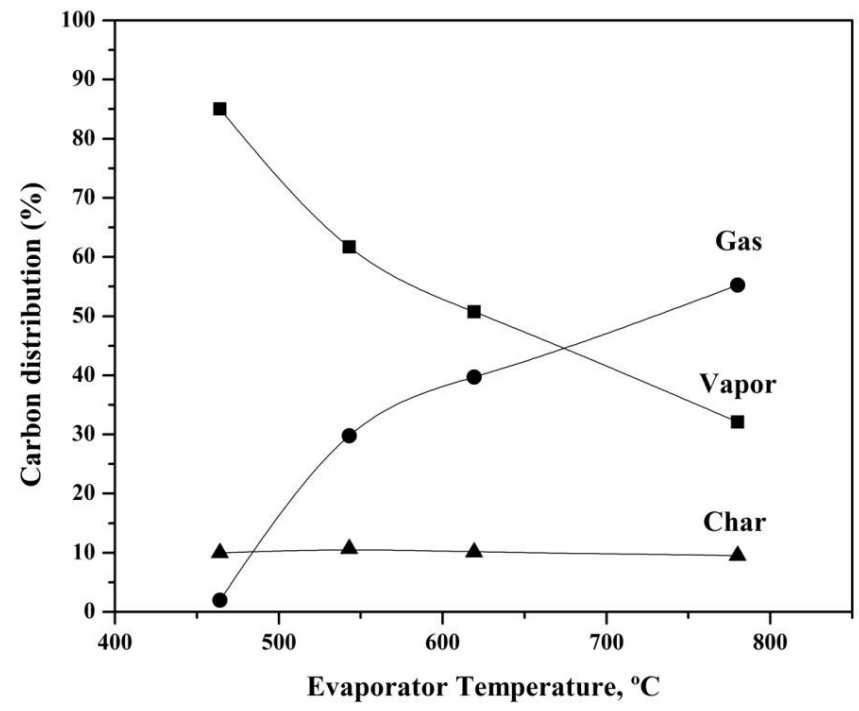

$6 B$ 


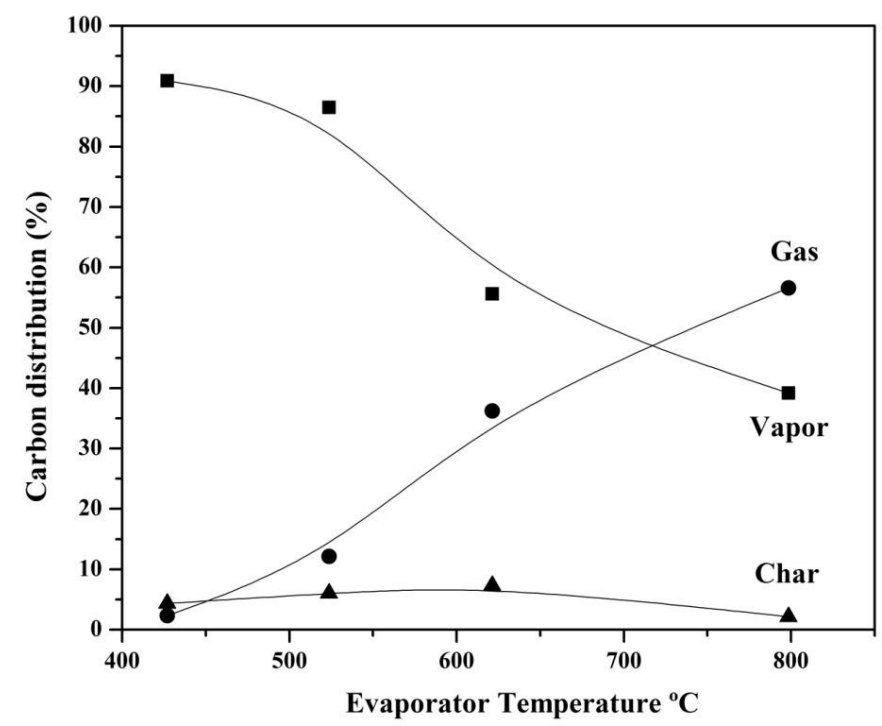

$6 C$

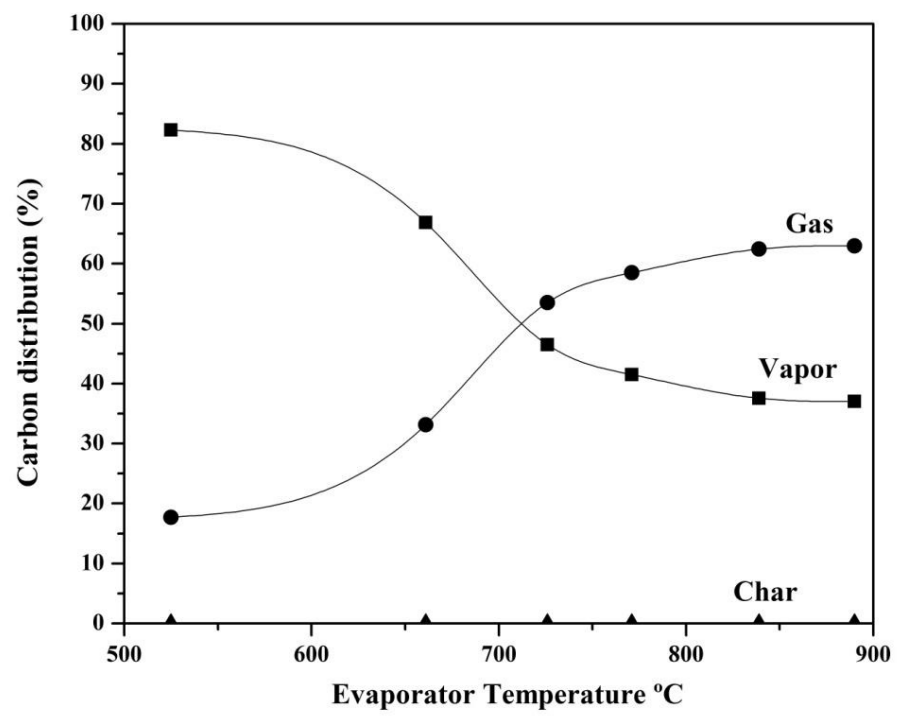

$6 D$

Figure 6: Carbon distribution over the gas, vapor and char during the gasification of glycerol (A) Pure glycerol (B) glycerol with $\mathrm{KOH}$ (C) crude glycerol 1 (D) crude glycerol 2. 


\subsubsection{Pre-reforming and steam reforming of pure glycerol using catalyst $A$}

To evaluate the process conditions of steam reforming, pure glycerol was reformed at LTR and HTR conditions. Figure 7 shows the gas production $\left(\mathrm{Nm}^{3} / \mathrm{kg}\right.$ dry glycerol) obtained at two different reaction conditions using catalyst $\mathrm{A}$ : (A) LTR at $\mathrm{S} / \mathrm{C}=3$ and (B) HTR at $\mathrm{S} / \mathrm{C}=3$. The results are summarized in Table 3. In both the cases, the carbon recovery to gases was $\sim 100 \%$. In the first $7 \mathrm{~h}$, pre-reforming of glycerol (LTR (A), $588^{\circ} \mathrm{C}, \mathrm{S} / \mathrm{C}=3$ ) was performed. The gas production was constant and carbon to gas conversion was $\sim 103 \%$. During the next $3 \mathrm{~h}$, temperature was increased to $\sim 788^{\circ} \mathrm{C}$ and $\mathrm{S} / \mathrm{C}$ was kept constant. In both the cases, the gas production was close to the equilibrium values, as shown in Table 3. At high temperature reforming conditions (Case B), almost no methane and $\mathrm{C}_{2-3}$ were observed, whereas at low temperature conditions, a considerable amount of methane and low amounts of $\mathrm{C}_{2-3}$ were observed in the product gas.

LTR was carried out over a long duration run of $25 \mathrm{~h}$ under similar conditions $(\mathrm{T}=$ $590^{\circ} \mathrm{C}, \mathrm{S} / \mathrm{C} \sim 3.5, \mathrm{GC}_{1} \mathrm{HSV}=543 \mathrm{~h}^{-1}$ ) in order to investigate the performance of catalyst A. Figure 8 shows the effect of time on-stream on the gas production. For the first $10 \mathrm{~h}, \mathrm{H}_{2}, \mathrm{CO}$ and $\mathrm{CO}_{2}$ gas productions were constant. For the next $5 \mathrm{~h}$, slight decrease in gas production was observed. There is a drop in the initial activity of the catalyst. Initially, the average carbon to gas conversion was $\sim 100 \%$, which decreased to $\sim 90 \%$ at the end of the run. Carbon deposited on the catalyst was estimated to be $0.024 \mathrm{~g} / \mathrm{g}$ of catalyst. The gas productions from the catalytic reforming and gasification of pure glycerol are given in Table 3. Selectivity (moles of methane/total moles of product gases) towards methane for LTR and gasification was found to be $\sim 12 \%$. This indicates that at LTR, hydrocarbons produced from the gasification of glycerol are not reformed as it is limited by thermodynamics. 
Table 3: Comparing reforming and gasification of pure \& crude glycerol 2

\begin{tabular}{|c|c|c|c|c|c|}
\hline Feedstock & Pure glycerol & Pure glycerol & $\begin{array}{c}\text { Pure } \\
\text { glycerol }\end{array}$ & $\begin{array}{c}\text { Pure } \\
\text { glycerol }\end{array}$ & $\begin{array}{c}\text { Crude } \\
\text { glycerol } 2\end{array}$ \\
\hline Experiment & LTR & HTR & Gasification & Gasification & Gasification \\
\hline $\mathrm{S} / \mathrm{C}$ & 3 & 3 & 1 & 1 & 1 \\
\hline Gasification temperature $\left({ }^{\circ} \mathrm{C}\right)$ & 526 & 548 & 570 & 796 & 839 \\
\hline Reactor temperature $\left({ }^{\circ} \mathrm{C}\right)$ & 588 & 787 & - & - & - \\
\hline $\mathrm{GC}_{1} \mathrm{HSV}\left(\mathrm{h}^{-1}\right)$ & 838 & 838 & - & - & - \\
\hline \multicolumn{6}{|c|}{$\begin{array}{l}\text { Gas production }\left(\mathrm{Nm}^{3} / \mathrm{kg} \text { dry feed }\right) \\
\text { at steady-state }\end{array}$} \\
\hline $\mathrm{H}_{2}$ & $1.26(1.38)$ & $1.40(1.40)$ & 0.05 & 0.63 & 0.41 \\
\hline $\mathrm{CH}_{4}$ & $0.09(0.05)$ & $0(5 e-4)$ & 0.02 & 0.06 & 0.067 \\
\hline $\mathrm{CO}$ & $0.14(0.15)$ & $0.34(0.31)$ & 0.09 & 0.22 & 0.28 \\
\hline $\mathrm{CO}_{2}$ & $0.51(0.54)$ & $0.42(0.43)$ & 0.014 & 0.18 & 0.06 \\
\hline $\mathrm{C}_{2-3}$ & $0.0055(0)$ & 0 & 0.017 & 0.01 & 0.01 \\
\hline $\operatorname{Cg}(\%)$ & 103 & 104 & 20 & 64 & 62 \\
\hline
\end{tabular}

LTR, low temperature reforming (pre-reforming);

HTR, high temperature reforming (primary reforming).

Equilibrium values are given in brackets for the respective process conditions. 


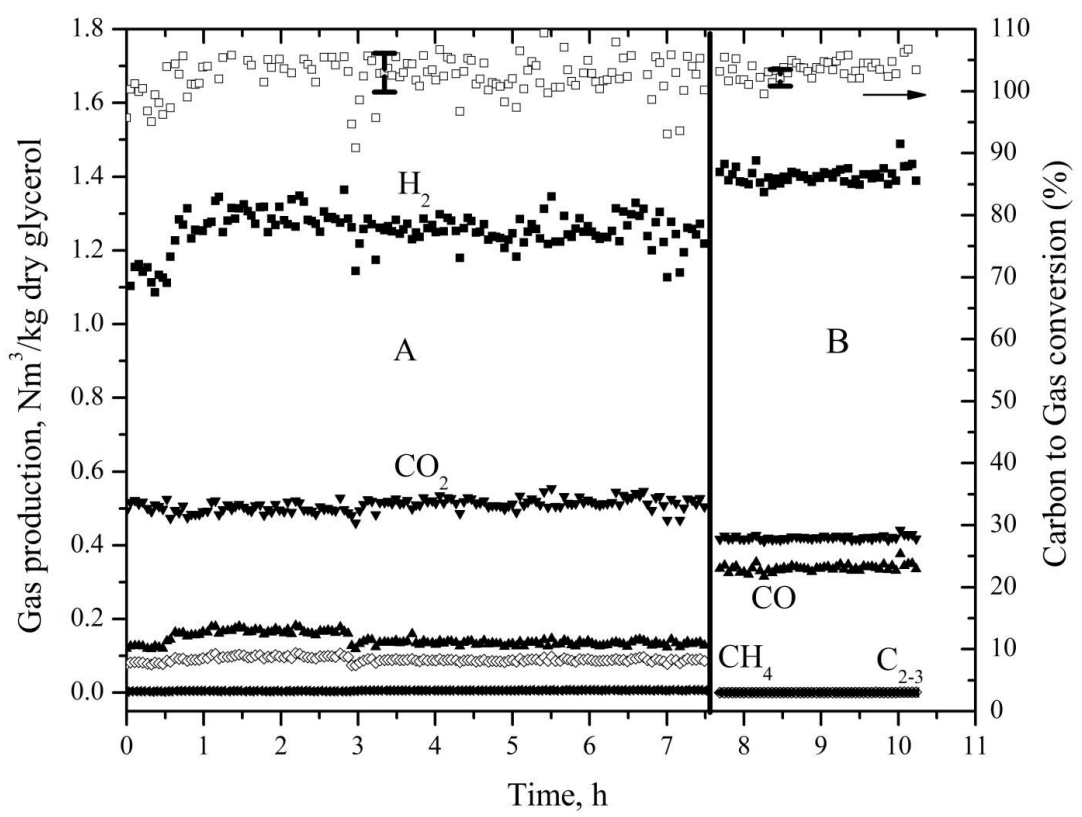

Figure 7: Pre-reforming and steam reforming of glycerol (A) $L T R, S / C=3, T_{\text {cat }}$ $=588^{\circ} \mathrm{C}$ and $(B) H T R, S / C=3, T_{\text {cat }}=787^{\circ} \mathrm{C}$. For all cases $G_{1} H S V=838 \mathrm{~h}^{-1}$.

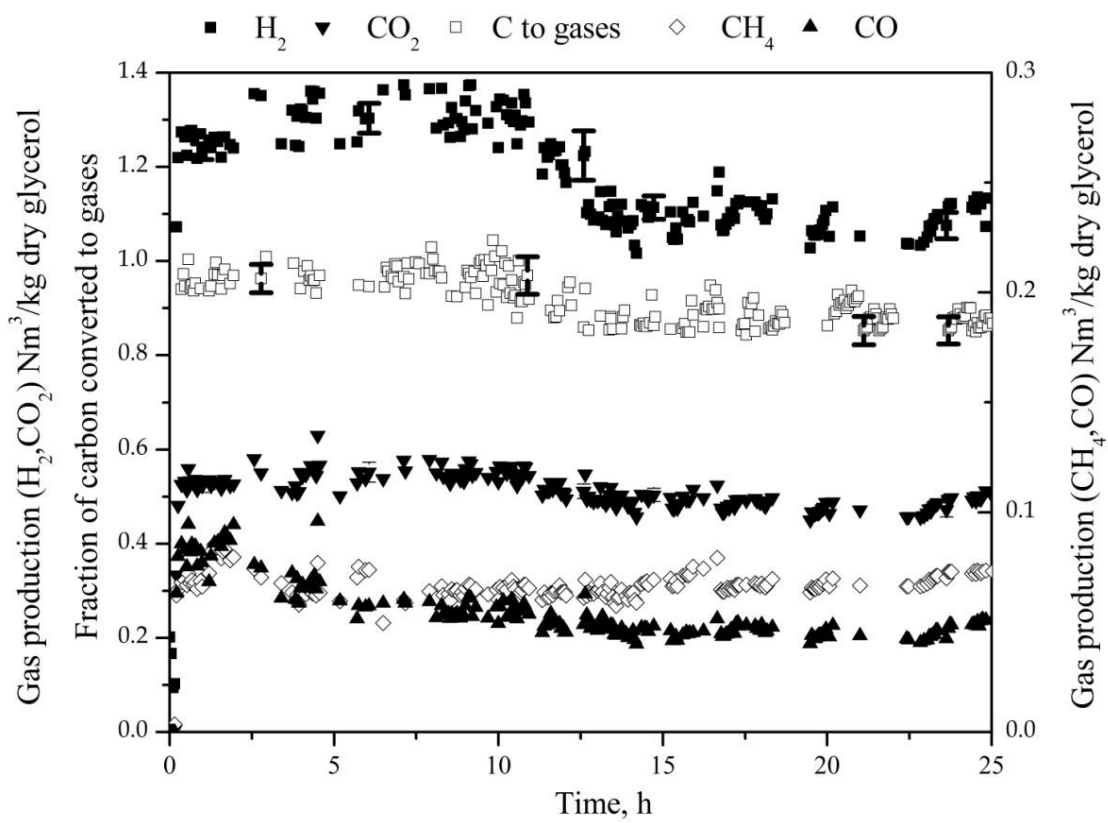

Figure 8: Long duration pre-reforming of glycerol at $\mathrm{T}=590^{\circ} \mathrm{C}, \mathrm{S} / \mathrm{C}=3.5$, $\mathrm{GC}_{1} \mathrm{HSV}=543 \mathrm{~h}^{-1}$. 


\subsubsection{Evaluation of catalysts performance on steam reforming of crude glycerol 2}

HTR conditions were chosen to evaluate the catalysts performance on steam reforming of crude glycerol 2 because it contains $\sim 2 \%$ of organic impurities which may be easier to reform at HTR conditions. No loss of activity or no $\mathrm{CH}_{4}$ was observed from the gaseous product obtained from steam reforming of pure glycerol using catalyst A at HTR conditions. Two Nickel on alumina commercial steam reforming catalysts (catalysts A and B) were chosen for steam reforming of crude glycerol 2. Figure 9 A,B and $\mathrm{C}$ shows two consecutive runs on crude glycerol 2 and pure glycerol (with $4 \mathrm{wt} \% \mathrm{KCl}$ ) steam reforming, which were done at similar process conditions $\left(\mathrm{T}=800^{\circ} \mathrm{C}, \mathrm{S} / \mathrm{C}=3, \mathrm{GC} 1 \mathrm{HSV}=600 \mathrm{~h}^{-1}\right) . \mathrm{KCl}$ was added to pure glycerol $(\sim 4 \mathrm{wt} \% \mathrm{KCl})$ to study the effect of inorganic impurities during steam reforming. This is to differentiate the effect of organic and inorganic impurities present in the crude glycerol 2.

In the first run for catalyst $\mathrm{A}$, a high gas production for $\mathrm{H}_{2}=1.25 \mathrm{Nm}^{3} / \mathrm{kg}$ dry feed, $\mathrm{CO}=0.28 \mathrm{Nm}^{3} / \mathrm{kg}$ dry feed, $\mathrm{CO}_{2}=0.38 \mathrm{Nm}^{3} / \mathrm{kg}$ dry feed was reached. The gas production was slowly decreased at the end of 25 th hour to $\mathrm{H}_{2}=1.10 \mathrm{Nm}^{3} / \mathrm{kg}$ dry feed, $\mathrm{CO}=0.23 \mathrm{Nm}^{3} / \mathrm{kg}$ dry feed, $\mathrm{CO}_{2}=0.37 \mathrm{Nm}^{3} / \mathrm{kg}$ dry feed. $\mathrm{CH}_{4}$ was continuously increased and reached a steady-state value of $0.044 \mathrm{Nm}^{3} / \mathrm{kg}$ dry feed. Similar trend was also observed for $\mathrm{C}_{2-3}$ gases. It should be noted that from the gasification of crude glycerol 2, $\mathrm{CH}_{4}$ and $\mathrm{C}_{2-3}$ were found to be $0.067 \mathrm{Nm}^{3} / \mathrm{kg}$ dry feed and $0.013 \mathrm{Nm}^{3} / \mathrm{kg}$ dry feed respectively at $770^{\circ} \mathrm{C}$ and $\mathrm{S} / \mathrm{C}=1, \mathrm{C}$ to gas $=62 \%$. This indicates that the catalyst A still has reasonable oxygenates reforming activity; nevertheless, its hydrocarbon reforming activity has lost to a certain extent. By comparing gasification (given in Table 3) and reforming of crude glycerol 2, it is observed that methane obtained from the gasification is converted $68 \%$ at the end of $25^{\text {th }} \mathrm{h}$.

Crude glycerol 2 flow was stopped and the catalyst A was regenerated using a mixture of air and nitrogen at $800^{\circ} \mathrm{C}$ and reactivated using $\mathrm{H}_{2}$ at $800^{\circ} \mathrm{C}$. There was no appreciable amount of coke on catalyst A was measured. In the second run, the 
activity of catalyst $\mathrm{A}$ was not retained to its initial high activity. $\mathrm{CH}_{4}$ production was raised rapidly when compared to the first run. Average carbon to gas conversion was dropped from 98 to $91 \%$ at the end of the second run. No $\mathrm{CH}_{4}$ was observed for $3 \mathrm{~h}$ for catalyst A when pure glycerol was used as feedstock, whereas for crude glycerol 2, $\mathrm{CH}_{4}$ was linearly increased initially and stayed constant after $20 \mathrm{~h}$.

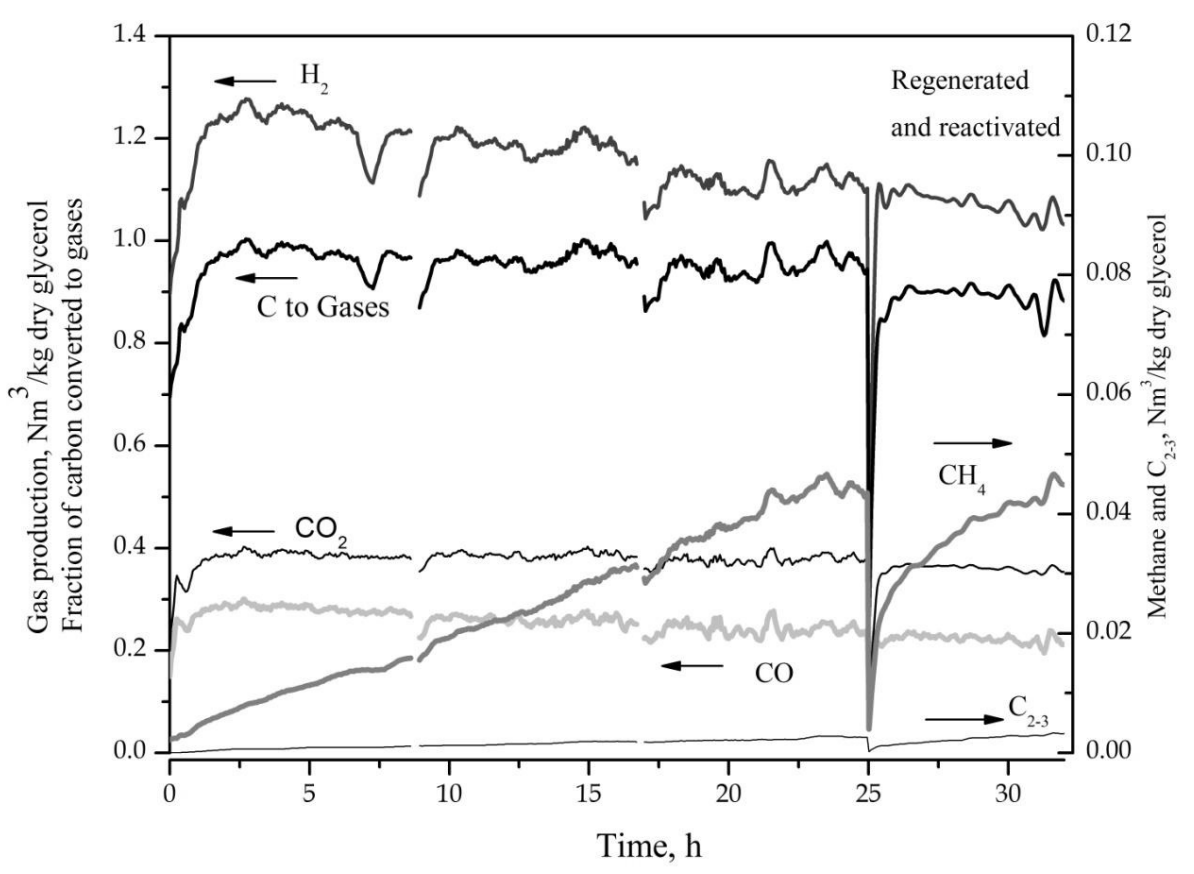

$9 A$ 


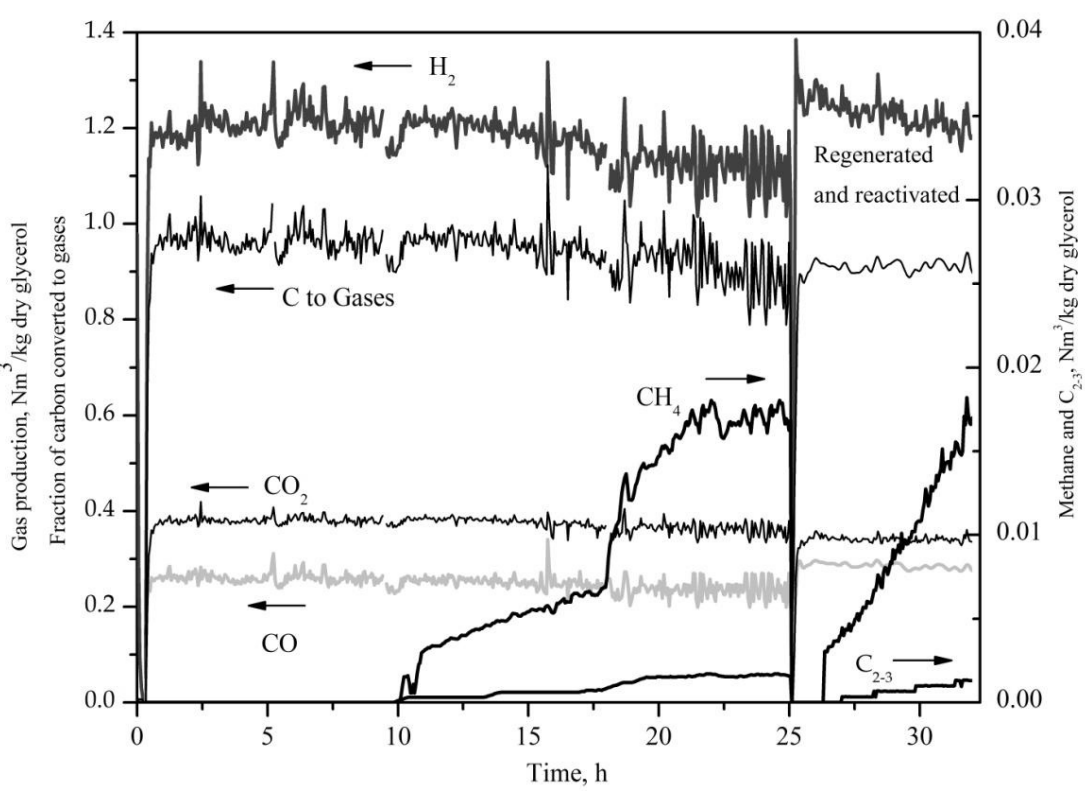

$9 B$

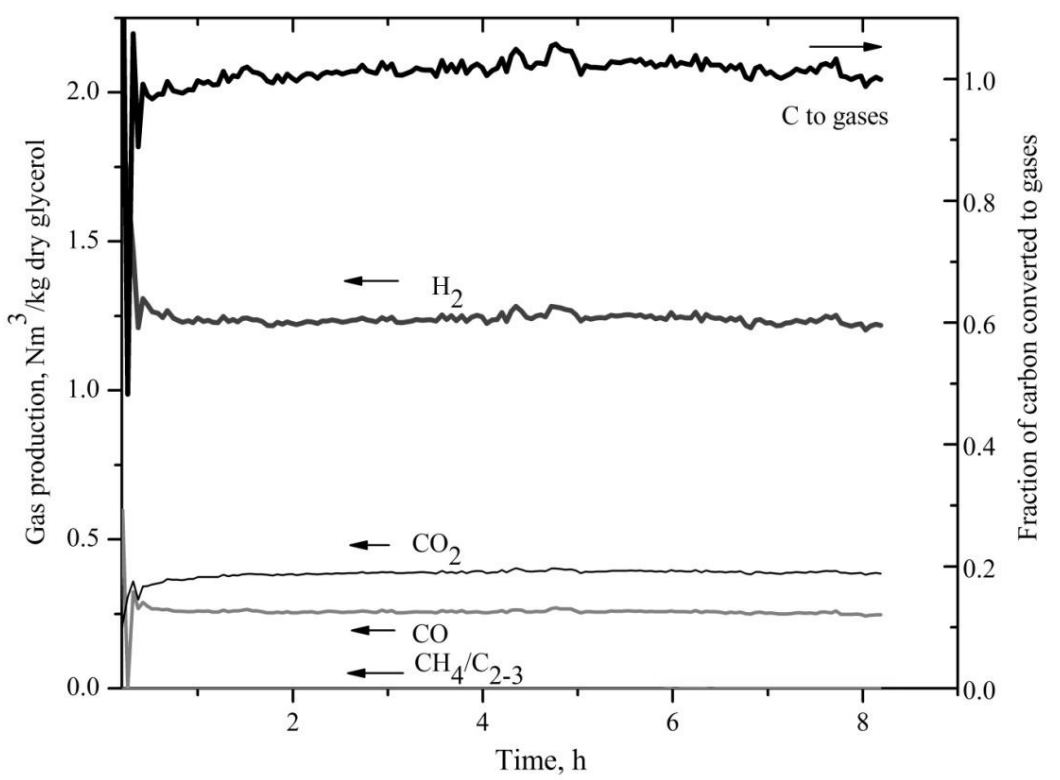

$9 C$

Figure 9: Steam reforming of crude glycerol 2 (A) catalyst $\mathrm{A}, \mathrm{S} / \mathrm{C}=3, \mathrm{~T}_{\text {cat }}=$ $804^{\circ} \mathrm{C}$ and (B) catalyst $\mathrm{B} \mathrm{S} / \mathrm{C}=3$, Tcat $=795^{\circ} \mathrm{C}$. C) pure glycerol with $4 \% \mathrm{KCl}$ by weight, catalyst $\mathrm{A}, \mathrm{S} / \mathrm{C}=3$, Tcat $=803^{\circ} \mathrm{C}$. For all cases $\mathrm{GC}_{1} \mathrm{HSV}=600 \mathrm{~h}^{-1}$. 
For catalyst $\mathrm{B}$, similar gas production as catalyst $\mathrm{A}$ was attained, except that no $\mathrm{CH}_{4}$ was observed in the first $10 \mathrm{~h} . \mathrm{CH}_{4}$ and $\mathrm{C}_{2-3}$ compounds were increased rapidly and reached a steady-state value of $0.018 \mathrm{Nm}^{3} / \mathrm{kg}$ dry feed for $\mathrm{CH}_{4}$ and $0.0018 \mathrm{Nm}^{3} / \mathrm{Kg}$ dry feed for $\mathrm{C}_{2-3}$ compounds, which is almost three times lesser than for catalyst $\mathrm{A}$ or $\sim 88 \%$ conversion of methane based on its selectivity from reforming and gasification experiments. After burn-off and reactivation, the activity of the catalyst was retained; nevertheless, $\mathrm{CH}_{4}$ and $\mathrm{C}_{2-3}$ compounds were rapidly increased. Similar trends on average carbon to gas conversion as catalyst A was noticed for catalyst B. As shown in Figure 9c, no $\mathrm{CH}_{4}$ was observed for catalyst $\mathrm{A}$ when $\mathrm{KCl}$ was added to pure glycerol, whereas for crude glycerol 2, $\mathrm{CH}_{4}$ was linearly increased from the beginning of the experiment. This indicates that the organic impurities present in crude glycerol 2 are solely responsible for reducing the initial activity of the catalyst A.

\subsubsection{Catalyst analysis}

The BET surface area, pore size distribution and Ni dispersion by chemisorption of fresh and used catalyst A are reported in Table 4. There is a progressive drop in the BET surface area of the catalyst A from 19.9 to $6.5 \mathrm{~m}^{2} / \mathrm{g}$. However, it is noticeable that surface area reduction also takes place during methane steam reforming at similar conditions. The surface area after methane steam reforming is comparable with low temperature reforming of glycerol. Since a reduction in the measured BET surface area might as well as be caused by obstruction in the pore system, the pore volume of the catalysts was determined before and after the reaction. No appreciable loss in pore volume was observed for used catalyst after steam methane reforming. However, there is appreciable loss in volume after steam reforming of crude glycerol 2 and low temperature reforming of pure glycerol. The pore volume was reduced further after the catalyst is regenerated. Since there is considerable decrease in pore volume, blockage of pores attribute to the reduction in surface area. The properties of the support and choice of promoters may also have an influence on pore volume reduction on the catalyst [20].

The Ni surface area, metal dispersion and $\mathrm{Ni}$ particle size were found from the hydrogen chemisorption measurements before and after the steam reforming of 
glycerol. It is observed that the quantity of hydrogen adsorbed, metal dispersion, $\mathrm{Ni}$ metal surface area and Ni particle diameter were found to be similar between steam methane reforming and low temperature reforming of glycerol. However, there is a drastic reduction in the metal dispersion, quantity of hydrogen adsorbed and Ni metal surface area when crude glycerol 2 was used as a feedstock. Ni particle size has grown from $\sim 349$ to $801 \mathrm{~nm}$. The increase in Ni particle size is attributed to sintering that depends on Ni loading and support properties. After regeneration, the catalyst A never retained its high initial activity. This may be due to obstruction in the pore system of the catalyst caused due to coke deposition. It may be due to presence of impurities present in the crude glycerol 2. This gives an indication that catalyst $\mathrm{A}$ is designed to work effectively either at low temperature $\left(<600^{\circ} \mathrm{C}\right)$ or for high purity feed stocks or combination of both.

For catalyst B, BET surface area and pore volume remained constant; however, the quantity of hydrogen adsorbed and $\mathrm{Ni}$ metal surface area reduced drastically. $\mathrm{Ni}$ particle diameter is increased from 199 to $\sim 4000 \mathrm{~nm}$. After regenerating the catalyst, the initial activity of unpromoted catalyst (Catalyst B) is retained. Therefore, sintering is not considered to be important, whereas coke deposition due to organic impurities on the catalyst is a critical design parameter.

\subsubsection{Hybrid steam reforming of methane and glycerol}

In the hybrid reforming experiment, $28 \mathrm{wt} \%$ of glycerol was co-reformed with 72 $w t \%$ of methane on $C_{1}$ basis. The test was carried out for $4 \mathrm{~h}$. Figure $10 \mathrm{a}$ shows the gas production obtained from the hybrid reforming experiment. Initially, there is a slight fluctuation in the gas productions due to the addition of hydrogen to keep the catalyst active. The gas production was almost constant over the period of $4 \mathrm{~h}$. An average carbon recovery of $\sim 97 \%$ was obtained. Figure $10 \mathrm{~B}$ shows the gas production obtained from three cases: (1) Methane steam reforming; (2) Hybrid reforming and (3) glycerol steam reforming. The line indicates the equilibrium gas production obtained at $800{ }^{\circ} \mathrm{C}$ and $\mathrm{S} / \mathrm{C}=3$. The gas production is expressed in mol of gas produced per carbon atom. For all the cases, the experimental values almost reached the equilibrium gas productions. 
Chapter 4 - Preliminary assessment of synthesis gas production via HSR of methane and glycerol

Table 4: Surface area, pore size and chemisorption measurements of fresh and used catalysts

\begin{tabular}{|c|c|c|c|c|c|c|}
\hline Catalyst & Feedstock & $\begin{array}{l}\text { BET } \\
\left(\mathrm{m}^{2} / \mathrm{g}\right)\end{array}$ & $\begin{array}{c}\text { Pore } \\
\text { volume } \\
\left(\mathrm{cm}^{3}\right)\end{array}$ & $\begin{array}{c}\mathrm{H}_{2} \\
\text { adsorbed } \\
\left(\mathrm{cm}^{3} / \mathrm{g}\right)\end{array}$ & $\begin{array}{c}\text { Metallic } \\
\text { surface } \\
\text { area } \\
\left(\mathrm{m}^{2} / \mathrm{g}\right. \\
\text { metal) }\end{array}$ & $\begin{array}{c}\text { Nickel } \\
\text { particle } \\
\text { size } \\
(\mathrm{nm})\end{array}$ \\
\hline Catalyst A - Fresh & - & 19.9 & 0.049 & 0.089 & 1.93 & 349 \\
\hline Catalyst A (25 h) & Crue glycerol 2 & 7.3 & 0.034 & 0.048 & 1.03 & 653 \\
\hline $\begin{array}{l}\text { Catalyst A (after } \\
\text { regeneration, } 8 \mathrm{~h} \text { ) }\end{array}$ & Crude glycerol 2 & 6.5 & 0.030 & 0.039 & 0.84 & 801 \\
\hline $\begin{array}{l}\text { Catalyst A (25 h, } \\
\text { LTR) }\end{array}$ & Pure glycerol & 6.83 & 0.029 & 0.061 & 1.33 & 508 \\
\hline Catalyst A (SMR) & Methane & 8.66 & 0.040 & 0.061 & 1.33 & 5.08 \\
\hline Catalyst B - Fresh & - & 3.4 & 0.011 & 0.14 & 3.39 & 199 \\
\hline Catalyst B (25 h) & Crude glycerol 2 & 3 & 0.011 & 0.006 & 0.15 & 4458 \\
\hline $\begin{array}{l}\text { Catalyst B A (after } \\
\text { regeneration, } 8 \text { h) }\end{array}$ & Crude glycerol 2 & 2.1 & 0.006 & 0.007 & 0.17 & 3983 \\
\hline
\end{tabular}




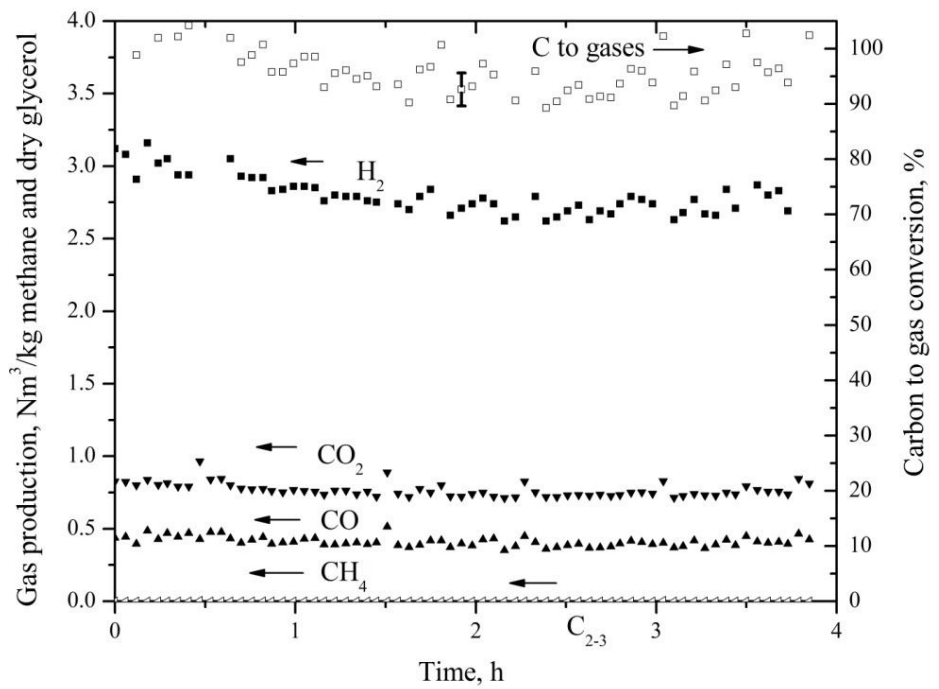

$10 \mathrm{~A}$

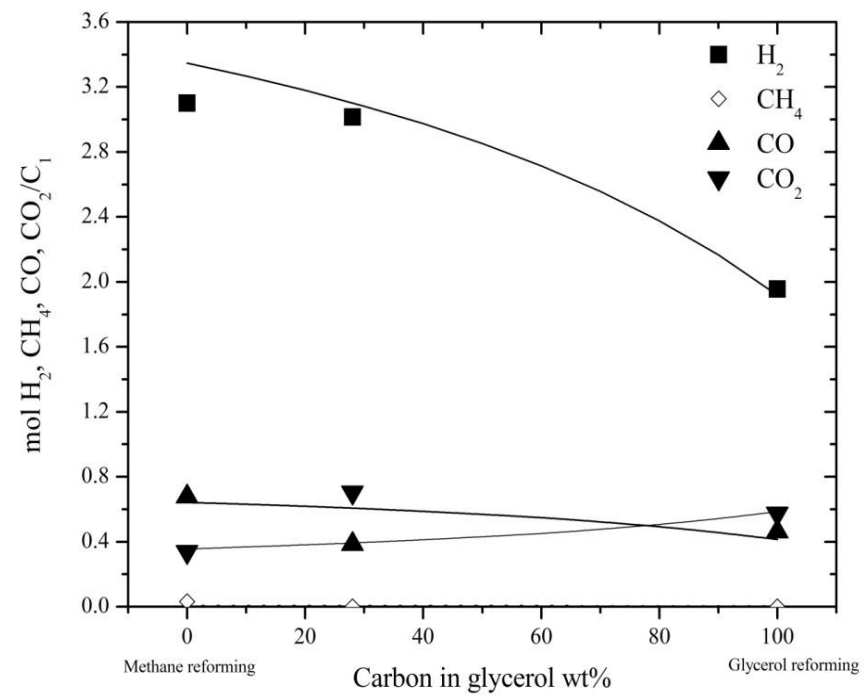

$10 B$

Figure 10: A) Hybrid reforming of methane with pure glycerol, Glycerol $28 \%$, Methane 72\%, Pre-reformer $-\mathrm{S} / \mathrm{C} \sim 15, \mathrm{~T}=590{ }^{\circ} \mathrm{C}, \mathrm{GC}_{1} \mathrm{HSV}=516 \mathrm{~h}^{-1}$, Primary reformer $-\mathrm{S} / \mathrm{C} \sim 3, \mathrm{~T}=791{ }^{\circ} \mathrm{C}, \mathrm{GC}_{1} \mathrm{HSV}=958 \mathrm{~h}^{-1} \mathrm{~B}$ ) Comparison of methane, hybrid and glycerol steam reforming with thermodynamic equilibrium. (Line represents thermodynamic equilibrium, points - experimental values). 


\subsubsection{Performance of Catalyst $\mathrm{A}\left(\mathrm{Ni} / \mathrm{K}-\mathrm{Mg}-\mathrm{Al}_{2} \mathrm{O}_{3}\right)$ and Catalyst $\mathrm{B}$ ( $\left.\mathrm{Ni} / \mathrm{Al}_{2} \mathrm{O}_{3}\right)$ catalysts during $\mathrm{HSR}$ of methane and crude glycerol}

Crude glycerol 2 was also studied in HSR process. Figure 11 shows the amount of the gas produced in moles per mol carbon of the crude glycerol and methane in the primary reformer and the bio-liquid refomer, when Catalyst A was used in the bioliquid reformer and Catalyst B was used in the primary reformer (HSR) as shown in Figure 2. The pre-reformer was operated at $800{ }^{\circ} \mathrm{C}, \mathrm{S} / \mathrm{C} \sim 8$ and 28 weight $\%$ carbon contribution from crude glycerol. As shown in Figure 11, for the first 10 hours, gas production in the pre-reformer was constant. The carbon conversion to gas was stable at $\sim 90 \%$ (not shown in figure). After $10 \mathrm{~h}$, the gas productions and $\mathrm{C}_{\mathrm{G}}$ started to decrease and remained stable after 20 hours. The $\mathrm{C}_{\mathrm{G}}$ was constant at $\sim 70 \%$ from 20 till $35 \mathrm{~h}$ (not shown in Figure) in the bio-liquid reformer. This means after $20 \mathrm{~h} \sim 30 \%$ of oxygenates (on carbon basis) from $28 \mathrm{wt} \%$ of crude glycerol break-through from the pre-reformer.

In the primary reformer, catalyst $\mathrm{B}$ is in contact with gases produced from the prereformer, oxygenates (from crude glycerol) and $\mathrm{CH}_{4}$ (added to the primary reformer). For first $25 \mathrm{~h}$ in the primary reformer, $\mathrm{H}_{2}, \mathrm{CO}$ and $\mathrm{CO}_{2}$ were found to be stable. This is expected because $\sim 90 \%$ carbon was in the product gas from the crude glycerol. This product gas together with methane would not be a problem to reform into synthesis gas. After $25 \mathrm{~h}, \mathrm{CH}_{4}$ started to appear and other gases started to decrease in the primary reformer. However, $\mathrm{C}_{\mathrm{G}}$ remained constant at $\sim 1.02 \pm 0.02$ and within the error limitations of gas measurement. This means that catalyst $\mathrm{B}$ able to handle a fraction of unconverted oxygenates for short period $(\sim 25 \mathrm{~h})$ and when the oxygenates breakthrough increased to $\sim 30 \%$ on carbon basis, $\mathrm{Ni} / \mathrm{Al}_{2} \mathrm{O}_{3}$ catalyst started to lose its methane reforming activity. This means that coke deposition (due to oxygenates) may play a role in decreasing the methane reforming activity of potassium free $\mathrm{Ni} / \mathrm{Al}_{2} \mathrm{O}_{3}$ catalyst. This also means that catalyst A act as "guard bed" by protecting catalyst B from activity loss. 


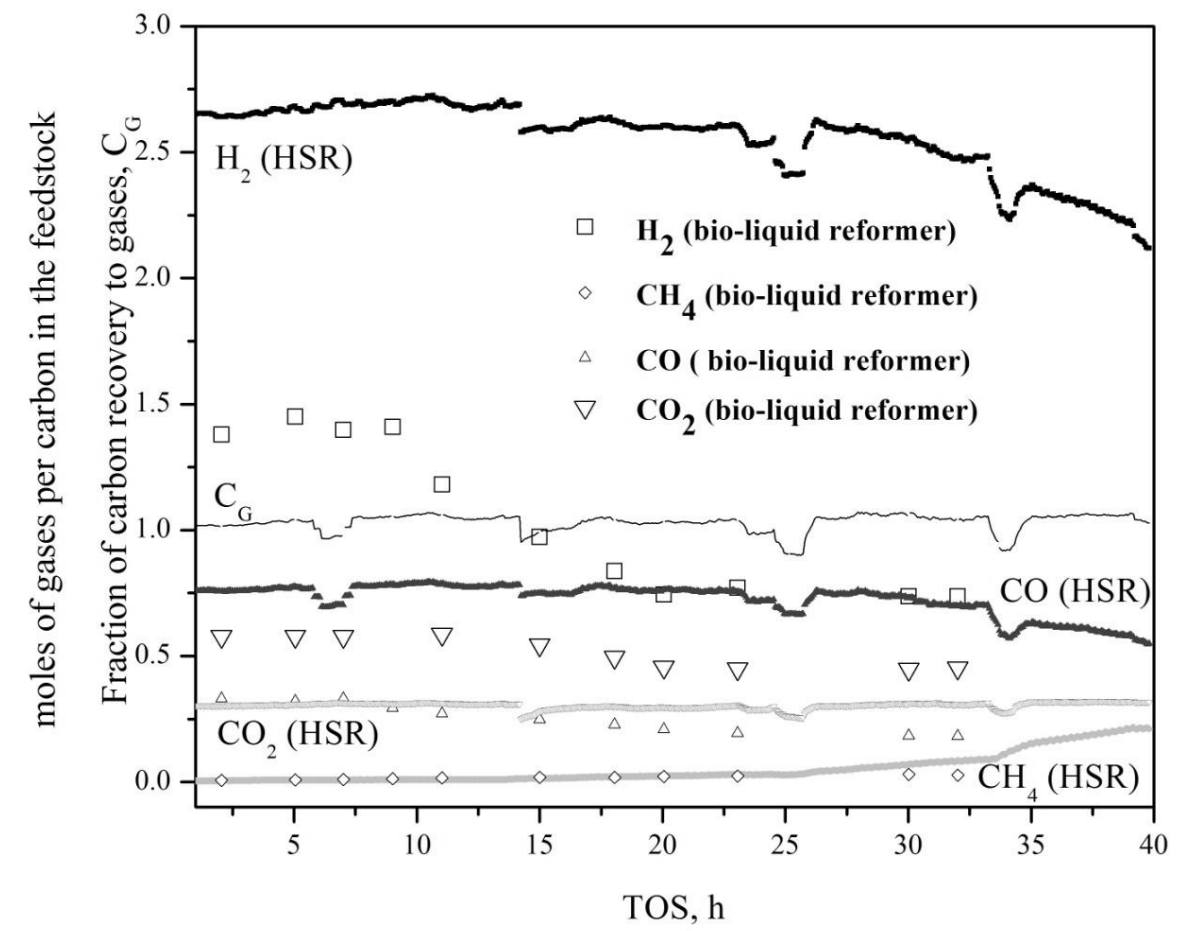

Figure 11: Performance of Catalyst $\mathrm{A}\left(\mathrm{Ni} / \mathrm{K}-\mathrm{Mg}-\mathrm{Al}_{2} \mathrm{O}_{3}\right)$ and Catalyst $\mathrm{B}$ $\left(\mathrm{Ni} / \mathrm{Al}_{2} \mathrm{O}_{3}\right)$ during $\mathrm{HSR}$ of methane and crude glycerol. Primary reformer $\left(\mathrm{CH}_{4}\right.$ :crude glycerol $=0.72: 0.28$ (carbon basis), $-\mathrm{T}_{\text {primary }} \sim 820{ }^{\circ} \mathrm{C}, \mathrm{S} / \mathrm{C}_{\text {primary reformer }}$ $=2.8$, Bio-liquid reformer (crude glycerol alone) (or pre-reformer) $\mathrm{H}_{2} /$ steam $=$ $0.1 \mathrm{~mol} / \mathrm{mol}, \mathrm{GC}_{1} \mathrm{HSV}=930 \mathrm{~h}^{-1} . \mathrm{T}_{\text {bio-liquid reformer }} \sim 800{ }^{\circ} \mathrm{C}, \mathrm{S} / \mathrm{C}_{\text {bio-liquid reformer }} \sim 8$, $\mathrm{GC}_{1} \mathrm{HSV}=260 \mathrm{~h}^{-1}$

(Empty boxes and lines represent bio-liquid reformer and HSR respectively) 


\subsection{Implications on glycerol steam reforming}

The gasification of crude glycerol is summarized in Figure 12. Crude glycerol 1 from the transesterifcation unit can be directly vaporized above $300{ }^{\circ} \mathrm{C}$ to produce vapors/gases. Due to the presence of $\mathrm{KOH}$ in the crude, carbon loss in the form of char $\sim 10 \%$ is inevitable. The solid residue primarily consists of char and inorganics. On the other hand, crude glycerol 1 can be neutralized using an acid and evaporated further to prevent polymerization. In both the options, solid handling becomes mandatory; nevertheless, in option 1 there are possibilities of converting the char by steam gasification, since the activity of char may be high due to the presence of salts $[21,22]$ or can be combusted to produce energy. To avoid solid handling in the steam reformer, catalyst for transesterification has to be changed to a heterogeneous catalyst instead of $\mathrm{KOH}$.

Based on the process conditions used ( 1 bar, $\sim 800{ }^{\circ} \mathrm{C}$ and $\tau \sim 3 \mathrm{~s}$ ) for gasification experiments, the complete conversion of glycerol to gases is possible only at higher temperatures $\left(\sim 800{ }^{\circ} \mathrm{C}\right)$. Therefore, in hybrid reforming process, gasification of glycerol can be combined with primary reformer, where methane is co-reformed with gases produced from the gasification step, only when complete conversion is achieved via gasification. This may eliminate the pre-reforming process. Therefore, the choice should be made between the high temperature gasification or low temperature steam reforming. However, results from pre-reforming at low temperature using commercial steam reforming catalyst were promising to use as an upstream step for primary reforming. Moreover, the catalyst in the pre-reformer acts as a "guard bed" and may protect the primary reforming catalyst. To utilize these liquids on a larger scale, a flexible pre-reformer that handles crude glycerol (treated or untreated) is required.

From the catalyst point of view, the promoted $\mathrm{Ni} / \mathrm{Al}_{2} \mathrm{O}_{3}$ catalyst suffers initial activity loss, which was not retained after regeneration. However, the unpromoted catalyst has retained its activity after regeneration. The dominant impurities present in the crude glycerol are FAMEs, tri,di glycerides and alkali salts. Our experimental results indicated that reforming pure glycerol or glycerol with chlorides does not affect the activity of the catalyst, whereas organic impurities affected the initial activity of 
commercial promoted $\mathrm{Ni} / \mathrm{Al}_{2} \mathrm{O}_{3}$ catalyst. However, commercial unpromoted $\mathrm{Ni} / \mathrm{Al}_{2} \mathrm{O}_{3}$ catalyst also loses its activity. Therefore, a frequent regeneration step is necessary to utilize crude glycerol for methanol production. However, the role and choice of promoters on the commercial catalyst to reform crude glycerol has to be investigated further.

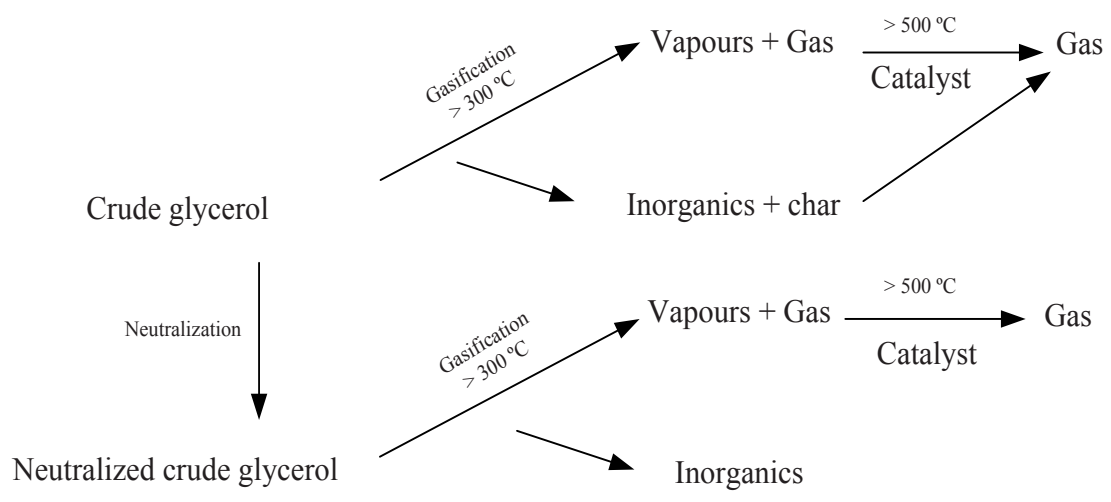

Figure 12: Mechanism of glycerol gasification.

\subsection{Conclusions}

The various stages of HSR such as gasification of crude glycerol, low temperature steam reforming (pre-reforming) and co-reforming glycerol with methane were studied. The main conclusions can be summarized as follows:

Presence of alkali hydroxides $(\mathrm{NaOH}$ and $\mathrm{KOH})$ in the glycerol enhances the char formation via polymerizing the intermediates in the liquid phase. Higher molecular mass intermediates formed near the boiling point of glycerol are responsible for char formation.

Pure glycerol and neutralized crude glycerol can be gasified with no loss of carbon as char. Solid handling, in processing neutralized glycerol (salts) and untreated glycerol (inorganics and char), becomes mandatory to scale up evaporator/gasifer. 
To upgrade realistic feedstocks such as crude glycerol to produce synthesis gas via steam reforming, a flexible steam reformer is required.

Pure glycerol can be reformed using commercial catalyst with no loss in the activity. For a realistic feedstock such as crude glycerol, organic impurities such as FAME, di and tri glycerides deteriorate the initial activity of the commercial steam reforming catalyst.

\section{References}

1. M.Pagliaro, M.Rossi, The Royal Society of Chemistry (2008), ISBN 978-085404-124-4

2. S.Adhikari, S.D.Fernando, S.D.Filip To, R.M.Bricka, P.H.Steele, A.Haryanto, Energy \& Fuels (2008), vol 22, 1220-1226

3. G.van Rossum, B.Potic, S.R.A.Kersten, W.van Swaaij, Catalysis today (2009), vol 145, 10-18

4. G.van Rossum, S.R.A.Kersten, W.P.M.van Swaaij, Ind. Eng, Chem, Res, (2007), vol 46, 3959-3967

5. G.van Rossum, S.R.A. Kersten, W.P.M.van Swaaij, Ind. Eng, Chem, Res, (2009), vol 48, 5857-5866

6. T.Hirai, N.Ikenaga, T.Miyake, T.Suzuki, Energy \& Fuels (2005), vol 19, 1761-1762

7. D.C.Rennard, J.S.Kruger, B.C.Michael, L.D.Schmidt, Ind. Eng, Chem, Res., (2010), vol 49, 8424-8432

8. S.R.A.Kersten, B.Potic, W.Prins, W.P.M.van Swaaij, Ind. Eng, Chem, Res, (2006), vol 45, 4169-4177

9. A.G.Chakinala, D.W.F.Brilman, W.P.M.van Swaaij, S.R.A.Kersten; Ind. Eng, Chem, Res (2010) vol 49, 1113-1122

10. G.W.Huber, S.Iborra, A.Corma, Chem. Rev (2006), vol 106, 4044-4098

11. A.Iriondo, V.L.Barrio, J.F.Cambra, P.L.Arias, M.B.Güemez, R.M.Navarro, M.C.Sánchez-Sánchez, J.L.G.Fierro, Top Catal (2008), vol 49, 46-58 
12. J.A.Medrano, M.Oliva, M.Ruiz, L.Garcia, J.Arauzo, International journal of hydrogen energy (2008), vol 33, 4387-4396

13. F.Bimbela, M.Oliva, M.Ruiz,, L.Garcia, J.Arauzo, Journal of analytical and applied pyrolysis (2009), vol 85, 204-213

14. B.M.Güell, I.Babich, K.P.Nichols, L.Gardeniers, L.Lefferts, K.Seshan, Applied catalysis B:Environmental (2009) vol 90, 38-44

15. S.Czernik, R.French, C.Feik, E.Chornet, Ind. Eng, Chem, Res., (2002), vol 41, 4209-4215

16. G.van Rossum, B.M.Güell, R.P.B.Ramachandran, K.Seshan, L/Lefferts, W.P.M.Swaaij, S.R.A.Kersten, AIChe journal (2010) vol 56, 2200-2210

17. R.P.B.Ramachandran, G.van Rossum, W.P.M.van Swaaij, S.R.A.Kersten, Environmental Progress \& Sustainable energy (2009) vol 28, 410-417

18. B.Dou, G.L.Rickett, V.Dupont, P.TWilliams, H.Chen, Y.Ding, M.Ghadiri, Bioresouce technology (2010), vol 101, 2436-2442

19. Y.Krishnandi, R.Eckelt, M.Schneider, A.Martin, M.Richter, ChemSusChem, (2008), vol 1, 835-844

20. J.Sehested, A.Carlsson, T.V.W.Janssens, P.L.Hansen, A.K.Datye, Journal of Catalysis (2001), vol 197, 200-209

21. P.Nanou, G.van Rossum, W.P.M.van Swaaij, S.R.A.Kersten, Energy \& Fuels, (2011), vol 25, 1242-1253

22. C.Di Blasi, A.Galgano, C.Branca, Ind. Eng. Chem. Res (2011), vol 50, 3864-3 


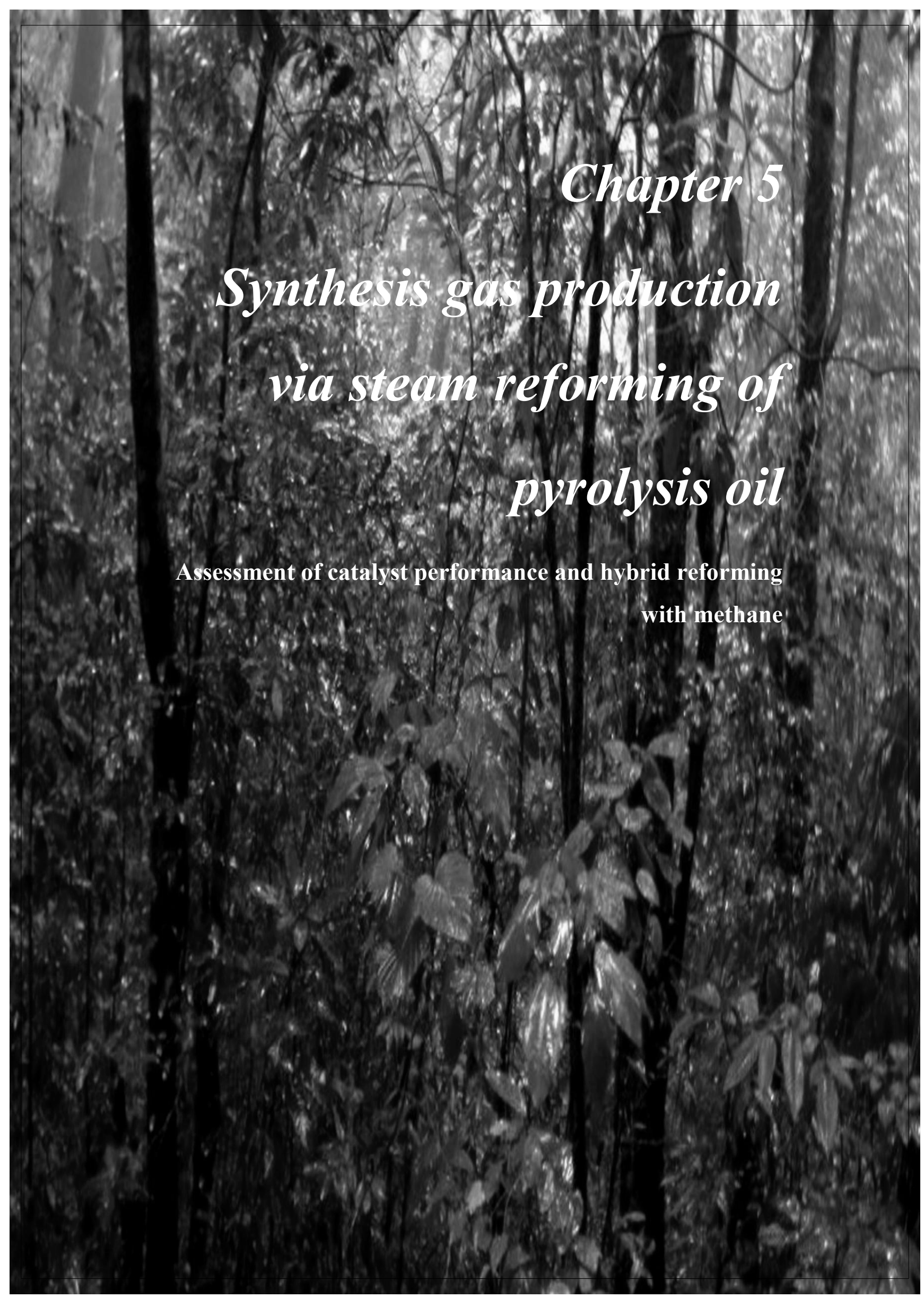




\section{Abstract}

The objective of the present investigation is to evaluate the performance of a commercial naphtha pre-reforming $\mathrm{Ni}_{/} \mathrm{Al}_{2} \mathrm{O}_{3}$ catalyst and an in-house $\mathrm{Mg}$ promoted $\mathrm{Ni}_{\mathrm{Al}} \mathrm{O}_{3}$ catalyst during steam reforming of pyrolysis oil. Both these catalysts presented a different deactivation behavior during steam reforming of pyrolysis oil. The commercial naphtha pre-reforming $\mathrm{Ni} / \mathrm{Al}_{2} \mathrm{O}_{3}$ catalyst showed an irreversible loss in methane reforming activity during pyrolysis oil reforming while magnesium promoted $\mathrm{Ni} / \mathrm{Al}_{2} \mathrm{O}_{3}$ catalysts presented reversible loss of methane reforming activity. After the coke removal step (regeneration), carbon conversion to gas remained more or less constant for the commercial naphtha pre-reforming catalyst, indicating that potassium enhanced coke gasification. For $\mathrm{Mg}$ promoted $\mathrm{Ni} / \mathrm{Al}_{2} \mathrm{O}_{3}$ catalyst, carbon conversion to gases and gas productions dropped much faster after regeneration than for the initial period of the experiment. The effect of potassium on glycerol reforming is investigated by impregnating $\mathrm{K}$ on $\mathrm{Ni}_{/} \mathrm{Al}_{2} \mathrm{O}_{3}$ catalyst. For the potassium impregnated catalysts, methane was observed in quantities, increasing with potassium loading while $C_{2-3}$ gases were observed only for the catalyst with high potassium loading. From the hybrid steam reforming (HSR) experiments, it is concluded that the bio-liquid pre-reforming catalyst acts as a 'guard bed' to protect the primary reforming catalyst which is supposed to reform methane and pre-reformed pyrolysis oil gases and vapors. However, in terms of performance, the HSR process still requires frequent regeneration of this primary reformer. 


\subsection{Introduction}

Presently, the oil and gas industries are showing interest to replace part of the raw materials base from fossil to renewable in a way adapted to the existing infrastructure. This is mainly due to the increase in fossil fuel price, global $\mathrm{CO}_{2}$ emissions and desire of security of supply. To meet this demand, thermal and biological conversion of biomass processes may provide a platform to make a significant impact on the production of fuels, bulk chemicals such as methanol, ethanol, hydrogen etc. within the next few decades. Several authors investigated the utilization of bio-based materials such as pyrolysis oil [1-4], aqueous sugar streams [2, 5] and glycerol [6, 7] to produce synthesis gas or hydrogen via steam reforming.

To integrate bio-based processes with a fossil refinery, biomass streams should be available near a refinery or bio-based intermediates can possibly be produced elsewhere and transported to the refinery for the applications mentioned before [2]. To bridge the gap between dispersed availability and demand for large-scale utilization, biomass fast pyrolysis is proposed as an intermediate step, where solid biomass is converted into pyrolysis oil that can more easily be transported over long distances and pressurized compared to the original feed. Another interesting liquid that can be utilized in steam reforming is glycerol [7], a by-product from the transesterification process (bio-diesel production). The present article focuses on converting these bioliquids in to synthesis gas via steam reforming and co-processing them with hydrocarbon feeds like natural gas.

During steam reforming of oxygenates, the following reactions play a vital role on carbon distribution to gases, vapors and solid. They are:

- Cracking of oxygenates

$$
\mathrm{C}_{\mathrm{n}} \mathrm{H}_{\mathrm{m}} \mathrm{O}_{\mathrm{k}} \Rightarrow \text { gases }\left(\mathrm{CO}+\mathrm{CO}_{2}+\mathrm{CH}_{4}+\mathrm{C}_{2-4}+\mathrm{H}_{2}\right)+\text { vapors }\left(\mathrm{C}_{\mathrm{a}} \mathrm{H}_{\mathrm{b}} \mathrm{O}_{\mathrm{c}}\right)+\text { solid char }
$$

- Steam reforming of oxygenates

$$
\mathrm{C}_{\mathrm{n}} \mathrm{H}_{\mathrm{m}} \mathrm{O}_{\mathrm{k}}+(\mathrm{n}-\mathrm{k}) \mathrm{H}_{2} \mathrm{O} \Rightarrow \mathrm{nCO}+(\mathrm{n}+\mathrm{m} / 2-\mathrm{k}) \mathrm{H}_{2}
$$


- Dry reforming of oxygenates

$$
\mathrm{C}_{\mathrm{n}} \mathrm{H}_{\mathrm{m}} \mathrm{O}_{\mathrm{k}}+(\mathrm{n}-\mathrm{k}) \mathrm{CO}_{2} \Rightarrow(2 \mathrm{n}-\mathrm{k}) \mathrm{CO}+(\mathrm{m} / 2) \mathrm{H}_{2}
$$

- Polymerization of oxygenates (liquid and vapor)

$$
\mathrm{C}_{\mathrm{n}} \mathrm{H}_{\mathrm{m}} \mathrm{O}_{\mathrm{k}} \Rightarrow \mathrm{C}_{\mathrm{a}} \mathrm{H}_{\mathrm{b}} \mathrm{O}_{\mathrm{c}}+\mathrm{dH}_{2} \mathrm{O}+\mathrm{eCO}_{2}
$$

- Methanation

$$
\mathrm{CO}+3 \mathrm{H}_{2} \Leftrightarrow \mathrm{CH}_{4}+\mathrm{H}_{2} \mathrm{O}(\Delta \mathrm{H}=-206 \mathrm{~kJ} / \mathrm{mol})
$$

- Water-gas shift

$$
\mathrm{CO}+\mathrm{H}_{2} \mathrm{O} \Leftrightarrow \mathrm{CO}_{2}+\mathrm{H}_{2}(\Delta \mathrm{H}=-41.1 \mathrm{~kJ} / \mathrm{mol})
$$

- Boudouard

$$
\mathrm{C}_{(\mathrm{S})}+\mathrm{CO}_{2} \Leftrightarrow 2 \mathrm{CO}(\Delta \mathrm{H}=170.7 \mathrm{~kJ} / \mathrm{mol})
$$

- Water-gas reaction

$$
\mathrm{C}_{(\mathrm{S})}+\mathrm{H}_{2} \mathrm{O} \Rightarrow \mathrm{CO}+\mathrm{H}_{2}(\Delta \mathrm{H}=131 \mathrm{~kJ} / \mathrm{mol})
$$

At targeted oxygenates steam reforming temperatures $\left(\leq 900{ }^{\circ} \mathrm{C}\right)$, steam and dry reforming, methanation and water gas shift need a catalyst to attain sufficient high reaction rates while cracking, polymerization and Boudouard can occur both catalytically and non-catalytically. In our earlier articles [7-9], thermal cracking of bio-liquids such as pyrolysis oil and glycerol was extensively studied by injecting the liquids as droplets into a hot environment. In this process, the bio-liquids are evaporated and the vapors are then converted to gases via thermal cracking. Additionally to char formation in the gas phase, solid char is formed via liquid phase polymerization which takes place in parallel during the evaporation/cracking of pyrolysis oil [8]. The combined processes of evaporation, thermal cracking and polymerization can be named gasification. The initial carbon product distribution between solids (char) and vapors/gasses for pyrolysis oil gasification was found to be only dependent on the liquid heating rate while temperature variation $\left(550-850^{\circ} \mathrm{C}\right)$ had an impact on the ratio of vapors and gases being formed [8, Chapter 2]. With pure and alkali neutralized crude glycerol, no char formation was observed during gasification [7].

Van Rossum et al. [1] extensively investigated steam reforming of whole pyrolysis oil in a fluidized bed using potassium/lanthanum promoted $\mathrm{Ni} / \mathrm{Al}_{2} \mathrm{O}_{3}$ catalyst at $\sim 815^{\circ} \mathrm{C}$ and $\mathrm{S} / \mathrm{C} \sim 3$. A decrease in $\mathrm{H}_{2}, \mathrm{CO}$ production and a steady increase in the $\mathrm{CH}_{4}$ 
production were observed over time. Similar behavior, however to lesser extent, was reported by Czernik et al. [2] for steam reforming of the aqueous fraction of pyrolysis oil and a hemi-cellulose rich solution. The formation of hydrocarbons $\left(\mathrm{CH}_{4}, \mathrm{C}_{2} \mathrm{H}_{4}\right)$ was related to thermal cracking of oxygenates which always accompanies catalytic reforming [2]. Van Rossum et al. [1] demonstrated steam reforming of pyrolysis oil in a staged concept (fluidized bed for the evaporation of pyrolysis oil followed by syngas production in a fixed bed of both $\mathrm{Ni} / \mathrm{K}-\mathrm{Mg}-\mathrm{Al}_{2} \mathrm{O}_{3}$ and $\mathrm{Ni} / \mathrm{Al}_{2} \mathrm{O}_{3}$ catalysts), where methane free synthesis gas was continuously produced for $\sim 12 \mathrm{~h}$. However, a large amount of catalyst was used $\left(\mathrm{GHC}_{1} \mathrm{SV} \sim 100 \mathrm{~h}^{-1}\right)$, which means that the possible loss in activity could have not been observed due to the time frame studied.

In this Chapter, catalytic performance of two catalysts, one commercial naphtha prereforming catalyst and one in-house made catalyst, for bio-liquid reforming is evaluated from a process development point of view at a commercial comparable gas hourly space velocity $\left(\mathrm{GHC}_{1} \mathrm{SV} \sim 1500 \mathrm{~h}^{-1}\right)$. Both (pre-) reforming of the bio-liquids and co-reforming of gases and vapors from pre-reformed bio-liquids with methane is reported. The latter concept is called hybrid steam reforming (HSR). At the level of the chemistry/catalysis, co-reforming may minimize the adverse characteristics of the bio-liquid, as has been observed for co-feeding upgraded pyrolysis oil with long residue in a micro FCC unit [11]. The role of potassium as a promoter on a catalyst is investigated by using glycerol as a model compound. One typical long duration run is presented for hybrid reforming of pyrolysis oil with methane using our lab scale pilot plant set-up. 


\subsection{Experimental}

\subsubsection{Materials}

The pyrolysis oil used was produced by VTT (Finland) from forest residue [10]. The elemental composition of the pyrolysis oil was $41 \%$ carbon, $8 \%$ hydrogen and $51 \%$ oxygen including $24 \%$ water by weight. Pure glycerol (>99.99\%) was obtained from Sigma Aldrich. Two Ni based catalysts were used for pyrolysis oil conversion: i) a commercial naphtha pre-reforming catalyst, named $\mathrm{Ni} / \mathrm{K}-\mathrm{Mg}-\mathrm{Al}_{2} \mathrm{O}_{3}$ which consisted of $\mathrm{Ni}$ promoted with $\mathrm{K}, \mathrm{Ca}, \mathrm{Mg}$ and $\mathrm{Si}$ (all oxides) on a $\mathrm{Al}_{2} \mathrm{O}_{3}$ support and ii) an inhouse prepared catalyst, named $\mathrm{Ni} / \mathrm{Mg}-\mathrm{Al}_{2} \mathrm{O}_{3}$ which was composed of $\mathrm{Ni}$ on $\mathrm{Al}_{2} \mathrm{O}_{3}$ and promoted with only $\mathrm{MgO}$. The procedure to prepare the later catalyst was described by Medrano et al. [12]. Both the catalysts were ground and sieved to a particle size ranging between 160 and $320 \mu \mathrm{m}$. For steam reforming of pure glycerol, a commercial methane steam reforming catalyst, named $\mathrm{Ni} / \mathrm{Al}_{2} \mathrm{O}_{3}$ which consisted of mainly $\mathrm{Ni}$ on $\mathrm{Al}_{2} \mathrm{O}_{3}$ was used directly and via $\mathrm{K}_{2} \mathrm{O}$ impregnating with two different $\mathrm{K} / \mathrm{Ni}$ molar ratios $(0.04$ and 0.32$)$. The catalysts thus obtained are denoted as Ni/K1$\mathrm{Al}_{2} \mathrm{O}_{3}$ and $\mathrm{Ni} / \mathrm{K} 2-\mathrm{Al}_{2} \mathrm{O}_{3}$ respectively. For HSR experiments, $\mathrm{Ni} / \mathrm{K}-\mathrm{Mg}-\mathrm{Al}_{2} \mathrm{O}_{3}$ catalyst is used.

\subsubsection{Experimental set up}

A schematic overview of the hybrid steam reforming (HSR) set-up is shown in Figure 1. The set-up consists of three stages: gasification of pyrolysis oil, followed by catalytic pre-reforming of vapors and catalytic reforming of methane together with the gas/vapor produced from the pre-reforming. The latter is called HSR or co-reforming. All the equipment components were made of stainless steel (type:R543). The set-up was operated at near atmospheric pressure.

Gasification section: The gasifier has an internal diameter of $40 \mathrm{~mm}$ and a height of $350 \mathrm{~mm}$. It consists of an ultrasonic atomizer that sprays droplets of $\sim 100 \mu \mathrm{m}$ with a liquid flow rate ranging from 0.2 to $0.4 \mathrm{ml} / \mathrm{min}$, using a HPLC pump (Instrument Solutions). Nitrogen stream (flow rate: $0.2 \mathrm{Nl} / \mathrm{min}$ ) was used to facilitate atomization. The atomizer was fitted in a copper ring in which water was circulated to keep the 
temperature below $70^{\circ} \mathrm{C}$. This is to protect the piezo-electric parts of the atomizer from thermal damage. A pre-heater (temperature $450^{\circ} \mathrm{C}$ ) was attached to the top of the gasifier to supply additional nitrogen (flow rate: $0.4 \mathrm{Nl} / \mathrm{min}$ ) and steam required for the reaction. This added stream kept the top of the gasifier at $\sim 400^{\circ} \mathrm{C}$ to minimize vapor condensation at the upper part of the gasifier. A filter was placed at the bottom of the gasifier to collect the solids. Temperatures were measured at the top, middle and bottom section of the gasifer. The reported gasification temperature was the average temperature of the middle and the bottom section of the gasifier.

Pre-reforming section (location 1): Beneath the evaporator, the fixed bed prereformer (40 $\mathrm{mm}$ internal diameter and $150 \mathrm{~mm}$ height) was placed, where the gas/vapor mixture from the gasifier is catalytically converted using a commercial steam reforming catalyst. The catalyst was placed in an inconel distribution plate at the bottom of the pre-reformer. This section was only used in the HSR experiment. Methane was supplied at the exit of the pre-reformer for HSR experiments.

Primary reforming section (location 2): The fixed bed primary reformer $(35 \mathrm{~mm}$ internal diameter and $300 \mathrm{~mm}$ height) was fitted with an inconel distribution plate at the middle of the reactor. The bed consists of a mixture of quartz and catalyst particles (3:1, quartz: catalyst), which was placed on top of the plate with a bed height of $\sim 100$ $\mathrm{mm}$.

Both the pre-reforming and primary reforming catalyst were reduced in situ with hydrogen $(0.2 \mathrm{Nl} / \mathrm{min})$ diluted with Nitrogen $(0.4 \mathrm{Nl} / \mathrm{min})$ at $800^{\circ} \mathrm{C}$ for $\sim 8 \mathrm{~h}$ before each experiment. Temperatures of the reformers were measured at the bottom and also at the middle of the catalyst bed, which was the reported temperature.

For HSR experiments, the pre-reformer (location 1) was used together with the primary reformer (location 2), whereas for tests investigating steam reforming of "pure" pyrolysis oil, the catalyst was placed in the primary reformer (location 2). $\mathrm{Ni} / \mathrm{K}-\mathrm{Mg}-\mathrm{Al}_{2} \mathrm{O}_{3}$ was used as both pre-reforming and primary reforming catalyst for HSR experiments whereas for steam reforming experiments, $\mathrm{Ni} / \mathrm{K}-\mathrm{Mg}-\mathrm{Al}_{2} \mathrm{O}_{3}$ and $\mathrm{Ni} / \mathrm{Mg}-\mathrm{Al}_{2} \mathrm{O}_{3}$ were used. 
The products from the reformer were immediately cooled after the cyclone to collect the condensables. A micro-GC (Varian CP-4900; $10 \mathrm{~m}$ mol sieve 5A Ar, $10 \mathrm{~m}$ mol sieve 5A He, 10 m PPQ He, 8 m Sil-5CB He) was used to detect $\mathrm{H}_{2}, \mathrm{O}_{2}, \mathrm{~N}_{2}, \mathrm{CH}_{4}, \mathrm{CO}$, $\mathrm{CO}_{2}, \mathrm{C}_{2} \mathrm{H}_{4}, \mathrm{C}_{2} \mathrm{H}_{6}, \mathrm{C}_{3} \mathrm{H}_{6}$ and $\mathrm{C}_{3} \mathrm{H}_{8}$. For HSR experiments, the gas samples were taken manually after the pre-reformer and for the hybrid reformer gas measurement was performed continuously using a micro gas chromatography (Varian CP-4900). The integral carbon balance and gas production for both the gasification and catalytic reforming and HSR experiments were made based on nitrogen as an internal standard, which was fed to the atomizer and pre-heater. The gas production from the primary reformer is reported as $\mathrm{Nm}^{3}$ of $\mathrm{H}_{2}$ or $\mathrm{CH}_{4}$ or $\mathrm{CO}$ or $\mathrm{CO}_{2}$ per kilogram of the dry feedstock.

The catalysts were regenerated using $100 \mathrm{ml} / \mathrm{min}$ of air to estimate the amount of carbon deposited (coke) on the catalyst. The carbon to gas conversion or fraction of carbon converted to gases was calculated at the steady-state operation that excludes the start-up profile. Gas hourly space velocity on $\mathrm{C}_{1}$ basis is defined as the volume of $\mathrm{C}_{1}$ equivalent species in the feed at the STP (standard temperature and pressure) per unit volume of the catalyst. $\mathrm{C}_{1}$ equivalent is used to compare feedstocks containing different number of carbon atoms per molecule. The carbon closure of experimental set-up was found to be adequate (i) $100 \pm 3 \%$ using methane and steam at $795^{\circ} \mathrm{C}$, $\mathrm{S} / \mathrm{C}=3$, (ii) $99 \pm 3 \%$ using pure glycerol at $805{ }^{\circ} \mathrm{C}, \mathrm{S} / \mathrm{C}=3$. There is a degree of fluctuation in the gas production due to pyrolysis oil, steam and nitrogen flows. 


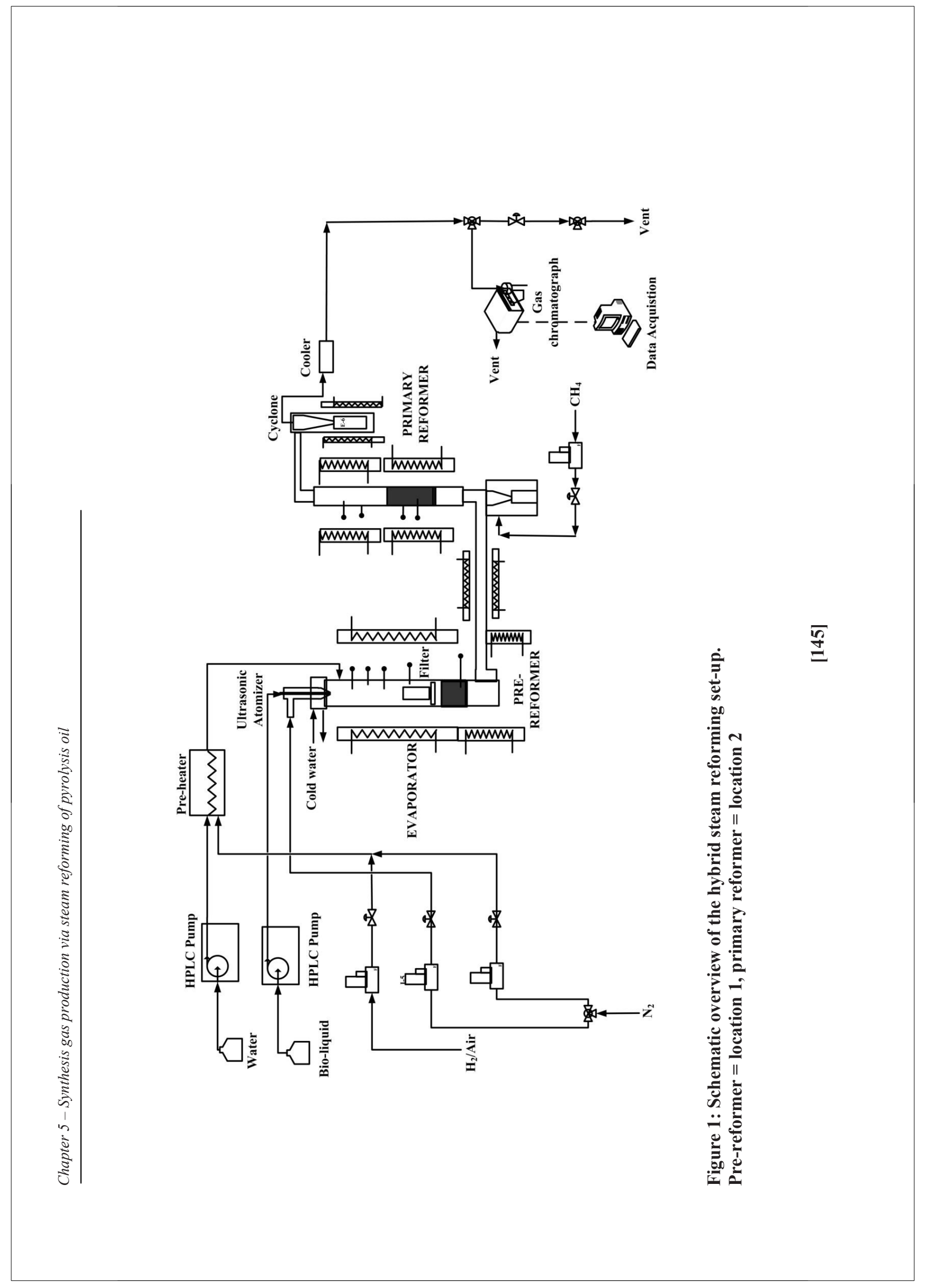




\subsection{Results and Discussion}

\subsubsection{Non catalytic results and the first 1 hour of catalytic reforming}

Table 1 summarizes the product distribution (averaged for 0.5 hour for non-catalytic and 1 hour for catalytic, both excluding the start-up profile) and carbon to gas conversion, char and coke production obtained from the non-catalytic and catalytic gasification of pyrolysis oil using $\mathrm{Ni} / \mathrm{K}-\mathrm{Mg}-\mathrm{Al}_{2} \mathrm{O}_{3}$. The non-catalytic gasification experiments were performed in the dedicated continuous gasification set-up (see Chapter 2). From the non-catalytic gasification experiments, it is observed that by increasing the temperature from 649 to $828^{\circ} \mathrm{C}$, a significant increase in the carbon to gas conversion was noticed $(37.2 \%$ to $62.3 \%)$. This significant increase is due to the thermal cracking of pyrolysis oil to gases at high temperature. From the selectivity of the gases, a significant increase in $\mathrm{CH}_{4}$ by increasing the temperature from 649 to $828^{\circ} \mathrm{C}$ can be seen. As reported in Chapters $2 \& 3$, the increase in $\mathrm{CH}_{4}$ may be via the thermal cracking of vapors (oxygenates). Summarizing: i) at low atomization/gasification temperature most of the fed pyrolysis is in the vapor phase but methane levels are low and ii) at high atomization temperature much more gases are produced including methane, but vapors are still present.

By increasing the $\mathrm{S} / \mathrm{C}$ ratio from 0.4 to 10 at constant temperature $820^{\circ} \mathrm{C}$, only a slight increase in the carbon to gas conversion from $62.3 \%$ to $68.5 \%$ was observed. Considering the error of measurement, this increase in carbon to gas conversion $\left(\mathrm{C}_{\mathrm{G}}\right)$ is not significant. The increase in $\mathrm{H}_{2}$ and $\mathrm{CO}_{2}$ cannot be explained by water-gas shift reaction because $\mathrm{CO}$ is almost constant by increasing $\mathrm{S} / \mathrm{C}$ from 0.4 to 10 . Also, $\mathrm{CH}_{4}$ is relatively constant at high temperature $\left(\sim 820^{\circ} \mathrm{C}\right)$. It is noticeable that even at high $\mathrm{S} / \mathrm{C}$, steam reforming of methane is not happening in the absence of catalyst.

Comparing the non-catalytic and catalytic results shows that the catalyst is, initially, able to reform the pyrolysis vapors to gases. This becomes particularly clear from the experiments performed at $\sim 600{ }^{\circ} \mathrm{C}$ for which the carbon to gas conversion increases from $\sim 40$ to $\sim 75-80 \%$ when applying catalysis. At a reform temperature of $800{ }^{\circ} \mathrm{C}$, the S/C seems to only effect the water gas shift reaction: a S/C of 1 and 15 have 
similar carbon to gas conversions while the $\mathrm{CO} / \mathrm{CO}_{2}$ distribution and $\mathrm{H}_{2}$ production clearly differs.

Table 1 also shows the yields according to equilibrium (values between brackets). From the comparison of these yields with the measured ones, it can be concluded that there is no fundamental problem in the chemistry / catalysis of steam reforming of pyrolysis oil as initially high carbon to gas conversions and near equilibrium yields (after correction for the $\mathrm{C}_{\mathrm{g}}$ ) of the steam reforming reaction are found for $\mathrm{S} / \mathrm{C}=1-15$ and $\mathrm{T}=600-850{ }^{\circ} \mathrm{C}$ and $\mathrm{GC}_{1} \mathrm{HSV}=350-1500 \mathrm{~h}^{-1}$.

Table 1: Results of non-catalytic gasification and catalytic reforming

\begin{tabular}{|c|c|c|c|c|c|c|c|}
\hline Process conditions & \multicolumn{3}{|c|}{ Non-catalytic gasification } & \multicolumn{3}{|c|}{ Catalytic steam reforming } & \\
\hline $\mathrm{S} / \mathrm{C}$ & 0.4 & 0.4 & 10 & 1 & 10 & 14 & 15 \\
\hline Average gasification temperature $\left({ }^{\circ} \mathrm{C}\right)$ & 649 & 828 & 820 & 600 & 614 & 627 & 616 \\
\hline Average reactor temperature $\left({ }^{\circ} \mathrm{C}\right)$ & n.a. ${ }^{1}$ & n.a. & n.a. & 800 & 596 & 591 & 788 \\
\hline $\mathrm{GC}_{1} \mathrm{HSV}\left(\mathrm{h}^{-1}\right)$ & n.a. & n.a. & n.a. & 1500 & 549 & 558 & 360 \\
\hline Residence time (s) - Gasification & $\sim 2-3$ & $\sim 2-3$ & $\sim 2-3$ & $\sim 5-6$ & $\sim 5-6$ & $\sim 5-6$ & $\sim 5-6$ \\
\hline Residence time (s) - Reforming & n.a. & n.a. & n.a. & $\sim 1$ & $\sim 0.7$ & $\sim 0.7$ & $\sim 0.7$ \\
\hline \multicolumn{8}{|c|}{ Gas production (averaged for $\sim 1$ hour after start-up, $\mathrm{Nm}^{3} / \mathrm{kg}$ dry feed) } \\
\hline $\mathrm{H}_{2}$ & 0.07 & 0.16 & 0.30 & $\begin{array}{c}1.16 \\
(1.36)\end{array}$ & $\begin{array}{c}1.2 \\
(2.07)\end{array}$ & $\begin{array}{l}1.33 \\
(2.1)\end{array}$ & $\begin{array}{c}1.65 \\
(2.04)\end{array}$ \\
\hline $\mathrm{CH}_{4}$ & 0.06 & 0.14 & 0.13 & $\begin{array}{l}0.009 \\
\left(6 \mathrm{e}^{-3}\right)\end{array}$ & $\begin{array}{c}0.08 \\
\left(2 \mathrm{e}^{-3}\right)\end{array}$ & $\begin{array}{c}0.06 \\
\left(1 \mathrm{e}^{-3}\right)\end{array}$ & $\begin{array}{c}0.012 \\
(0)\end{array}$ \\
\hline $\mathrm{CO}$ & 0.21 & 0.31 & 0.30 & $\begin{array}{c}0.64 \\
(0.77)\end{array}$ & $\begin{array}{c}0.05 \\
(0.08)\end{array}$ & $\begin{array}{c}0.04 \\
(0.06)\end{array}$ & $\begin{array}{c}0.11 \\
(0.12)\end{array}$ \\
\hline $\mathrm{CO}_{2}$ & 0.04 & 0.07 & 0.13 & $\begin{array}{c}0.23 \\
(0.22)\end{array}$ & $\begin{array}{c}0.65 \\
(0.91)\end{array}$ & $\begin{array}{c}0.71 \\
(0.94)\end{array}$ & $\begin{array}{c}0.8 \\
(0.88)\end{array}$ \\
\hline $\mathrm{C}_{2-3}$ & 0.03 & 0.05 & 0.06 & $0(0)$ & 0.002 & $\begin{array}{c}0.002 \\
(0)\end{array}$ & $0(0)$ \\
\hline $\mathrm{C}_{\mathrm{g}}(\%)$ & 39.2 & 63.1 & 68.5 & 87.3 & 75.8 & 79.6 & 89.5 \\
\hline $\mathrm{C}_{\mathrm{c}}(\%)$ [char in atomization] & 8.2 & 5.3 & 5.3 & $\sim 6$ & 4.3 & 4.0 & 4.5 \\
\hline
\end{tabular}

${ }^{1}$ n.a. not applicable

${ }^{2}$ equilibrium yields between brackets 


\subsubsection{Long duration runs}

Figure 2 shows the gas productions and carbon to gas conversion versus time on stream (excluding start-up) for two catalysts, namely (A) $\mathrm{Ni} / \mathrm{K}-\mathrm{Mg}-\mathrm{Al}_{2} \mathrm{O}_{3}$ and (B) $\mathrm{Ni} / \mathrm{Mg}-\mathrm{Al}_{2} \mathrm{O}_{3}$. The pyrolysis oil was first gasified at $\sim 600{ }^{\circ} \mathrm{C}$ en then converted over a catalytic bed (Figure 1: location 2 ) at $\sim 800{ }^{\circ} \mathrm{C}$. The catalytic bed temperature was set to a value similar to methane steam reforming since lower temperatures $\left(\sim 600{ }^{\circ} \mathrm{C}\right)$ results in excessive coking on the catalyst [13]. A low steam over carbon $(\sim 1)$ ratio and commercial comparable gas hourly space velocity of $\sim 1500 \mathrm{~h}^{-1}$ were used to evaluate the catalytic performance under harsh conditions. In the evaluation, also a regeneration step was included where possible carbon deposits were burnt off using air after which the catalyst was activated again via hydrogen reduction (not shown in Figure 2A).

When the commercial $\mathrm{Ni} / \mathrm{K}-\mathrm{Mg}-\mathrm{Al}_{2} \mathrm{O}_{3}$ catalyst was used (Figure 2A) initially, for a period of $1 \mathrm{~h}$, the amounts of $\mathrm{H}_{2}, \mathrm{CO}_{2}, \mathrm{CO}$ and carbon to gas conversion $\left(\mathrm{C}_{\mathrm{G}}\right)$ were stable with $\mathrm{H}_{2} / \mathrm{CO}$ molar ratio $\sim 2$. After approximately $1.5 \mathrm{~h}, \mathrm{CH}_{4}$ and low amount of $\mathrm{C}_{2-3}$ hydrocarbons gases were observed in the product stream. The gas production of $\mathrm{H}_{2}$ and $\mathrm{CO}$ started to decrease and $\mathrm{CH}_{4}$ reached a stable value of around $0.11 \mathrm{Nm}^{3} / \mathrm{kg}$ dry pyrolysis oil, which is similar to the one obtained via only gasification of pyrolysis oil at similar conditions $\left(\sim 0.14 \mathrm{Nm}^{3} / \mathrm{kg}\right.$ dry pyrolysis oil, see Table 1$)$. The production of $\mathrm{CO}_{2}$ was found to be stable all through the run. Despite the increase in $\mathrm{CH}_{4}$, the $\mathrm{C}_{\mathrm{G}}(\sim 80 \%)$ was higher than for gasification of pyrolysis oil which was only $\sim 65 \%$ (see Table 1) and moreover, $\mathrm{C}_{\mathrm{G}}$ is stable with time on stream. Since the catalytic methane conversion, as compared to only gasification, dropped from full conversion to $\sim 25 \%$, the $\mathrm{Ni} / \mathrm{K}-\mathrm{Mg}-\mathrm{Al}_{2} \mathrm{O}_{3}$ catalyst was regenerated using $100 \mathrm{~mL} / \mathrm{min}$ of air and again reactivated using $100 \mathrm{~mL} / \mathrm{min}$ of pure $\mathrm{H}_{2}$.

As observed from the Figure 2A, the methane reforming activity was not recovered but instead seems to be totally lost. The average $\mathrm{C}_{\mathrm{G}}$ was $78 \%$ after regeneration which is still $\sim 13 \%$ above thermal cracking of pyrolysis oil. What is important to note is that hydrogen production is still higher as compared to gasification (see Table 1) which 
indicates that the catalyst only maintains activity for the water gas shift reaction or steam gasification.

The performance of $\mathrm{Ni} / \mathrm{Mg}-\mathrm{Al}_{2} \mathrm{O}_{3}$ catalyst is presented in Figure 2B. For the first $2 \mathrm{~h}$, the gas productions and carbon to gas conversion were constant. After $2 \mathrm{~h}$, the hydrogen, carbon monoxide and subsequently carbon to gas conversion started to drop. The carbon to gas conversion $\left(\mathrm{C}_{\mathrm{G}}\right)$ for instance decreases from $86 \%$ to $65 \%$, which is being the non-catalytic $\mathrm{C}_{\mathrm{G}}$. However, unlike Ni/K-Mg- $\mathrm{Al}_{2} \mathrm{O}_{3}$ catalyst, no $\mathrm{CH}_{4}$ and $\mathrm{C}_{2-3}$ were observed for a period of $5 \mathrm{~h}$. $\mathrm{CH}_{4}$ production was stable around $0.02 \mathrm{Nm}^{3} / \mathrm{kg}$ dry pyrolysis oil, which is much lower than reforming using Ni/K-Mg$\mathrm{Al}_{2} \mathrm{O}_{3}$ catalyst. Due to activity drop, which is mainly expressed here for $\mathrm{C}_{\mathrm{G}}$, the catalyst was regenerated at $800^{\circ} \mathrm{C}$ using $100 \mathrm{~mL} / \mathrm{min}$ of air and reactivated using pure $\mathrm{H}_{2}$. Unlike the commercial Ni/K-Mg- $\mathrm{Al}_{2} \mathrm{O}_{3}$, the in house made catalyst $\mathrm{Ni} / \mathrm{Mg}-\mathrm{Al}_{2} \mathrm{O}_{3}$ regained its full methane conversion and carbon to gas conversion. However, an immediate loss in carbon conversion was now observed when pyrolysis oil conversion was started again.

To summarize above experiments, both catalysts exhibited different performance for steam reforming of pyrolysis oil. The commercial Ni/K-Mg- $\mathrm{Al}_{2} \mathrm{O}_{3}$ catalyst showed irreversible activity loss for methane reforming while maintaining better its carbon to gas conversion during $10 \mathrm{~h}$. Similar behavior, however in a fluidized bed, was reported by Van Rossum et al. [1]. The in-house made $\mathrm{Ni} / \mathrm{Mg}-\mathrm{Al}_{2} \mathrm{O}_{3}$ catalyst showed reversible activity loss for the carbon to gas conversion and methane reforming. For this catalyst methane activity remains for several hours while carbon to gas activity starts to drop faster. 


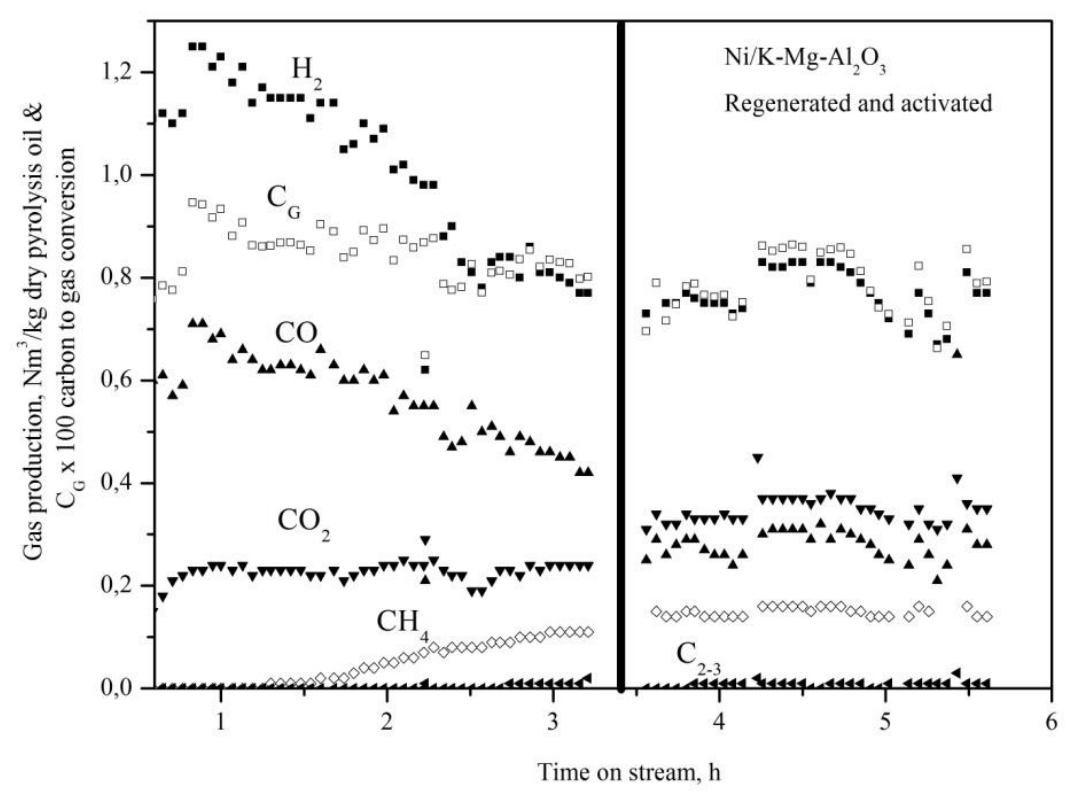

$2 \mathrm{~A}$

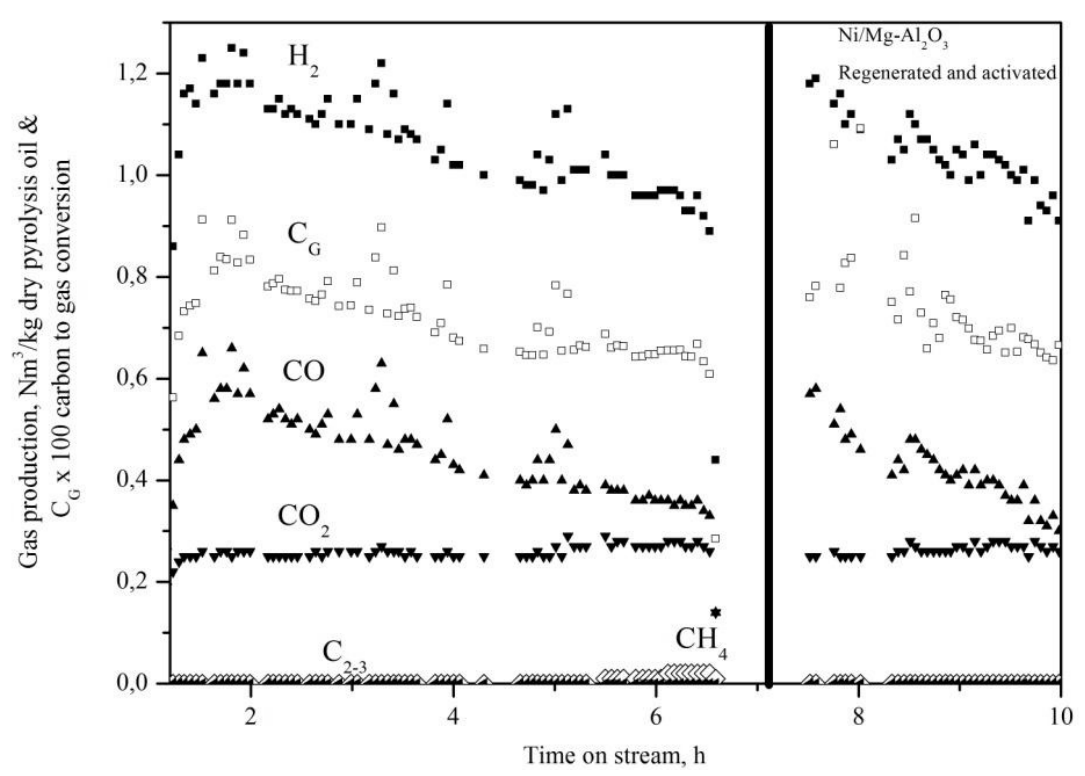

$2 \mathrm{~B}$

Figure 2: Steam reforming of pyrolysis oil: gas production and carbon to gas conversion versus time at $\mathrm{S} / \mathrm{C} \sim 1, \mathrm{~T}_{\text {gasification }} \sim 600^{\circ} \mathrm{C}, \mathrm{T}_{\text {reforming }} \sim 800^{\circ} \mathrm{C}, \mathrm{GC}_{1} \mathrm{HSV}$ $\sim 1500 \mathrm{~h}^{-1}$ using: (A) Ni/K-Mg- $\mathrm{Al}_{2} \mathrm{O}_{3}$ catalyst (B) Ni/Mg- $\mathrm{Al}_{2} \mathrm{O}_{3}$ catalysts. 


\subsubsection{The role of potassium as promoter on steam reforming catalyst}

Composition wise, the main difference between the commercial $\mathrm{Ni} / \mathrm{K}-\mathrm{Mg}-\mathrm{Al}_{2} \mathrm{O}_{3}$ and in- house $\mathrm{Ni} / \mathrm{Mg}-\mathrm{Al}_{2} \mathrm{O}_{3}$ catalysts is the usage of potassium as a promoter. The potassium is added presumably to suppress excessive coking of the catalyst via enhancing its gasification [14] which is indirectly seen in Figure 2A, where the carbon to gas conversion remained more or less constant over time. However, the conversion of methane seemed to be negatively affected by the presence of potassium. This effect of potassium addition was investigated further via glycerol steam reforming experiments. With glycerol steam reforming, a full carbon to gas conversion could be obtained when pure glycerol was being converted [7, Chapter 4]. By using glycerol as a model compound, the effect of combined gasification and steam reforming can be decoupled and methane reforming ability can be studied separately. This was done by loading different amounts of potassium on the unpromoted $\mathrm{Ni} / \mathrm{Al}_{2} \mathrm{O}_{3}$ catalyst with two different $\mathrm{K} / \mathrm{Ni}$ molar ratios of 0.04 and 0.32 (catalysts named $\mathrm{Ni} / \mathrm{K} 1-\mathrm{Al}_{2} \mathrm{O}_{3}$ and $\mathrm{Ni} / \mathrm{K} 2-\mathrm{Al}_{2} \mathrm{O}_{3}$ respectively).

Figure 3 shows the methane production obtained for $\sim 7$ hours from steam reforming of pure glycerol using $\mathrm{Ni} / \mathrm{Al}_{2} \mathrm{O}_{3}, \mathrm{Ni} / \mathrm{K} 1-\mathrm{Al}_{2} \mathrm{O}_{3}$ and $\mathrm{Ni} / \mathrm{K} 2-\mathrm{Al}_{2} \mathrm{O}_{3}$ catalysts. Table 2 summarizes the average gas productions and carbon to gas conversion values of pure glycerol steam reforming using potassium impregnated catalysts. No activity loss was observed for all the catalysts for $7 \mathrm{~h}$ and nearly complete carbon to gas conversions was obtained. Neither methane nor $\mathrm{C}_{2-3}$ gases were observed for the $\mathrm{Ni} / \mathrm{Al}_{2} \mathrm{O}_{3}$ catalyst. However, for the potassium impregnated catalysts, methane was observed, increasing with potassium loading, and $\mathrm{C}_{2-3}$ gases were observed only for the catalyst with high potassium loading. The effect which potassium can have on steam reforming was reported by Rostrup et al. [13]. The possible explanations for this phenomenon are:

Potassium present in the bulk reaches the surface via volatilization at high temperature and interacts with active Ni phase [15-17]. This interaction disturbs $\mathrm{CH}_{\mathrm{x}}$ adsorption on the active phase [17]. Due to increase in methane apparent activation energy for dissociation which slowed down methane reforming activity $[15,17]$ and $\mathrm{CO}$ and $\mathrm{C}_{\mathrm{x}} \mathrm{H}_{\mathrm{y}} \mathrm{O}_{\mathrm{z}}$ (glycerol vapors and coke) may have adsorbed on the active phase 
that resulted in more $\mathrm{CO}_{2}$ production only via coke gasification for potassium impregnated catalysts.

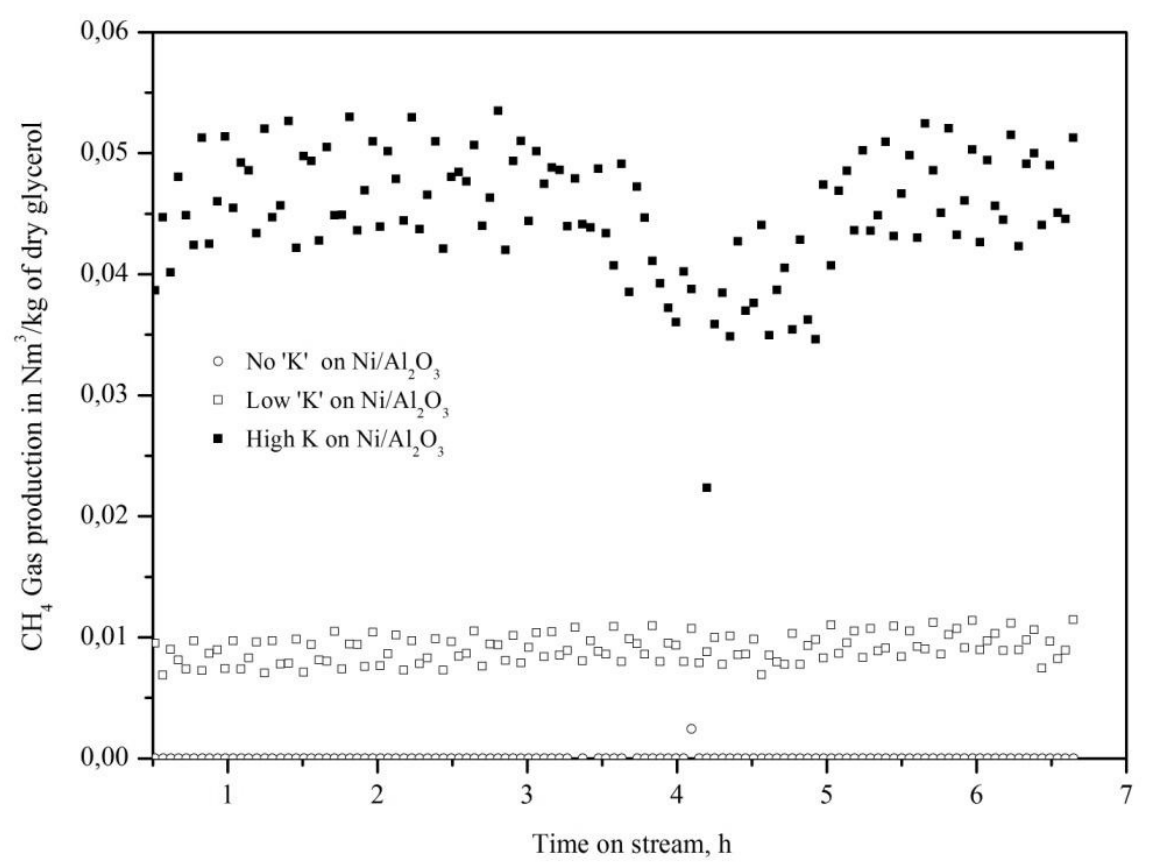

Figure 3: Steam reforming of pure glycerol at $\mathrm{T}=800^{\circ} \mathrm{C}, \mathrm{S} / \mathrm{C}=3$ using potassium impregnated on $\mathrm{Ni} / \mathrm{Al}_{2} \mathrm{O}_{3}$ catalyst. Gas production of methane is presented. 
Table 2: Performance of potassium impregnated catalysts on $\mathrm{Ni} / \mathrm{Al}_{2} \mathrm{O}_{3}$ during steam reforming of glycerol

\begin{tabular}{|c|c|c|c|}
\hline $\begin{array}{l}\text { Average Gas } \\
\text { production ( } \sim \text { hours): } \\
\text { (mol/mol glycerol) }\end{array}$ & $\mathrm{Ni} / \mathrm{Al}_{2} \mathrm{O}_{3}$ & $\mathrm{Ni} / \mathrm{K} 1-\mathrm{Al}_{2} \mathrm{O}_{3}$ & $\mathrm{Ni} / \mathrm{K} 2-\mathrm{Al}_{2} \mathrm{O}_{3}$ \\
\hline $\mathrm{H}_{2}$ & 5.03 & 4.88 & 4.40 \\
\hline $\mathrm{CH}_{4}$ & 0.00 & 0.04 & 0.18 \\
\hline $\mathrm{CO}$ & 1.44 & 1.52 & 1.23 \\
\hline $\mathrm{CO}_{2}$ & 1.44 & 1.49 & 1.49 \\
\hline $\mathrm{C}_{2-3}$ & 0.00 & 0.00 & 0.03 \\
\hline $\mathrm{C}_{\mathrm{G}}$ & $97 \%$ & $101.7 \%$ & $98.5 \%$ \\
\hline
\end{tabular}

\subsubsection{Hybrid steam reforming of methane and pyrolysis oil}

From the tested catalysts, the commercial $\mathrm{Ni} / \mathrm{K}-\mathrm{Mg}-\mathrm{Al}_{2} \mathrm{O}_{3}$ catalyst seemed to be most promising, at least for the initial pre-reforming step to be used in a hybrid configuration for combined pyrolysis oil and methane steam reforming. This is because a steady operation is needed where most of the pyrolysis oil is transferred to permanent gas. The hybrid reforming concept was successfully demonstrated for pure glycerol in Chapter 4 [7]. Figure 4 shows a typical long duration run for pyrolysis oil and methane hybrid reforming, where the gas production after the primary reformer (moles gases/carbon of combined feed) as well as after the pre-reformer (moles of gases/carbon from pyrolysis oil) are plotted versus time on stream. The horizontal dash line in Figure 4 represents the equilibrium gas productions for MSR.

Stage 1 (MSR): For the first 10 hours, MSR was performed in the primary reformer. Together with the steam, some hydrogen $\left(\mathrm{H}_{2} / \mathrm{steam}=0.1 \mathrm{~mol} / \mathrm{mol}\right)$ was added to avoid oxidation the catalyst in the primary reformer when running on methane only [18]. For the first $5 \mathrm{~h}$, gas production was close to equilibrium. Thereafter, the gas production decreased slightly and then reached a steady-state from $5^{\text {th }}$ till $10^{\text {th }}$ hour. The average unconverted methane in the product stream was found to be 0.13 mol per mol $\mathrm{C}_{1}$ over the period of $10 \mathrm{~h}$ (which means $\sim 87 \%$ conversion of methane with 
carbon recovery of $\mathrm{C}_{\mathrm{G}}$ of $\sim 101 \%=1.01$. The permanent loss in methane reforming activity is probably caused by the potassium loading as mentioned previously and was also reported by Juan-Juan et al. [19] and Graf et al. [20] on dry reforming of methane.

Stage 2 (HSR): MSR was stopped and $\mathrm{N}_{2}$ flow of $\sim 0.4 \mathrm{N1} / \mathrm{min}$ was supplied over the catalyst placed in the primary reformer. Prior to the HSR experiment, $\mathrm{H}_{2}$ flow of 0.1 $\mathrm{Nl} /$ min was supplied to the pre-reformer and the $\mathrm{N}_{2}$ flow position was altered to prereformer. When the GC measured no carbon gases, a required amount of methane and steam was supplied to the primary reformer. After few measurements, when the gas production was similar to stage 1, pyrolysis oil was injected in the gasifier by reducing the appropriate amount of methane supplied to the primary reformer. This means that the amount of the carbon supplied for both stage $1 \& 2$ are similar. A decrease in $\mathrm{H}_{2}$ and $\mathrm{CO}$ was observed while $\mathrm{CH}_{4}$ and $\mathrm{CO}_{2}$ were stable for $\sim 5$ hours. Also, there is a slight degree of fluctuation that was observed in the carbon recovery to gases. After 17 hours, methane started to increase in the product gas of the primary reformer. During this stage, $\mathrm{H}_{2}, \mathrm{CO}$ and $\mathrm{CO}_{2}$ productions dropped in the pre-reformer, while $\mathrm{CH}_{4}$ was relatively constant. The drop in effectiveness of methane conversion or methane break-through occurs in the primary reformer when the carbon to gas conversion in the bio-liquid pre-reformer decreases from $\sim 85 \%$ to $\sim 60 \%$.

Stage 3: Pyrolysis oil flow was stopped and both the catalysts were regenerated by first using $100 \mathrm{ml} / \mathrm{min}$ of air at $800{ }^{\circ} \mathrm{C}$ to burn-off coke. After reducing the catalysts using $\mathrm{H}_{2}$ at $800{ }^{\circ} \mathrm{C}$, MSR was continued from the $27^{\text {th }}$ hour after stage 2. It was observed that the MSR activity of the catalyst in the primary reformer was slowly retained and reached a new steady-state value after $40 \mathrm{~h}$ for all the gases, having a $\mathrm{CH}_{4}$ conversion of $\sim 60 \%$. The methane reforming activity of the $\mathrm{Ni} / \mathrm{K}-\mathrm{Mg}-\mathrm{Al}_{2} \mathrm{O}_{3}$ was somewhat recovered. Nevertheless, the gas production was far away from the equilibrium values. The slow regain in MSR activity during dry reforming of methane was reported by El-Bousiffi et al. [18]. Possible explanations for this may be i) slight oxidation of active Nickel due to drop in temperature from $800{ }^{\circ} \mathrm{C}$ may decrease the gas production [18] and ii) initial formation of Nickel micro-crystallites and their disappearance due to the formation of spinel phase [18] may have caused permanent 
loss. Other possible explanation for oxidation would be continuous exposure of steam over pre-reforming catalyst.

Stage 4: Similar to stage 2, HSR experiment was again performed. Approximately for 3 hours, the individual gas productions were almost constant and similar to the gas productions of stage 3 . However, the gas productions were low by comparing it with the initial high gas production and first HSR experiment. After 53 hours, methane started to break-through from the primary reformer and other gases such as $\mathrm{H}_{2}, \mathrm{CO}$ and $\mathrm{CO}_{2}$ dropped. It should be noted that the catalyst maintained its MSR activity for a short period even though the gas production in the pre-reformer decreased significantly, indicating that HSR in fixed bed for this specific catalyst at the experimental conditions studied is not viable for long term operation.

Stage 5: After the drop in the gas production, pyrolysis oil injection was stopped and $\mathrm{Ni} / \mathrm{K}-\mathrm{Mg}-\mathrm{Al}_{2} \mathrm{O}_{3}$ catalyst was regenerated using $100 \mathrm{ml} / \mathrm{min}$ of air at $800{ }^{\circ} \mathrm{C}$ to burnoff coke as $\mathrm{CO}_{2}$. MSR was continued after $62 \mathrm{~h}$ time on stream. A slow recovery in the MSR activity of the catalyst was observed during this stage and obtained $\mathrm{CH}_{4}$ conversion similar to stage 3. As shown in Figure 2A, carbon recovery to gas was still around $\sim 100 \%$. Methane was found to be $0.37 \mathrm{~mol}$ per mol $\mathrm{C}_{1}$ (overall $63 \%$ methane conversion) at the end of this stage. 


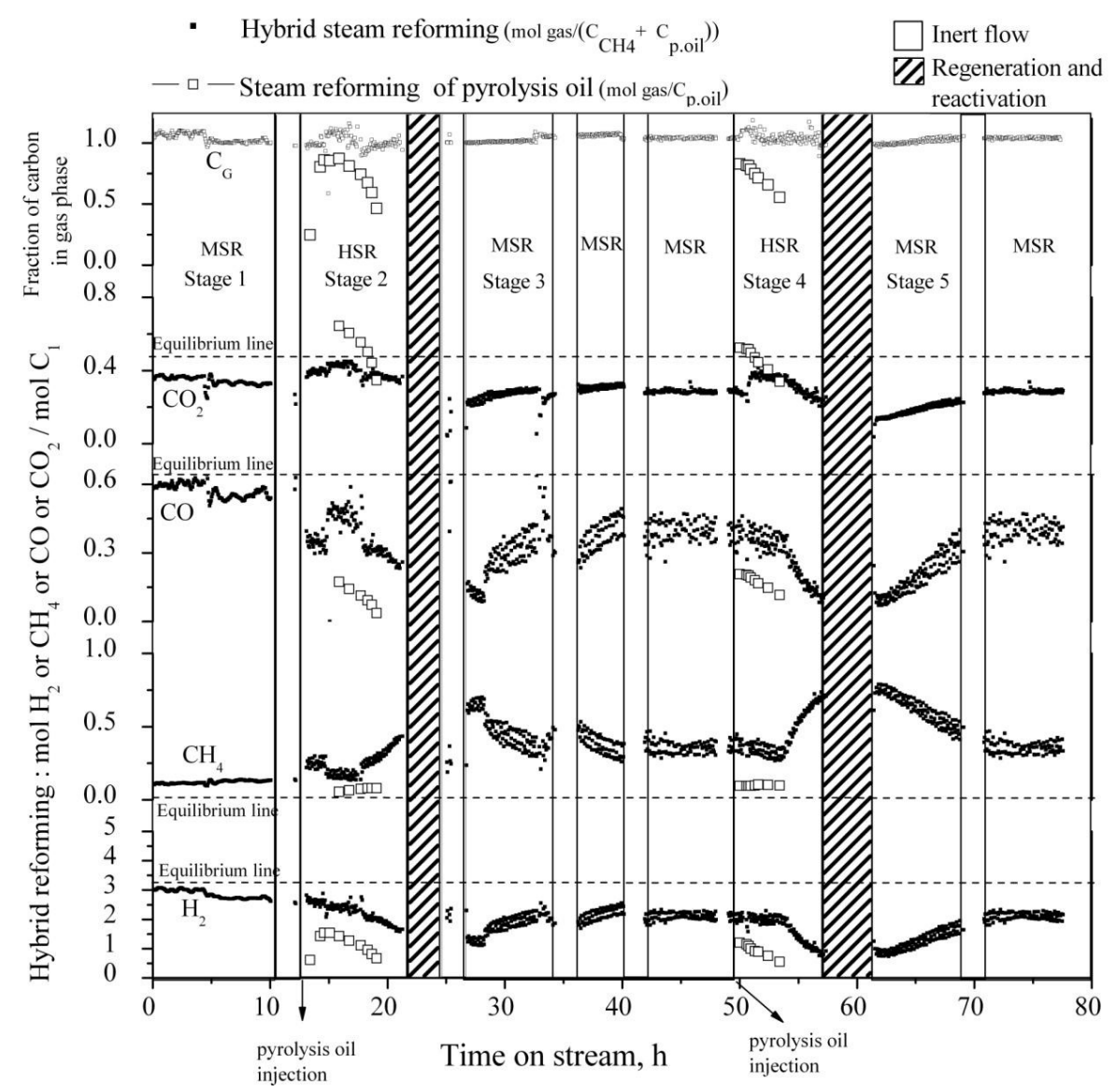

Figure 4: Performance of $\mathrm{Ni} / \mathrm{K}-\mathrm{Mg}-\mathrm{Al}_{2} \mathrm{O}_{3}$ catalyst during MSR and HSR. Horizontal dash lines represent equilibrium gas yield for MSR and HSR),

MSR - $\mathrm{T}_{\text {primary }} \sim 820{ }^{\circ} \mathrm{C}, \mathrm{S} / \mathrm{C}_{\text {primary reformer }}=2.8, \mathrm{H}_{2} / \mathrm{steam}=0.1 \mathrm{~mol} / \mathrm{mol}$ (in bioliquid reformer), $\mathrm{GC}_{1} \mathrm{HSV}=850 \mathrm{~h}^{-1}$. $\mathrm{HSR}-\mathrm{T}_{\text {gasifier }} \sim 600^{\circ} \mathrm{C}, \mathrm{S} / \mathrm{C}_{\text {bio-liquid reformer }} \sim 9$, $\mathrm{T}_{\text {bio-liquid reformer }} \sim 80{ }^{\circ} \mathrm{C}, \mathrm{GC}_{1} \mathrm{HSV}=390 \mathrm{~h}^{-1}, \mathrm{CH}_{4}$ :pyrolysis oil $=0.7: 0.3$ (carbon basis).

In the HSR concept, the critical unit operation is the bio-liquid reformer because the catalyst is in direct contact with the pyrolysis oil vapors (oxygenates). The primary reformer deals with high temperature $\left(\sim 800^{\circ} \mathrm{C}\right)$ vapors and methane. Both the catalyst beds $\left(\mathrm{Ni} / \mathrm{K}-\mathrm{Mg}-\mathrm{Al}_{2} \mathrm{O}_{3}\right)$ were burnt off using air at $800^{\circ} \mathrm{C}$ at different time-on-stream. First, the catalyst of the primary reformer was burnt by supplying air directly in to the primary reformer. $\mathrm{CO}_{2}$ was measured continuously using a micro-GC. Then, 
temperature in the primary reformer was reduced from 800 to $20{ }^{\circ} \mathrm{C}$ and air was supplied to pre-reformer. The determined coke yields are excluding coke possibly gasified by steam after stopping the pyrolysis oil feed. The result is presented in Figure 5 .

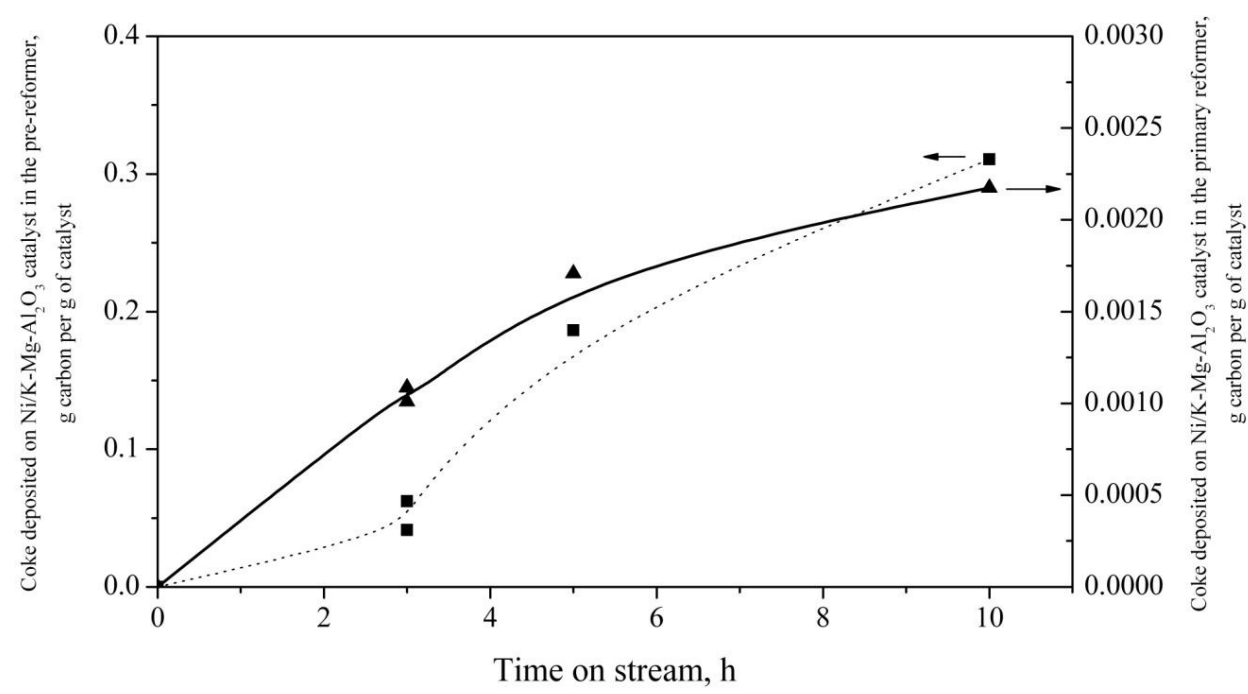

Figure 5: Coke deposition on $\mathrm{Ni} / \mathrm{K}-\mathrm{Mg}-\mathrm{Al}_{2} \mathrm{O}_{3}$ catalyst in the bio-liquid reformer (operated at $\mathrm{S} / \mathrm{C} \sim 12, \mathrm{~T}_{\text {bio-liquid reformer } \sim 750}{ }^{\circ} \mathrm{C}, \mathrm{CH}_{4}:$ pyrolysis oil $=74: 26$ on carbon weight basis, $\mathrm{G}_{\mathrm{C} 1} \mathrm{HSV} \sim 750 \mathrm{~h}^{-1}$ ) and primary reformer (operated at $\mathrm{S} / \mathrm{C}$ $\left.\sim 3, T_{\text {primary }}=785^{\circ} \mathrm{C}, \mathrm{G}_{\mathrm{Cl}} \mathrm{HSV} \sim 1150 \mathrm{~h}^{-1}\right)$. The time on stream is of the duration of hybrid steam reforming.

It is evident from Figure 5 that the $\mathrm{Ni} / \mathrm{K}-\mathrm{Mg}-\mathrm{Al}_{2} \mathrm{O}_{3}$ has more coke deposition in the bio-liquid reformer than in the primary (co-)reformer. The amount of coke deposited on the bio-liquids reforming catalyst started to increase from the beginning of the experiment. Coke deposition in this reformer became severe after a few hours; the gas production in the bio-liquid reformer started to decrease and approached towards gas production equivalent to thermal/catalytic cracking of pyrolysis oil. The results show that indeed the bio-liquids reformer acts as a "guard bed" by protecting the primary reforming catalyst because coke is much less in this latter reformer. However, the degree of protection is not enough as during co-reforming of methane and pyrolysis gases and vapors the primary reformer still shows fast deactivation of the catalyst. 


\subsection{Conclusions}

The main conclusions of this work are summarized as follows:

- Pyrolysis oil steam reforming requires high temperature $\left(\sim 800^{\circ} \mathrm{C}\right)$ to maximize the carbon conversion to gases. At low temperature $\left(\sim 600^{\circ} \mathrm{C}\right)$, the catalysts are exposed to vapors (oxygenates) produced from the pyrolysis oil and as a result more vapors have to be dealt in the down-streaming primary reforming process.

- The potassium promoted $\mathrm{Ni} / \mathrm{Al}_{2} \mathrm{O}_{3}$ catalyst show an irreversible decrease in methane reforming activity during pyrolysis oil reforming while magnesium $(\mathrm{Mg})$ promoted $\mathrm{Ni} / \mathrm{Al}_{2} \mathrm{O}_{3}$ catalysts presented reversible decrease in methane reforming activity.

- After the coke removal step, carbon conversion to gas conversion remained constant for the potassium promoted catalyst whereas for $\mathrm{Mg}$ promoted $\mathrm{Ni} / \mathrm{Al}_{2} \mathrm{O}_{3}$ catalyst, carbon to gas conversion dropped much faster than the initial period of the experiment. The stable carbon to gas conversion for potassium promoted $\mathrm{Ni} / \mathrm{Al}_{2} \mathrm{O}_{3}$ catalyst indicated that potassium enhanced coke gasification.

- The addition of potassium to $\mathrm{Ni} / \mathrm{Al}_{2} \mathrm{O}_{3}$ catalyst deteriorated the methane reforming activity because of potassium interaction with surface Nickel.

- From hybrid steam reforming of pyrolysis oil and methane, it is concluded that fixed bed reforming is not suitable for the bio-liquids which have high coking tendencies especially in the case of pyrolysis oil. To utilize such bio-liquids in the existing reformers, a frequent regeneration step is required. 


\section{References}

1. G. van Rossum, S.R.A. Kersten, W.P.M. van Swaaij, Ind. Engg. Chem. Res. 46 (2007) 3959-3967

2. S. Czernik, R. French, C. Feik, E. Chornet, Ind. Eng. Chem. Res. 41 (2002) 4209-4215

3. D.C.Elliott, Energy \& Fuels 21 (2007) 1792-1815

4. T.Davidian, N. Guilhaume, E. Iojoiu, H.Provendier, C.Mirodatos, Applied catalysis B: Environmental 73 (2007) 116-127

5. C. Rioche, S. Kulkarni, F.C. Meunier, J.P.Breen, R.Burch, Applied catalysis B : Environmental 61 (2005) 130-139

6. S.Adhikari, S.; Fernando, S.D.; Filip To, S.D.; Bricka, R.M.; Steele, P.H.; Haryanto, A; Energy \& Fuels 22 (2008) 1220-1226

7. R.P.B.Ramachandran, G. van Rossum, W.P.M van Swaaij, S.R.A.Kersten, Energy \& Fuels 25 (2011), 5755-5766

8. G. van Rossum, B. Matas Güell, R.P.B.Ramachandran, K.Seshan, L.Lefferts, W.P.M van Swaaij, S.R.A.Kersten, AIChe journal 56 (2010), 2200-2210

9. R.P.B.Ramachandran, G. van Rossum, W.P.M van Swaaij, S.R.A.Kersten, Environmental progress \& Sustainable energy 28 (2009), 410-417

10. A.Oasmaa, D.Meier, Journal of Analytical and applied pyrolysis 73 (2005) 323-334

11. F de Miguel Mercader, M.J. Groeneveld, S.R.A. Kersten, N.W.J. Way, C.J. Schaverien, J.A. Hogendoorn, Applied Catalysis B: Environmental 96 (2010) $57-66$

12. J.A.Medrano, M.Oliva, J.Ruiz, L.Garcia, J.Arauzo, Journal of analytical and applied pyrolysis 85 (2009), 214-225

13. G. van Rossum, S.R.A.Kersten W.P.M van Swaaij, Ind. Eng. Chem. Res 46 (2007), 3959-3967

14. J.R.Rostrup-Nielsen, J.Sehested, Adv. Catal 47 (2002), 65-139

15. J.R.Rostrup-Nielsen, Journal of Catalysis 33 (1974), 184-201

16. J.R.Rostrup-Nielsen, Catalysis today 63 (2000), 159-164

17. J.R.Rostrup-Nielsen, J.Sehested, J.K. Nørskov, Advances in Catalysis 47 (2002) 65-139 
18. J. Juan-Juan, M.C. Román-Martínez, M.J. Illán-Gómez. Applied Catalysis A: General 301 (2006) 9-15.

19. P.O. Graf, B.L. Mojet, L.Lefferts, Applied catalysis A:General 346 (2008), 9095

20. M.A. El-Bousiffi, D.J.Gunn, International Journal of Heat and Mass transfer 50 (2007), 723-733 


\section{Chapter 6}

Techno-economic assessment of nethanol production via hybrid stearn reforming of bio-liquids with

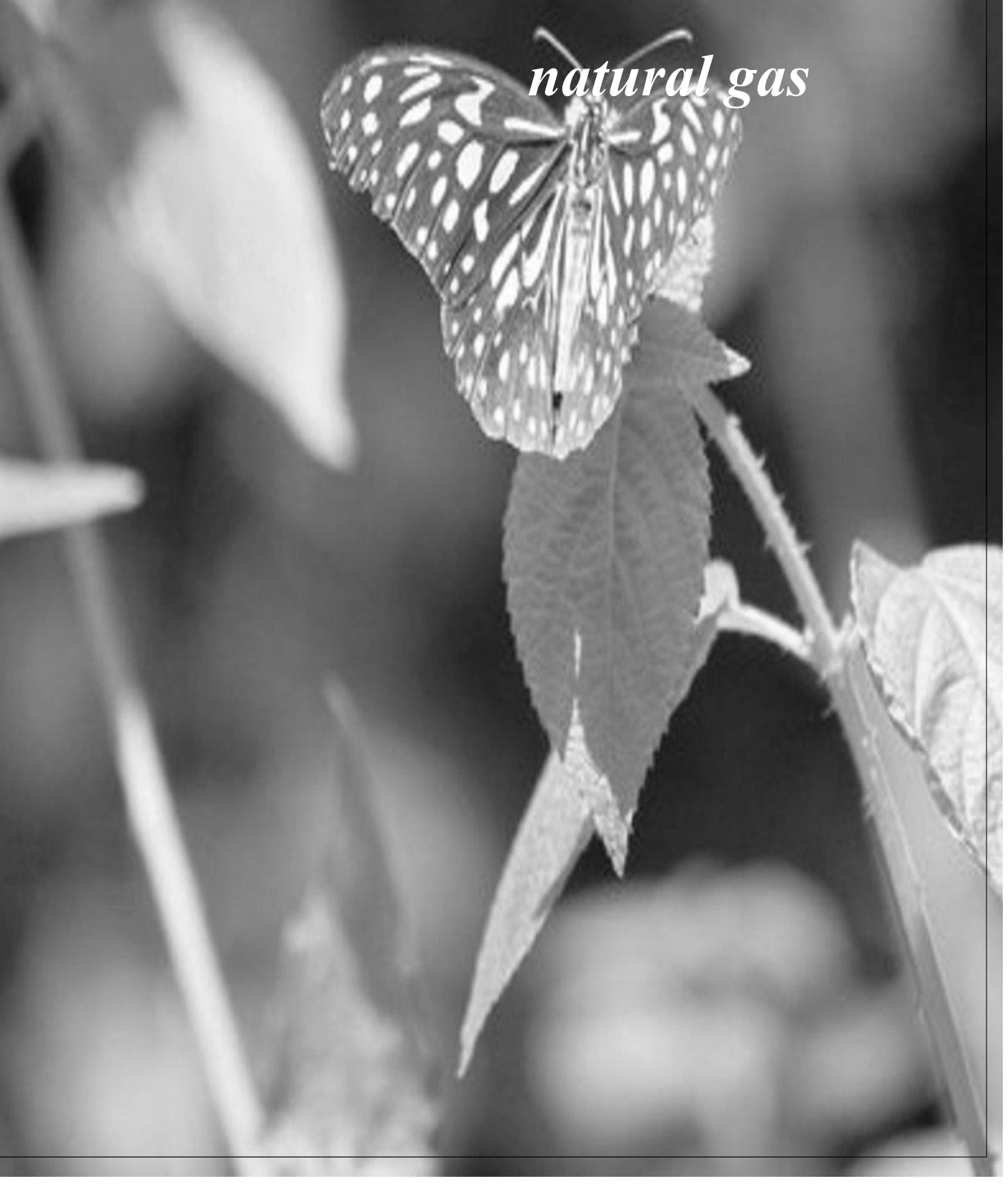




\section{Abstract}

This Chapter deals with the techno-economic assessment of the hybrid steam reforming (HSR) process of glycerol (obtained via transesterification) together with natural gas to produce bio-methanol via the synthesis gas route. In this technoeconomic assessment, a model is developed in the UniSim ${ }^{\circledR}$ Design Suite process simulator using different glycerol amounts up to $\sim 54 \%$ (on carbon basis) together with natural gas to produce synthesis gas at reforming conditions of $900{ }^{\circ} \mathrm{C}, \mathrm{S} / \mathrm{C} \sim 3$. The techno-economic analysis shows that at the current market scenario (2012) with a natural gas price of $0.2 € / \mathrm{Nm}^{3}$ and with an assumed glycerol price of $200 €$ /tonne, the average cost of (bio)methanol is estimated as $\sim 432 € /$ tonne for a feed of $\sim 54 \mathrm{wt} \%$ of glycerol (on carbon basis) with natural gas, which is $\sim 75 € /$ tonne higher than for the methanol obtained via only natural gas steam reforming. It is concluded that (bio)methanol from a hybrid steam reforming process becomes more attractive when the natural gas price exceeds $0.45 € / \mathrm{Nm}^{3}$ or when glycerol is available at lesser than $90 € /$ tonne. Splitting the production capacity in methanol and bio-methanol according to the feed composition would result in a price of $358 € /$ tonne and 470 - $500 € /$ tonne of methanol and bio-methanol respectively depending on the amount of glycerol in the feed. This means that currently bio-methanol is not competitive with methanol unless special arrangements are made (regulations, subsidies) to promote the use of biomethanol. For example, the EC Renewable Energy Directive [1] states that the energy content of biofuels from wastes and residues (for instance crude glycerol) counts double.

From the sensitivity analysis, it is concluded that feedstock prices and total capital investment have major influence on the final product value of bio-methanol. Furthermore, it is concluded that at the current price scenario, utilizing glycerol either in the furnace or in reformer has no effect on the cost price. However, burning is not an option since the bio-methanol will not contain the required C14 isotopes 


\subsection{Introduction}

Methanol is considered to be one of the highly versatile chemicals, which is used as a starting raw material to synthesize several chemicals such as formaldehyde, gasoline, di-methyl ether, acetic acid, olefins, methyl tertiary butyl ether etc. Apart from being used for the production of chemicals, methanol is also used as solvent, anti-freeze, denaturing agent, energy carrier etc. The global production of methanol exceeded 40 million tons in 2010 and the demand is increasing every year because of its various applications [2]. The primary raw materials for methanol synthesis are fossil reserves such as coal, natural gas, naphtha, petroleum residue, light oil etc [3]. Despite some reduction in the crude oil prices in the recent months/years, global energy costs remain high when compared to the average price over the last 10 years. Figure 1 shows the price development of methanol (Free on board Rotterdam port, The Netherlands) in $€ /$ tonne and crude oil $€ /$ barrel since the first quarter of 2010 till the first quarter of 2012 [4]. Also, as shown in Figure 1, the methanol price is related to the crude oil price and in the current situation any increase in feedstock price will have an impact on the methanol price.

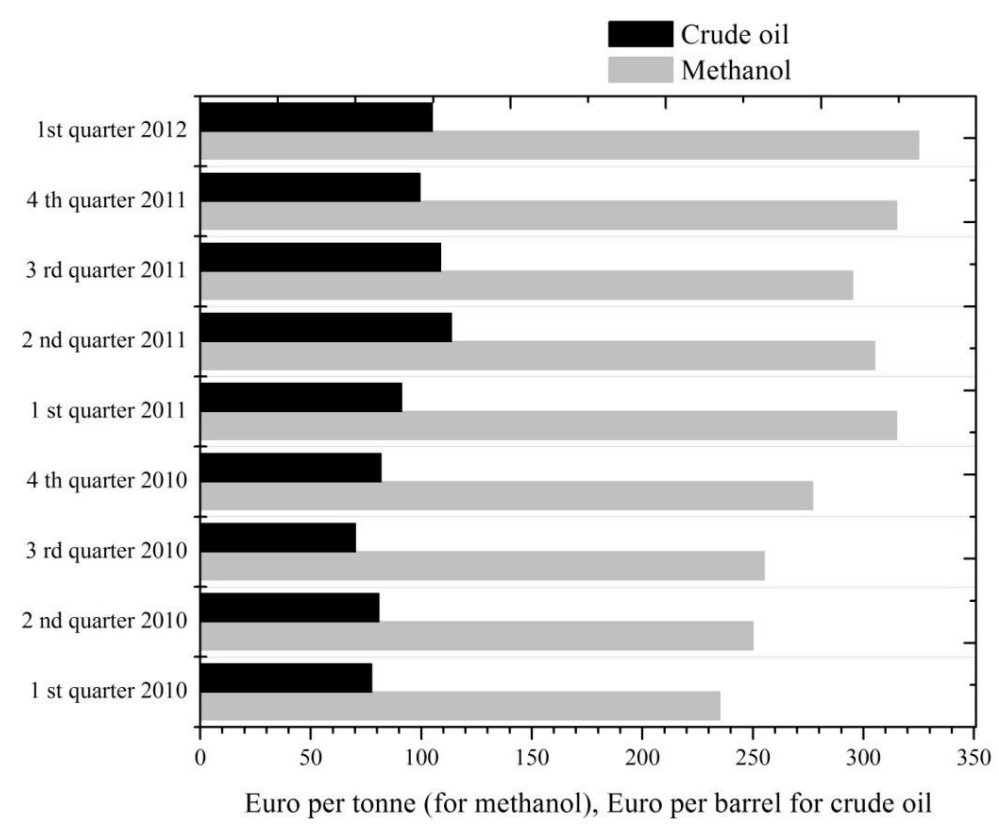

Figure 1: Methanol and crude oil price trend since the first quarter of 2010 [4]. 
In 2011, EU's renewable energy directive has set targets to utilize at least $10 \%$ of biobased feed stocks by 2020 especially in the transport sector which is already a few million barrels per day [5]. This implies that to produce methanol (as a gasoline additive) in the future, an appropriate technology has to be chosen to efficiently exploit the existing infrastructure and to search for alternative feed stocks. Almost all commercial methanol production processes such as (1) steam methane reforming (SMR); (2) two-step reforming with SMR and auto-thermal reforming (ATR) and (3) stand-alone ATR are based on a synthesis gas $\left(\mathrm{CO}+\mathrm{H}_{2}\right)$ production route [6]. The aforementioned process routes are selected based on the total capital cost investment, availability of specific feedstock locally and plant efficiency [3, 6, and 7]. SMR has been used for decades to convert different hydrocarbon feeds to synthesis gas at $900^{\circ} \mathrm{C}, 20-30$ bar with steam supplied in a molar (Steam/Carbon) feed ratio of $\sim 1-2$ using a Nickel on alumina catalyst [8]. The synthesis gas is further converted to methanol at $250-300^{\circ} \mathrm{C}$ and $75-80$ bar using a $\mathrm{Cu} / \mathrm{ZnO}$ catalyst [6]. These two processes are very mature and the technology is well known for decades.

The stand-alone tubular steam reformer is a predominant choice for methanol plants up to 3000 metric tons per day (MTPD) [3]. It is necessary to get a stoichiometric value $\mathrm{S}=\left(\left[\mathrm{H}_{2}\right]-\left[\mathrm{CO}_{2}\right]\right) /\left([\mathrm{CO}]+\left[\mathrm{CO}_{2}\right]\right)=2$ in the synthesis gas [6]. This value is optimal for the methanol synthesis, which is $2 \mathrm{H}_{2}+\mathrm{CO} \Leftrightarrow \mathrm{CH}_{3} \mathrm{OH}$ at the appropriate conditions $\left(\mathrm{T}=250-275^{\circ} \mathrm{C}, \mathrm{P}=70-80\right.$ bar). To make this ratio 2 , the process conditions such as temperature are adjusted [6]. In the case of an $\mathrm{H}_{2}$-rich stream, the ratio can be adjusted either by purging from the recycle stream or by adding a required amount of $\mathrm{CO}_{2}$ [5]. It is also well known that ATR becomes more attractive for plant capacities above 5000 MTPD of methanol [3].

Over the last two decades, research in renewable energy focuses on replacing fossil reserves by an alternative feedstock for synthesis gas and hydrogen production $[8,9]$. Considering the fact that the synthesis gas can be generated from any carbon-based feedstock, ligno-cellulosic biomass and other waste biomass streams such as glycerol may provide an excellent platform as they are the main carbon based renewable source. However, the biomass from agriculture and forestry are resources with variable composition, wide geographical distribution and low energy density [11]. 
Especially, considering biomass, it is very important to take into account its availability for large-scale production (few hundred/thousand tons per day), which may decide the selection of either ATR or SMR.

Considering the availability of biomass, it has a potential to replace a part of the fossil feed like natural gas for methanol production via steam reforming $(<3000$ MTPD methanol). In our earlier articles and in Chapter 4, this concept is proposed as "hybrid steam reforming (HSR)" $[12,13]$. For large-scale utilization of biomass, fast pyrolysis is proposed because it produces a bio-oil, which can be transported over long distances, pressurized and possibly utilized in a reformer, cracker or furnace. Crude glycerol, another bio-liquid obtained as a by-product from the transesterification process for bio-diesel, is also an interesting source to be utilized in a steam reformer. This is currently demonstrated on an industrial scale by BioMCN [14].

The aim of the present study is to design and evaluate a process, which utilizes pure glycerol in a large-scale steam reformer to produce methanol via the synthesis gas route. Glycerol is selected instead of pyrolysis oil because the reforming on laboratory scale of pure and well refined glycerol technically works [12]. Following the description of the HSR concept, a brief summary on process conditions (T, Steam over carbon ratio $(\mathrm{S} / \mathrm{C})$ etc.), utilities and feedstocks required for HSR is given. The HSR process is designed according to a systematic procedure [15] and simulated in the commercial flowsheeter UniSim ${ }^{\circledR}$ Design. The operation window for the HSR process is based on the stoichiometric ratio (S) necessary for the methanol synthesis with the option of only $\mathrm{CO}_{2}$ addition to make $\mathrm{S}=2$. Based on this window of operation, mass and energy balances for different amounts of glycerol in the HSR concept and a techno-economic evaluation (TEE) were performed. From the TEE, the cost price of (bio)methanol produced via the HSR process was estimated. A sensitivity analysis is performed to study the impact of several parameters such as feed stock prices (natural gas, glycerol), capital cost, utilities and labor cost on the (bio)methanol cost price. Also the option of feeding the glycerol to the furnace is investigated and compared to the glycerol reform option. 


\subsection{Conceptual design}

There are several options to utilize bio-liquids in a natural gas steam reformer to produce synthesis gas. As a first option, synthesis gas can be produced separately from natural gas $\left(\mathrm{S} / \mathrm{C}=1,900{ }^{\circ} \mathrm{C}\right)$ and bio-liquids $\left(\mathrm{S} / \mathrm{C}=1-3,>800{ }^{\circ} \mathrm{C}\right)$. Bio-liquids need a higher $\mathrm{S} / \mathrm{C}$ ratio compared to natural gas to suppress coke deposition. Then the synthesis gas can be mixed before (bio)methanol synthesis. This means "stand-alone" steam reforming of bio-liquids. As shown in Chapter 5, the "stand-alone" bio-liquids steam reforming requires a frequent regeneration step.

In the Hybrid Steam Reforming (HSR) option we propose, the bio-liquid is evaporated and reformed to gases $\left(\mathrm{CH}_{4}\right.$, etc) in the bio-liquids reformer. The gas produced from the bio-liquids reformer is mixed with methane and reformed in the primary reformer. This means two reformers are needed. The proof of concept of HSR was shown for pure and well-refined glycerol [12, 13, Chapter 4 \& 5]. Results also show that pyrolysis oil and crude glycerol require frequent catalyst regeneration. Figure 2 summarizes the HSR concept. It can be divided into three steps: (1) decentralized multiple fast pyrolysis units and/or transesterification processes, (2) HSR of methane and bio-liquids at a central steam reforming unit (including the refining of the bio-liquid if necessary), (3) (bio)methanol synthesis from syngas.

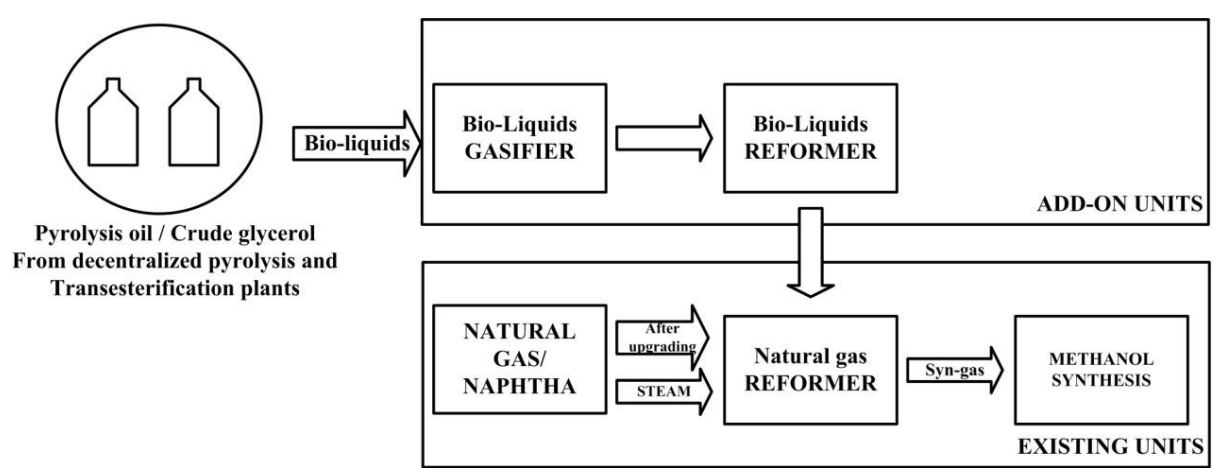

Figure 2: Schematic representation of the HSR concept. 


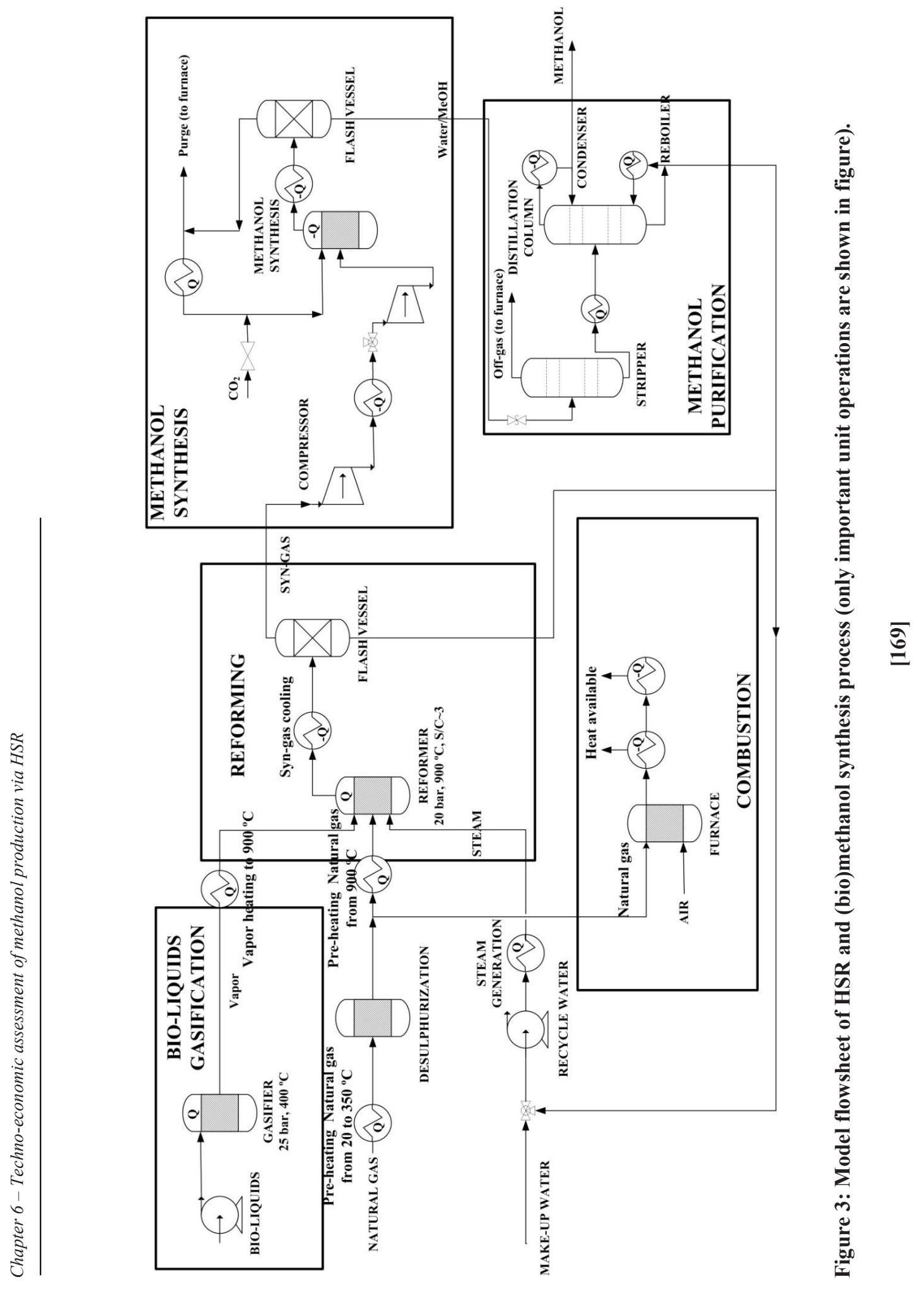




\subsection{Model description and assumptions}

Based on the concept development, for the HSR design case, the capacity of the (bio)methanol plant is fixed at 1370 tons a day ( 450 kton per year) which is the proposed (bio)methanol production from glycerol and natural gas by BioMCN, The Netherlands [14]. Using the principles of conceptual design, an index flow sheet of the (bio)methanol synthesis via hybrid steam reforming is designed and shown in Figure 3. This process is simulated in the process flowsheeter UniSim ${ }^{\circledR}$ Design. It is assumed in the HSR model that the bio-liquids are available at the central reforming unit. Methanol synthesis via natural gas steam reforming is selected as the base case, to compare with the HSR concept.

Model set-up: The HSR model was built using the following base components: $\mathrm{CH}_{4}$, $\mathrm{N}_{2}$, Air, pure glycerol, $\mathrm{CO}, \mathrm{CO}_{2}, \mathrm{H}_{2}, \mathrm{H}_{2} \mathrm{O}$ and $\mathrm{CH}_{3} \mathrm{OH}$. It is assumed that the results for pure glycerol are representative for pyrolysis oil and other bio-liquids when the reforming technology of these liquids is more developed. The Peng-Robinson equation of state was selected as fluid package to describe thermodynamic properties. The feedstock's composition, main unit operations and global reaction set are described in the following section.

Feed stocks: The HSR concept consists of three feed streams: (1) natural gas, (2) bioliquids (in this case pure glycerol) and (3) water. These feed streams are converted into synthesis gas and later into (bio)methanol. In the model, it is assumed that natural gas consists of $99 \% \mathrm{CH}_{4}$ and $1 \% \mathrm{~N}_{2}$. The pure properties of glycerol $\left(\mathrm{C}_{3} \mathrm{H}_{8} \mathrm{O}_{3}\right)$ were well defined in the pure component database in the UniSim ${ }^{\circledR}$ Design Suite.

Evaporation: The first step in the HSR model is the evaporation of bio-liquids. The process conditions used are: $\mathrm{T}=400{ }^{\circ} \mathrm{C}, \mathrm{P}=25$ bar. The temperature was set well above the boiling point of glycerol $\left(\sim 290^{\circ} \mathrm{C}\right)$. For the sake of simplicity, it is assumed in the model that all the carbon supplied in bio-feed is converted to the vapor phase. Therefore, it is assumed that the phase change from liquid to vapor occurs without any chemical reaction, i.e. it is modeled as an evaporator. 
Reforming: In the model, glycerol vapor is directly fed to the natural gas primary reformer as shown in Figure 3. Equilibrium is assumed for the glycerol reaction with steam at a fixed temperature. As shown in Figure 3, natural gas, glycerol vapor and steam are fed directly to the fixed bed reformer which is operated at $900{ }^{\circ} \mathrm{C}, 20 \mathrm{bar}$ and $\mathrm{S} / \mathrm{C}=2.8$ and is modeled as a Gibbs reactor. An S/C of 2.8 is above the value for methane but because bio-liquids are expected to give more coke a high $\mathrm{S} / \mathrm{C}$ has been selected.

In the reformer $\mathrm{CH}_{4}$ and glycerol vapor together with steam are converted to $\mathrm{H}_{2}, \mathrm{CO}$ and $\mathrm{CO}_{2}$. It is assumed in the HSR model that steam necessary for the reaction is supplied directly to the reformer. Components such as $\mathrm{NH}_{3}, \mathrm{COS}, \mathrm{H}_{2} \mathrm{~S}$ are not considered in the HSR model. The produced synthesis gas is cooled to $40{ }^{\circ} \mathrm{C}$ and fed to a flash column to remove the excess water, which is recycled to the steam generator. The water-free reformer product gas is compressed to $80 \mathrm{bar}$.

(Bio)methanol synthesis: The compressed synthesis gas produced from the reformer is fed to the (bio-)methanol synthesis reactor which is operated at $250{ }^{\circ} \mathrm{C}, 80$ bar $[3,6]$ and modeled as a Gibbs reactor. A known amount of $\mathrm{CO}_{2}$ was supplied to the synthesis gas mixture to adjust the stoichiometric ratio (S) to 2 in the feed of the methanol reactor. $\mathrm{CO}_{2}$ removal from the synthesis gas mixture is not considered as an option in the model. For evaluation of the (bio)methanol product price, the $\mathrm{CO}_{2}$ cost is not taken into account because the capture cost of $\mathrm{CO}_{2}$ depends on various factors such as plant size, absorbent etc. and it is assumed that $\mathrm{CO}_{2}$ is available within the plant.

The following reactions occur in the methanol synthesis:

$$
\begin{array}{ll}
2 \mathrm{H}_{2}+\mathrm{CO} \Leftrightarrow \mathrm{CH}_{3} \mathrm{OH} & (-90.8 \mathrm{~kJ} / \mathrm{mol}) \\
3 \mathrm{H}_{2}+\mathrm{CO}_{2} \Leftrightarrow \mathrm{CH}_{3} \mathrm{OH} & (-49.2 \mathrm{~kJ} / \mathrm{mol}) \\
\mathrm{CO}+\mathrm{H}_{2} \mathrm{O} \Leftrightarrow \mathrm{CO}_{2}+\mathrm{H}_{2} & (-41.1 \mathrm{~kJ} / \mathrm{mol})
\end{array}
$$

The crude (bio)methanol obtained from the methanol synthesis is cooled and separated in to two streams in a flash column. The (bio)methanol rich bottom product is distilled to obtain $\sim 99 \%$ pure (bio)methanol, whereas the major part of the top 
(bio)methanol lean vapor stream is recycled back to the methanol synthesis step. A small fraction of the recycle stream $(5 \%)$ is fed to the furnace and used for heat generation. Besides the main feed streams, there is also a stream of natural gas, which is mixed with air and combusted in the furnace. The energy generated from the furnace supplies heat to the evaporator, primary reforming and steam generation section. The total natural gas consumption is a sum of natural gas supplied to the reformer and the furnace. In this study, based on all the assumptions mentioned before, the HSR model was simulated using different amounts of glycerol (on carbon basis) at fixed process conditions. A detailed equipment cost evaluation is given in Table 4 and explained at the end of this Chapter (Appendix 1).

\subsection{Methodology for the techno-economic assessment}

From the mass and energy balances, the techno-economic analysis of the HSR process using different amounts of glycerol was accomplished. Based on mass and energy balances, the total bare equipment cost was estimated. Based on the total equipment cost, the capital cost investment was calculated. The average (bio)methanol cost price was estimated based on a fixed natural gas and glycerol price. This value was compared with the methanol cost price for a conventional process via steam reforming of natural gas (base case). Furthermore, a sensitivity analysis was performed to study the effect of different parameters such as feed stock prices (natural gas, glycerol), utilities cost (mainly electricity), total capital investment, labor cost etc. on the (bio)methanol cost price. Also the option of feeding the glycerol to the furnace is investigated and compared to the glycerol reform option. 


\subsubsection{Net Present Value (NPV) analysis}

Based on the fixed capital investment cost and the cash flow at each successive year, the NPV of the project is calculated. The two widely used measures for evaluating an investment are based on calculating NPV and the internal rate of return (IRR). The NPV is calculated using this formula

Present value $=\frac{\text { Income amount }}{(1+\text { IRR })^{\mathrm{n}}}$

Where, $n$ is the corresponding year.

$\mathrm{NPV} \quad=\quad I_{0}+\frac{\mathrm{CF}_{1}}{(1+\mathrm{IRR})}+\frac{\mathrm{CF}_{2}}{(1+\mathrm{IRR})^{2}}+\ldots .+\frac{\mathrm{CF}_{\mathrm{n}}}{(1+\mathrm{IRR})^{\mathrm{n}}}$

where, CF's is the constant Cash Flow after tax for each year. $\mathrm{I}_{0}$ represents the capital investment at the start of the project. In this case the internal rate of return (IRR) is chosen and assumed to be constant in the future i.e. till $n$ years. For the NPV calculation, the pay- back period is assumed to be 10 years with an IRR of $15 \%$. The rate between 10 and $15 \%$ is generally assumed for refinery operations [16]. The biomethanol cost price is calculated for the situation that NPV $=0$ at $n=10$ and $I R R=15 \%$ which are reasonable values to evaluate a business case.

\subsubsection{Methodology}

1. Design major equipment based on mass and energy balances. The level of detail is related to the evaluation accuracy. The result will be an equipment list with the values of the important cost drivers.

2. The bare equipment cost is estimated based on the major unit dimensions (for e.g. heat transfer area, flow rate etc), process conditions (pressure, temperature) and material selection.

3. The total capital investment is obtained from the total bare equipment cost using a factor estimation method

4. The raw material and utilities cost are calculated based on mass and energy balances 
5. Maintenance cost is assumed to be $5 \%$ of the total capital investment [17].

6. Labor cost is estimated based on 25 employees at an average salary of 100,000 $€$ p.a. However, in the sensitivity analysis, this parameter is varied to study the effect on bio-methanol product value.

7. Other costs such as insurance and miscellaneous costs are assumed to be $2 \%$ of the total capital investment [17].

8. License fees, royalty payments and research costs are assumed to be $2 \%$ of the total capital investment [17].

9. The calculated cost price of the bio-methanol is based on a constant cash flow after Tax necessary to obtain a NPV $=0$ after 10 years assuming an IRR of $15 \%$.

Cash flow

$=\quad$ Sales $-($ Raw materials + Utilities +

Depreciation Maintenance + Labor + Others)

Taxable income (Profit)

$=\quad 10 \%$ of total capital investment

Tax

$=\quad$ Cash flow - Depreciation

Profit after tax

$=\quad \%$ Taxation $\mathrm{x}$ Taxable income (Profit)

Cash flow after tax

$=\quad$ Taxable income - Tax

$=\quad$ Profit after tax + Depreciation

The cash flow after tax (assumed constant for each year during a 10 years period) can be calculated for a given $I_{0}$ and $\mathrm{NPV}=0$. Based on this cash flow, the average cost price of the (bio)methanol is calculated. Average here means the price based on the total production including natural gas and glycerol as feed. The raw material and utilities cost price are summarized in Table 1. 
Chapter 6-Techno-economic analysis of methanol production via HSR

Table 1: Summary of raw materials and utilities cost price

\begin{tabular}{|c|c|}
\hline Raw materials/Utilities cost & Value \\
\hline Natural gas & $0.2 € / \mathrm{m}^{3}[18]$ \\
\hline Glycerol (initial assumption) & $200 € /$ tonne \\
\hline Steam reforming \& Methanol synthesis catalyst & $10 € / \mathrm{kg}$ each (assumption) \\
\hline $\begin{array}{l}\text { Process water (distilled) } \\
(2.25-4 \$ / 1000 \text { gallon - 1990) } \\
\left(0.79-1.4 € / \mathrm{Nm}^{3}-2010\right)\end{array}$ & $1 € /$ tonne $[17]$ \\
\hline $\begin{array}{l}\text { Cooling water (tower) } \\
(0.06-0.26 \$ / 1000 \text { gallon - 1990) } \\
\left(0.02-0.09 € / \mathrm{Nm}^{3}-2010\right)\end{array}$ & $0.1 € /$ tonne $[17]$ \\
\hline Electricity & $100 € / \mathrm{MWh}[18]$ \\
\hline $\begin{array}{l}\text { Compressed air } \\
\left(0.06-0.20 \$ / 1000 \mathrm{ft}^{3}-1990\right) \\
\left(0.003-0.009 € / \mathrm{Nm}^{3}-2010\right)\end{array}$ & $0.0066 € / \mathrm{Nm}^{3}[17]$ \\
\hline
\end{tabular}




\subsection{Results and discussions}

This section summarizes the results of the mass and energy balance calculations of the different process configurations modeled in the UniSim ${ }^{\circledR}$ Design process simulator. The results are presented in Table 2 and 3 respectively.

Table 2: Mass balance for various HSR process cases

\begin{tabular}{|c|c|c|c|c|c|c|}
\hline Mass Balance & $\begin{array}{l}\text { Case } 1 \\
\text { (Base) }\end{array}$ & Case 2 & Case 3 & Case 4 & Case 5 & Case 6 \\
\hline \multicolumn{7}{|l|}{ Reformer input (kg/h) } \\
\hline Glycerol & 0 & 14276 & 20317 & 26905 & 32203 & 40143 \\
\hline \multicolumn{7}{|l|}{ Natural gas $\left(99 \% \mathrm{CH}_{4}, 1 \% \mathrm{~N}_{2}\right)$} \\
\hline To reformer & 27901 & 22552 & 20317 & 17937 & 16102 & 13381 \\
\hline To furnace & 5628 & 5613 & 5527 & 5389 & 5257 & 5010 \\
\hline Total Natural gas supplied & 33529 & 28165 & 25844 & 23326 & 21359 & 18391 \\
\hline Process water & 22031 & 19992 & 19069 & 18142 & 17555 & 17196 \\
\hline \multicolumn{7}{|l|}{ Reformer output without steam (kmol/h) } \\
\hline $\mathrm{H}_{2}$ & 5078 & 4983 & 4940 & 4898 & 4875 & 4843 \\
\hline$\overline{\mathrm{CO}}$ & 1082 & 1139 & 1158 & 1177 & 1193 & 1216 \\
\hline $\mathrm{CO}_{2}$ & 463 & 591 & 649 & 713 & 768 & 851 \\
\hline $\mathrm{CH}_{4}$ & 180 & 133 & 118 & 103 & 93 & 80 \\
\hline $\mathrm{S}$ value of reformer product & 2.99 & 2.54 & 2.38 & 2.21 & 2.09 & 1.93 \\
\hline \multicolumn{7}{|l|}{ Methanol reactor input (kmol/h) } \\
\hline $\mathrm{H}_{2}$ & 15841 & 14992 & 14676 & 14345 & 14126 & 13843 \\
\hline $\mathrm{CO}$ & 1606 & 1626 & 1631 & 1641 & 1649 & 1660 \\
\hline $\mathrm{CO}_{2}$ (including extra $\mathrm{CO}_{2}$ added) & 4213 & 3907 & 3788 & 3683 & 3605 & 3499 \\
\hline $\mathrm{CH}_{4}$ & 3462 & 2561 & 2242 & 1952 & 1758 & 1510 \\
\hline $\mathrm{CO}_{2}$ added $(\mathrm{kmol} / \mathrm{h})$ & 617 & 425 & 344 & 255 & 184 & 80 \\
\hline S value at methanol reactor input & 2.00 & 2.00 & 2.01 & 2.00 & 2.00 & 2.01 \\
\hline Methanol after purification $(\mathrm{kg} / \mathrm{h})$ & 56739 & 56696 & 57072 & 57161 & 57439 & 56659 \\
\hline $\begin{array}{lccc}\text { Carbon } & \text { contribution } & \text { from } & \text { glycerol } \\
\left(\mathrm{C}_{\text {gly }} /\left(\mathrm{C}_{\text {gly }}+\mathrm{C}_{\text {natural gas }}\right)\right) & & \\
\end{array}$ & 0 & 0.21 & 0.29 & 0.38 & 0.44 & 0.54 \\
\hline Carbon efficiency* (\%) & 86 & 81 & 79 & 77 & 75 & 73 \\
\hline Green $\mathrm{CO}_{2}{ }^{*}$ & 0 & 0.05 & 0.07 & 0.08 & 0.10 & 0.12 \\
\hline
\end{tabular}

[176] 
Chapter 6 - Techno-economic analysis of methanol production via HSR

\begin{tabular}{|l|c|c|c|c|c|c|}
\hline Black $\mathrm{CO}_{2}{ }^{*}$ & 0.12 & 0.13 & 0.13 & 0.14 & 0.14 & 0.14 \\
\hline Parameters for economics & & & & & & \\
\hline tonne natural gas/tonne methanol & 0.59 & 0.50 & 0.45 & 0.41 & 0.37 & 0.32 \\
\hline tonne glycerol/tonne methanol & 0 & 0.25 & 0.36 & 0.47 & 0.56 & 0.71 \\
\hline
\end{tabular}

Definitions for Table 2

* Carbon efficiency is defined as the moles of carbon in methanol to moles of carbon in the feedstock (natural gas and glycerol) Green $\mathrm{CO}_{2}$ is defined as the moles of $\mathrm{CO}_{2}$ emitted from glycerol alone relative to the moles of carbon in the feedstock.

It is assumed that $1 \mathrm{~mol}$ of green $\mathrm{CO}_{2}$ is produced per mole of glycerol consumed according to the overall reaction $\mathrm{C}_{3} \mathrm{H}_{8} \mathrm{O}_{3} \rightarrow 2$ $\mathrm{CH}_{3} \mathrm{OH}+\mathrm{CO}_{2}$

Black $\mathrm{CO}_{2}$ is defined as the moles of $\mathrm{CO}_{2}$ emitted from natural gas relative to the moles of carbon in the feedstock

Table 3: Energy balance for various HSR process cases

\begin{tabular}{|c|c|c|c|c|c|c|}
\hline Energy balance (MW) & $\begin{array}{l}\text { Case } 1 \\
\text { (MSR) } \\
\text { Base } \\
\text { case }\end{array}$ & Case 2 & Case 3 & Case 4 & Case 5 & Case 6 \\
\hline \multicolumn{7}{|l|}{ Heat required } \\
\hline Pre-heating natural gas from 20 to $350^{\circ} \mathrm{C}$ & 7.2 & 5.8 & 5.2 & 4.6 & 4.1 & 3.4 \\
\hline Pre-heating natural gas from 350 to $900^{\circ} \mathrm{C}$ & 17.7 & 14.3 & 12.9 & 11.4 & 10.2 & 8.5 \\
\hline Pre-heating glycerol from 20 to $400^{\circ} \mathrm{C}$ & 0 & 5.7 & 8.2 & 10.8 & 12.9 & 16.1 \\
\hline Glycerol vaporization at $400^{\circ} \mathrm{C}$ & 0 & 2.2 & 3.2 & 4.2 & 5.0 & 6.2 \\
\hline Glycerol vapor heating from 400 to $900^{\circ} \mathrm{C}$ & 0 & 5.1 & 7.2 & 9.5 & 11.4 & 14.2 \\
\hline Pre-heating water from 47 to $234^{\circ} \mathrm{C}$ & 22.3 & 24.8 & 26.1 & 27.4 & 28.6 & 30.5 \\
\hline Steam by water evaporation at $234^{\circ} \mathrm{C}$ & 42.2 & 44.9 & 46 & 47.2 & 48.4 & 50.0 \\
\hline Super heating of steam from 235 to $900^{\circ} \mathrm{C}$ & 36.6 & 39.6 & 40.9 & 42.3 & 43.6 & 45.6 \\
\hline Reforming process at $900^{\circ} \mathrm{C}$ & 92.8 & 85.5 & 82.3 & 78.8 & 76.2 & 72.2 \\
\hline Methanol reboiler at $109^{\circ} \mathrm{C}$ & 32.8 & 32.2 & 31.0 & 30.7 & 30.5 & 30.2 \\
\hline $\begin{array}{l}\text { Heating recycle methanol steam from } 47 \\
\text { to } 250^{\circ} \mathrm{C}\end{array}$ & 35.7 & 31.5 & 29.9 & 28.5 & 27.5 & 26.2 \\
\hline Total required & 287 & 292 & 293 & 296 & 299 & 303 \\
\hline \multicolumn{7}{|l|}{ Heat available in MW } \\
\hline $\begin{array}{l}\text { Reformer gas cooling from } 900 \text { to } 155^{\circ} \mathrm{C} \\
\text { (for case } 6 \text { it is } 166^{\circ} \mathrm{C} \text { ) }\end{array}$ & 69.8 & 74.4 & 76.4 & 78.7 & 80.8 & 84 \\
\hline $\begin{array}{l}\text { Reformer gas cooling from } 155 \text { (for case } 6 \\
\text { it is } 166^{\circ} \mathrm{C} \text { ) to } 40^{\circ} \mathrm{C}\end{array}$ & 41.6 & 49.1 & 52.2 & 55.8 & 58.8 & 63.4 \\
\hline Cooling compressed syngas from 130 to & 5.3 & 5.3 & 5.4 & 5.4 & 5.4 & 5.5 \\
\hline
\end{tabular}

[177] 
Chapter 6-Techno-economic analysis of methanol production via HSR

\begin{tabular}{|l|c|c|c|c|c|c|}
\hline $40^{\circ} \mathrm{C}$ & & & & & & \\
\hline Methanol reactor at $250^{\circ} \mathrm{C}$ & 33.0 & 34.4 & 35.0 & 35.6 & 36.1 & 36.8 \\
\hline $\begin{array}{l}\text { Methanol reactor product cooling from } \\
250 \text { to } 137^{\circ} \mathrm{C} \text { (for case } 6 \text { it is } 144^{\circ} \mathrm{C} \text { ) }\end{array}$ & 30.4 & 26.8 & 25.5 & 24.2 & 23.4 & 22.3 \\
\hline $\begin{array}{l}\text { Methanol reactor product cooling from } \\
137 \text { to } 40^{\circ} \mathrm{C}\end{array}$ & 45.6 & 43.8 & 43.1 & 42.5 & 42.0 & 41.4 \\
\hline Distillation condenser at $55^{\circ} \mathrm{C}$ & 29.2 & 28.7 & 27.6 & 27.4 & 27.2 & 27.3 \\
\hline Furnace heat from $\sim 1804$ to $910^{\circ} \mathrm{C}$ & 92.8 & 85.5 & 82.3 & 78.8 & 76.2 & 72.2 \\
\hline Furnace heat from 910 to $150^{\circ} \mathrm{C}$ & 67.8 & 62.7 & 60.4 & 57.9 & 56.1 & 53.3 \\
\hline Total available & 416 & 411 & 408 & 406 & 406 & 406 \\
\hline
\end{tabular}

Table 2 presents i) the input streams of the reformer, furnace and methanol reactor, ii) the synthesis gas product stream from the reformer, iii) the methanol production, iv) the fresh $\mathrm{CO}_{2}$ addition to the methanol section, $\mathrm{v}$ ) the carbon contribution from the glycerol, and vi) the fraction "green" and black $\mathrm{CO}_{2}$. From Table 2, it is noticed that the hydrogen production is slightly reduced by adding glycerol to the reformer. It is obvious because the $\mathrm{H} / \mathrm{C}$ ratio is decreased when natural gas is replaced by glycerol. As observed from Table 2, the $\mathrm{S}$ value of the reformer product stream is decreased from 2.99 to 1.93 when glycerol is added to the reformer. This is mainly because more $\mathrm{CO}_{2}$ is produced as a result of the reforming equilibrium of glycerol. Since the S-ratio is defined as $\left(\left[\mathrm{H}_{2}\right]-\left[\mathrm{CO}_{2}\right]\right) /\left([\mathrm{CO}]+\left[\mathrm{CO}_{2}\right]\right)$, due to more $\mathrm{CO}_{2}$ from the reformer exit, the $\mathrm{S}$ value will decrease.

It is also observed that the amount of $\mathrm{CO}_{2}$ added to the methanol synthesis (to set $\mathrm{S}$ value $=2$ ) was reduced from $617 \mathrm{kmol} / \mathrm{h}$ (for methane steam reforming - case 1 , Base case) to $80 \mathrm{kmol} / \mathrm{h}$ (for case $6,54 \%$ glycerol on carbon basis). This means to utilize more than $60 \%$ glycerol (carbon based), there must be a facility to remove $\mathrm{CO}_{2}$ to make the $\mathrm{S}$ value 2. This fixes the operating window for the HSR process. Therefore the techno-economic evaluation is based up to $54 \%$ carbon contribution from glycerol, which is case 6 .

By increasing the amount of glycerol in the HSR process, the carbon efficiency is decreased from $86 \%$ to $73 \%$ to produce the same amount of methanol. This is due to 
the oxygen present in the glycerol, which will be emitted as extra $\mathrm{CO}_{2}$. Therefore, the net mole of $\mathrm{CO}_{2}$ emitted from the process (from furnace) is doubled (0.12 to 0.26 ). However, "black $\mathrm{CO}_{2}$ " $\left(\mathrm{CO}_{2}\right.$ emitted from natural gas alone) remains almost constant while the "green $\mathrm{CO}_{2}$ " (assumed one $\mathrm{CO}_{2}$ produced per glycerol converted) is increased when glycerol is added to the process. Overall the amount of $\mathrm{CO}_{2}$ emitted will be constant since the "green $\mathrm{CO}_{2}$ " (considering "green $\mathrm{CO}_{2}$ " is from biomass) will be recycled via photosynthesis. Table 2 also reports some important parameters for the economic evaluation such as tonne of natural gas and glycerol required to produce a tonne of methanol. It requires 0.59 tonne of natural gas per tonne of methanol of which 0.5 tonne of methane for the reforming. These data obtained for the SMR (base case) is in agreement with the data given in the literature (which is 0.5 tonne of $\mathrm{CH}_{4}$ to produce a tonne of methanol) [19].

Table 3 summarizes the energy balance for all the six cases. It is observed that the overall heat required is slightly increased for the hybrid steam reforming process (relative to the base case). The rise is due to i) glycerol heating and vaporization and ii) additional water heating and vaporization since more water (including recycle) is required for the HSR process than the MSR (base case). This is partly compensated by less consumption of natural gas in the HSR process and furthermore, the glycerol addition makes the overall reforming less endothermic than in the SMR case. The overall excess heat available for all the cases remained almost the same. This excess heat can partly be utilized elsewhere.

Pinch technology was applied to analyze the energy flows in the system and to optimize the heat integration for the HSR concept. As an example, the composite curve for the cold and hot streams is presented for case 6 in Figure 4. The composite curves represent the heating and cooling demands of the entire system and identify minimum utility requirements. The pinch point is defined as the closest temperature difference between the hot and cold streams $\left(\Delta \mathrm{T}_{\min }\right)$. In this case, the pinch point $(\Delta \mathrm{T})$ was set to $10^{\circ} \mathrm{C}$. From the composite curve, it is identified that the minimum hot and cold utility requirements were found to be $0.4 \mathrm{MW}$ and $103.5 \mathrm{MW}$ respectively at the pinch temperature of $900{ }^{\circ} \mathrm{C}$. The small amount of hot utility is obtained through a slight increase of furnace duty. The waste heat of $\sim 103 \mathrm{MW}$ (case 6 ) and a closed 
cooling circuit of water at $\Delta \mathrm{T}=20 \mathrm{~K}$ will lead to cooling of $\sim 4285$ tonne $/ \mathrm{hr}$ of water or $\sim 75 \mathrm{~m}^{3}$ of cooling water per tonne of methanol. The high temperature heat available from the furnace $\left(\sim 1804\right.$ to $\left.910{ }^{\circ} \mathrm{C}\right)$ can be supplied to the reformer and the heat available from the methanol reactor can be used to make steam by evaporating water at $234{ }^{\circ} \mathrm{C}$. In principle, it is always possible to design a heat exchanger network to achieve the energy targets from the pinch analysis. However, this is not the focus of the present investigation.

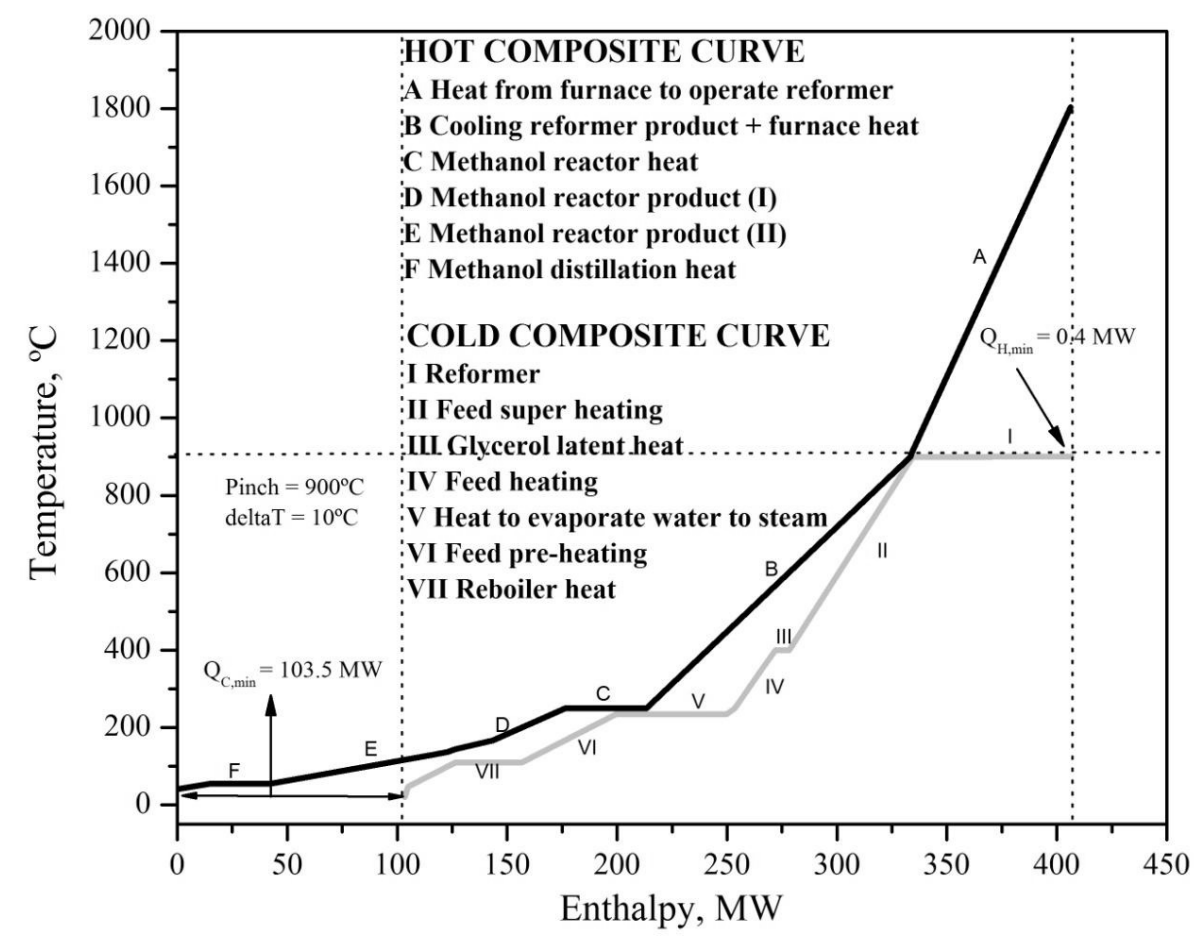

Figure 4: Pinch analysis for (bio)methanol production via hybrid steam reforming of glycerol with methane (Case 6).

\subsubsection{Estimation of total capital investment cost for HSR process}

The total equipment cost was estimated based on the costs of the major unit operations with dimensions and cost drivers for the HSR process for Case 6. It is summarized in Table 4 and explained in Appendix 1 at the end of this Chapter. The purchased process equipment cost is estimated with Peter's cost estimator tool 
$[17,20]$. From the equipment cost evaluation, it is observed that the major cost contribution is from the reactors (reforming and methanol synthesis units), heat exchangers and compressors. However, the cost depends on many parameters such as the material of construction, accessories, operating pressure dimensions etc. Particular for the special components such as the reformer tubes and the methanol synthesis reactor, the costs are derived based on the cost of one single tube of specified size. It is generally assumed that the minimum cost of a single reformer tube is $\sim 20,000 \$$ [21]. Based on the reformer duty and reported heat flux $\left(87 \mathrm{~kW} / \mathrm{m}^{2}\right.$ [22]), the total heat transfer area is estimated. This area corresponds with 250 reformer tubes of 0.13 $\mathrm{m}$ diameter and $8 \mathrm{~m}$ length. Therefore, the cost of the reformer are estimated at $5 \mathrm{M} \$$ which corresponds nicely with the estimation of Peter's cost estimator [17, 20] which estimates 5.2 M\$ for a reformer furnace of the same duty. For consistency the last value is used for the rest of the evaluation. In case of the heat exchangers, the heat transfer area determines the cost. This heat transfer area (A) depends on the heat required for cooling/heating, the overall heat transfer coefficient (U) and the logarithmic mean temperature difference (LMTD). Based on U and LMTD, A was determined. Using the value of $\mathrm{A}$, the heat exchanger cost was estimated. The other costs such as building, piping, valves, installations, process control, electrical, assembly, engineering costs are summarized in Table 5 using a factor method. The probable degree of accuracy of this study estimate is between -30 and $+40 \%$ [16]. Additionally, the results of two short-cut methods to estimate the ISBL plant costs are added. The method of Lang [16] and the rapid cost estimation method based on historical data [23] are applied.

Table 4: Overview of main equipment with dimensions, process conditions and estimated purchased costs for the HSR process (Case 6).

\begin{tabular}{|c|c|c|}
\hline Unit operations & Specifications & Cost $\left(\begin{array}{ll}x & 1000 \$)\end{array}\right.$ \\
\hline \multicolumn{3}{|l|}{ Reactors } \\
\hline Fixed bed reformer & $\begin{array}{l}\text { Reformer furnace equipped with SS tubes, Number of tubes }=250, D=0.13 \mathrm{~m} \text {, } \\
\mathrm{L}=8 \mathrm{~m}, 20 \mathrm{k} \$ \text { per tube. }\end{array}$ & 5,200 \\
\hline Methanol synthesis reactor & $\begin{array}{l}\mathrm{D}=0.13 \mathrm{~m}, \mathrm{~L}=8 \mathrm{~m}, \text { Number of tubes }=345 \text { tubes, cost of } \mathrm{D}=0.13 \mathrm{~m}, \mathrm{~L}=8 \mathrm{~m} \\
\text { tube }=17,500 \$, \text { Cost of } 345 \text { tubes }=345 \times 17,500 \$=6,038,000 \$\end{array}$ & 6,038 \\
\hline \multicolumn{3}{|l|}{ Separation vessels } \\
\hline $\begin{array}{l}\text { Column to remove water from } \\
\text { reformer product }\end{array}$ & $\begin{array}{l}\text { Assumed } \mathrm{D}=2 \mathrm{~m}, \mathrm{~L}=8 \mathrm{~m}[23], \mathrm{SS} \text { material, Pressure rating of } 10,000 \mathrm{kpa}= \\
448,000 \$+\text { demister }\end{array}$ & 448 \\
\hline
\end{tabular}


Chapter 6 - Techno-economic analysis of methanol production via HSR

\begin{tabular}{|c|c|c|}
\hline $\begin{array}{l}\text { Second column to remove } \\
\text { water from reformer product }\end{array}$ & $\begin{array}{l}\text { Assumed } \mathrm{D}=2 \mathrm{~m}, \mathrm{~L}=6 \mathrm{~m}[23], \mathrm{SS} \text { material, Pressure rating of } 10,000 \mathrm{kpa}= \\
360,000 \$+\text { demister }\end{array}$ & 360 \\
\hline $\begin{array}{l}\text { Column after methanol } \\
\text { synthesis }\end{array}$ & $\begin{array}{l}\text { Assumed } \mathrm{D}=2.5 \mathrm{~m}, \mathrm{~L}=9 \mathrm{~m}[23], \mathrm{SS} \text { material, Pressure rating of } 10,000 \mathrm{kpa}= \\
760,000 \$ \text { in case of } \mathrm{D}=3 \mathrm{~m} \text { and } 492,000 \$ \text { in case of } \mathrm{D}=2 \mathrm{~m} \text {, Assume the } \\
\text { column will cost } 625,000 \$+\text { Demister }\end{array}$ & 625 \\
\hline Column to remove lights & $\begin{array}{l}\text { Assumed D=2 m, L=10m, SS material, Pressure rating of } 1035 \mathrm{kpa}=186,000 \\
\$\end{array}$ & 186 \\
\hline Column to purify methanol & $\begin{array}{l}\text { Active area necessary for gas flow is } 8 \mathrm{~m}^{2} \text {. Total cross-sectional area is about } \\
10 \mathrm{~m}^{2} \text {.Diameter is } 3.5 \mathrm{~m} \text {, Number of stages: } 16 \text { ideal, } 23 \text { real stages ( } 70 \% \text { eff.). } \\
\text { Height of column about } 15 \mathrm{~m} \text {. }\end{array}$ & 570 \\
\hline \multicolumn{3}{|l|}{ Heat exchangers } \\
\hline $\begin{array}{l}\text { Natural gas pre-heating }(20 \text { to } \\
350^{\circ} \mathrm{C}\end{array}$ & $\begin{array}{l}\text { Floating head heat exchangers, Area } 680 \mathrm{~m}^{2} \text {, Shell is CS, tube is SS, Design } \\
\text { pressure }=31 \text { bar }\end{array}$ & 135 \\
\hline $\begin{array}{l}\text { Natural gas heating }(350 \text { to } \\
900^{\circ} \mathrm{C}\end{array}$ & $\begin{array}{l}\text { Floating head heat exchangers, Area } 1700 \mathrm{~m}^{2} \text {, Shell is CS, tube is SS, Design } \\
\text { pressure }=30 \mathrm{bar}\end{array}$ & 336 \\
\hline $\begin{array}{l}\text { Glycerol gasification (20 to } \\
\left.400^{\circ} \mathrm{C}\right)\end{array}$ & $\begin{array}{l}\text { Floating head heat exchangers, Area } 1600 \mathrm{~m}^{2} \text {, Shell is CS, tube is SS, Design } \\
\text { pressure }=30 \mathrm{bar}\end{array}$ & 320 \\
\hline $\begin{array}{l}\text { Glycerol vaporization at } 400 \\
{ }^{\circ} \mathrm{C}\end{array}$ & $\begin{array}{l}\text { Floating head heat exchangers, Area } 600 \mathrm{~m}^{2} \text {, Shell is CS, tube is SS, Design } \\
\text { pressure }=30 \mathrm{bar}\end{array}$ & 120 \\
\hline $\begin{array}{l}\text { Glycerol vapor heating from } \\
400 \text { to } 900{ }^{\circ} \mathrm{C}\end{array}$ & $\begin{array}{l}\text { Floating head heat exchangers, Area } 3000 \mathrm{~m}^{2} \text {, Shell is CS, tube is SS, Design } \\
\text { pressure }=30 \mathrm{bar}\end{array}$ & 610 \\
\hline $\begin{array}{l}\text { Water heating from } 47 \text { to } 234 \\
{ }^{\circ} \mathrm{C}\end{array}$ & $\begin{array}{l}\text { Floating head heat exchangers, Area } 3000 \mathrm{~m}^{2} \text {, Shell is CS, tube is SS, Design } \\
\text { pressure }=30 \mathrm{bar}\end{array}$ & 610 \\
\hline $\begin{array}{l}\text { Water evaporation to steam at } \\
235^{\circ} \mathrm{C}\end{array}$ & $\begin{array}{l}\text { Floating head heat exchangers, Area } 5000 \mathrm{~m}^{2} \text {, Shell is CS, tube is SS, Design } \\
\text { pressure }=30 \text { bar }\end{array}$ & 1,015 \\
\hline $\begin{array}{l}\text { Steam heating from } 235 \text { to } 900 \\
{ }^{\circ} \mathrm{C}\end{array}$ & $\begin{array}{l}\text { Floating head heat exchangers, Area } 10000 \mathrm{~m}^{2}, \text { Shell is CS, tube is SS, Design } \\
\text { pressure }=30 \text { bar }\end{array}$ & 2,030 \\
\hline $\begin{array}{l}\text { Heating recycle methanol } \\
\text { stream from } 47 \text { to } 250^{\circ} \mathrm{C}\end{array}$ & $\begin{array}{l}\text { Floating head heat exchangers, Area } 1200 \mathrm{~m}^{2} \text {, Shell is CS, tube is SS, Design } \\
\text { pressure }=70 \mathrm{bar}\end{array}$ & 320 \\
\hline $\begin{array}{l}\text { Cooling reformer gas } 900 \text { to } \\
155^{\circ} \mathrm{C}\end{array}$ & $\begin{array}{l}3 \text { floating head heat exchangers of } \\
62 \mathrm{MW}: \quad 900^{\circ} \mathrm{C} \rightarrow 350{ }^{\circ} \mathrm{C}, \mathrm{A}=1400 \mathrm{~m}^{2} \\
11 \mathrm{MW}: \quad 350^{\circ} \mathrm{C} \rightarrow 250{ }^{\circ} \mathrm{C}, \mathrm{A}=915 \mathrm{~m}^{2} \\
11 \mathrm{MW} \quad 250^{\circ} \mathrm{C} \rightarrow 155^{\circ} \mathrm{C}, \mathrm{A}=1000 \mathrm{~m}^{2}\end{array}$ & 847 \\
\hline $\begin{array}{l}\text { Cooling reformer gas from } 155 \\
\text { to } 40^{\circ} \mathrm{C}\end{array}$ & $\begin{array}{l}\text { Floating head heat exchangers, Area } 6000 \mathrm{~m}^{2} \text {, Shell is CS, tube is SS, Design } \\
\text { pressure }=30 \text { bar }\end{array}$ & 1,200 \\
\hline $\begin{array}{l}\text { Cooling compressed gas } 130 \text { to } \\
40{ }^{\circ} \mathrm{C}\end{array}$ & $\begin{array}{l}\text { Floating head heat exchangers, Area } 713 \mathrm{~m}^{2} \text {, Shell is CS, tube is SS, Design } \\
\text { pressure }=70 \text { bar }\end{array}$ & 181 \\
\hline $\begin{array}{l}\text { Cooling methanol product } 250 \\
\text { to } 137^{\circ} \mathrm{C}\end{array}$ & $\begin{array}{l}\text { Floating head heat exchangers, Area } 2700 \mathrm{~m}^{2} \text {, Shell is CS, tube is SS, Design } \\
\text { pressure }=70 \mathrm{bar}\end{array}$ & 690 \\
\hline $\begin{array}{l}\text { Cooling methanol product } 137 \\
\text { to } 40^{\circ} \mathrm{C}\end{array}$ & $\begin{array}{l}\text { Floating head heat exchangers, Area } 5200 \mathrm{~m}^{2} \text {, Shell is CS, tube is SS, Design } \\
\text { pressure }=70 \text { bar }\end{array}$ & 1,300 \\
\hline $\begin{array}{l}\text { Condenser for methanol } \\
\text { distillation column }\end{array}$ & $\begin{array}{l}\text { Floating head heat exchangers, Area } 1700 \mathrm{~m}^{2} \text {, Shell is CS, tube is SS, Design } \\
\text { pressure }=7 \mathrm{bar}\end{array}$ & 200 \\
\hline $\begin{array}{l}\text { Reboiler for methanol } \\
\text { distillation column }\end{array}$ & $\begin{array}{l}\text { Floating head heat exchangers, Area } 300 \mathrm{~m}^{2} \text {, Shell is CS, tube is SS, Design } \\
\text { pressure }=7 \mathrm{bar}\end{array}$ & 60 \\
\hline \multicolumn{3}{|l|}{$\begin{array}{l}\text { Compressors and } \\
\text { pumps }\end{array}$} \\
\hline Synthesis gas compressor from & Two centrifugal turbine compressors each 5.2 MW power rating, Material CS & 6,400 \\
\hline
\end{tabular}

[182] 
Chapter 6-Techno-economic analysis of methanol production via HSR

\begin{tabular}{|l|l|l|}
\hline 20 to 80 bar & & \\
\hline $\begin{array}{l}\text { Methanol recycle compressor } \\
\text { from } 75 \text { to } 80 \mathrm{bar}\end{array}$ & Centrifugal rotary motor, Power rating $900 \mathrm{KW}$, Material CS & 634 \\
\hline Bio-liquid pump & Centrifugal cast iron pump (water duty), volumetric flow $=0.009 \mathrm{~m}^{3} / \mathrm{s}$ & 11 \\
\hline Water pump & Centrifugal cast iron pump (water duty), volumetric flow $=0.005 \mathrm{~m}^{3} / \mathrm{s}$ & 11 \\
\hline & & 31 \\
\hline Total equipment cost (Million US\$) 2002 & 47 \\
\hline $\begin{array}{l}\text { Total equipment cost (Million US\$) } 2012 \\
\text { CECPI in 2002 }=390[24] \text { and CECPI in } 2012 \text { (April) }=596[24]\end{array}$ & 36 \\
\hline $\begin{array}{l}\text { Total equipment cost (Million } € \text { ) } 2012 \\
€: \$ \text { exchange rate in } 2012=1: 1.34\end{array}$ & \\
\hline
\end{tabular}

Table 5: Summary of total capital investment for the HSR process; capacity = 450,000 tonne/year (bio)methanol

\begin{tabular}{|c|c|c|c|}
\hline Group & Capital cost items & Comment/Definition & Million EUR \\
\hline I & Production building & $\begin{array}{l}\text { For fluid processing plant it is } \\
5-18 \% \text { of equipment cost at existing site } \\
\text { new unit [17] It is assumed } \sim 5 \% \text { in this calculation }\end{array}$ & 2 \\
\hline II & $\begin{array}{l}\text { HVAC installations and } \\
\text { insulations }\end{array}$ & $\begin{array}{l}\text { It is } 10-20 \% \text { of all purchased equipment or } 3-10 \% \text { of fixed capital } \\
\text { investment [17]. It is assumed } 20 \% \text { of total equipment cost. }\end{array}$ & 7 \\
\hline III & Total equipment cost & Refer Appendix 1 & 36 \\
\hline IV & Piping and valves cost & $\begin{array}{l}\text { This is usually } 10-80 \% \text { of total equipment cost [17]. For the } \\
\text { selected equipments it is assumed to be } 80 \% \text { of total equipment } \\
\text { cost }\end{array}$ & 29 \\
\hline VI & $\begin{array}{l}\text { Process instrumentation } \\
\text { and analysis }\end{array}$ & $\sim 30 \%$ of total equipment cost [17] & 11 \\
\hline VII & $\begin{array}{l}\text { Assembly and } \\
\text { installation }\end{array}$ & $50 \%$ of total equipment cost [17] & 18 \\
\hline Sum (I-VII) & Direct plant costs & Sum of costs from (I-VII) & 103 \\
\hline VIII & Engineering cost & This is $75 \%$ of total equipment cost [17] & 27 \\
\hline IX & Contingency & $\begin{array}{l}\text { Unforeseen events such as strikes, storms, floods, price variations } \\
\text { may have an effect on the cost of the manufacturing operation } \\
\text { [17]. This is usually } 1-5 \% \text { of total capital investment or } 50 \% \text { of } \\
\text { equipment cost }\end{array}$ & 18 \\
\hline & ISBL plant costs & Direct plant costs + Sum (VIII-IX) & 148 \\
\hline & OSBL plant costs & Usually $30 \%$ of ISBL costs & 44 \\
\hline & Total capital investment & Sum of ISBL and OSBL costs & 192 \\
\hline Lang method & $\begin{array}{l}\text { Total capital investment } \\
\text { (in million } € \text { ) } \\
\text { (only ISBL) }\end{array}$ & $\begin{array}{l}\mathrm{C}_{\mathrm{f}}=\mathrm{F}_{\text {lang }} \Sigma \mathrm{C}_{\mathrm{p}} \\
\mathrm{C}_{\mathrm{f}} \text { is the fixed capital cost of the plant, } \Sigma \mathrm{C}_{\mathrm{p}} \text { is the total delivered } \\
\text { cost of all the major equipment items such as reactors, heat } \\
\text { exchangers, furnace, } \\
\text { distillation columns, pumps etc. } \\
\mathrm{F}_{\text {lang }} \text { is the Lang factor. Usually for fluid processing plants, a Lang } \\
\text { factor between } 4 \text { and } 5 \text { is used [16]. In the model, a Lang factor of } \\
5 \text { is used. }\end{array}$ & 180 \\
\hline
\end{tabular}

\section{[183]}




\begin{tabular}{|l|l|l|l|}
\hline $\begin{array}{l}\text { Rapid cost } \\
\text { estimation } \\
\text { method }\end{array}$ & $\begin{array}{l}\text { Total capital investment } \\
\text { (in million } € \text { ) } \\
\text { (only ISBL) }\end{array}$ & $\mathrm{C}_{2}=\mathrm{C}_{1}\left(\frac{\mathrm{S}_{2}}{\mathrm{~S}_{1}}\right)^{n} \rightarrow \mathrm{C}_{2}=\mathrm{S}_{2}{ }^{\mathrm{n}} a$ (million \$) \\
& $\begin{array}{l}\mathrm{C}_{2}, \text { Capital cost of the plant with capacity } \mathrm{S}_{2} \\
\mathrm{C}_{1}, \text { Capital cost of the plant with capacity } \mathrm{S}_{1} \text { Parameters given in } \\
\text { Hydrocarbon processing journal for methanol plant according to } \\
\text { 2006 US gulf coast, a }=2.775, \mathrm{n}=0.6, \mathrm{~S}_{2}=1370 \text { tonne methanol a } \\
\text { day [23]. CEPCI in 2006 }=499.6 \text { and in 2011 = 581.7.[24] } \\
€: \$ \text { exchange rate }=1: 1.34\end{array}$ & 185 \\
& & \\
\hline
\end{tabular}

The Lang method [16] is based only on the purchased equipment cost. However, the equipment cost varies from place, availability of materials and plant type. The rapid cost estimation method is based on the historical data of a methanol plant [23]. This method is based on a conventional methanol plant and gives an approximate capital cost with an accuracy of $\pm 30-50 \%$. The results in Table 5 show that the ISBL plant costs are estimated in the range between 148 and 185 Million Euro. For further evaluation, a total capital investment (ISBL + OSBL) of 250 Million Euro for a production capacity of $450 \mathrm{ktpa}$ of methanol is assumed.

\subsubsection{Techno-economic evaluation}

The cost prices of (bio)methanol produced at $450 \mathrm{ktpa}$ from natural gas (MSR) and natural gas mixed with glycerol (HSR) are estimated. The total capital investment for all configurations was fixed as 250 million $€$ including ISBL and OSBL (OSBL is assumed $30 \%$ of ISBL) costs. All the cost which includes approximate natural gas price, labor cost, utilities (electricity), equipment and taxation are related to the central European region.

Table 6 summarizes the estimation of the (bio)methanol cost price. From the cost comparison between the MSR and HSR process, it is observed that the raw material costs and especially glycerol dictates the (bio)methanol product costs. The utilities and depreciation contribute $9-11 \%$ and $13-15 \%$ respectively to the methanol production cost. Other costs such as labor cost, maintenance cost, license and miscellaneous (insurance) which are directly related to the total capital investment contribute also $13-15 \%$. The product cost of methanol for the MSR and HSR (case 6) process differs by $\sim 75 € /$ tonne assuming a raw material price of $200 € /$ tonne glycerol. Glycerol is cheaper than natural gas but mass balance calculations show that each 
tonne of natural gas has to be replaced by 2.7 tonne of glycerol resulting in a net higher cost price for the methanol. This means that the glycerol is too expensive relative to the natural gas price.

Table 6: Cost price calculation of (bio)methanol for the MSR and HSR process

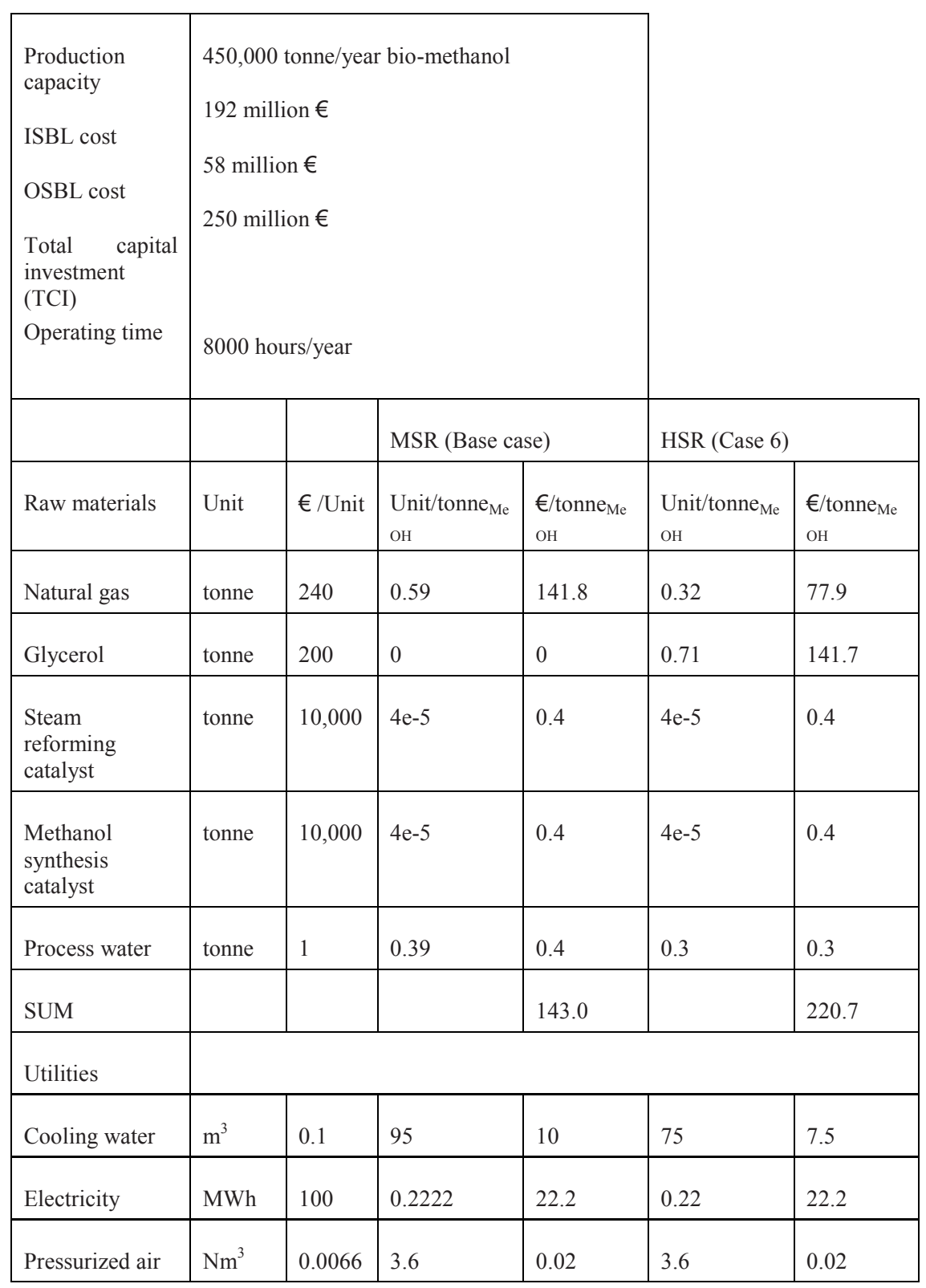


Chapter 6-Techno-economic analysis of methanol production via HSR

\begin{tabular}{|c|c|c|c|c|}
\hline SUM & & & 32.2 & 29.5 \\
\hline \multicolumn{5}{|l|}{ Labor cost } \\
\hline $\begin{array}{l}\text { Number } \\
\text { employees }\end{array}$ & 25 & $\begin{array}{l}100,00 \\
0\end{array}$ & 5.6 & 5.6 \\
\hline $\begin{array}{l}\text { Maintenance } \\
\text { cost }\end{array}$ & $\begin{array}{l}5 \% \\
\text { TCI }\end{array}$ & & 27.8 & 27.8 \\
\hline License & $\begin{array}{l}2 \% \\
\text { TCI }\end{array}$ & & 11.1 & 11.1 \\
\hline Insurance & $\begin{array}{l}2 \% \\
\text { TCI }\end{array}$ & & 11.1 & 11.1 \\
\hline Total cash cost & & & 230.8 & 305.8 \\
\hline Depreciation & $10 \%$ & & 55.6 & 55.6 \\
\hline $\begin{array}{l}\text { Total } \\
\text { production cost }\end{array}$ & & & 286.4 & 361.3 \\
\hline $\begin{array}{l}\text { NPV } \\
\text { calculations }\end{array}$ & & & & \\
\hline $\begin{array}{l}\text { Rate of interest } \\
\& \text { Number of } \\
\text { years }\end{array}$ & \multicolumn{4}{|c|}{$15 \%, 10$ years, $\mathrm{I}_{0}=250$ Million Euro } \\
\hline $\begin{array}{l}\text { Cash flow } \\
\text { needed for NPV } \\
=0\end{array}$ & & & 110.8 & 110.8 \\
\hline Profit after tax & & & 55.2 & 55.2 \\
\hline Taxation & $23 \%$ & & 16.5 & 16.5 \\
\hline Profit before tax & & & 71.7 & 71.7 \\
\hline $\begin{array}{ll}\text { Cash flow } \\
\text { before tax }\end{array}$ & & & 127.3 & 127.3 \\
\hline $\begin{array}{l}\text { PRODUCT } \\
\text { COST PRICE }\end{array}$ & & & 358 & 433 \\
\hline
\end{tabular}


The gross bio-methanol cost price is calculated based on a production split in methanol (natural gas based) stream and a bio-methanol (glycerol based) stream based on the carbon \% of glycerol in the feed and assuming the price of methanol is 358 $€ /$ tonne (case 1). This cost price ranges from 472 to $497 € /$ tonne of bio-methanol for the cases 2 to 6 .

The final average cost of methanol for all cases is summarized below:-

$\begin{array}{llll}\text { Case } 1 & \text { Methanol via natural gas reforming } & - & 358 € / \text { tonne } \\ \text { Case } 2 & \text { (Bio)methanol via } 21 \% \text { glycerol } & - & 382 € / \text { tonne } \\ \text { Case } 3 & \text { (Bio)methanol via } 29 \% \text { glycerol } & - & 393 € / \text { tonne } \\ \text { Case } 4 & \text { (Bio)methanol via } 38 \% \text { glycerol } & - & 404 € / \text { tonne } \\ \text { Case } 5 & \text { (Bio)methanol via } 44 \% \text { glycerol } & - & 415 € / \text { tonne } \\ \text { Case } 6 & \text { (Bio)methanol via } 54 \% \text { glycerol } & - & 433 € / \text { tonne }\end{array}$

\subsubsection{Estimation of bio-methanol cost at various feed stock prices}

In Figure $5 \mathrm{~A} \& \mathrm{~B}$, a detailed cost analysis for case 6 (54 wt $\%$ glycerol on carbon basis) is presented. As shown in Figure 5a, the price of the natural gas was varied from 0.1 to $0.5 / \mathrm{Nm}^{3}$ and the glycerol price was varied from 50 to $600 € /$ tonne. The black horizontal line in Figure 5a indicates the European posted methanol price which is $\sim 340 € /$ tonne for the first quarter in 2012 [25].

As shown in Figure 5a, (bio)methanol produced via the HSR process can only compete with the MSR process if the glycerol price is below $90 € /$ tonne at the current natural gas price of $\sim 0.2 € / \mathrm{Nm}^{3}$. The HSR concept is quite an attractive option for the glycerol price of $200 € /$ tonne when the natural gas price is above $\sim 0.45 € / \mathrm{Nm}^{3}$. However, from the current natural gas price development [18] over the last decade, a price of $0.45 € / \mathrm{Nm}^{3}$ or higher is currently not realistic. As shown in Figure 5b ("go/no-go" for HSR), the economics of the HSR process at a pure glycerol price of $600 € /$ tonne [25], is only feasible at a natural gas price of minimal $1.3 € / \mathrm{Nm}^{3}$. Therefore, currently, utilizing pure glycerol in a reformer is quite an unrealistic situation. Fortunately, there are other possible feedstocks such as pyrolysis liquids, sugar fractions and direct crude glycerol etc. which will be available at a price lot 
cheaper than pure glycerol. However, these feedstocks still have some technical challenges ahead before they can be applied.

The results indicate that the HSR concept will only be attractive in places where natural gas is not available or in places where it is relatively more expensive than bioliquids. In the case of glycerol, the cost price per tonne should be a factor 2.7 lower to be compatible with natural gas as a feed stock. This also means that the crude obtained immediately after transesterification process would be an interesting feed to reform/combust as this feed may be a lot cheaper than the refined one. Currently biomethanol is not competitive with methanol unless special arrangements are made (regulations, subsidies) to promote the use of bio-methanol. For example: according to the EC Renewable Energy Directive it is allowed to count the heating value of biomethanol double if the bio-methanol is produced from waste (for instance crude glycerin) or second generation bio-feed [1]. This increases the market value of this type of bio-methanol significantly. Recently, in October 2012, it is even proposed to count in this case four times the energy content [26].

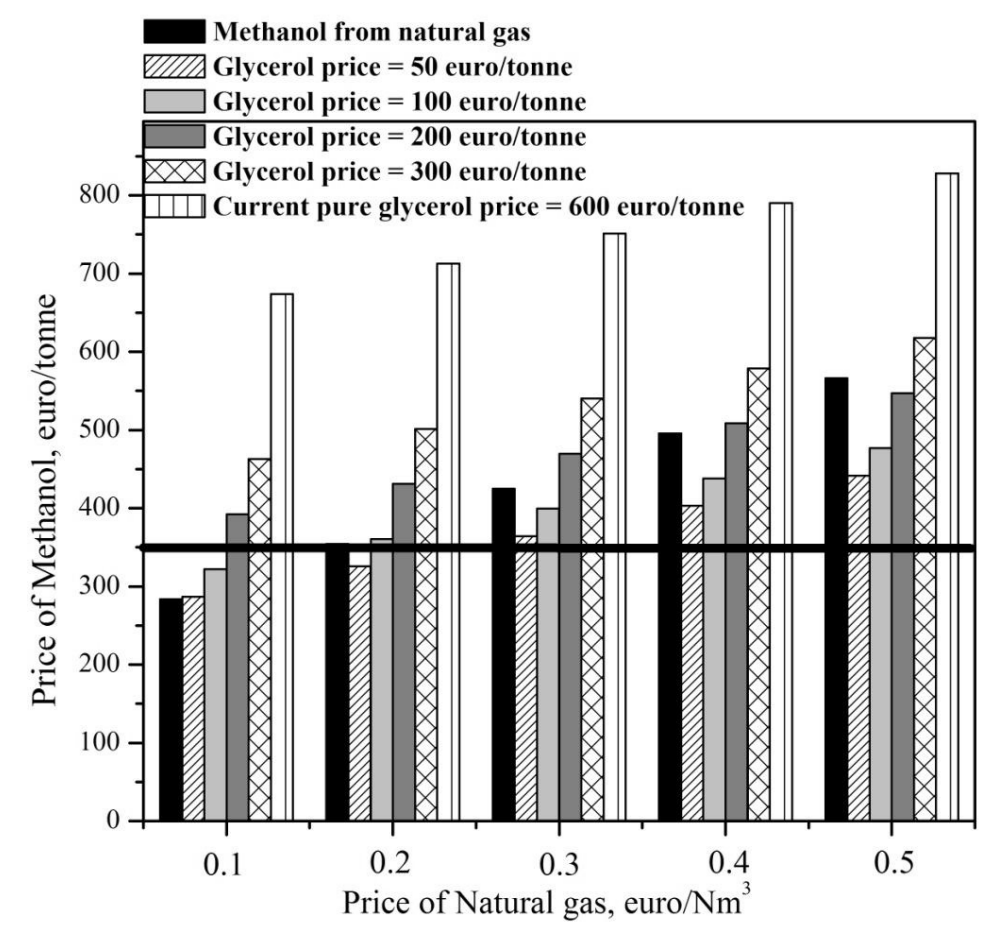

$5 \mathrm{~A}$ 


\begin{tabular}{|c|c|c|c|c|c|}
\hline NG price & \multicolumn{5}{|c|}{ Glycerol price (euro/tonne) } \\
\hline euro/ $\mathrm{Nm}^{3}$ & 50 & 100 & 200 & 300 & 600 \\
\hline 0.1 & $+/-$ & $\times$ & $\times$ & $\times$ & $\times$ \\
\hline 0.2 & $\checkmark$ & $+/-$ & $\times$ & $\times$ & $\times$ \\
\hline 0.3 & $\checkmark$ & $\checkmark$ & $\times$ & $\times$ & $\times$ \\
\hline 0.4 & $\checkmark$ & $\checkmark$ & $+/$ & $\times$ & $\times$ \\
\hline 0.5 & $\checkmark$ & $\checkmark$ & $\checkmark$ & $\times$ & $\times$ \\
\hline 1.3 & $\checkmark$ & $\checkmark$ & $\checkmark$ & $\checkmark$ & $\checkmark$ \\
\hline
\end{tabular}

$5 B$

Figure 5: Estimation of (bio)methanol cost price as a function of natural gas price for (A) case 6 and (B) possible scenarios of HSR (case 6) - go and no-go for HSR process.

\subsubsection{Sensitivity analysis}

The sensitivity analysis was performed to study the effects of changes in several parameters such as total capital investment, raw material, electricity cost and labor cost on the average (bio)methanol cost price. The results are summarized from high to low sensitivity in Table 7 .

Table 7: Sensitivity analysis of bio-methanol cost for case 6

\begin{tabular}{|c|c|c|c|c|c|}
\hline $\begin{array}{l}\text { Change of } \% \text { from } \\
\text { base case }\end{array}$ & $-40 \%$ & $-20 \%$ & Case 6 & $20 \%$ & $40 \%$ \\
\hline For Case 6 & & & Case $6-433 € /$ tonne & & \\
\hline Parameters & $€ /$ tonne & $€ /$ tonne & & $€ /$ tonne & $€ /$ tonne \\
\hline Plant investment & 361 & 396 & 250 million $€$ & 466 & 501 \\
\hline Glycerol price & 374 & 402 & $200 € /$ tonne & 458 & 487 \\
\hline Natural gas price & 400 & 416 & $0.2 € / \mathrm{Nm} 3$ & 447 & 462 \\
\hline Electricity cost & 422 & 426 & $100 € / \mathrm{MWh}$ & 436 & 441 \\
\hline Labor cost & 429 & 430 & $50000 €$ p.a & 432 & 433 \\
\hline Reformer catalyst & 431 & 431 & $10000 € /$ tonne & 432 & 432 \\
\hline $\begin{array}{l}\text { Reformer catalyst } \\
\text { weight }\end{array}$ & 431 & 431 & 20 tonne/y & 432 & 432 \\
\hline
\end{tabular}


The sensitivity analysis shows that the glycerol price, total capital investment and natural gas show a strong impact on the cost price of (bio)methanol. The price of glycerol was varied between 120 and $280 € /$ tonne ( -40 to $40 \%$ ) resulting in a (bio)methanol price increase of $\sim 0.7 € /$ tonne $((458-432) /(240-200))$ for every euro increase per tonne of glycerol starting from $200 € /$ tonne. To obtain a (bio)methanol price between $340-370 € /$ tonne, the estimated crude glycerol price should be between 70 and $110 € /$ tonne. At this price, glycerol is not available on the market; nevertheless, there is no fixed price for crude glycerol obtained after the transesterification process. At the present spot price [2012] of tallow based technical glycerine $\sim 600 € /$ tonne [25], the (bio)methanol price via the HSR (case 6) concept would be $\sim 713 € /$ tonne.

In the sensitivity analysis the capital investment was varied between 150 and 350 million $€$ to study its effect on the (bio)methanol cost price. From the sensitivity analysis, $\pm 0.7 € /$ tonne of (bio)methanol for every \pm 1 million $€$ in total capital investment is estimated. Over the last 5 years the natural gas price fluctuated between $0.197 € / \mathrm{Nm}^{3}$ ( $240 € /$ tonne natural gas) and $0.07 € / \mathrm{Nm}^{3}$ ( $84 € /$ tonne natural gas) at a peak value of $0.3 € / \mathrm{Nm}^{3}$ in June 2008 [30]. The model predicts a (bio)methanol price between 400 and $461 € /$ tonne for the natural gas price range between 0.12 and 0.28 $€ / \mathrm{Nm}^{3}$, provided the crude glycerol is available at $200 € /$ tonne.

Among the utilities, power/electricity cost is important to predict the cost price of (bio)methanol. However, the share of utilities has a relative small effect on the (bio)methanol price. According to the European energy consortium, the electricity price varies between $77 € / \mathrm{MWh}$ (in Sweden, Nov 2011 [18]) and 156.5 €/MWh (in Italy, Nov 2011 [18]) at an average cost of 110-120 €/MWh in many countries including The Netherlands, Denmark, Belgium etc. In the sensitivity analysis, electricity cost was varied between 60 and $140 € / M W h$ to evaluate the (bio)methanol price. It increased from 422 to $441 € /$ tonne The sensitive to electricity costs is small compared to other parameters like raw material costs.

In the model, the average labor cost was fixed as $100,000 € /$ year or $\sim 50 € / \mathrm{h}$ for $\sim 25$ employees (including shift workers, maintenance labor and control room operation 
workers). It is observed from the sensitivity analysis that the change in labor cost has almost no effect on the (bio)methanol price. The cost of reforming and methanol synthesis catalysts is varied between 6 and $14 € / \mathrm{kg}$ (12 and 28 tonne/year) in the model. Calculations show that catalysts prices hardly affected the final product value. This indicates that it is affordable to change the catalyst over a stipulated period, which depends on the behavior of the catalyst especially regarding deactivation and pressure drop on the catalyst bed due to coke deposition. Since deactivation is one of the major bottlenecks in the HSR concept, the process can also be operated in A-B reactor mode to avoid time-out of production during regeneration. This means during regeneration, the other reactor may be operated. However, this comes with an additional equipment cost.

The methanol cost price is also estimated when only glycerol is supplied to the furnace instead of natural gas. This means natural gas of $5628 \mathrm{~kg} / \mathrm{h}$ (or $5572 \mathrm{~kg} / \mathrm{h}$ of $\mathrm{CH}_{4}$ or $348 \mathrm{kmol} / \mathrm{h}$ of carbon) can be replaced by $17222 \mathrm{~kg} / \mathrm{h}$ of glycerol (resulting in a 25\% carbon based contribution of the glycerol to the feed, compare with case 2 and 3 in Table 2). The required amount of glycerol to the furnace is estimated in Appendix 2 , and is also in agreement with the model results of the UniSim ${ }^{\circledR}$ simulation. This case requires 0.3 tonne of glycerol per tonne of methanol produced. Moreover, this case requires no evaporation of the glycerol. The methanol price of $394 € /$ tonne is estimated for this case. By comparing this case against case 1, an increase of 36 $€ /$ tonne in methanol price is observed. This price is also interesting to compare against case 2 (HSR) and case 3, which has a (bio)methanol price of 382 and 393 $€ /$ tonne respectively. This means that utilizing glycerol as a furnace or reformer feed results in the same cost price of methanol. However, in this case, the reforming option is preferred because it will result in a final product with the required $\mathrm{C} 14$ isotope to prove the bio-based feed. 


\subsection{Conclusions}

This study focused on the techno-economic evaluation of the HSR concept in which part of the natural gas is replaced by (pure) glycerol to produce (bio)methanol via synthesis gas production. At laboratory scale it has been shown that this works technically for pure and well-refined glycerol. For other liquids such as crude glycerol and pyrolysis there are still technical challenges ahead. In this paper, mass and energy balances and the first estimates on the economics are presented for HSR of pure glycerol. It is assumed that within the accuracy of the methods used these numbers will be also indicative for crude glycerol and pyrolysis oil once reforming of these liquids becomes technically more realistic.

The main conclusions from this work are as follows:

- From the HSR model cases, it is concluded that conceptually, bio-liquids can replace natural gas by at least $50 \%$ in the existing reformers to produce synthesis gas. Up to this amount $\mathrm{CO}_{2}$ addition is still needed to adjust the stoichiometric value $\mathrm{S}$ of the synthesis gas to 2 , which is necessary for the methanol synthesis.

- For several feed combinations of the HSR concept, mass, energy balances and a techno-economic evaluation to estimate the average (bio)methanol price were performed. At the current natural gas price of $0.2 € / \mathrm{Nm}^{3}$ and an assumed crude glycerol price of $\sim 200 € /$ tonne, the (bio)methanol cost price of $\sim 433$ $€ /$ tonne is estimated for a feed with $54 \mathrm{wt} \%$ glycerol, which is $\sim 75 € /$ tonne higher than the methanol obtained via natural gas steam reforming.

- The HSR process becomes attractive when the natural gas price rises above $0.45 € / \mathrm{Nm}^{3}$ at an assumed glycerol price of $200 € /$ tonne. The process becomes attractive when glycerol is available at a price below $90 € /$ tonne. Pure glycerol as a reformer feed becomes an attractive option at natural gas price of 1.3 $€ / \mathrm{Nm}^{3}$. Considering the current price of natural gas, this situation is unrealistic at present.

- The sensitivity analysis of the HSR model shows that the feed stock prices (glycerol, natural gas) and total capital investment have a major impact on the final product cost price of (bio)methanol. Overall, to realize the HSR concept, 
glycerol should be available at $<100 € /$ tonne (for e.g. $90 € /$ tonne) and NG price should rise $>0.3 € / \mathrm{Nm}^{3}$.

- In case the production is split in fossil-methanol and bio-methanol based on the carbon \% of glycerol in the feed, the cost price of bio-methanol ranges between 470 and $500 € /$ tonne at a methanol price of $358 € /$ tonne. This means that currently bio-methanol is not competitive with methanol unless special arrangements are made (regulations, subsidies) to promote the use of biomethanol. For example the EC Renewable Energy Directive, which states that the energy content of biofuels from wastes and residues count double [1]

- Model calculations show that, at the present price scenario, utilizing glycerol either as a furnace or reformer feed has no effect on the cost price of methanol. The reformer option is preferred since it will yield methanol with $\mathrm{C}^{14}$ isotopes to prove the biobased feed.

\section{References}

1. Communication from the commission on the practical implementation of the EU biofuels and bio-liquids sustainability scheme and on counting rules for biofuels (2010/C 160/02).

2. www.methanol.org (The Methanol Institute, global trade association).

3. M.E. Dry, A.P. Steynberg, Studies in surface science and Catalysis 152 (2004), 406-581.

4. http://www.portofrotterdam.com/ (Port of Rotterdam portal).

5. Communicating from the commission to the European parliament and the council, EU directive, Renewable energy: Progressing towards the 2020 target (2011). Document by European commission, Brussels, Belgium,

6. K. Aasberg-Petersen, C.S. Nielsen, I. Dybkjaer, Natural gas Conversion VIII (2007), 243-248.

7. K. Aasberg-Petersen, T.S. Christensen, I. Dybkjaer, J. Sehested, M. Ostberg, R.M. Coertzen, M.J. Keyser, A.P. Steynberg, Studies in surface science and Catalysis 152 (2004), 258-405.

8. J.R. Rostrup-Nielsen, J. Sehested, Advanced Catalysis 47 (2002), 65-139. 
9. D. Wang, S. Czernik, E. Chornet, Energy \& Fuels 12 (1998), 19-24.

10. G. van Rossum, S.R.A. Kersten, W.P.M. van Swaaij, Ind. Engg. Chem. Res. 46 (2007) 3959-3967.

11. R.P. Balegedde Ramachandran, R.J.M. Westerhof, G. van Rossum, W.P.M. van Swaaij, D.W.F. Brilman, S.R.A. Kersten, Proceedings of the 18th European biomass conference 2010, DOI 10.5071/18thEUBCE2010-OB4.3.

12. R.P.B. Ramachandran, G. van Rossum, W.P.M. van Swaaij, S.R.A. Kersten, Energy \& Fuels 25 (2011), 5755-5766.

13. R.P.B. Ramachandran, J.A. Medrano, W.P.M. van Swaaij, K. Seshan, S.R.A. Kersten, G. van Rossum (Article under preparation).

14. www.biomcn.eu

15. W.D. Seider, J.D. Seader, D.R.Lewin and S. Widagdo, Product and Process Design Principles: Synthesis, Analysis and Evaluation, Third Edition, John Wiley\&Sons, 2010.

16. D.W. Green, R.H. Perry, Perry's chemical engineer's handbook, Eighth edition, McGraw-Hill.

17. M. Peters, K. Timmerhaus, R. West, Plant design and economics for chemical engineers, 5th edition, McGraw Hill Publications.

18. www.energy.eu (Europe's energy portal).

19. Ullmann's encyclopedia of Industrial Chemistry, Vol 23, Chapter: Methanol, WILEY-VCH publications, DOI: 10.1002/14356007.a16_465.pub2

20. http://www.mhhe.com/engcs/chemical/peters/data/ce.html (Open source: M.Peters, K.Timmerhaus, R.West, Plant design and economics for chemical engineers).

21. R.D. Roberts, J. Brightling, Open source Non-destructive testing 10 (2005), www.ndt.net.

22. Chemical engineering design fundamentals, Rice University, Online source, http://www.owlnet.rice.edu/ ceng403/nh3ref97.html

23. Coulson and Richardson's Chemical engineering book volume 6, Chemical engineering design $5^{\text {th }}$ edition (2005)

24. www.che.com.

25. www.icis.com (World's largest information provider for the chemical and energy industries) 
26. Proposal for a directive of the European Parliament and of the council amending Directive 98/70/EC relating to the quality of petrol and diesel fuels and amending Directive 2009/28/EC on the promotion of the use of energy from renewable sources. http://ec.europa.eu/energy/renewables/targets_en.htm

27. Chemical engineering design fundamentals, Rice University, Online source, http://www.owlnet.rice.edu/ ceng403/nh3ref97.html
28. Fixed-bed reactor design, http://www.fischer- tropsch.org/DOE/DOE_reports/91005752/de91005752_sec2.pdf

29. www.xe.com

\section{Appendix 1}

Overview of main equipment with dimensions, process conditions and estimated purchased costs for the HSR process (Case 6). Cost data is obtained from the website of Peters et al. [20].

\section{Reformer}

$\mathrm{Q}=72200 \mathrm{KW}$, Assumed heat transfer, $\mathrm{H}=87 \mathrm{KW} / \mathrm{m}^{2}$ [27]

Area required, $\mathrm{A}_{\mathrm{R}}=\mathrm{Q} / \mathrm{H}=830 \mathrm{~m}^{2}$

$\mathrm{D}=0.13 \mathrm{~m}, \mathrm{~L}=8 \mathrm{~m}$, Area of 1 tube, $\mathrm{A}_{\mathrm{T}}=\pi^{*} \mathrm{D} * \mathrm{~L}=3.3 \mathrm{~m}^{2}$

Number of tubes, $\mathrm{N}_{\mathrm{T}}=\mathrm{A}_{\mathrm{R}} / \mathrm{A}_{\mathrm{T}}=250$ tubes

Cost of 1 tube is $20,000 \$$

Cost of 250 tubes $=250 \times 20,000 \$=5,000,000 \$$

Cost of shell and connections are still missing.

Cost of a reformer furnace with a duty of $72 \mathrm{MW}$ and equipped with stainless steel tubes $(\mathrm{P}=13,790 \mathrm{kpa})=5.2 \mathrm{M} \$$ (This value is taken for the TEE) 


\section{Methanol reactor}

$\mathrm{Q}=36800 \mathrm{KW}$, Assumed heat transfer, $\mathrm{H}=18.9 \mathrm{KW} / \mathrm{m}^{2}$ [28]

Area required, $A_{R}=Q / H=1947 \mathrm{~m}^{2}$

$\mathrm{D}=0.13 \mathrm{~m}, \mathrm{~L}=8 \mathrm{~m}$, Area of 1 tube, $\mathrm{A}_{\mathrm{T}}=\pi^{*} \mathrm{D} * \mathrm{~L}=5.64 \mathrm{~m}^{2}$

Number of tubes, $N_{T}=A_{R} / A_{T}=345$ tubes

Cost of 1 tube (for an assumed column tube) of $\mathrm{D}=0.5 \mathrm{~m}, \mathrm{~L}=8 \mathrm{~m}$, carbon steel,

$\mathrm{P}=10000 \mathrm{kpa}=69,871 \$$, The cost of $\mathrm{D}=0.13 \mathrm{~m}, \mathrm{~L}=8 \mathrm{~m}$ tube $=17,468 \$$

Cost of 345 tubes $=345 \times 17,468 \$=6,026,460 \$$

Cost methanol reactor: $6.0 \mathrm{MS}$

\section{Heat exchangers}

Based on heat duty equation, $\mathrm{Q}=\mathrm{UA}(\mathrm{LMTD})$

$\mathrm{U}=$ Overall heat transfer coefficient, $\mathrm{KW} / \mathrm{m}^{2} \mathrm{~K}$

$\mathrm{A}=$ Area required, $\mathrm{m}^{2}$ (To determine cost)

LMTD $=\left(\left(T_{h, \text { in }}-T_{c, \text { out }}\right)-\left(T_{h, \text { out }}-T_{c, \text { in }}\right)\right) / \ln \left(\left(T_{h, \text { in }}-T_{c, \text { out }}\right)-\left(T_{h, \text { out }}-T_{c, \text { in }}\right)\right)$

$\mathrm{F}=1$ (assumed)

Temperature, cooling/heating media for heat exchangers:

$\mathrm{T}>=350{ }^{\circ} \mathrm{C} \quad$ flue gas (assume in this case a sufficiently high LMTD)

$250<\mathrm{T}<350^{\circ} \mathrm{Cheating}$ oil

$200<\mathrm{T}<250^{\circ} \mathrm{Chigh}$ pressure steam

$150<\mathrm{T}<200{ }^{\circ} \mathrm{C} \quad$ medium pressure steam

$\mathrm{T}<150{ }^{\circ} \mathrm{C} \quad$ low pressure steam

\section{Pre-heating natural gas from 20 to $350{ }^{\circ} \mathrm{C}$}

$\mathrm{Q}=3400 \mathrm{KW}$

Assume a LMTD of $100{ }^{\circ} \mathrm{C}$. $\mathrm{U}=50 \mathrm{~W} / \mathrm{m}^{2} \mathrm{~K}$, Heating gas: Flue gas $A=680 \mathrm{~m}^{2}$ 
Chapter 6 - Techno-economic analysis of methanol production via HSR

Purchased cost of floating-head heat exchangers with 0.019-m OD $\mathrm{x}$ 0.0254-m-m (3/4-in. x 1-in.) square pitch and 4.88-m (16-ft) bundles of carbon steel construction. 14-19. Design pressure $3100 \mathrm{kpa}$ (450 psia)

Shell is CS, tubes are SS: $135,000 \$$

\section{Pre-heating natural gas from 350 to $900{ }^{\circ} \mathrm{C}$}

\section{$\mathrm{Q}=8485 \mathrm{KW}$}

Assume a LMTD of $100^{\circ} \mathrm{C}$, and a $\mathrm{U}$ of $50 \mathrm{~W} / \mathrm{m}^{2} \mathrm{~K}$ (Assumption: flue gas to heat the gas stream) $\rightarrow 1700 \mathrm{~m}^{2}$

This will result in two heat exchanger of $850 \mathrm{~m}^{2}$ each.

Purchased cost of floating-head heat exchangers with $0.019-\mathrm{m}$ OD $\mathrm{x}$ 0.0254-m (3/4-in. x 1-in.) square pitch and 4.88-m (16-ft) bundles of carbon steel construction. 14-19. Design pressure 30 bar

Shell is CS, tubes are SS

Each will cost $168,000 \$$. Total $2 * 168=336,000 \$$

\section{Glycerol gasification 20 to $400{ }^{\circ} \mathrm{C}$}

\section{$\mathrm{Q}=16134 \mathrm{KW}$}

Assume a LMTD of $100{ }^{\circ} \mathrm{C}$, and a $\mathrm{U}$ of $100 \mathrm{~W} / \mathrm{m}^{2} \mathrm{~K}$ (Assumption: one side flue gas and other side liquid) $\rightarrow 1600 \mathrm{~m}^{2}$

This will result in two heat exchanger of $800 \mathrm{~m}^{2}$ each.

Purchased cost of floating-head heat exchangers with 0.019-m OD $\mathrm{x}$ 0.0254-m-m (3/4-in. x 1-in.) square pitch and 4.88-m (16-ft) bundles of carbon steel construction. 14-19. Design pressure 30 bar

Shell is CS, tubes are SS

Each will cost $158,000 \$$. Total $2 * 158=320,000 \$$ 


\section{Glycerol vaporization at $400{ }^{\circ} \mathrm{C}$}

\section{$\mathrm{Q}=6233 \mathrm{KW}$}

Assume a LMTD of $100{ }^{\circ} \mathrm{C}$, and a $\mathrm{U}$ of $100 \mathrm{~W} / \mathrm{m}^{2} \mathrm{~K}$ (Assumption: one side flue gas and other side liquid) $\mathrm{A} \rightarrow 600 \mathrm{~m}^{2}$

Purchased cost of floating-head heat exchangers with 0.019-m OD $x$ 0.0254-m-m (3/4-in. x 1-in.) square pitch and 4.88-m (16-ft) bundles of carbon steel construction. 14-19. Design pressure 30 bar

Shell is CS, tubes are SS

This will cost 120,000 \$

\section{Glycerol vapor heating from 400 to $900{ }^{\circ} \mathrm{C}$}

$\mathrm{Q}=14199.8 \mathrm{KW}$

Assume a LMTD of $100{ }^{\circ} \mathrm{C}$, and a $\mathrm{U}$ of $50 \mathrm{~W} / \mathrm{m}^{2} \mathrm{~K}$ (Assumption: one side flue gas and other side glycerol vapors) $\mathrm{A} \rightarrow 3000 \mathrm{~m}^{2}$

This will result in three heat exchanger of $1000 \mathrm{~m}^{2}$ each.

Purchased cost of floating-head heat exchangers with $0.019-m$ OD $x$ 0.0254-m-m (3/4-in. x 1-in.) square pitch and 4.88-m (16-ft) bundles of carbon steel construction. 14-19. Design pressure 30 bar

Shell is CS, Tubes are SS

Each will cost 203,000 \$. Total $=610,000 \$$

\section{Water heating from 47 to $234^{\circ} \mathrm{C}$}

\section{$\mathrm{Q}=30476 \mathrm{KW}$}

Assume a LMTD of $100{ }^{\circ} \mathrm{C}$, and a $\mathrm{U}$ of $100 \mathrm{~W} / \mathrm{m}^{2} \mathrm{~K}$ (Assumption: one side flue gas and other side water) $\mathrm{A} \rightarrow 3000 \mathrm{~m}^{2}$

This will result in three heat exchanger of $1000 \mathrm{~m}^{2}$ each.

Purchased cost of floating-head heat exchangers with 0.019-m OD $x$ 0.0254-m-m (3/4-in. x 1-in.) square pitch and 4.88-m (16-ft) bundles of carbon steel construction. 14-19. Design pressure 30 bar

Shell is CS, Tubes are SS 
Each will cost 203,000 \$. Total $=610,000 \$$

\section{Water evaporating to steam $235^{\circ} \mathrm{C}$}

\section{$\mathrm{Q}=50016 \mathrm{KW}$}

Assume a LMTD of $100{ }^{\circ} \mathrm{C}$, and a $\mathrm{U}$ of $100 \mathrm{~W} / \mathrm{m}^{2} \mathrm{~K}$ (Assumption: one side flue gas and other side water) $\mathrm{A} \rightarrow 5000 \mathrm{~m}^{2}$

This will result in five heat exchangers of $1000 \mathrm{~m}^{2}$ each.

Purchased cost of floating-head heat exchangers with 0.019-m OD $x$ 0.0254-m-m (3/4-in. x 1-in.) square pitch and 4.88-m (16-ft) bundles of carbon steel construction. 14-19. Design pressure 30 bar

Shell is CS, Tubes are SS

Each will cost 203,000 \$. Total $=1,015,000 \$$

\section{Steam heating from 235 to $900^{\circ} \mathrm{C}$}

\section{$\mathrm{Q}=45600 \mathrm{KW}$}

Assume a LMTD of $100{ }^{\circ} \mathrm{C}$, and a $\mathrm{U}$ of $50 \mathrm{~W} / \mathrm{m}^{2} \mathrm{~K}$ (Assumption: one side flue gas and other side steam) $\mathrm{A} \rightarrow 10000 \mathrm{~m}^{2}$

This will result in 10 heat exchangers of $1000 \mathrm{~m}^{2}$ each.

Purchased cost of floating-head heat exchangers with $0.019-m$ OD $\mathrm{x}$ 0.0254-m-m (3/4-in. x 1-in.) square pitch and 4.88-m (16-ft) bundles of carbon steel construction. 14-19. Design pressure 30 bar

Shell is CS, Tubes are SS

Each will cost 203,000\$. Total $=2,030,000 \$$

\section{Heating recycle methanol stream from 47 to $250^{\circ} \mathrm{C}$}

\section{$\mathrm{Q}=26232 \mathrm{KW}$}

Assume hot oil is used on Shell side $\left(350^{\circ} \mathrm{C}\right.$ and cooled to $\left.250^{\circ} \mathrm{C}\right)$ have a LMTD of $150{ }^{\circ} \mathrm{C}$, and a $\mathrm{U}$ of $150 \mathrm{~W} / \mathrm{m}^{2} \mathrm{~K}$ (Assumption: one side syngas at high pressure and other side oil) $\mathrm{A} \rightarrow 1200 \mathrm{~m}^{2}$

This will result in 2 heat exchangers of $600 \mathrm{~m}^{2}$ each. 
Chapter 6-Techno-economic analysis of methanol production via HSR

Purchased cost of floating-head heat exchangers with 0.019-m OD $\mathrm{x}$ 0.0254-m-m (3/4-in. x 1-in.) square pitch and 4.88-m (16-ft) bundles of carbon steel construction. 14-19. Design pressure 70 bar

Shell is CS, Tubes are SS

Each will cost $160,000 \$$. Total $=320,000 \$$

\section{Cooling reformer gas 900 to $155^{\circ} \mathrm{C}$}

$\mathrm{Q}=83955 \mathrm{KW}$

Assumption: Cool using water to make steam at different pressure levels. For that staged cooling is required.

$62 \mathrm{MW}: \quad 900{ }^{\circ} \mathrm{C} \rightarrow 350{ }^{\circ} \mathrm{C} \mathrm{HP}$ steam is used $\left(250^{\circ} \mathrm{C}\right), \mathrm{U}=150 \mathrm{~W} / \mathrm{m}^{2} \mathrm{~K}, \mathrm{LMTD}=$ $300{ }^{\circ} \mathrm{C} \rightarrow \mathrm{A}=1400 \mathrm{~m}^{2} \rightarrow 2 * 700 \mathrm{~m}^{2} \rightarrow 2 * 178=356,000 \$$

11 MW: $\quad 350{ }^{\circ} \mathrm{C} \rightarrow 250{ }^{\circ} \mathrm{C}$ with this make MP steam (at $210{ }^{\circ} \mathrm{C}$ ), $\mathrm{U}=150$ $\mathrm{W} / \mathrm{m}^{2} \mathrm{~K}, \mathrm{LMTD}=80^{\circ} \mathrm{C} \rightarrow \mathrm{A}=915 \mathrm{~m}^{2} \rightarrow 233,000 \$$

$11 \mathrm{MW} \quad 250{ }^{\circ} \mathrm{C} \rightarrow 155^{\circ} \mathrm{C}$ with this make low pressure steam (at $120^{\circ} \mathrm{C}$ ), $\mathrm{U}=$ $150 \mathrm{~W} / \mathrm{m}^{2} \mathrm{~K}, \mathrm{LMTD}=72^{\circ} \mathrm{C} \rightarrow \mathrm{A}=1000 \mathrm{~m}^{2} \rightarrow=258,000 \$$

Total: $847,000 \$$

\section{Cooling reformer gas 155 to $40^{\circ} \mathrm{C}$}

$\mathrm{Q}=63350 \mathrm{KW}$

LMTD $70{ }^{\circ} \mathrm{C}$ (cooling media: Water at $20^{\circ} \mathrm{C}$ )

$\mathrm{T}_{\mathrm{c}, \text { in }}$ and $\mathrm{T}_{\mathrm{c}, \text { out }}$ are based on UNISIM heat exchanger calculations.

assume $150 \mathrm{~W} / \mathrm{m}^{2} \mathrm{~K}$

$\mathrm{A}=6000 \mathrm{~m}^{2}$

6 heat exchangers in parallel, each $1000 \mathrm{~m}^{2}$. (shell CS, tube SS)

Each will cost $200,000 \$$ (at $\mathrm{P}=30$ bar). Total $\rightarrow 1,200,000 \$$

\section{Cooling compressed gas 130 to $40^{\circ} \mathrm{C}$}

$\mathrm{Q}=5456 \mathrm{KW}$

$\mathrm{LMTD}=64^{\circ} \mathrm{C}$, (cooling media: Water at $\left.20^{\circ} \mathrm{C}\right), \mathrm{U}=150 \mathrm{~W} / \mathrm{m}^{2} \mathrm{~K}, \mathrm{~A}=713 \mathrm{~m}^{2}$ 
Purchased cost of floating-head heat exchangers with $0.019-\mathrm{m}$ OD $\mathrm{x}$ 0.0254-m-m (3/4-in. x 1-in.) square pitch and 4.88-m (16-ft) bundles of carbon steel construction. 14-19. Design pressure 70 bar

Shell is CS, Tubes are SS

$=181,000 \$$

\section{Cooling methanol product 250 to $137^{\circ} \mathrm{C}$}

$\mathrm{Q}=22306 \mathrm{KW}$

$\mathrm{U}==150 \mathrm{~W} / \mathrm{m}^{2} \mathrm{~K}$,

low pressure steam at $120^{\circ} \mathrm{C}, \mathrm{LMTD}$ would be $55^{\circ} \mathrm{C}, \mathrm{U}=150 \mathrm{~W} / \mathrm{m}^{2} \mathrm{~K}$ (based on one side pressurized gas, other side boiling water). $A=2700 \mathrm{~m}^{2}=3 * 900 \mathrm{~m}^{2} \rightarrow 3 * 230$ $=690,000 \$$, Assuming floating head at 70 bar. Shell CS, Tube SS.

\section{Cooling methanol product 137 to $40^{\circ} \mathrm{C}$}

$\mathrm{Q}=41403 \mathrm{KW}$

LMTD $=53{ }^{\circ} \mathrm{C}$ (cooling media: Water at $\left.20{ }^{\circ} \mathrm{C}\right), \mathrm{U}=150 \mathrm{~W} / \mathrm{m}^{2} \mathrm{~K} ; \mathrm{A}=5200 \mathrm{~m}^{2}=$ $5^{*} 1000 \mathrm{~m}^{2} \rightarrow 5 * 260=1300,000 \$$, Assuming floating head at 70 bar. Shell CS, Tube SS.

\section{Condenser for distillation column}

$\mathrm{Q}=27,000 \mathrm{KW}, \mathrm{T}=55^{\circ} \mathrm{C}$ and $\mathrm{P}=1 \mathrm{~atm}$

Utility: use cooling water. Inlet $\mathrm{T}=20^{\circ} \mathrm{C}$, outlet $\mathrm{T}=25^{\circ} \mathrm{C}$

LMTD $=32{ }^{\circ} \mathrm{C}, \mathrm{U}=500 \mathrm{~W} / \mathrm{m}^{2} \mathrm{~K}$ (combination of cooling water and condensing organic vapor), $\mathrm{A}=1700 \mathrm{~m}^{2}=2 * 850 \mathrm{~m}^{2} \rightarrow 2 * 100,000 \$=200,000 \$$ (shell CS, tube $\mathrm{SS}, \mathrm{P}=7$ bar)

\section{Reboiler}

$30 \mathrm{MW}, \mathrm{T}=109^{\circ} \mathrm{C}$ and $\mathrm{P}=1 \mathrm{~atm}$

Utility: use MP steam $212^{\circ} \mathrm{C}$

$\mathrm{LMTD}=100{ }^{\circ} \mathrm{C}, \mathrm{U}=1000 \mathrm{~W} / \mathrm{m}^{2} \mathrm{~K}$ (boiling organic liquid, combined with condensing steam $) \rightarrow \mathrm{A}=300 \mathrm{~m}^{2} \rightarrow 60,000 \$$ 


\section{Columns}

1. Column to remove water from reformer gas product

Assumed $\mathrm{D}=2 \mathrm{~m}, \mathrm{~L}=8 \mathrm{~m}$ [23], SS material, Pressure rating of 10,000 kpa

$=448,000 \$+$ demister

2. Second Column to remove water from reformer gas product

Assumed $\mathrm{D}=2 \mathrm{~m}, \mathrm{~L}=6 \mathrm{~m}$ [23], SS material, Pressure rating of 10,000 kpa

$=360,000 \$+$ demister

3. Column after methanol synthesis

Assumed D=2.5 m, L=9m [23], SS material, Pressure rating of 10,000 kpa

$=760,000 \$$ in case of $\mathrm{D}=3 \mathrm{~m}$ and $492,000 \$$ in case of $\mathrm{D}=2 \mathrm{~m}$

Assume the column will cost $625,000 \$+$ Demister

4. Column to remove lights

Assumed $\mathrm{D}=2 \mathrm{~m}, \mathrm{~L}=10 \mathrm{~m}, \mathrm{SS}$ material, Pressure rating of 1035

$\mathrm{kpa}$

$=186,000 \$$

5. Column to purify methanol

Active area necessary for gas flow is $8 \mathrm{~m}^{2}$. Total cross-sectional area is about $10 \mathrm{~m}^{2}$.

Diameter is $3.5 \mathrm{~m}$

Number of stages: 16 ideal, 23 real stages (70\% eff.).

Height of column about $15 \mathrm{~m}$.

Material: SS

$\mathrm{D}=3 \mathrm{~m} \quad \rightarrow 395,000 \$$

$\mathrm{D}=4 \mathrm{~m} \quad \rightarrow 473,000 \$ \rightarrow$ assume $440 \mathrm{k} \$$

Stages:

$\mathrm{D}=3.5 \mathrm{~m} \rightarrow 130,000 \$$

Total is $570,000 \$$ 


\section{Compressors and pumps}

Two compressors used to compress from 20 to 80 bar centrifugal turbine compressors (material :CS)

Power 5.2 MW $\rightarrow 3.2 \mathrm{MS}$

For two $\rightarrow 2 * 3.2 \mathrm{M} \$=6.4 \mathrm{M} \$$

Methanol recycle stream - compress from 75 to 80 bar

Purchased cost of compressors, including drive, gear mounting, base plate,

Centrifugal rotary motor, Power rating $=900 \mathrm{~kW}$

centrifugal turbine (material :CS)

Power $900 \mathrm{~kW} \rightarrow 634,000 \$$

Bio-liquid pump, volumetric flow $=0.009 \mathrm{~m}^{3} / \mathrm{s}$, pressure rating $=5000 \mathrm{kpa}$

Purchased cost of Centrifugal cast iron pump

$=11,373 \$$

Water pump from, volumetric flow $=0.005 \mathrm{~m}^{3} / \mathrm{s}$, pressure rating $=5000 \mathrm{kpa}$ Purchased cost of Centrifugal cast iron pump for $0.009 \mathrm{~m}^{3} / \mathrm{s}$

$=11,373 \$$

$\begin{array}{llr}\text { Reactors } & = & 11.3 \mathrm{M} \$ \\ \text { Heat exchangers } & = & 10.0 \mathrm{M} \$ \\ \text { Columns } & = & 2.2 \mathrm{M} \$ \\ \text { Pumps and compressors } & = & 7.1 \mathrm{M} \$\end{array}$

Total equipment cost of major unit operations $=30.5 \mathrm{M} \$(2002)$

The calculated costs are based on 2002. CECPI in $2002=390$ [24]

CECPI in 2012 (April) $=596$ [24]

Total equipment cost of major unit operations $=46.6 \mathrm{M} \$(2012)$

$1 \$=0.77 €($ avg. 2012 value [29])

Total equipment cost of major unit operations $\quad=\quad 35.9 €(2012)$ 
Assume a Lang factor of 5 [16] for fixed capital investment: $180 \mathrm{M} €$ ( ISBL)

OSBL is assumed $30 \%$ of ISBL: $54 \mathrm{M} €$

Total capital investment $=180+54=234 \mathrm{M} €$.

The TEE analysis are performed for $250 \mathrm{M} €$ since only major equipments was considered. 


\section{Appendix 2}

Calculation of glycerol requirement to the furnace

Case 1: Methane steam reforming to produce synthesis gas

$$
\begin{array}{ll}
\text { Methane requirement to the furnace } & =348 \mathrm{kmol} / \mathrm{h} \\
\text { Heat of combustion of methane } & =890 \mathrm{~kJ} / \mathrm{mol} \\
& =86 \mathrm{MW}
\end{array}
$$

tonne glycerol for combustion/tonne methanol

$=17222 / 56739$

$$
=0.3
$$

By introducing these numbers in Table 6 for the base case,

The cost of methanol produced by introducing glycerol to the furnace $=394 € /$ tonne 


\section{Outlook and recommendations for further work}

Overall it can be concluded from the work described in this thesis that Hybrid Steam Reforming (HSR) of purified low coking bio-liquids such as purified or neutralized glycerol is a technically viable process and under special conditions also economically feasible. For pyrolysis oil and crude glycerol the current available catalysts, both commercial and newly developed ones, are not good enough when the process is performed in fixed bed reactors. Design of stable (pre-reform) catalysts for the efficient gasification of biomass should take into account the ability of the catalysts to depolymerize deposits because suppressing oligomerisation is nearly impossible as it occurs almost on any surface.

The focus of the pre-reforming catalyst should be on maximizing the stable conversion of the bio-liquid vapors to permanent gases or hydrocarbons that can be dealt with in the primary co-reformer. Process development should focus on i) atomization under industrial conditions (e.g. high pressure) and the handling of the produced solids in this stage and ii) additional systems to "protect" the catalysts as much as possible. To protect the catalyst from a too high amount of vapors, a few strategies can be applied; e.g. raising the temperature of gasification prior to prereforming, usage of cheap catalysts for vapor cracking which can be regenerated and/or applying a high degree of non-catalytic cracking (e.g. coking) and subsequently gasifying the char/coke which is being formed. Fast regenerating fluidized systems such as FCC could be an option, but such fluidized bed steam reforming or cracking catalysts will need considerable research attention. Besides, in case of a steam reform catalyst, if the active metal is oxidized during coke burn-off this will result in an additional reduction step making a total cycle of catalyst possible: reaction - deactivation - coke burn-off - reduction - reaction. A completely different catalyst system without requiring the reduction step after coke burn off might then be required. Another option is to carry out gasification in the presence of steam and/or oxygen just as in the case of typical auto-thermal reforming. The role of oxygen in this case is to help to combust coke/oligomer and keep the catalytic sites clean. 


\section{Publications}

1. Ragavendra P. Balegedde Ramachandran, Guus van Rossum, Wim P.M van Swaaij,Sascha R. A. Kersten, Evaporation of biomass fast pyrolysis oil : Evaluation of char formation, Environment progress and sustainable energy, 2009, $28,410-417$

2. Guus van Rossum, Berta Matas Güell, Ragavendra P. Balegedde Ramachandran, K.Seshan, L.Lefferts, Wim P.M van Swaaij, Sascha R.A. Kersten, Evaporation of pyrolysis oil: Product distribution and residue char analysis, AIChE journal, 2010, $56,2200-2210$

3. Ragavendra P. Balegedde Ramachandran, Guus van Rossum, Wim P.M van Swaaij,Sascha R. A. Kersten, Synthesis gas production via hybrid reforming of methane and Glycerol, Energy \& Fuels 25 (2011), 5755-5766

4. Ragavendra P. Balegedde Ramachandran, J.A. Medrano, Guus van Rossum, K.Seshan, Wim P.M van Swaaij, Sascha R. A. Kersten, Synthesis gas production via Steam reforming of pyrolysis oil: Assessment of catalyst performance and hybrid reforming with methane. hybrid reforming of methane and pyrolysis oil (article under preparation)

5. Ragavendra P. Balegedde Ramachandran, Stijn Oudenhoven, Guus van Rossum, Wim P.M van Swaaij, Sascha R. A. Kersten, Process plant design to produce synthesis gas via hybrid reforming of methane and bio-liquids (article under preparation) 


\section{Posters and Presentations}

1. Evaporation of biomass fast pyrolysis oil : Evaluation of char formation, Presentation: Thermo-chemical conversion and science conference held at Chicago, USA, between Sep 16 \& 18, 2009

2. Combined optimization of fast pyrolysis and catalytic reforming of pyrolysis oil to produce renewable syn-gas from biomass residues, Presentation: Proceedings of the 18 th European Biomass conference held at Lyon, France, between May 3 \& 7, 2010

3. Synthesis gas production via hybrid steam reforming of methane and pyrolysis oil, Presentation: Netherlands process technology symposium held at Veldhoven, Netherlands, between Oct 25 \& 27, 2010

4. Utilization of glycerol and pyrolysis oil in the existing reforming units to produce syn-gas, Presentation and Poster: Bioenergy conference held at Lanzarote, Spain, between May 23 \& 27, 2011

5. Steam reforming of pyrolysis oil to produce syn-gas, Poster:Proceedings of the 19 th European Biomass conference held at Berlin, Germany, between June 6 \& 10, 2011 


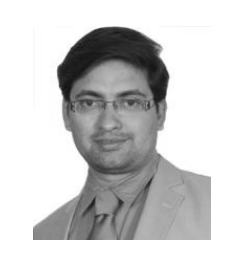

\section{About the author}

R.Prasad Balegedde Ramachandran was born on $27^{\text {th }}$ October, 1980 in Chennai (formerly called as Madras), India. He studied Bachelor's in Chemical Technology (B-Tech) in Sri Venkateswara College of Engineering (affiliated to University of Madras) from 1998 till 2002. He completed his B-Tech degree with first class and distinction. After his B-Tech, he worked as a Chemical Engineer in Carborundum Universal Limited (Murugappa Group of companies) from 2002 till 2004. In 2004, he received scholarships from Shell, Netherlands and Bharat Petroleum Corporation, India to study Master's in Chemical Engineering (Process Technology track) at the University of Twente, Enschede, The Netherlands. He performed his Master's Thesis in the Thermo-chemical conversion of Biomass (TCCB) group (now called as Sustainable Process Technology group) in the University of Twente under the supervision of Prof.dr.S.R.A.Kersten. He completed his Master's in 2006.

Later, he joined the same group (TCCB) as a Researcher. He worked on "Modeling of biomass gasification" project in co-operation with Energy Center of Netherlands (ECN). Then, he continued his PhD in TCCB from January 2008 till February 2012 under the supervision of Prof. dr. S.R.A. Kersten, Prof. dr.ir. W.P.M. van Swaaij and Dr.ir.Guss van Rossum. He worked on the topic "Synthesis gas production from biomass". The results of this multi-disciplinary research focused on process engineering and catalysis. From March 2012, he is working as a Process Engineer in BASF, Ludwigshafen, Germany. 


\section{Acknowledgements}

This PhD work has been kept on track and seen through to completion with the support and encouragement of numerous people including my well wishers, my friends and colleagues. I thoroughly enjoyed every moment in this journey and I would like to express my gratitude to all those who gave me the possibility to complete this Thesis.

I would like to start giving my special thanks to Shell (India and The Netherlands), Bharat Petroleum (India) for scholarships and Ing. H.A.Akse (International student co-ordinator) for giving me a wonderful opportunity to study Master's in Chemical Engineering (Process Technology track) in the University of Twente, Enschede, Netherlands) in the year 2004. Indeed, it is a very long journey. From 2004, I am associated with SPT (Sustainable Process Technology group, formerly called as TCCB (Thermo-chemical conversion of Biomass group).

I would like to thank my promoters Prof.dr.ir. Wim P.M. van Swaaij and Prof. dr. Sascha Kersten who gave me the opportunity to contribute in my favorite field of research which is biomass conversion technologies. It is a dream come true for me to work in Prof.dr.ir. Wim P.M. van Swaaij's group. It's truly an honour to interact with the professor. His quick, witty sharp comments on any topic made me to think for hours.

Sascha is truly an inspiration for me. I learnt from him everyday especially during my $\mathrm{PhD}$ days not only about biomass technologies but also about managing projects, selfcriticism and enthusiasm to learn new things. The Master course on Sustainable development in 2005 was an eye-opener for me to continue as a Researcher in TCCB group. After he came to know about my interest to do $\mathrm{PhD}$, Sascha offered me a modeling project from Energy Center of Netherlands on Biomass gasification (from 2006-2008). Thank you for your guidance throughout our research project and for the fruitful research discussions. Thanks for your understanding and support during difficult periods of my $\mathrm{PhD}$ life.

This $\mathrm{PhD}$ work could not have been a reality without the contribution from Guus, Assistant promoter, daily supervisor (in person + also in Skype), guide and a good friend. I continued his work on Steam reforming of pyrolysis oil. Since I knew Guus from 2004, it became easy for me to follow the project. Initially, (in 2008) I had tough time in experimental project since I had modeling experience. It was Guus who made me comfortable working in the Lab. At this point, I would also like to thank Agnes who was very co-operative and made this project a bit easier for me to start. I would like to thank Guus for his scientific input in this work. I still remember that during one of our discussions, the concept of hybrid steam reforming concept has been proposed and we could able to implement in our lab with the help of able technicians. Thanks a lot Guus for your wonderful support and you helped me a lot in solving critical issues in the area of steam reforming. I learnt a lot especially about data interpretation from you which I am still learning to perform better. Besides work, I would like to thank you for all the wonderful gatherings, discussions, breaks, trips etc. I am sure this will continue in the future as well. 
I am very grateful to Dragan who guided me during my Master's project on Biomass liquefaction. It was Dragan who introduced me to Hoge Druk Lab and taught me how to deal with liquefaction in a small capillary tube. I lost my count but I am sure that I would have done 1000s of such tubes. I learnt a lot from Dragan during my Master's days regarding the stages in research, life of a $\mathrm{PhD}$ student and mainly how research works in TCCB. It was Dragan who first encouraged me to do a PhD. Together with Dr.Wang, we shared the same office in Langezijds. Of course, we had useful political and general discussions about everything.

Technicians are the backbones of our TCCB group. Without them, $\mathrm{PhD}$ work is almost impossible. I express my gratitude to Johan (helped me during my Master's), Benno, Karst, Robert (built excellent experimental set ups) and Erna (for analyzing samples). I would like to express my special thanks to Benno who not only involved in building set ups but also actively involved in design of experiments and shared his knowledge and experience. It was very useful to solve critical issues. I don't know how many times I took the atomizer and mass flow controllers to Robbert and Benno. Not only technical stuffs but also I learnt many useful "Dutch words and sentences" (which I cannot reveal here) from Benno and Robert. Special thanks to Yvonne for taking care of all official work and she translated many letters from Dutch to English in my early Master's days.

I would like to thank also my students Rahim, Yonina, Marco and Peter. Also, I would like to mention special thanks to Joram, Peter, Felix and Jan who worked part time on pyrolysis and reforming/cracking. I would also like to thank Louise and Bert from CPM group, Mark Smithers and Gerard Kip from MESA group for their characterization work. Also, special thanks to ECN (Van der Drift, Christiaan) for assisting me in Milena gasification project, BioMCN (Nanne, Ruud) for giving valuable inputs for Chapter 4 and Univeristy of Zaragoza for testing the catalysts.

I would like to thank my wonderful Paranymphs Jose and Laura. I involved in catalysis work after we collaborated with Jose from the University of Zaragoza. Special thanks to Prof.dr.Jesus Arauzo for the collaboration and also he accepted to be in my $\mathrm{PhD}$ committee. It was really convenient for me to work together with Jose because his $\mathrm{PhD}$ work was similar to mine. He shared lot of his experience on catalysis and reforming and actively involved in experimental work. Besides research, we shared many things on personal level and I am sure it will continue in the future. Laura, you have been wonderful and helped me in many ways in analyzing samples and also printing my Thesis work. I cannot forget the day we met in a party. Your first question to me was 'Do you know Ferran?? .... The conferences we went together are unforgettable. You took lot of efforts in taking time out of the research by organizing small coffee breaks, borrels and chit-chats. I am sure our friendship will continue in the future.

I would like to express my gratitude to Louis who helped me a lot during my Master's course on Flowsheeting and he continued his support to finish my last Chapter in Thesis which is economics. I would also like to thank all the lecturers those who taught me during my Master's. I would like to extend my gratitude to all my colleagues from 2004 till now: Biljana, Xie, Dragan, Guus, Marieken, Roel (you made 
me as your paranymph and that was the only time I performed that duty, cannot forget Barcelona experience together with Antal and Xavi), Pavlina (She is the first person I talked in The Netherlands....the girl next door in Witbreuksweg 399), Elly (we had a tough competition on number of capillaries), Ferran (thanks for all your support and the knowledge you shared with me regarding biomass), Anand (called him as Chaki ...thanks Chaki for all your support and sometimes you stayed longer in the lab and over night to perform experiments... sometimes we worked on US timings like typical software engineers of India. Since we both worked on catalysis and sometimes on similar feed and catalysts we were bamboozled ! by our own outcomes), Kumar (Thanks for all your sharing about catalysis and the best thing is I can disturb him any time... It became very easy for me when we shared the same office in Meander), Rens (you are the best neighbor I have ever had and keep doing the same things to the people nearby... when I heard the word $\mathrm{CO}_{2}$ you are coming into my mind... keep up the good work), Stijn (He is a wonderful co/worker. We worked on a small project called combined pyrolysis and reforming. He has answers to all the problems in the biomass world.

I would also like to express my thanks to Judith, Maria, Shushil, Samuel, Martin, Mathijs, Petra, Jothi, Cindy, Wim (Thanks for introducing me to the teaching world and it's an unforgettable experience), Miriam, Frank and Hector. I would also like to express my thanks to TCCB family Diana, Clara, Rebeca, Dimitris, Can (thanks for giving me pacharaki and an awesome party on my 30 th birthday at Veldhoven), Roger (you are the best Spanish I have ever seen ....are you happy now?), Michael, Nandana, Lavanya, Marije, Kate (the only veggie partner for me in Zaragoza).

Enschede always remain as my second hometown because of Indian contingent. Many Indian friends helped me in various ways. I would like to express my special thanks to Anand Mohan who introduced me to the Indian community and to Indian cuisine. His interest on cooking made me to take cooking as a hobby. He also let me stay together with him in Westerstraat. I hope I was a good tenant. It's because of Shankar I gained confidence in my Master track. He assisted me in various ways on course works and how to face the problems. Besides work we (Shank, Anand, Kumar) actively involved in Hengelo cricket which is my first cricketing experience abroad. It was in a Deepavali event in 2004 I met Balaji. I became friends with him the moment I met him. I know for sure it's an everlasting one. It was Shankar and Balaji who introduced me to Seshan and Jeyanti. With Seshan, I discussed not only catalysis but also cricket (not played but only watched) and many many things. I had wonderful time with Jeyanti and learnt a lot from her cuisines. Thanks for inviting me to all religious events at your house and took time out of research.

I would like to thank Pramod for making me comfortable in Enschede. When I needed a computer to work at home, he immediately solved the problem. He also introduced me to Enschede tape ball cricket in 2004. Special thanks to Enschede cricket folks: Tomar, Ravi, Kiran, Sunny, Niraj, Anurag, Khurrem, Makrand. I would like to express my thanks to Srinivas, Kavitha, Kiran, Murali, Vishaka, Chandra for introducing me to many Indian events that happened between 2004 and 2006. The karaoke singing together with Shankar, Kavitha, Rajavishnu, Sameer and Digvijay was a wonderful experience to share stage during big events. 
I would like to thank both Vishnupully and Vignesh for sharing house with me. You guys are just wonderful in-mates and extremely understandable when I was coming late or when I was in crisis. I cannot forget Vishnu's pappu and Vignesh's kollu rasam. I still cannot get the same quality. Thanks to CP Suresh, Vishi, Dinesh, Sastry, Vijay and Jithin for organizing several "Tamil parties". I would also like to Vishi for introducing me to Hilversum cricket club, Srikanth Akkiraju (for cricket and personal discussions), Kalai, Jeevitha (for awesome erode and coimbatore cuisines), Ranjani (for extensive long debates), Hrudaya (for nice long chats), Subhashni, Archana, Rajesh, Jigar, Falguni, Mayur, Tina, Avinash, Dinesh Rajah, Koti, Ganesh, Krishna, Gayathri, Giri, Varsha, Sandeep, Jalaja, Rajaram and Vivek. It's incredible that I have more Indian friends abroad than in India at this moment. I made a lot of Pakistani friends as well through Cricket. It's a memorable experience with Hammad, Waqar, Khurrem, Rahim, Adheel in Indoor table ball cricket (Sports centrum) and Kite festivals.

I would also like to express my special thanks to Hengelo and Hilversum cricket board for accepting me as a member. Not only I developed my cricketing skills but also I built a good network from various cricket playing nations. This developed my social skills also outside lab work. Thanks to many borrels organized by Alembic (Chem. Eng), Stijn and Roel (in TCCB). The conference trips to Chicago, Lyon and Lanzarote are an unforgettable experience. Besides conference trips, I appreciate the effort taken by Nick, Maria, Laura, Elly and others for organizing some memorable trips. The Wadlopen trip still remains as a terrific experience. I would also like to thank my close friends outside University who spent valuable time with me: Katrina, Eghard and Wout.

I would like to extend my gratitude to my college and school friends from SVCE and Vellayan Chettiar Higher Secodary School : Senthil, Ambarish, Anand and Vadivelan (SVCE), Saravanan, Senthil, Prabu, Sridhar, Narene (VCHSS) for their continuous support. I would also like to thank my best friends (tvt_hunks) Chidambaram, Asif, Palani, Sarath, Prabu, Vijay, Prem and Lavanya who are there for me anytime. Special thanks to Lavanya who read each Chapter with utmost care and proof read several times.

I also extend my heartfelt thanks to Balegedde and Thottakudi family members. I would like to convey my namaskarams to my family members Mom, Dad, Guru and Subha. Without my mom's encouragement, my dad's and Guru's financial support my journey to study Master's would have been impossible. Special thanks to wonderful niece Harshnna.

Finally, I would like to thank my wife Soumya. Her support and encouragement at the end of my $\mathrm{PhD}$ made this dissertation possible. 
